Portland State University

PDXScholar

Environmental Science and Management

Professional Master's Project Reports

Summer 2017

\title{
Urban Connections: A Comparison of Connectivity Assessment Methods
}

Natalie M. Rogers

Portland State University

Follow this and additional works at: https://pdxscholar.library.pdx.edu/mem_gradprojects

Part of the Environmental Monitoring Commons, and the Environmental Studies Commons Let us know how access to this document benefits you.

\section{Recommended Citation}

Rogers, Natalie M., "Urban Connections: A Comparison of Connectivity Assessment Methods" (2017). Environmental Science and Management Professional Master's Project Reports. 37.

https://pdxscholar.library.pdx.edu/mem_gradprojects/37

https://doi.org/10.15760/mem.12

This Project is brought to you for free and open access. It has been accepted for inclusion in Environmental Science and Management Professional Master's Project Reports by an authorized administrator of PDXScholar. Please contact us if we can make this document more accessible: pdxscholar@pdx.edu. 


\title{
Urban Connections: A comparison of connectivity assessment methods
}

\author{
By \\ Natalie M Rogers \\ A report submitted in fulfillment \\ of the degree requirements for: \\ Professional Science Masters \\ in the department of \\ Environmental Science and Management
}

Thesis Committee:

Joseph Maser

Catherine de Rivera

Martin Lafrenz

Carrie Butler

\section{Portland State University}

August 14 ${ }^{\text {th }}, 2017$ 


\section{Table of Contents}

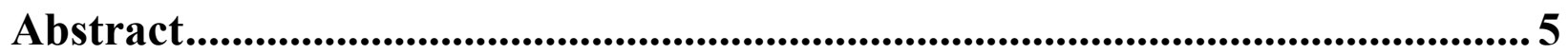

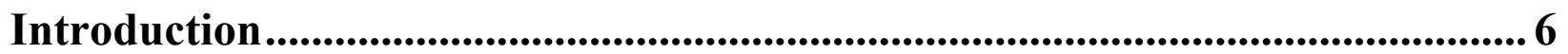

Background ...........................................................................................................................8 8

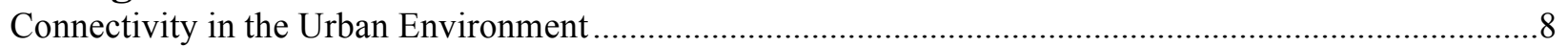

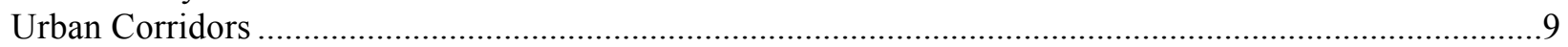

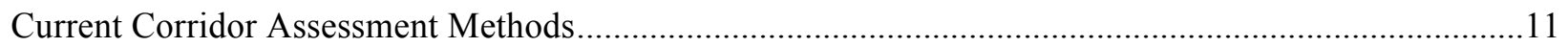

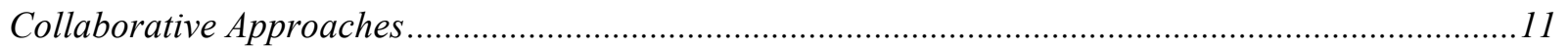

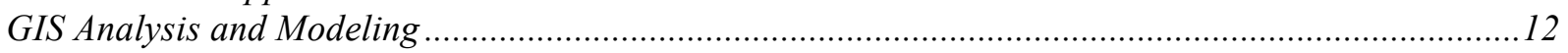

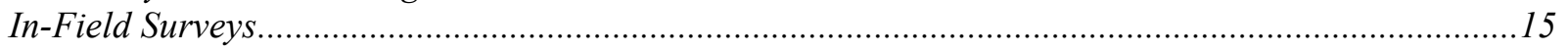

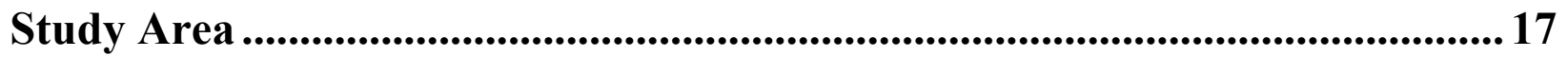

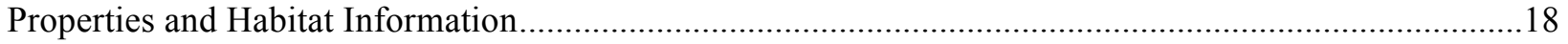

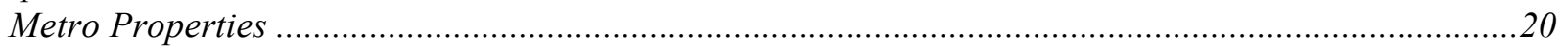

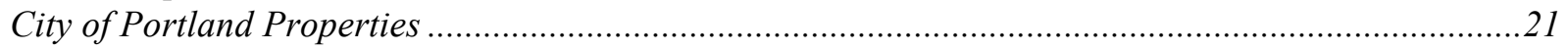

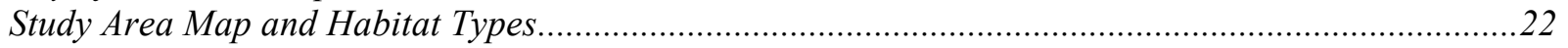

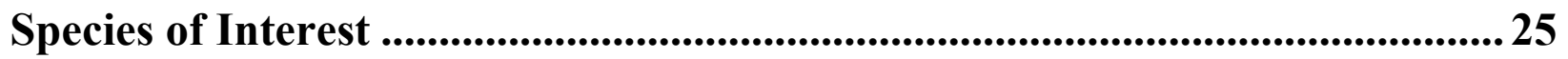

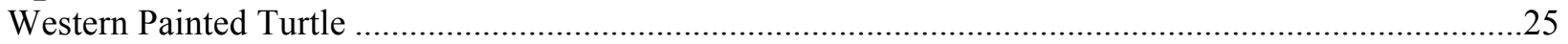

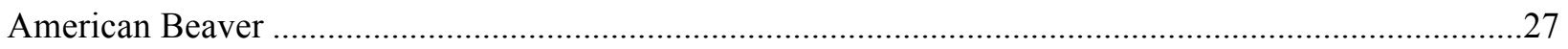

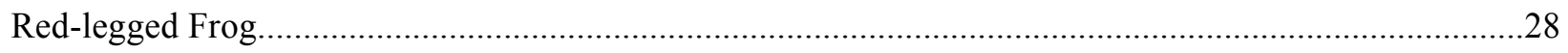

Corridor Assessment Methods...........................................................................30 30

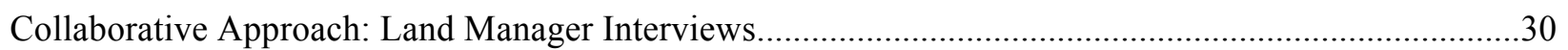

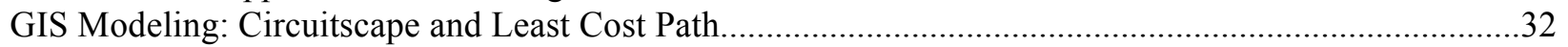

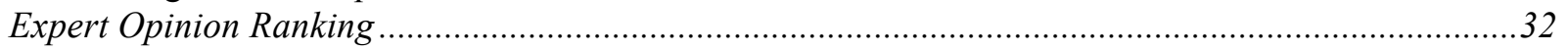

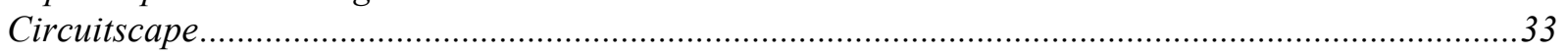

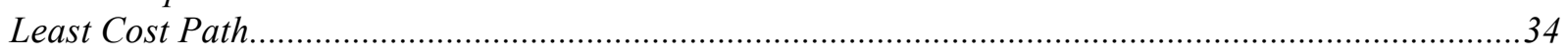

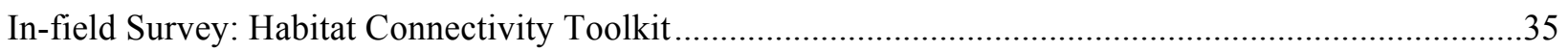

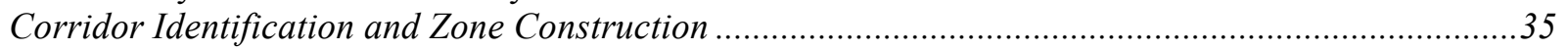

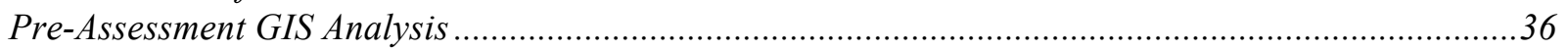

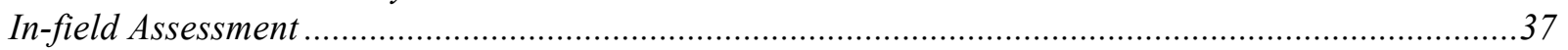

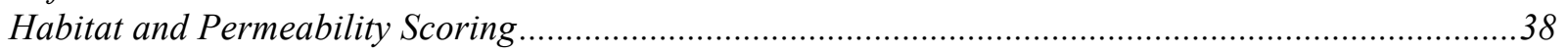

Results ................................................................................................................... 41

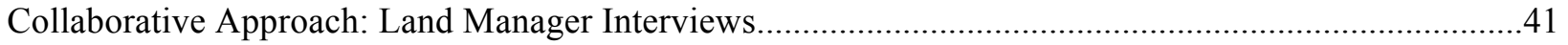

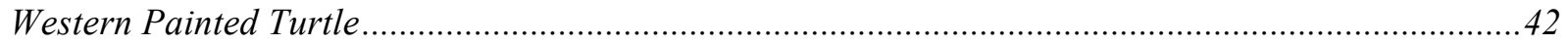

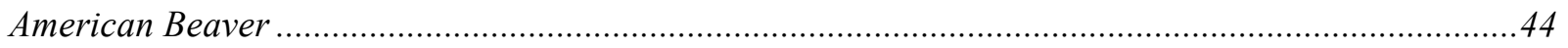

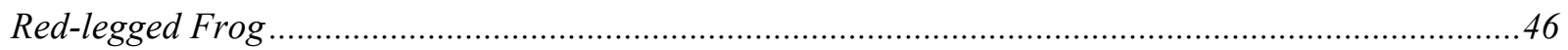

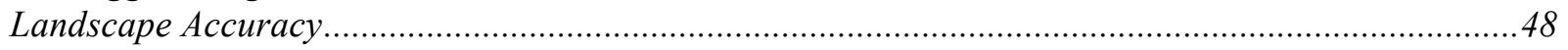

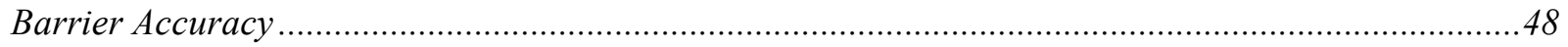

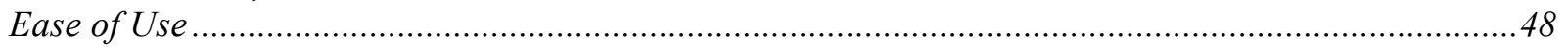

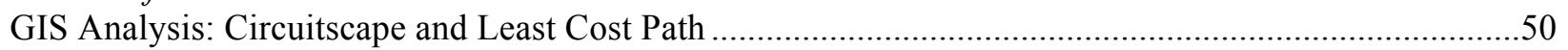

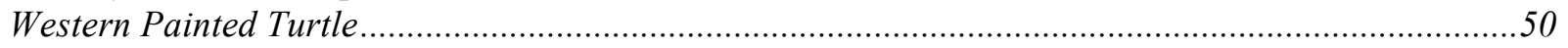

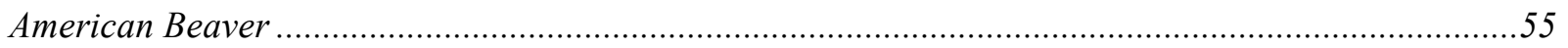

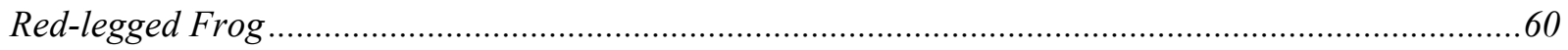

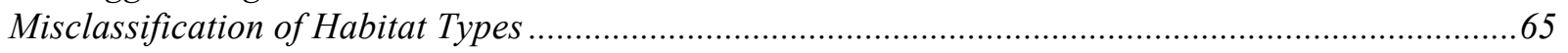

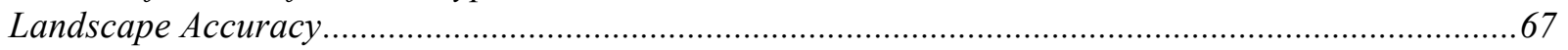

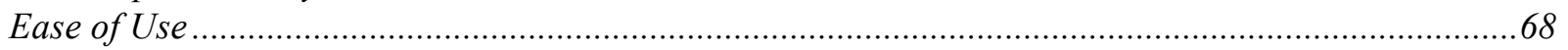




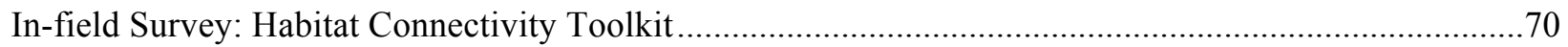

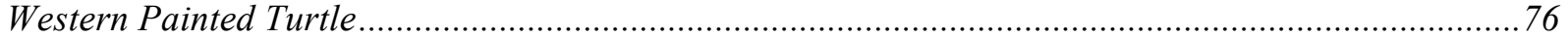

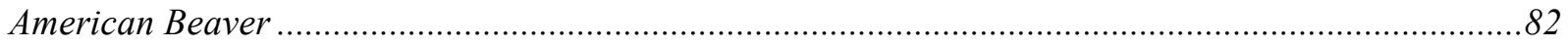

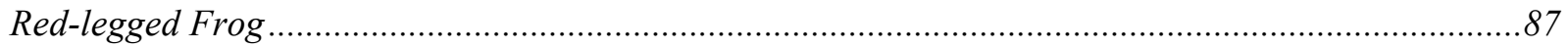

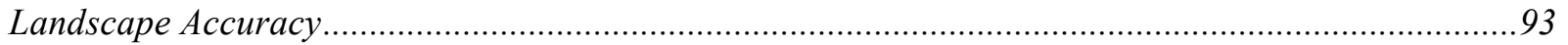

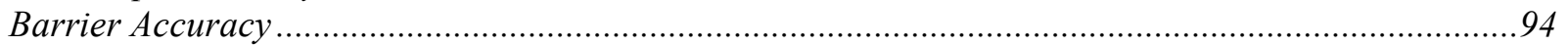

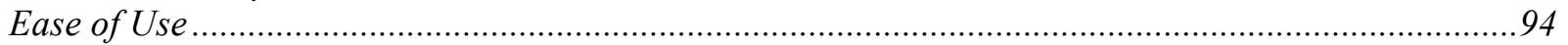

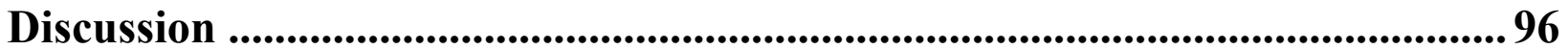

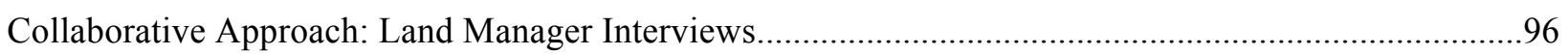

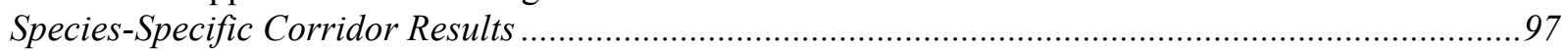

Disadvantages of the Land Manager Interview Method .................................................................97

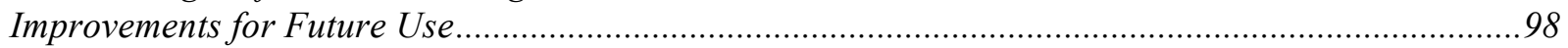

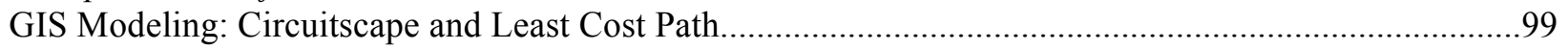

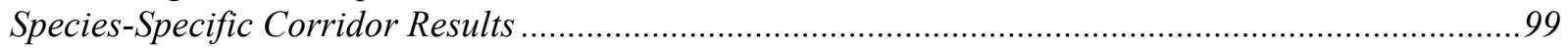

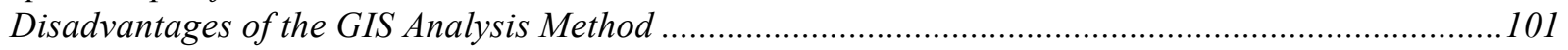

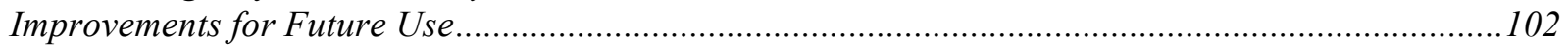

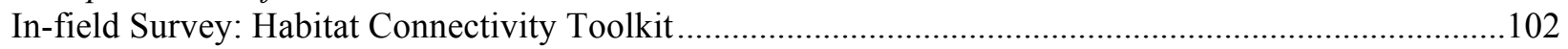

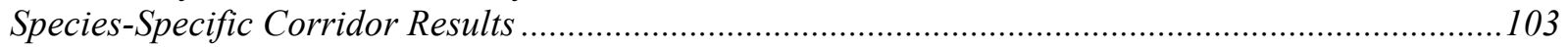

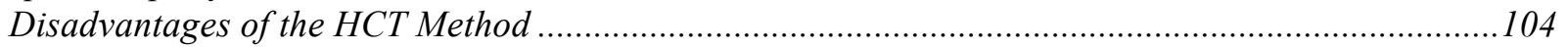

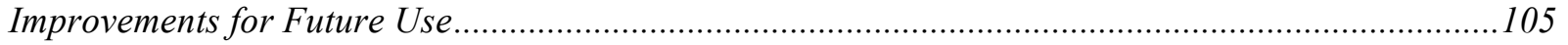

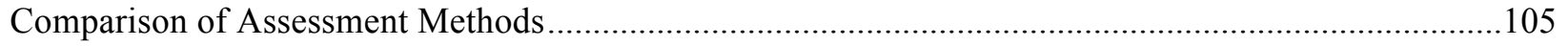

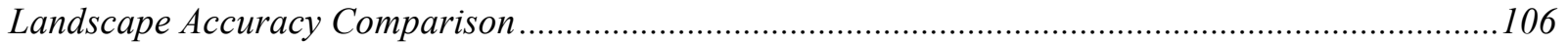

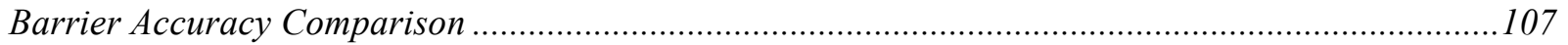

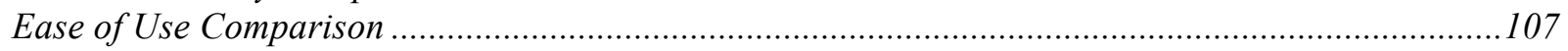

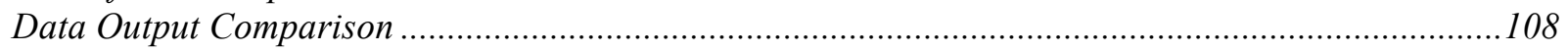

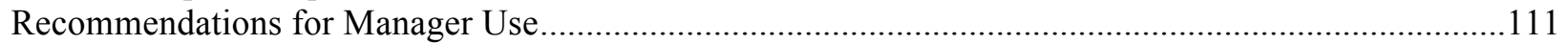

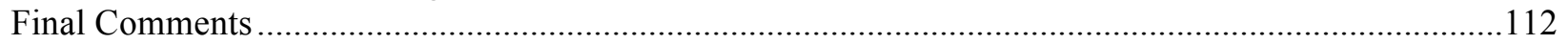

Referenced Literature ...................................................................................... 114

Referenced GIS Data and Tools ....................................................................... 120 


\section{Acknowledgements}

I would first like to thank my advisor Dr. Joseph Maser for his instruction and help in this program. I would not be completing this project without his encouragement and time.

I also want to thank Dr. Catherine de Rivera for the and the endless support and guidance through this work. Her dedication to supporting her students is something for which I cannot thank her enough.

I'd like to thank the de Rivera lab for their help and friendship through this effort.

Many thanks to Leslie Bliss-Ketchum, who offered me abundant advice and opportunities, and to Martin Lafrenz, who spent countless hours helping me troubleshoot and understand the world of GIS.

I would also like to thank my community partners at Port of Portland, especially Carrie Butler and Sarah Wilson, for their valuable input and for helping me navigate the development process for the project. And a special thank you to the land managers and species experts who contributed their time and knowledge to this work.

Finally, I want to thank my husband Joe Yrigoyen, for the endless reassurance and support which kept me afloat and moving forward. 


\begin{abstract}
Habitat connectivity in urban settings is critical for facilitation of safe species movement, species health, and biodiversity. Predicting the movement of wildlife through the urban environment is difficult due to the presence of barriers - natural or built features in the landscape that restrict or prohibit movement of species. Urban properties and greenspaces can serve as pathways of connectivity for wildlife movement across the complex developed matrix. Thus, land managers should assess their properties for possible connectivity functionality to promote safe wildlife movement. Land managers may not be aware of current connectivity assessment methods, therefore this project provides introductory information on connectivity assessments, including comparison of methods and results, to help land managers choose the best process for their goals and resources.

Highlighting three current connectivity assessment methods, we assess connectivity for wildlife in a north Portland greenspace and determine the relative achievements and failings for each method. The methods used include a collaborative approach to corridor mapping through land manager interviews, GIS modeling with Circuitscape and Least Cost Path analysis, and an in-field survey using the Habitat Connectivity Toolkit, a novel surveying method developed by Portland State University researchers and Metro. Connectivity is estimated for three wetland species: American beaver (Castor canadensis), northern red-legged frog (Rana aurora aurora) and western-painted turtles (Chrysemys picta). All methods were judged on landscape accuracy, barrier accuracy, ease of use and final data output to assist land managers with choosing the right method for their needs and resources.

Through a comparison of results from all methods, the Habitat Connectivity Toolkit performs best in every category except for ease of use due to the time and resources required for in-field surveying. It is recommended that managers interested in assessing corridors either use the Habitat Connectivity Toolkit for the most comprehensive corridor assessment, or use a combination of methods to best remediate the potential challenges and inaccuracies of the other methods.
\end{abstract}




\section{Introduction}

Habitat connectivity in urban settings is critical for facilitation of safe species movement, species health and biodiversity (Metro 2010). The urban environment is difficult for many species to move through due to the presence of barriers - natural or built features in the landscape that restrict or prohibit movement of species (Jackson 2000). In addition, urban habitat patches can be of poor quality and fragmented (Cadenasso and Pickett 2008; Pickett and Cadenasso 2008). However, urban properties and greenspaces can serve as corridors for wildlife movement across the complex developed matrix (Bolger et al. 2001). The availability for wildlife to use these stepping stones to move to distant habitat patches facilitates healthy populations and promotes resource availability for wildlife (Lidicker and Koenig 1996; Bennett and Mulongoy 2006). Land managers should be conscious of the potential use of their property as wildlife corridors so that actions can be taken to manage for wildlife movement. Assessments of corridor functionality and quality should be performed to maximize safe wildlife passages and manage for high quality habitat where possible. However, some private or public land and property managers may not be aware of current corridor assessment methods, or have the background information to initiate an assessment. Our goal is to introduce land managers to available corridor assessment methods and discuss their resulting products, advantages, and disadvantages of use for managers to choose the best method for their objectives. We hope that when provided with the need, method and an explanation of the product, land managers will be more likely to choose an applicable assessment method to their goals and follow through with the process.

In order to compare assessment methods, we used the same Portland, Oregon study area for all methods. We describe the process, the advantages, and the disadvantages of three commonly used corridor assessment method types: a collaborative approach for corridor identification, GIS modeling, and in-field surveys. A species-specific methodology was performed to determine movement suitability for three wetland species: American beaver (Castor canadensis), red-legged frog (Rana aurora aurora), and western painted turtle (Chrysemys picta bellii). Each species has unique habitat and barrier requirements and preferences to move through a corridor, and can model the corridor permeability for a similar wildlife functional group based in life-history similarity. In the end, a comparison of all three methods aims to provide land managers with a resource to determine which method would provide the most useful results for a given objective. 
This research was performed in collaboration with Port of Portland. Port of Portland manages multiple restoration and mitigation properties with goals of increasing habitat presence and connectivity between sites. This project assessed the connectivity between two Port of Portland properties that provide valuable wildlife habitat, the T5 Powerline site and Vanport Wetlands sites. With this research, the level of connectivity in the study area was visualized, and the connecting greenspaces can be analyzed for habitat composition and barrier permeability contributing to wildlife corridors through the area. 


\section{Background}

\section{Connectivity in the Urban Environment}

Urban landscapes are mosaics of development and greenspaces such as residential yards and city parks. These greenspaces can serve as habitat patches for local vertebrate and invertebrate wildlife species and provide stepping stones for movement across a city (Rudd et al 2002). As urbanization causes these patches to become fragmented and more isolated, the connectivity of the landscape decreases and the ability of wildlife to move safely across the landscape becomes more impaired (Metro 2010). When isolated to habitat patches due to low connectivity, wildlife will face resource constraints (Taylor et al. 1993), genetic isolation (Monsen and Bouin 2004; Burgman and Lindenmayer 1998; Hedrick 2001), limited access to mates, and local extinction (Forman et al. 2003; Millenium Ecosystem Assessment 2005; Austin 2012). While there are many challenges to urban habitat patches, they have been shown to be vital for local biodiversity and wildlife (Alvey 2006; Dearborn and Kark 2009; Metro 2010). Small, accessible patches of habitat aide wildlife migrating across the city (Hanski and Gilpin 1991), and the greater in number and the closer they are in proximity, the likeliness of colonization of adjacent patches increases by dispersing species (Hanski and Thomas 1994). This points to a need for both increasing the number of habitat patches in an urban environment as well as increasing the level of connectivity between the patches to facilitate wildlife dispersal.

The level of habitat connectivity is dependent on the permeability of the landscape and the level to which it facilitates or hinders wildlife movement (Rothley 2005). In an urban environment, connectivity can be limited due to hardscaping, the presence of infrastructure (Forman and Alexander 1998; Fahrig and Rytwinski 2009), and human activity that affects species movement such as construction, vehicular traffic and urban lighting (Metro 2012). Management and property design to limit human trespassing can also have consequences on wildlife movement, preventing accessibility of habitat to wildlife through fencing and other property boundary markings. In order to avoid this complex matrix, wildlife take advantage of corridors and zones of connectivity connecting habitat patches in the area. Zones of connectivity can vary in size and composition, including urban greenspaces and urban properties which can serve as stepping stones for wildlife movement (Hilty and Lidicker 2006). Both corridors and zones of connectivity can help wildlife avoid the harsh matrix and facilitate safe movement from 
patch to patch, increasing connectivity in the city and promoting population dispersal and access to new resources (Lidicker and Koening 1996; Haddad et al. 2003).

\section{Urban Corridors}

A corridor is a stretch of habitat that connects two or more habitat patches. Corridors can be seen as 'green roadways' that connect similar habitat while being surrounded by a matrix, the surrounding landscape that differs in habitat composition compared to the corridor or habitat patches of interest (Hilty et al. 2006). In the urban context, these corridors are often stretches of greenspace that weave in between a matrix of development, industry and complex residential areas. Corridors are linear features (Rosenburg et al. 1997), but can appear as stepping stones if the functionality is not compromised (Hilty and Lidicker 2006). Corridors are used by wildlife for migration and dispersal (Metro 2012). A corridor network can improve the habitat connectivity of a landscape, and provide safe passage for wildlife movement (Lidicker and Koening 1996; Gibbons 2003). Corridors do have disadvantages, as they may facilitate movement of invasive species (Hobbs 1992), disease, and predators (Adams and Dove 1989; Duerksen et al. 1997), all of which are costs that must be considered when managing urban corridors. Urban corridors face other challenges as well, including edge effects (Soule and Gilpin 1991), the presence of infrastructure or barriers spanning the corridor, and the unique features each species requires in a corridor for full functionality (Metro 2012).

The stark contrast between the biotic composition of the corridor and the developed matrix may impact the integrity of the corridor by increasing the edge effect, the level and extent of dissimilarity between the edge of the corridor and the interior (Soule and Gilpin 1991). Edge effects can include greater abundance of invasive species (Metro 2012), higher levels of noise and light pollution (Delgado et al. 2007; Gaston et al. 2002; Pocock and Lawrence 2005), and are similar in concept as the zones of disturbance around development which impacts wildlife (Theobald 1997). Increasing these elements constricts the pathways of intact undeveloped habitat and may decrease permeability of the corridor for some species.

Many urban corridors and connectivity zones are adjacent to or crossed by infrastructure, such as roads, railroads, trails and fences. These structures impact movement behavior for multiple species (Shepard et al. 2008). The infrastructure elements serve both as physical barriers to movement as well as deterring elements that wildlife will actively avoid due to 
foreign stimuli (Forman and Alexander 1998; Fahrig and Rytwinski 2009). Wildlife may stop dispersing, seek an alternative route, or they may attempt at crossing the barrier which could lead to injury or death (Yale Conrey and Mills 2001; Olsson and Widen 2008; Shepard et al. 2008' Corlatti et al. 2009). The impact of a barrier is species dependent, as some species' methods of mobility allows avoidance while others can be affected by its presence, such as avian versus amphibian movement across a highway.

In order to mitigate the effects of a barrier, wildlife crossing structures can be implemented to allow safe movement across, under, or over the barrier. Crossing structures come in a variety of sizes and design, from small pipes and culverts to large viaducts and bridged overcrossings. Retrofitting of storm water infrastructure or purely aquatic crossing structures is often needed for terrestrial species use, and can be accomplished through addition of a shelf or floating structures (Metro 2009). Similar to corridor requirements, each suite of species will have requirements and preferences to move through the crossing structure, including structure size, height, substrate, and water level, and level of human avoidance (Clevenger et al. 2003; Clevenger and Waltho 2005; Woltz et al. 2008). Crossing structure features, such as water velocity, negatively impact species use (Toepfer et al. 1998; Gibson et al. 2011). Bridges can be used as a method of crossing for many species and serve the same benefit as a wildlife crossing structure, if not modified with an additional barrier such as a fence or road built underneath and instead left as a structure similar to a viaduct (Metro 2009).

An effective corridor is one that a species expends the least amount of time, resources and effort moving through (Soule 1991). Wildlife may show corridor habitat composition preference, such as vegetation cover and width (Lindenmayer et al. 1994; Laurance and Laurance 1999; Hilty and Merenlender 2004). Urban corridors can consist of a compilation of multiple habitat types, which may create altering levels of functionality for a species along the length of the corridor.

Encroachment of development, infrastructure barriers and habitat composition are only a few of the challenges to urban corridors that impact the permeability and connectivity of an area. Recognizing the significance of these influences, land managers should perform corridor assessments to determine the current composition and permeability of their local corridors. Corridors need to be considered on a species-specific level, as particularities regarding habitat features, barriers and crossing structure will have different impacts on wildlife groups. 


\section{Current Corridor Assessment Methods}

There are multiple methods to assess habitat suitability for wildlife, but fewer for corridor assessments. Habitat for wildlife is often assessed based on functionality for residence, while corridors need to be assessed based on habitat features best suited for movement as well as the permeability of barriers spanning the corridor. Even fewer assessment methods have been created to study corridors exclusively in urban areas and in small scale. There are limited tools available for land managers who wish to perform local corridor assessments, including collaborative approaches, GIS modeling, and in-field assessments. Below is an overview of these three categories and their functionality for assessing corridors.

\section{Collaborative Approaches}

A popular method for environmental decision-making is to use a collaborative approach, or a pooling of information from stakeholders to solve environmental problems (Gray 1985). As Selin and Chavez (1995) write, “...power is shared, and stakeholders take collective responsibility for their actions and subsequent outcomes from those actions". A collaborative approach can be an efficient way to identify corridors, and can be used for regional planning (Ashor et al. 1996) and shared management efforts (Rao and Giesler 1990). A collaborative approach to corridor assessments involves the participation of multiple stakeholders and experts to identify current corridors in a region (Metro 2010), including welcoming non-scientists to the table for participation (Beier et al. 2009).

An example of this process is the work done by Metro and the Regional Connectivity Work Group (Metro 2010). Metro, the tri-county regional government containing the city of Portland, Oregon, used a collaborative approach in an attempt to map current corridors inside the urban growth boundary. Initial corridors inside the growth boundary were drawn by Metro based off of existing landscape and greenspace knowledge. Next, a workgroup was assembled consisting of regional stakeholders, including landscape and species experts, and they were asked to contribute by editing and drawing new corridors on large maps by hand and identifying potential core habitats and focal species. This was then digitized and is now a resource for the local Regional Connectivity Work Group to plan, implement management strategies, and establish recommendations for management of regional corridors. 
Another collaborative approach was a statewide connectivity map for California, organized by the California Department of Transportation and the California Department of Fish and Game, called the California Essential Habitat Connectivity Project (Spencer et al. 2010). Approximately 200 individual stakeholders in local, regional, federal, state, and tribal land managing or conservation agencies participated in identifying essential connectivity areas and natural landscape blocks. The group created a statewide map with related habitat connectivity data, as well as a document guiding the mitigation of fragmenting effects of roads.

A collaborative approach method is useful for corridor identification; however, it relies heavily on experts being aware of the current landscape status and agreeing on species and habitat needs. Conflicting ideas may lead to disagreement regarding corridor functionality, and as equal power must be distributed to all members in the decision making process (Selin and Chavez 1995), the length of the workshop may extend until a joint decision can be reached or a higher committee makes a concluding decision. In addition, the method increases in organizational difficulty as the method receives higher participation from stakeholders. This can be mitigated through detailed management of the process to improve efficiency and participation.

\section{GIS Analysis and Modeling}

There are many Geographic Information System (GIS) tools to define and map connectivity across the landscape (Corridordesign 2013). A few examples are FRAGSTATS, which quantifies landscape structure to determine landscape influences on ecological characteristics (McGarigal and Marks 1994), the Connectivity Analysis Toolkit, which maps habitat linkages between source and target habitat patches (Carrol 2013), and LINK, which is a set of Environmental Systems Research Institute (ESRI) ArcGIS tools that analyze habitat patterns and compare conservation potential in the surrounding landscape (USGS 2014). Corridors can be identified from some of these modeling methods by identifying stretches of suitable habitat connecting larger habitat patches across the landscape, and linking habitat patches together through suitable pathways across the matrix. Vegetation and landscape data can distinguish paved or built features, allowing researchers to separate the built environment from potential habitat in a city. 
Issues of spatial extent arise using GIS for ecological purposes. Scale in cartography and mapping efforts can be explained by the comparison of the distance between two points on a map to the same spatial points in the real world, such as a 1: 12,000 scale. In landscape ecology, scale represents grain, which is the resolution, and extent, which is the size of an area (Houston 2002; Gontier 2007). When performing habitat connectivity modeling using GIS, grain and extent must be carefully considered, as changes could affect landscape characteristic identification ( $\mathrm{Wu}$ 2004; Gontier 2007). Time is also recommended to be considered as an additional component to grain and extent in habitat modeling (Gontier 2007).

Working with GIS habitat modeling, the datasets themselves must be accurate in classification of habitat. Raster datasets, a type of data used in GIS, define continuous pixels on a map with a numerical or categorical classification, such as vegetation type or slope. This is similar to how pixels on a picture have unique colors to create an image. These pixels can range in size, from very fine-scale data (such as a pixel representing a few square meters of land), up to larger scales (each pixel representing square kilometers or more). The pixel will be coded with the classification occupying the largest area in the cell. So if you were using a cell size of one square mile, and two-thirds of the area was paved, the cell would appear as if the entire area was paved on the map (Berry 1993). This creates problems in an urban area, as valuable small habitat patches can be unrepresented in a pavement classified cell, or conversely, infrastructure will be unnoticed in a vegetative classified cell, resulting in misclassification. In order to mitigate this issue of scale, urban GIS habitat modeling should be performed using fine resolution data to capture the true picture of the landscape (Adriaensen et al. 2003).

In addition to the issue of scale, GIS modeling requires accurate and detailed landscape data (Adriaensen et al. 2003). In addition, some require ranking of habitat features for particular species. This requires in-depth knowledge of the species of interest, especially in regards to mobility and dispersal habitat. There is a lack of literature on movement habitat for many species, especially in an urban environment. Because of this, the method may have to rely on expert opinion to fill in the gaps of knowledge. Since expert opinion is subjective and utilizes anecdotal data as well as existing knowledge, the results of a ranking exercise can vary depending on the individual, community, or region. This makes a standardized approach to GIS modeling difficult, as one source of data could be dependent on opinion. 
One tool for connectivity modeling is Circuitscape, a GIS software that uses circuit theory to model landscape permeability and can be used to predict wildlife movement (Shah and McRae 2008). Circuitscape was originally developed to model gene flow by the path of least resistance through a landscape. It works by encoding pixels with numeric resistance factors, then sending an 'electric current' from source nodes representing the starting points of movement, to ground nodes representing the ending points. This results in a landscape map reflecting areas of high movement and areas of low movement based on the overall resistance of the pixels. It can show high value areas for movement, as well as pinch points in the landscape where movement is funneled through the area with the lowest resistance (McRae and Shah 2009).

The use of the software can be applied to model wildlife movement in order to quantify and visualize landscape connectivity. The resistance factors reflect the permeability of a habitat type for wildlife movement (ranked on the preference of a species to move through it), and the source and ground nodes are the patches that are being connected (McRae and Shah 2009). This valuable tool has been used by multiple studies and government agencies for conservation and research efforts for connectivity (Ziegler et al. 2011; Phillipsen and Lytle 2013; Welch 2015). Circuitscape is also being used in land management decisions by non-government organizations (NGO's) such as The Nature Conservancy. The Nature Conservancy uses Circuitscape to assess terrestrial connectivity, allowing them to identify resistant habitat patches for management or potential land acquisition (Buttrick 2015; McRae 2016).

An increasingly popular tool for habitat patch connectivity is Least Cost Path (LCP) analysis (Adriaensen et al. 2003; Rothley 2005). Least cost paths use cells coded with resistance values based on a factor such as wildlife habitat permeability and create a single defined path between two habitat patches (Meegan and Maehr 2002, Larkin et al. 2004) considering cell resistance and the shortest distance. It works by adding up the 'costs' of the path and reflecting the path with the lowest cost (Rothley 2005). This results in a predicted dispersal path that wildlife might take between two habitat patches (Larkin et al. 2004). This approach is valuable where single paths need to be visualized, and where habitat resistances are similar on a landscape so a path is not clear through aerial imagery or other GIS methods such as Circuitscape. However, there are concerns regarding using LCP exclusively for connectivity modeling. Problems with LCPs arise when no low-resistance route is available and so the model defaults to the shortest route. Hence, the model identifies a path through high resistance areas in order to 
take the shortest route totaling the lowest cost possible, sometimes referred to as a 'crack' in the LCP model (Rothley 2005). When considering wildlife movement and habitat resistances, this may suggest them moving through areas where movement is technically possible, but not realistic. In addition, LCP's work by adding up costs for a path based on the resistance and distance, and showing the path with the lowest combined cost. Paths with similar but slightly higher software-calculated costs are not shown, and therefore potential wildlife paths of similar functionality will be undisclosed to the researcher (Pinto and Kiett 2008).

GIS tools are valuable to researchers and land managers due to easily accessible programs and data. In addition, the models can be applied to any region where land cover data are available, and can be used for any species as long as the researcher has a ranking or score of microhabitat preferences for a given species.

\section{In-Field Surveys}

There are numerous in-field methods to assess habitat suitability for wildlife species, including standardized approaches such as the Habitat Suitability Index for species-specific habitat assessments (USGS 2017), the USFS Habitat Evaluation Procedures (USFS 1980), or habitat quality assessments like the QBR (the "Qualitat del Bosc de Ribera" or "Riparian Forest Quality”) index for riparian habitat quality (Prat et al 2002). These survey tools allow for quick, simple habitat assessments that can be quantified for management decisions. Usually involving a small field sheet and simple calculations, the numerical outputs of in-field assessment tools are easily interpretable and are not spatially limited by regions. In-field methods require researchers to be present on site to survey the area, which can be time and resource intensive, but allows for a current and accurate record of the site features and quality.

In-field assessments for corridor functionality exist, but many are geared towards stream habitat and water quality, such as the National Resources Conservation Service's "Stream Visual Assessment Protocols" (NRCS, 1998), the Freshwater Connectivity Toolkit in development by The Nature Conservancy (Conservationtoolkit.org 2017), or the state of Maryland's "Stream Corridor Assessment Survey" (Yetman 2002). In these surveys, barriers and infrastructure related to water flow and stream alteration are incorporated due to their high impact on stream morphology. Freshwater, wetland, and riparian habitat conditions are also assessed for quality and habitat functionality for aquatic wildlife. Maryland's Stream Corridor Assessment Survey 
uses a derivation of the Environmental Protection Agency's Rapid Bioassessment Protocols for a quick habitat survey method (Yetman 2002). These stream survey methods are useful tools to quantify current water quality and habitat conditions, but are rarely species specific and would only encapsulate a small portion of urban greenspaces available for wildlife movement. In addition, training on stream and wetland conditions are often needed to accurately complete the survey, which increases difficulty if an urban land manager wishes to assess a corridor on their property without access to training resources.

Currently in development is a corridor assessment tool called the Habitat Connectivity Toolkit which combines GIS analysis and in-field surveys. The Habitat Connectivity Toolkit is being developed by researchers at Portland State University and Metro and uses a combination of habitat scoring and permeability scoring of barriers to quantify the connectivity of a corridor for a species. Select surrogate species, or species whose lifestyles and mobility are representative of a suite of other species, have unique scoring cards for both habitat features and structure as well as the characteristics of infrastructure barriers such as roads and fences. Using data collected in the field and verified GIS information, a land manager or researcher can score an identified corridor for a surrogate species and get a picture of the feasibility of movement through the area (Bliss-Ketchum et al. 2016; Lafrenz et al. 2017). The Habitat Connectivity Toolkit is still being modified and is slated for publication in the next few years. 


\section{Study Area}

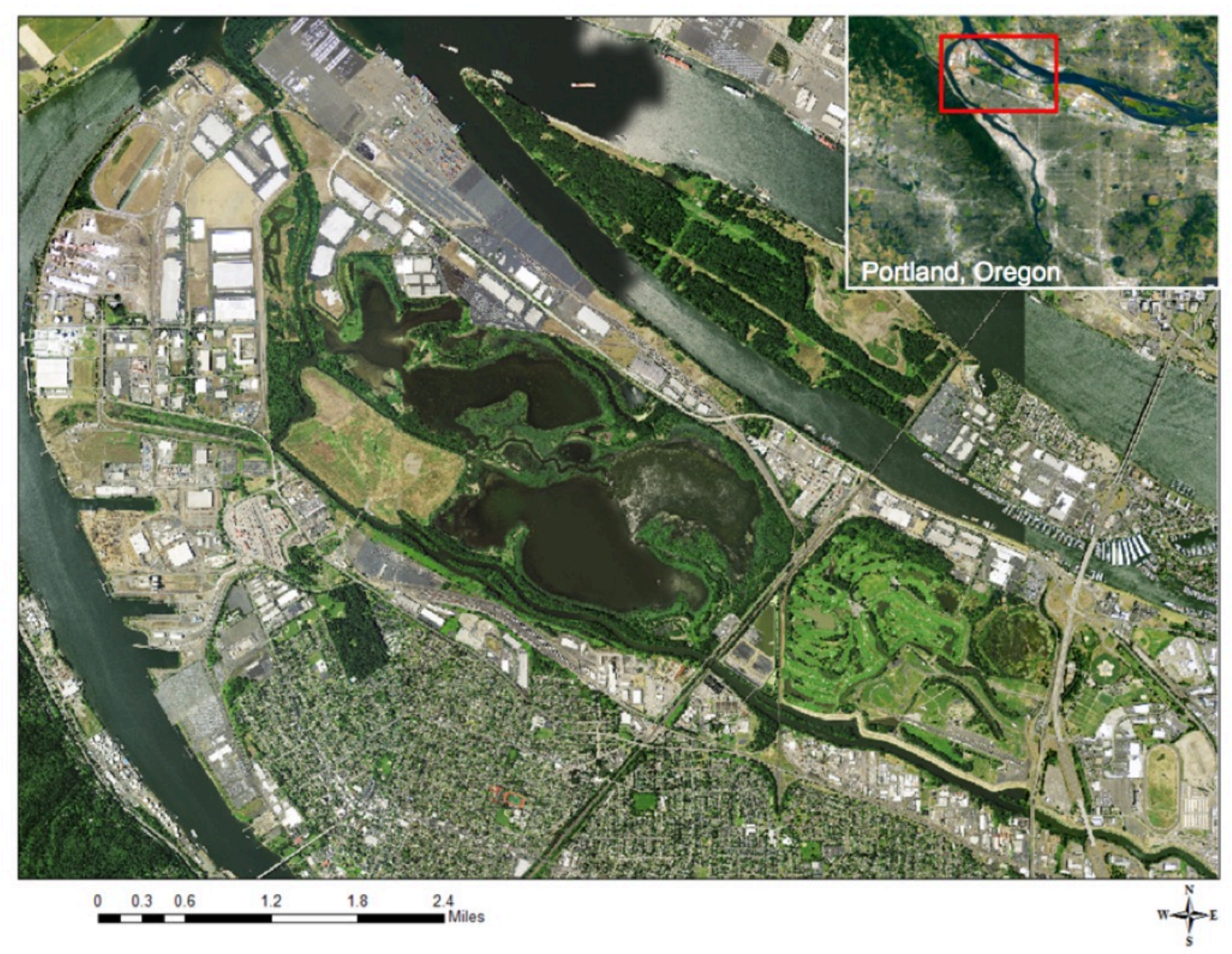

Figure 1: Study area located in north Portland, Oregon, United States.

This project focuses on a greenspace located north of the St. John's Neighborhood in an urbanized area of Portland, Oregon (See Figure 1). Properties of multiple government and nongovernment organizations connect to form a 'green belt' of natural areas and recreational areas bounded by built environment, predominantly industrial properties. Large shipping and trade terminals owned by Port of Portland surround the northwest corner of the study area, with the north and south edges of the greenspace being mostly private commercial industrial properties. The study area contains popular natural areas such as Smith and Bybee Wetlands as well as city managed recreational properties including Heron Lakes Golf Course and the Portland International Raceway.

The study area falls in the Columbia Slough Watershed, which covers about 32,700 acres on the south side of the Columbia River and extends eastwards towards Fairview, Oregon. The 
watershed is named for the Columbia Slough, a waterway, which begins at Fairview Lakes and travels 19 miles west towards Kelly Point Park at the northern tip of the study area. The slough borders the bottom of the study area, but cuts upwards along the west side of Smith and Bybee Wetlands and empties into the confluence of the Columbia and Willamette Rivers (The City of Portland 2017).

\section{Properties and Habitat Information}

The study area contains properties from three major land owning agencies - Port of Portland, Metro, and City of Portland. The appropriate permits were acquired for access to all properties where on-site assessments were performed. Aerial imagery of properties can be found in Appendix D: Maps.

\section{Port of Portland Properties}

Port of Portland is the port district managing the local Portland International Airport and several marine terminals around the city. It controls much of the industrial ports and properties surrounding the west and north sides of the study area. These properties are largely paved and have shipping terminals, storage and other facilities on site. Port of Portland does manage multiple mitigation properties, some of which are included in the study area. These sites are actively managed for native habitat conservation, and are described below.

\section{T5 Powerline, West Wye, Bonneville Pond Sites}

The T5 Powerline site is adjacent to the Willamette River and serves as a mitigation property for Port of Portland, created out of an existing dredge-fill material storage site in the late 1990's. The goals of the mitigation work were to restore hydrology, enhance native vegetation and conserve the use of the property as a wildlife habitat and corridor, especially for the native western painted turtle (Chrysemys picta bellii). The site is ephemeral wetland habitat, scrub-shrub wetlands and grassland meadow habitat. It is a known western painted turtle nesting site, with an active population on the property supported by an existing perennial pond that provides overwintering habitat (Port of Portland 2015). A wildlife crossing structure was built in 2004 by the Port of Portland to facilitate movement across an active trucking road and railroad line to the east of the property, with the passage leading to Port of Portland's West Wye site. 
West Wye contains similar scrub shrub wetland habitat and grassland/low herbaceous vegetation. It is bordered by roads with moderate traffic and trucking activity, and is crossed by active railroad lines. The remaining stretch of property extending to the Columbia Slough is similar in composition, but not actively managed for invasive species (predominantly blackberries). Bonneville Pond, a small sized ponded wetland site, is located close to the slough and is separated by railroad lines. It is managed partially by Port of Portland, though mostly by Bonneville Power Administration (Port of Portland 2012), and supports a second western painted turtle population (Hays 1999).

\section{Rivergate Enhancement and Ramsey Lakes Sites}

The Rivergate Enhancement Site and Ramsey Lakes Site are mitigation sites initiated by Port of Portland to restore and enhance riparian and wetland habitats in the Rivergate area after wetland fills in the Rivergate Industrial Park. Emphasis was placed on the restoration of wetlands functions, fish, amphibian and waterfowl habitats, as well as enhancement of meadow habitat and native plant presence (Port of Portland 2015). The sites consist of riparian wetland and forested riparian habitat buffering the Columbia Slough as it exits into the confluence of the Willamette and Columbia Rivers. Ramsey Lake's open water habitat and meadow habitat lies to the west of the Columbia Slough, north-west of St. John's Prairie. The sites are crossed by road and railroad bridges, and are surrounded by active industrial properties (Port of Portland 2015).

\section{Vanport Wetlands}

Vanport Wetlands is the most westward Port of Portland mitigation site in the study area, covering more than 90 acres west of Interstate 5. It has an open water center that seasonally fills and drains depending on the precipitation and ground water input. Water levels are currently lowered and maintained by a pumping station due to the disconnection of the historical wetland hydrology from the Columbia River Floodplain. The center lake and emergent wetland of the site transitions to a border of scrub-shrub wetland and forested wetland. Upland forested areas and meadow habitat are also present on the property. Many mammalian, amphibian, reptile and avian species have been observed using the site, including over 100 species of birds that use the site for nesting and breeding (Port of Portland, 2004). A large grassy turf lies to the south of the wetland, and serves as a community dog park as well as an overflow parking area by City of Portland's Portland International Raceway. A road repurposed as a trail runs around Vanport Wetland and 
in between the wetland and Heron Lake Golf Course to the west. The Expo Center and the Expo parking lots lie to the north of the wetland, and are managed by Metro.

\section{Metro Properties}

Metro is the regional government for the Portland metropolitan area. The Metro region includes Multnomah, Washington, and Clackamas Counties and has responsibilities in land use planning, transportation and the control of urban expansion (Metro 2017: What is Metro?). Metro owns and manages over 16,000 acres of natural areas and parks (Metro 2016), including Smith and Bybee Wetlands and the St. John's Prairie, a historic landfill now converted to a prairie conservation site (Metro 2017: St. John's Landfill). The Metro owned properties with the study area are discussed below.

\section{Smith and Bybee Wetlands}

Smith and Bybee Wetlands consists of almost 2,000 acres of preserved wetland and riparian habitat surrounding Smith Lake and Bybee Lake, historical remnants of the past hydrological modifications imposed by early urbanization. After community consensus of the value of the wetlands in 1990, the Smith and Bybee Wetlands Comprehensive Natural Resource Plan was developed to restore the wetlands to a natural area with recreational opportunities. The wetland is now one of the largest preserved natural areas in the Portland Metro area and provides the community with recreational spaces and activities, including nature trails and kayaking. The wetland is surrounded by industrial properties, and bordered by St. John's Prairie and Port of Portland mitigation sites to the west and southwest, and Heron Lakes Golf Course to the east. Many busy roads and rail lines are adjacent to the wetlands, including a rail yard to the north of the wetlands, in between Smith and Bybee Wetlands and the Columbia River. Due to its size and topographical variation, Smith and Bybee Wetlands contains a multitude of habitats, including open water, scrub-shrub wetlands and marsh habitat, upland forest and riparian areas, and upland prairie habitat (Metro 2012). A new effort in 2011 by Metro emphasizes the conservation of wildlife habitat in Smith and Bybee, including preservation of habitats of importance to the western painted turtle (C. picta bellii) and the streaked horned lark (Eremophila alpestris strigata) (Metro 2012: Supplemental Appendix).

The water depths of Smith and Bybee Lakes are managed by a water control structure that facilitates water movement between the wetland and the Columbia Slough. The wetlands 
experience seasonal flooding and drawdown, with high water levels maintained until late June when the water levels are lowered to reach equilibrium with the Columbia River (Metro 2012).

\section{St. John's Prairie}

Reclamation of the St. John's Landfill in the late 1990's led to creation of over 200 acres of upland prairie habitat for wildlife habitat. Metro continues to collect methane emissions from the landfill underneath the prairie, and the property is currently closed off to public access. Future development of the property includes a public trail that connects Smith and Bybee Wetlands to St. John's Prairie (Metro 2012). The grassland cover of the landfill is being managed for native Willamette Valley upland prairie, with Metro management goals of restoring 140 acres of degraded upland prairie to fair condition for native forbs by 2021 (Metro 2012). Riparian habitat surrounds the sloping perimeter of the prairie as the Columbia Slough splits into the Blind Slough and the North Slough around the property. The Smith the Bybee water control structure is at the northeast corner of the prairie, and consists of a concrete structure with three control gates, approximately 40 feet long with a surface road.

\section{City of Portland Properties}

City of Portland owns and manages two large recreational properties in the study area: Heron Lakes Golf Course and the Portland International Raceway. The City of Portland is highly interested in environmental conservation and management, and employs methods to preserve wildlife habitat for both properties (Audubon 2017, City of Portland 2005). These properties are described below.

\section{Heron Lakes Golf Course}

City of Portland manages a recreational public golf course east of Smith and Bybee Wetlands and west of interstate 5 and Vanport Wetlands. The golf course itself is predominantly composed of managed turf, with occasional sand traps and ponds interspersed on the property. In the northwest corner of Heron Lakes Golf Course is a heron rookery with dense shrubs and vegetation to limit public access and interference with wildlife nesting (Platt et al 1994). The golf course is designated as a "Certified Audubon Cooperative Sanctuary" through the Audubon Cooperative Sanctuary Program for Golf Courses, an Audubon International program that places an emphasis on natural resource and wildlife habitat preservation (Audubon International 2017). 
The property's east edge is adjacent to both Vanport Wetlands and the Portland International Raceway. Small tributaries and offshoots of the Columbia Slough lie on the east edge of the property, as well as Force Lake, a small open water lake that is frequented by waterfowl. Trails for motorized golf carts crisscross the property, and a central clubhouse and parking lot are located at the center of the course.

\section{Portland International Raceway}

The Portland International Raceway (PIR) consists of a large grassy turf with a racing track for vehicular racing. Some riparian habitat, forested wetland and scrub-shrub wetland is located on site due to extensions of the Columbia Slough and ponding that occurs on the south side of the property.

\section{Columbia Boulevard Wastewater Treatment Plant Lagoon}

Located southwest of Heron Lakes Golf Course is a large treatment pond for wastewater, operated by the Columbia Boulevard Wastewater Treatment Plant. The lagoon is off limits to the public and fenced to ensure no wildlife accesses the ponds by terrestrial or aquatic means. The lagoon landscape is either paved or a man-made body of open water with concrete substrate.

\section{Study Area Map and Habitat Types}

A map compiling the study area properties is included below (Figure 2). The map details the notable sites contained in the study area, including Port of Portland (POP) properties, City of Portland (COP) Parks and Recreation managed properties, and Metro properties. A table of the habitats contained in the properties is also included (Table 1). Habitat classifications are copied from habitat management documents for each property, or if no document exists, was identified through aerial imagery and the National Wetland Inventory wetland mapper (U.S. Fish and Wildlife Service 2016) so some habitat types may possess different nomenclature depending on the classification used by the land managers. 


\section{Study Area Properties}

Property Managers: Port of Portland (POP), City of Portland (COP), Metro, Bonneville Power Administration (BPA)
A POP: T5 Powerline Site
F Metro: Smith and Bybee Wetlands
B POP: West Wye Site
GOP: Columbia Boulevard
C POP/BPA: Bonneville Pond Site
H COP: Heron Lakes Golf Course
D POP: Rivergate Enhancement Site / Ramsey Lakes
E Metro: St. John's Prairie
I COP: Portland International Raceway
J POP: Vanport Wetlands

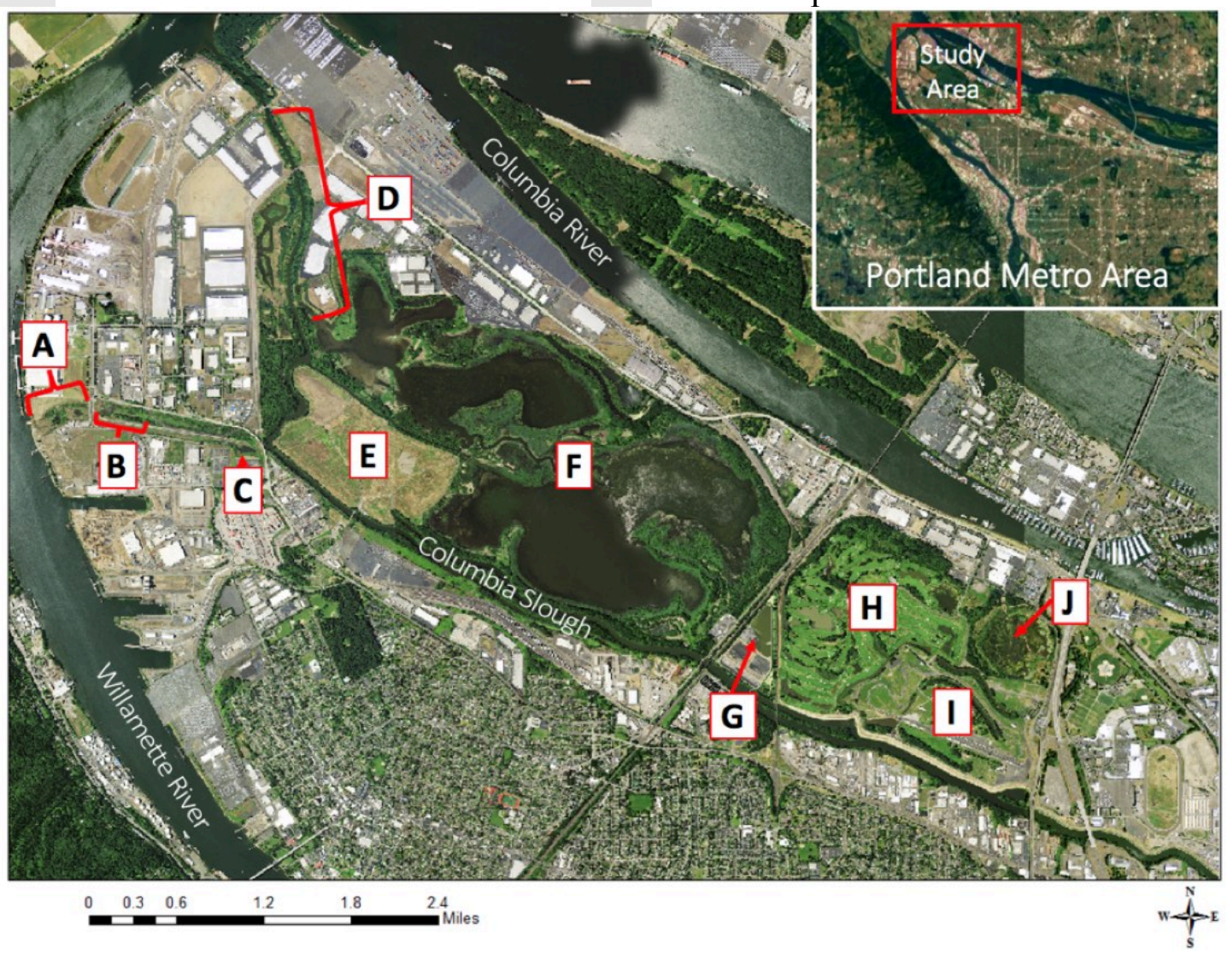

Figure 2: North Portland study area property names and managing agencies. 
Table 1: Habitat Categories Contained in Study Area

\section{Property Habitat Composition}

\begin{tabular}{|c|c|c|}
\hline Property Manager & Property Name & Habitat Types \\
\hline \multirow[t]{5}{*}{ Port of Portland } & Rivergate/T5 Powerline & $\begin{array}{l}\text { Freshwater Emergent Wetland } \\
\text { Scrub-Scrub Wetland } \\
\text { (Port of Portland 2015) }\end{array}$ \\
\hline & West Wye & $\begin{array}{l}\text { Grassland/Low Herbaceous } \\
\text { Scrub-Shrub Wetland } \\
\text { (Port of Portland 2015) }\end{array}$ \\
\hline & Bonneville Pond & $\begin{array}{l}\text { Scrub-Shrub Wetland } \\
\text { Open Water } \\
\text { (Port of Portland 2015) }\end{array}$ \\
\hline & $\begin{array}{l}\text { Rivergate Enhancement and } \\
\text { Ramsey Lakes }\end{array}$ & $\begin{array}{l}\text { Riparian Wetland } \\
\text { Forested Riparian } \\
\text { Meadow } \\
\text { Palustrine Scrub Shrub } \\
\text { (Port of Portland 2015) }\end{array}$ \\
\hline & Vanport Wetlands & $\begin{array}{l}\text { Scrub-Shrub Wetland } \\
\text { Emergent Wetland } \\
\text { Freshwater Forested Wetland } \\
\text { Meadow } \\
\text { Forested Uplands } \\
\text { (Port of Portland 2004) }\end{array}$ \\
\hline \multirow[t]{2}{*}{ Metro } & St. John’s Prairie & $\begin{array}{l}\text { Upland Prairie } \\
\text { Riparian Forest } \\
\text { (Metro 2012) }\end{array}$ \\
\hline & Smith and Bybee Wetlands & $\begin{array}{l}\text { Scrub-shrub Wetland } \\
\text { Open Water } \\
\text { Upland Prairie } \\
\text { Riparian Forest } \\
\text { Bottomland Hardwood Wetland } \\
\text { (Metro 2102) }\end{array}$ \\
\hline \multirow[t]{2}{*}{ City of Portland } & Heron Lakes Golf Course & $\begin{array}{l}\text { Managed Turf, } \\
\text { Forested/shrub habitat } \\
\text { Freshwater Emergent Wetland } \\
\text { Pavement/Development } \\
\text { (Aerial imagery, USFWS 2017) }\end{array}$ \\
\hline & PIR international raceway & $\begin{array}{l}\text { Managed Turf } \\
\text { Freshwater Forested Wetland } \\
\text { Freshwater Emergent Wetland } \\
\text { Pavement/Development } \\
\text { (Aerial imagery, USFWS 2017) }\end{array}$ \\
\hline
\end{tabular}




\section{Species of Interest}

Three wetland species were selected to model corridor functionality and quality: the western painted turtle, the red-legged frog, and the American beaver. Wetland species were used due to the high proportion of wetland habitat in the study area. Each species is also of special interest to land managers in the Portland Metro area, and information on the mobility of individuals and connectivity of populations from this study would benefit management plans. These species are also representative of other wildlife sharing similar life strategies and corridor structure needs (Bliss-Ketchum 2016). While this project focuses on western painted turtle, redlegged frog and American beaver, the methods used can be tailored for any species of interest or habitat type where the corridor presence for a particular species would represent the connectivity of that particular habitat.

\section{Western Painted Turtle}

The western painted turtle (Chrysemys picta bellii) is a species native to the Pacific Northwest United States, and is one of the most common turtles in North America. While it is widely distributed across the United States, its populations are limited in Oregon to the northern part of the state, primarily in the Columbia River Basin and the northern portion of the Willamette Basin (Gervais and Rosenburg 2009). The City of Portland, Port of Portland and Metro all have participated in conservation efforts to preserve urban western painted turtle populations, and the species is listed as a priority species by the state of Oregon (ODFW 2006, Gervais and Rosenburg 2009).

The western painted turtle resides in shallow, low-flow water bodies, including ponds, lakes, streams and wetlands (Carr 1952; Ernst and Lovich 2009). The turtles can be found in densities of up to 840 turtles per hectare of water surface, though fewer may be seen in colder climates and water bodies where preferred habitat is concentrated to the shoreline (Ernst et al 1994). The western painted turtle prefers aquatic habitats with emergent vegetation and muddy substrates, which the turtle can use for overwintering. Terrestrial habitats are also required by western painted turtles for nesting activities. Preferred nesting habitats are sparsely vegetated, with south facing sun exposure and substrate such as sand or fill material (Gervais and Rosenburg 2009). Terrestrial habitat is also used for movement between aquatic habitats and terrestrial nesting sites (Baldwin et al. 2004; Bowne et al. 2006; Guzy et al. 2013). 
Western painted turtle movement may be driven by many motivators, including resource needs (Bowne and White 2004), seasonal draining or drying of aquatic habitats (Gibbons et al. 1983), mate acquisition (Gibbons et al. 1990), and most commonly, nesting behaviors (Gervais and Rosenburg 2009). They have been recorded moving up to 2100 meters (McAuliffe 1978), with the general consensus that larger turtles moving further distances than smaller turtles (Gibbons et al. 1990), though some turtle movement studies found no such relation (House et al. 2010). There is little literature regarding preferential or challenging habitat for turtle movement or habitat structures that will lead to turtle avoidance. In a study on turtle richness in urban, rural and golf course ponds, Guzy et al. found that golf course ponds showed the highest richness of turtle species out of all pond types. In addition, richness and occupancy by turtles increased with greater connectivity of greenspace (Guzy et al. 2013). This may point to a possible turtle preference for managed turf, low vegetation habitats with aquatic ponding. Western painted turtles are more likely to move ponds when several ponds are in close proximity and when facing drought conditions (Baldwin et al. 2004; Bowne et al. 2006). Considering the morphology and mobility of the western painted turtle, we can guess that aquatic habitats would be easier for movement and terrestrial habitat more inhospitable (Bowne and White 2004). However, anecdotal evidence with local western painted turtle researchers in the Portland, Oregon urban area seems to suggest that turtles make no deliberate shift in course to avoid terrestrial habitats when moving from site to site. This is backed by a study showing that even when dispersing long distances, western painted turtles will move in linear paths, though they will have pauses of inactivity that differ in length depending on the habitat being traversed, possibly due to varying movement difficulty through the habitat types (Bowne and White 2004).

Disregard for the potential hazards of moving through an urban, terrestrial site can be fatal for the western painted turtle. Roads, railroads and highways are often deadly to the slow moving turtle (Shepard et al. 2008). The fragmentation of urban turtle habitats by infrastructure barriers can lead to isolation and local extinction of western painted turtle populations (Gibbs and Shriver 2002). Barriers such as walls, fences, roads and railroads are challenging for turtles to move across, though turtles have been seen attempting movement across all of these structures. The availability of habitat and safe movement corridors is essential for urban western painted turtle populations to thrive in the Portland Metro area. 


\section{American Beaver}

While North American beavers (Castor canadensis) were once almost trapped to extinction, wildlife management and conservation of the species has lead to a reestablishment of populations around Oregon (Jenkins and Busher 1979; ODFW n.d. Living with wildlife:

American Beavers). Beavers have been successful in urban areas, including the Portland Metro region (City of Portland 2010). Local agencies work to both develop and conserve beaver habitat and corridors (City of Portland 2010), as well as deter beaver activity or remove individuals from sites where beavers have a detrimental effect on facilities or infrastructure (City of Portland 2010, ODWF 2012).

The American beaver favors habitats with perennial water sources. Rivers, $2^{\text {nd }}$ to $4^{\text {th }}$ order streams, lakes and sloughs are all popular beaver habitat, provided they are wooded or partially wooded with geomorphology allowing dam construction (Naiman et al 1988; Suzuki and McComb 1998). Riparian and wetland areas are suitable beaver habitat, given a continuous water source and woody vegetation for consumption or building materials (Naiman et al 1988). Beavers will construct dams that span waterways, causing upstream flooding and increased channel depth (Naiman et al 1988; City of Portland 2010). In an urban environment, they will block culverts and drainage infrastructure to maximize ponding (USDA 2005). A corridor managed for beaver movement would consist of a permanent waterway with a wide perimeter of woody tree species (preferably ash) and undisturbed riparian habitat.

Beaver populations disperse up and down stream, usually following continuous waterways. Beavers will disperse a few miles to establish in new habitat (Verts and Carraway 1998; Havens et al 2013), though they have been recorded moving greater distances in the range of 6 to 10 miles (Libby 1957; Hibbard 1958; Leege 1968). Most dispersing individuals are 2 years of age or older (Sun et al 2000; McClintic et al 2014), though some studies have found dispersal activities in younger individuals (McNew and Woolfe 2004). Females disperse father from their natal colonies than males, with males preferring closer available sites (Sun et al 2004). The cycle of young adult dispersal repeats as beavers colonize the new habitat, establish lodges, and produce their own young (Verts and Carraway 1998). Beavers will also make multiple daily foraging trips from a lodge to a resource patch, returning to the lodge to avoid predators, to consume food and to care for young (McClintic et al 2014). 
Beavers will travel over dry terrain to forage but predominantly use waterways for long range movement (Verts and Carraway 1998; City of Portland 2010). Beavers will limit terrestrial foraging distances to about 50 meters due to predatory risk and the exertion cost of transporting large vegetation (Pinkowski 1983). Beaver foraging behavior changes depending on the distance from water (Gallant et al 2004; Raffel et al 2009). A study on beaver foraging behavior showed that beavers would move larger distances on land if the resource reward was greater (Pinkowski 1983). This brings into question whether or not a beaver will traverse farther on land than usual foraging distances if they were in great need of new habitat. Many studies of beaver movement measure stream miles moved, and make limited note of terrestrial movements. There is a gap in information about beaver movements over land rather than by waterway, though beavers have been observed in a variety of non-aquatic habitats, including agricultural fields, parks, and urban lots in foraging activities.

\section{Red-legged Frog}

The northern red-legged frog (Rana aurora aurora) is also native to the Pacific Northwest and the Portland Metro area (Waye 1999). The species has a current state listing of 'sensitive' in Oregon, and faces many challenges such as predation from invasive bullfrog species and loss of upland habitat (IUCN 2017). Both Metro and City of Portland monitor for red-legged frog populations, and participate in programs that aid in their conservation. One such program is the 'bucket brigade', where a community in northwest Portland helps facilitate redlegged frog movement across Highway 30 in the species' effort to move to and from breeding grounds (The Oregonian 2014). The red-legged frog is not found in the study area of this project, but due to the local interest and the ability for the species to be used as a model for other amphibians with similar life strategies, the red-legged frog was used for this project.

The red-legged frog has both terrestrial and aquatic life stages. As an adult and juvenile, it lives in the vicinity of permanent water bodies, residing in the cool damp understory of dense vegetation or wooded areas (Leonard et al. 1993; Corkran and Thoms 1996; IUCN 2017).

During breeding periods, the frogs require cool, still, and shallow water (often ephemeral wetlands) with sun exposure for egg masses. These breeding habitats may be seasonal ephemeral pools, as long as the water lasts until summer and there is emergent vegetation to which egg masses can attach (Nussbaum et al. 1983; Biosystems Analysis 1989). During non-breeding 
seasons, the red-legged frog may move back to upland forests and out of riparian zones (Orchard 1984; Corkran and Thoms 1996). In Oregon, riparian habitats are preferred by red-legged frogs, and deciduous tree cover is preferred over other vegetative covers, including shrub and conifers (Gomez and Anthony 1996). Riparian habitats also serve as locations for aestivation, prolonged periods of dormancy, where the red-legged frog hides under leaf litter (IUCN 2017).

Similar to the western painted turtle, there is limited information on red-legged frog movement, especially micro-habitat preferences. Red-legged frogs may move up to $5 \mathrm{~km}$ between breeding sites, but little is known about other terrestrial habitat use (Hayes et al. 2008). There is research showing that red-legged frogs will direct movement towards large patch sizes of trees ( 0.8 ha or greater) rather than small residual trees (Chan-McLeod and Moy 2007). This suggests that appropriate red-legged frog corridors must consist of larger forested patches to encourage directional movement from patch to patch. In addition, red-legged frogs may be attracted to certain habitat features, such as small streams with widths less than 1.5 meters rather than larger streams and rivers (Chan-McLeod 2003). Moist habitats will be more permeable for the redlegged frog as well (Chan-McLeod 2003), possibly due to the preference of the frogs to avoid potential sites for desiccation.

Red-legged frogs face many challenges with habitat loss and fragmentation (Cushman 2005). Habitat change has great effects on juvenile pond-breeding amphibians which disperse the farthest, since they are more likely to feel the effects of habitat fragmentation (Vos and Chardon 1998; Funk et al. 2005). A study on amphibian movement through fragmented forest showed old field habitat with no canopy cover significantly altered juvenile spotted salamander (Ambystoma maculatum) and American toad (Bufo americanus) dispersal in their effort to located canopy cover (Rothermel and Semlitsch 2002). Amphibians such as red-legged frogs are also particularly vulnerable to the impermeability of roads and other barriers (Gibbs 1998; Andrews et al. 2008). Recently metamorphosized amphibians are at risk for desiccation in low moisture environments, such as sun-exposed habitat or human altered environments like clear-cuts (Rittenhouse et al. 2007). Because of the red-legged frog's likeliness to face multiple fragmented urban habitat types (Waye 1999), efforts to improve connectivity for the species are needed to keep the population viable in the Portland Metro area. 


\section{Corridor Assessment Methods}

Three methods were chosen to assess the corridors in the north Portland study area based on their current application in the region and the variety of resources required and results that each method provides, including identification of pathways of connectivity and quantification of habitat quality and barrier permeability for species movement. Each method was performed with the intent of discovering the connectivity of the study area, extending from the western properties adjacent to the Willamette River (Port of Portland T5 Powerline site, Ramsey Lakes mitigation site, and the Rivergate Enhancement site) to Vanport Wetlands and the Columbia Slough on the eastern portion of the study area. All methods were completed between June 2016 to March 2017.

Methods were performed and evaluated for the following features: landscape accuracy, barrier accuracy, ease of use, and data output. Landscape accuracy refers to how well the method reflects the true habitat composition on the landscape, including microhabitat presence and habitat structure details on a site-specific level. The methods were also evaluated for barrier accuracy, or how well and to what detail the method identifies and considers barriers in it's assessment of landscape connectivity. Ease of use, or the time and resources required, was assessed for each method, as well as data output, or the volume of quantitative and qualitative data produced from the method. These features were then compared across methods to determine which method performed the best for each category.

\section{Collaborative Approach: Land Manager Interviews}

The collaborative approach methodology consisted of a series of in-person interviews with land managers of each of the large natural areas and greenspaces contained in the study area. Metro, City of Portland Department of Parks and Recreation and Port of Portland managed all properties surveyed, with one to two land managers representing each property. Each property was assessed individually, which meant some managers repeated the interview process multiple times if they managed multiple properties of interest. A few properties in the study area were not included in the property manager interviews due to time and purposeful exclusion of wildlife (Portland International Raceway, Columbia Boulevard Wastewater Treatment Plant Lagoon). 
Land managers were contacted over email, and asked for voluntary participation in the project. All land managers consented to participation, and interview dates were chosen based on the most convenient time for their schedule. In line with the human subjects permit restrictions, all questions asked and materials collected were to be kept anonymous and manager names were not to be included on any report materials.

For the -in-person interviews, land managers were asked a series of questions regarding species presence on their properties, and the movement of species across the properties. First, managers were asked to confirm species presence on site. It was noted if the observation of species on site was through anecdotal evidence or through past surveys. Only the species that were confirmed to be present on site were included in the next portion of the interview process.

The next portion of the interview was paired with an interactive mapping exercise. The land managers were asked to identify barriers on the property for each species of interest, marking them on a map of the property with identifying symbology for each barrier type (e.g., fence, road, pipe). Next, land managers were asked to identify and draw paths of movement for each species across the property, moving in a West-East or East-West direction. Identified paths were to be either existing high frequency movement corridors on the property that the managers are aware of, or if no such corridor could be identified, the paths were to be the most likely location of corridors based on habitat quality, existing barriers to movement, and expert opinion on species life history and needs. Next, land managers were asked to identify what locations on the property were inaccessible to wildlife (due to exclusion fencing, buildings, or other structural barriers) and were asked to mark them on the map with identifiable symbology. Finally, land managers were asked if there were any locations on the property with high human activity.

The mapped results from the interview process were then digitized on ArcMap (Version 10.4.1) for each property. The digitized PDFs were send back to the land managers that were interviewed for confirmation that their responses were recorded correctly. Once confirmation was gained regarding accuracy, maps were created for each species that contained the identified corridors for all properties.

The results from interview questions about areas inaccessible to wildlife and areas of high human traffic identified by the land managers were used to compare results of the GIS modeling and in-field survey methodologies with land manager expert opinion. 


\section{GIS Modeling: Circuitscape and Least Cost Path}

The Geographic Information System (GIS) modeling process involved Circuitscape and Least Cost Path (LCP) analysis, two modeling tools used with ArcGIS software (Version 10.4.1) with the Spatial Analyst package. The modeling tools were used to determine potential corridor locations based on the most suitable habitat for species movement. Both Circuitscape and LCP produce a visual map of corridors using spatial data and input from species experts. When combined, the maps can show the most likely corridor as well as the relative permeability of the habitat types contained within the study area. The following steps were taken for western painted turtle, red-legged frog and American beaver.

\section{Expert Opinion Ranking}

The first step in both the Circuitscape and the Least Cost Path GIS analysis was to create a score sheet of habitat types with a relative resistance value for each species. In order to model the potential movement of a species, we needed to know which habitat types would have low resistance to species movement, and which habitat types would have high resistance to species movement. No such ranking currently exists for this projects' species of interest, therefore, one had to be created to input into the GIS models.

Habitat classifications were made using vegetation land cover data from the Regional Conservation Strategy 2011 Land cover dataset (Regional Conservation Strategy 2011) combined with a wetland delineation from the National Wetland Inventory (USFWS 2016) to discriminate between wetland and non-wetland habitats. A resulting list of 34 habitat types was created (Appendix B: Ranking Habitat Types). This final dataset was used for the ranking exercise for experts, and later used in the Circuitscape and Least Cost Path models as the final list of microhabitat types for the models.

A ranking sheet was created to distribute to local species experts for western painted turtle, red-legged frog, and American beaver. This sheet explained the ranking process and contained microhabitat descriptions (Appendix B: Ranking Sheets). Experts were asked to evaluate the list of habitat types and rank them from least resistant (lowest resistance value, highest permeability) to most resistant (highest resistance value, lowest permeability). If habitat types were equal in resistance, then they would receive the same value. This ranking exercise 
was sent out electronically to local researchers, agencies, and work groups in order to have the highest amount of participation to rank habitats for each species.

Final scores were calculated by converting all ranking scores into the same proportion as the highest value ranked sheet. For example, if Expert $A$ had the highest resistance score of 10, and Expert $B$ had the highest resistance score of 20, then Expert $A$ 's habitat score of 5/10 would be converted to reflect a score of 10/20. Finally, all scores were averaged to give the overall resistance score for each habitat type. Variation of respondent scores for a single habitat type would be used as a way to assess expert consensus on the microhabitat preference of a species. Habitat rankings that resulted in identical final scores were not altered to compensate for duplication, and no other habitat scores were changed in response to the multiple identical scores.

\section{Circuitscape}

Circuitscape is an open source modeling tool that uses circuit theory to map the likely paths of movement for wildlife based on 'resistances' of land cover. Circuitscape version 4.0 toolbox for ArcMap (V. 10.4.1) was used for this project, and is currently open-source for public use (McRae and Shah 2009).

For each species, the Institute of Natural Resources (INR) vegetation layer was reclassified to contain the expert opinion resistance scores. This is done by maintaining the spatial extent of all microhabitats in the study area, but replacing all habitat type information contained in the dataset with only the resistance values. This is now the resistance layer that is directly entered into the Circuitscape tool.

Next, source points and ground points are identified. Source points are where wildlife movement would be initiated, or the 'source' of the electrical current that Circuitscape's circuit theory is based off of. The ground points are where wildlife movement is directed to, or where the electrical current will be 'grounded'. Source points for this project were just west of Vanport Wetlands, and then directly south in the center of the Columbia Slough. Ground points were at the edge of the T5 Powerline site in the Willamette River, and at the confluence of the Willamette River and the Columbia River where the Columbia Slough ends. Source points are digitized using point shapefiles, as are ground points in a separate vector layer. These are then converted into raster datasets, and entered into the Circuitscape tool in ArcMap. 
Once all data is entered into the Circuitscape tool, a current map is produced that shows the paths of likely movement across the landscape based on the resistance of the microhabitats contained within. This was repeated for each species of interest. Source and ground points remained the same for all species, only the resistance scores of microhabitats changed based on expert opinion rankings for a given species.

\section{Least Cost Path}

Least Cost Path (LCP) analysis is a tool in the Spatial Analyst toolbox in ArcMap (V. 10.4.1). It uses landscape data (raster layer) coded with resistance rankings to determine a path through a landscape that minimized resistance and cost travelled. Unlike Circuitscape, LCP creates a single line on the map.

While Circuitscape was performed using resistance scorings consisting of unevenly spaced values (e.g. 1, 3, 14, 21), LCP must be performed with ranking values that are equal in

spacing (e.g. 1,2,3,4). To do this, the expert opinion scores were ordered from lowest to highest scores, then assigned sequential rank. Identical scores were given the same rank. The same landscape data used in the Circuitscape model can then be reclassified with the LCP rankings. Similar to the source and ground points, the LCP needs start and end points for the path of movement. The same source and ground points used in the Circuitscape model were used for the start and end points for the LCP model. The appropriate raster layers were entered into the LCP tool, and a LCP was created. Start and end points are flipped in the process to confirm that pathways don't change based on east/west directional movement. LCP landscape data and maps were constrained to the study area after checks with the model showed unrealistic movement outside the study area.

The LCP process was repeated for all species of interest. The LCP was then overlaid on top of the Circuitscape map for better perspective on the GIS modeling results for corridor identification. 


\section{In-field Survey: Habitat Connectivity Toolkit}

The in-field survey was performed using the Habitat Connectivity Toolkit (HCT), a novel method developed by Portland State University researchers and Metro. The toolkit is still in development, so the version used below is subject to modifications before the final release date in June, 2018. The toolkit uses habitat connectivity zones to break up a corridor into measurable habitat areas. GIS analysis of the habitat zones and in-field assessment of each zone is combined with assessments of barriers spanning the corridor. This information is then scored for a species of interest and a percent habitat quality and a percent permeability is created based on the present corridor features for a particular species. While modifications of the scoring sheets and the GIS analysis are still being made, the first version of the toolkit uses the same general steps to determine the permeability of the corridor, though the scores may differ with future HCT version results. Due to the toolkit being in development during this project, the surveying process was pushed into the late fall, early winter season. Summer aerial imagery was used to aid in the assessment of the habitat in order to confirm vegetation type and presence which may occur due to the late fall surveying period.

\section{Corridor Identification and Zone Construction}

The initial step in the HCT is to define a corridor and break it apart into habitat zones. Unlike the previous methods, the HCT does not identify corridors on the landscape, rather it assesses the quality of the corridor once identified for a given species. A north and south corridor was identified in the study area for the HCT based on visual assessment of the landscape using aerial imagery and best judgment. The start and end points of the corridors created align with the GIS modeling methods. In addition, a Circuitscape map was created using one species expert's resistance scoring of western painted turtle microhabitats to determine if the drawn corridors matched GIS predictions of a wetland species movement. After confirmation that the north and south drawn corridors appeared to include the best habitat and limited barriers for all species, the path was digitized on ArcMap. After the linear path is created, a 250-meter buffer around the polyline is created and the corridor is divided into 500-meter-wide zones. While the width of the zone is always 500 meters, the length varies as the corridor is divided where barriers such as roads and railroads perpendicularly cross the corridor. Zone lengths ranged from approximately 
100 meters to 550 meters. Zone labeling is not sequential, as new zones were created later with barrier identification through closer aerial image analysis and in-field surveys. Zones were defined with the goal of limiting the amount of barriers contained in the zone, and keeping barriers as dividing points between zones as to not skew the habitat information with the inclusion of road/railroad land cover types.

\section{Pre-Assessment GIS Analysis}

A habitat assessment sheet (Appendix C) was created for each habitat zone. Before an infield assessment was performed, habitat information was gathered through GIS data analysis. Examples of information from GIS include percent cover of a range of habitat types (wetland, development, open water, etc.) as well as maximum gap distance in canopy or in vegetation. Information was gathered both through existing land cover datasets or through aerial imagery (Table 2). Barriers were also identified using road and railroad layers from the Regional Landscape Information System hosted by Metro (Table 2) in order to determine sites needing surveying for barrier permeability. Any barrier that crossed perpendicular to the corridor and completely blocked off a portion of the habitat zone was marked to be assessed.

Information required by the habitat assessment sheet that could not be located in existing GIS datasets was not included on the sheets or in the scoring process. Pre-assessment GIS information for permeability score sheets were not collected, but instead recorded during the infield process.

Table 2: GIS layers used for the Habitat Connectivity Toolkit and associated sources.

\begin{tabular}{|l|l|}
\hline Layer & Source \\
\hline Aerial Imagery Layer & ESRI World Imagery Basemap \\
\hline Wetland Layer & $\begin{array}{l}\text { National Wetland Inventory regional map } \\
\text { (USFWS 2016) }\end{array}$ \\
\hline Riparian Layer & $\begin{array}{l}\text { Metro Regional Land Information System } \\
\text { (RLIS) Riparian Layer }\end{array}$ \\
\hline Vegetation Land Cover Layer & $\begin{array}{l}\text { Regional Conservation Strategy Land cover } \\
\text { dataset (2011). }\end{array}$ \\
\hline Road Layer & Metro RLIS Arterial Layer (2017) \\
\hline Railroad Layer & Metro RLIS Railroads Layer (2016) \\
\hline
\end{tabular}




\section{In-field Assessment}

Following the GIS assessment, an in-field assessment was performed of all habitat zones and barriers in the corridor. In-field assessments were performed within visual range of each habitat zone and barrier structure along with an aerial map for reference. If the properties contained in the habitat zone were accessible, the habitat zone would be walked from edge to edge to record as many habitat structures and features as possible. Barriers would be walked the entire length of corridor intersection. If either area was blocked off or dangerous to walk (such as near rail yards and high traffic) a clear line of sight of the habitat zone or barrier would suffice, as long as all elements of the assessment sheets could be completed.

Habitat zone assessments followed the prompts of the HCT assessment sheets (Appendix C). Elements of habitat structure, microhabitat cover, basic hydrologic information, native and nonnative species presence and absence, wildlife observations and human activity were recorded for each habitat zone. All pre-assessment GIS analysis information was verified in the field, or edited for accuracy. Any non-prompted information or observations were also noted for future assessment purposes or management decisions.

Permeability assessments for barriers were performed wherever pre-assessment GIS showed a complete barrier to habitat, or when an unexpected barrier was encountered in-field. The permeability assessment sheets for barriers followed a similar format to the habitat zone assessments (Appendix C). Every barrier was assessed independently, even when adjacent to another barrier. For example, if a road had a non-attached noise wall, the road and the wall were each given an individual assessment sheet. Barriers were assessed for height, material and substrate, human presence and activity, continuity with waterways, and barrier features such as medians, shoulders, and crossing structures. Crossing structures were recorded in detail. Any elements that could affect passability for certain suites of species were recorded, including light, flooding and terrestrial passage, size and shape of the culvert. Any wildlife observations and signs were recorded to the highest taxonomic detail possible. 


\section{Habitat and Permeability Scoring}

Once all habitat zones and barriers are assessed using the HCT sheets, they are scored for each species of interest. Literature on species life history, mobility, habitat requirements, resource requirements and aversion to structures are all taken into consideration when creating a scoring rubric for the habitat zone assessment. Permeability assessments use a similar process for determining the scoring of the barriers for a given species, with an emphasis on biology and mobility of the species to determine if the barrier or crossing structure is suitable for species passage.

This project used the completed habitat and permeability scoring sheets that were developed by Portland State University researchers and Metro for the red-legged frog and American beaver scoring (Appendix C). The western painted turtle was not originally included in the suite of surrogate species that the HCT was developed for. Thus, a score sheet for habitat quality and barrier permeability was developed using turtle literature along with the help of a local western painted turtle researcher (Appendix C). Research and anecdotal data was used to score species habitat needs and ability to pass barriers and crossing structures, with a high reliance on in-field observation as there is limited literature on western painted turtle mobility and habitat preferences.

\section{Habitat Scoring}

The scoring process for the assessment of habitat zones assigns a numeric score GIS analysis and in-field survey observations. For fields using an ordinal scale (such as no woody debris, some woody debris, high woody debris), a score from 0 to 3 is assigned to each tier. Scores of 3 represent the best option for the species of interest. The quality then decreases incrementally to a score of 0 , which means the feature is very poor or even a deterrent for the species. For fields using an interval scale (such as percent cover of open water or wetland), a range of values is assigned a score from 0 to 3 . For dichotomous nominal scales (such as yes/no fields for wildlife presence), the 'yes' and the 'no' option are each assigned a score. There are no requirements for a field to contain the entire range of scores from 0 to 3 . Once all fields are scored, a final sum of field scores can be calculated and divided by the maximum score possible, resulting in a percent habitat quality for movement for that habitat zone. 
This was performed for all habitat zones in both the North and South corridors to achieve percent habitat quality values for each zone. All zones were then reclassified in ArcMap to reflect their habitat quality percent.

\section{Permeability Scoring}

A similar scoring process is taken for the permeability scoring sheets, with an additional component for crossing structure inclusions. Barriers features were all scored similar to the habitat features, from 0 to 3 , with 3 representing the best option for the species (as if the feature didn't even exist) and 0 representing the worst option for the species (little to no chance of passage). If no crossing structures existed, then the barrier feature scores were totaled and calculated as a percentage permeability by dividing it by the maximum score possible given the amount of fields scored. For example, a fence without a crossing structure would be scored for features, including height, material, and type. If the fence scored 1/3 for height, 1/3 for material, and $1 / 3$ for type, it would total 3 points out of 9 points possible, giving a 33\% permeability score. If the fence possessed a crossing structure, the score could increase.

The permeability score of barriers could be increased though the presence of a crossing structure that is suitable for the species of interest. In this version of the HCT, crossing structures could remediate $50 \%$ of a barrier, meaning that $50 \%$ of the points below a maximum permeability score of a barrier structure could be regained through the presence of a perfect (100\% quality) crossing structure. For example, if the permeability scoring was 30/40 points for a barrier, the crossing structure could gain back $50 \%$ of the 10 lost points, raising the barrier's permeability score by 5 points, or $12.5 \%$. A value of $50 \%$ was decided upon due to the reasoning that a perfect crossing structure could almost remediate a barrier, however, it is still less permeable than if the barrier did not exist. This value is still under debate and may change in future versions of the HCT.

To factor in this calculation, the crossing structures were scored independently and their percent quality score was used to calculate the number of points a barrier could 'gain back'. The points gained back by a crossing structure could only add up to $50 \%$ of the missing points from the permeability barrier assessment scoring. If a crossing structure was present, the crossing structure features were scored using the 0 (worst) to 3 (best) scaling for ordinal, interval and nominal features on the sheet. The sum of these scores were then divided by the maximum 
possible score to determine the crossing structure quality percentage. This percentage was then multiplied by the missing barrier permeability points, then again by $50 \%$ to determine the points gained back by the crossing structure.

Once all barriers were scored for permeability, they were digitized in ArcMap and classified with their permeability percentages to create a visual map. 


\section{Results}

\section{Collaborative Approach: Land Manager Interviews}

All land managers were asked to draw corridors or paths of movement for the western painted turtle, American beaver, and red-legged frog. The method showed high ease of use, with scheduling time being the longest component of the process. Interviews were scheduled and performed within an eight-week time span. Land manager interviews lasted approximately 30 minutes to an hour. Digitization of results took approximately one hour per interview, with an additional hour to identify and mark barriers crossed by the drawn paths. All digitized results were sent back to the land managers to confirm paths were drawn accurately, and all managers responded within a week. In total, the land manager interview process took about 10 weeks, though the processes could be condense depending on land manager availability and scheduling.

Landscape accuracy for the method was high, as managers were aware of habitat types and vegetation on their properties, and used this information to determine paths of movement where anecdotal evidence or existing knowledge of corridors were not available. Barrier accuracy was also high, as all managers were able to point out potential barriers on the property for each species, as well as habitat types that are not likely to support movement of specific species. Only two locations of wildlife exclusion were identified, one being a small fenced area on St. John's Prairie associated with the methane collection process on site, and the other being the Columbia Boulevard Wastewater Treatment Plant Lagoon.

The data output for the method was low, as only a few species-specific maps were created. A single map for each species was created using a compilation of the corridors drawn for each property. No connecting paths were drawn between identified corridors, thus, some pathways end abruptly at the edge of a property. If land manager drawn corridors aligned at a property's edge, they were connected to form one continuous line. 


\section{Western Painted Turtle}

Western Painted Turtle (Chrysemys picta bellii) Land Manager Assigned Corridors

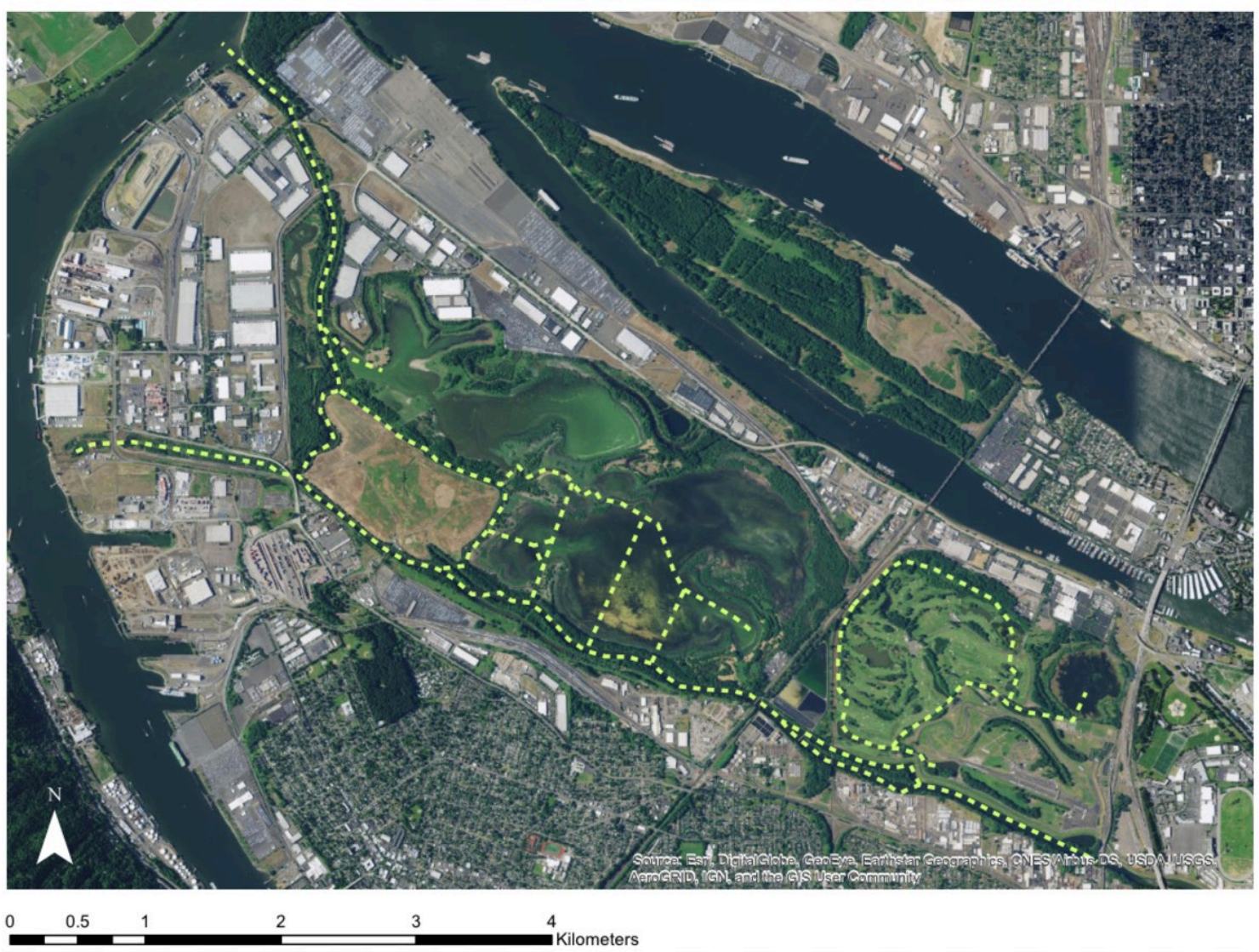

Figure 3: Land manager identified corridors for western painted turtle (C. picta bellii). Pathway disconnect represents that no connections between property pathways were identified.

\section{Corridor Identification}

All land managers confirmed western painted turtle presence on their properties, and a map of identified high movement pathways or corridors was drawn for the study area (Figure 3). Use of waterways appeared to be maximized by land managers where multiple pathways were available. Turtle pathways followed the slough, and took advantage of pond and water body stepping stones across the properties, including Heron Lakes Golf Course.

A single path of high movement was not identified in Smith and Bybee, instead intertwined pathways of movement were drawn that have equivalent likeliness of use as corridors. Western painted turtles were marked as moving between Smith and Bybee wetlands and the Columbia Slough to continue to the east properties. No land managers identified a connecting pathway between Heron Lakes Golf Course and Vanport Wetlands to the rest of the 
properties, including Smith and Bybee directly west of the golf course. There is no established population of western painted turtle at Vanport Wetlands, so land managers may have been limited in anecdotal evidence of turtle movements around the Vanport Wetland area.

Barriers to Movement

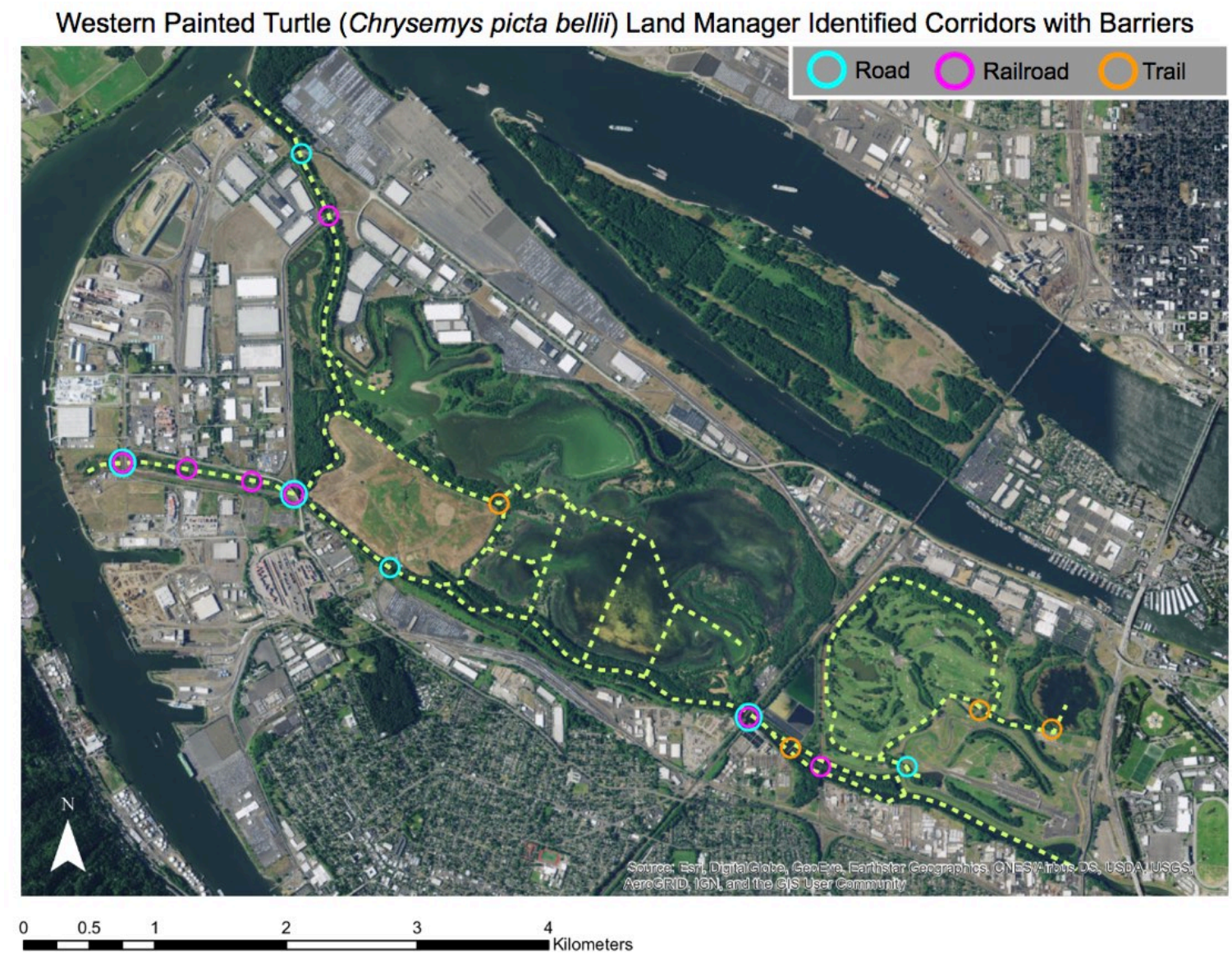

Figure 4: Barriers crossing western painted turtle (C. picta bellii) manager-identified pathways. Circle symbols surround the barrier and pathway cross point, with blue circles representing road barriers, pink representing railroads, and orange representing trails.

After drawing paths, land manager identified the presence of barriers crossing the pathways (Figure 4), though permeability of barriers was not assigned a quantitative value. These barriers included roads, railroads and trails. Fences were largely avoided in all land manager pathways, or if fences were crossed, land managers identified holes and gaps in fences for wildlife use. Some barriers were bridged over waterways, with land managers identifying them as viable movement corridors. 
A total of 17 barriers were crossed by land manager-drawn corridors for western painted turtles. Pathways drawn by managers crossed six roads, seven railroads, and four trails. Utility roads with low frequency use were included in the trail classification, however, it should be noted that even infrequent use by motor vehicle on these trails can cause turtle mortality. In total, ten of the barriers crossed by the western painted turtle land manager path were fitted with crossing structures or could be used as a crossing structure. Seven of the barriers required direct movement over or through the barrier structure without aid of a crossing structure.

\section{American Beaver}

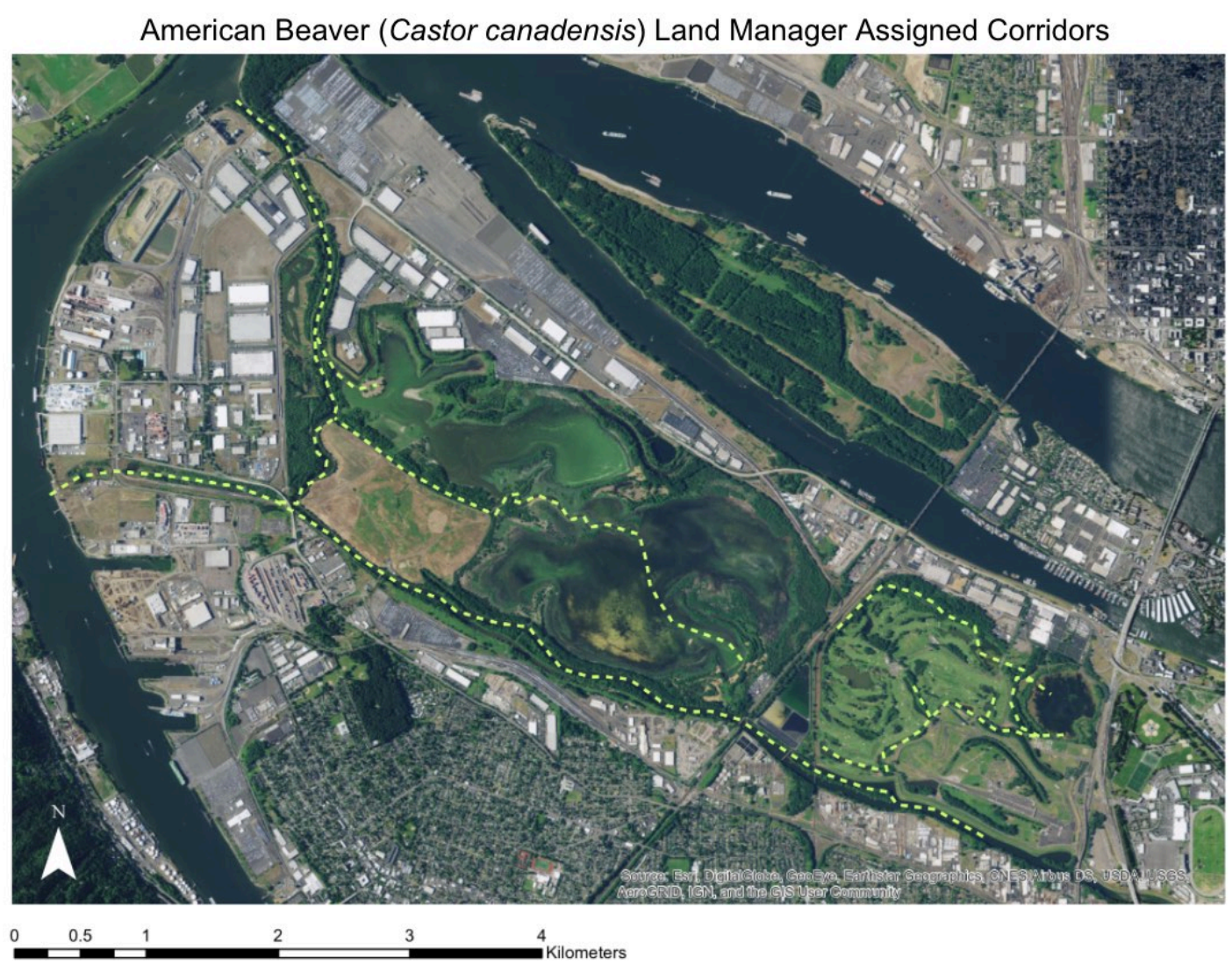

Figure 5: Land manager identified corridors for American Beaver (C. canadensis) Pathway disconnect represents that no connections between property pathways were identified

\section{Corridor Identification}

All land managers confirmed American beaver presence on all properties in the study area, thus a complete corridor map was created (Figure 5). Beaver movement was drawn through riparian habitat or waterways, with ponds and water bodies serving as stepping stones. Non- 
riparian or wetland habitat was generally avoided, such as the deviation of movement around center of St. John's prairie). Paths seemed to be directed towards the wooded or vegetated habitat, and less exposed open water, as seen by the corridor through Smith and Bybee. Similar to western painted turtles, land managers identified the Columbia Slough as a main corridor for movement through the study area.

\section{Barriers to Movement}

American Beaver (Castor canadensis) Land Manager Identified Corridors with Barriers

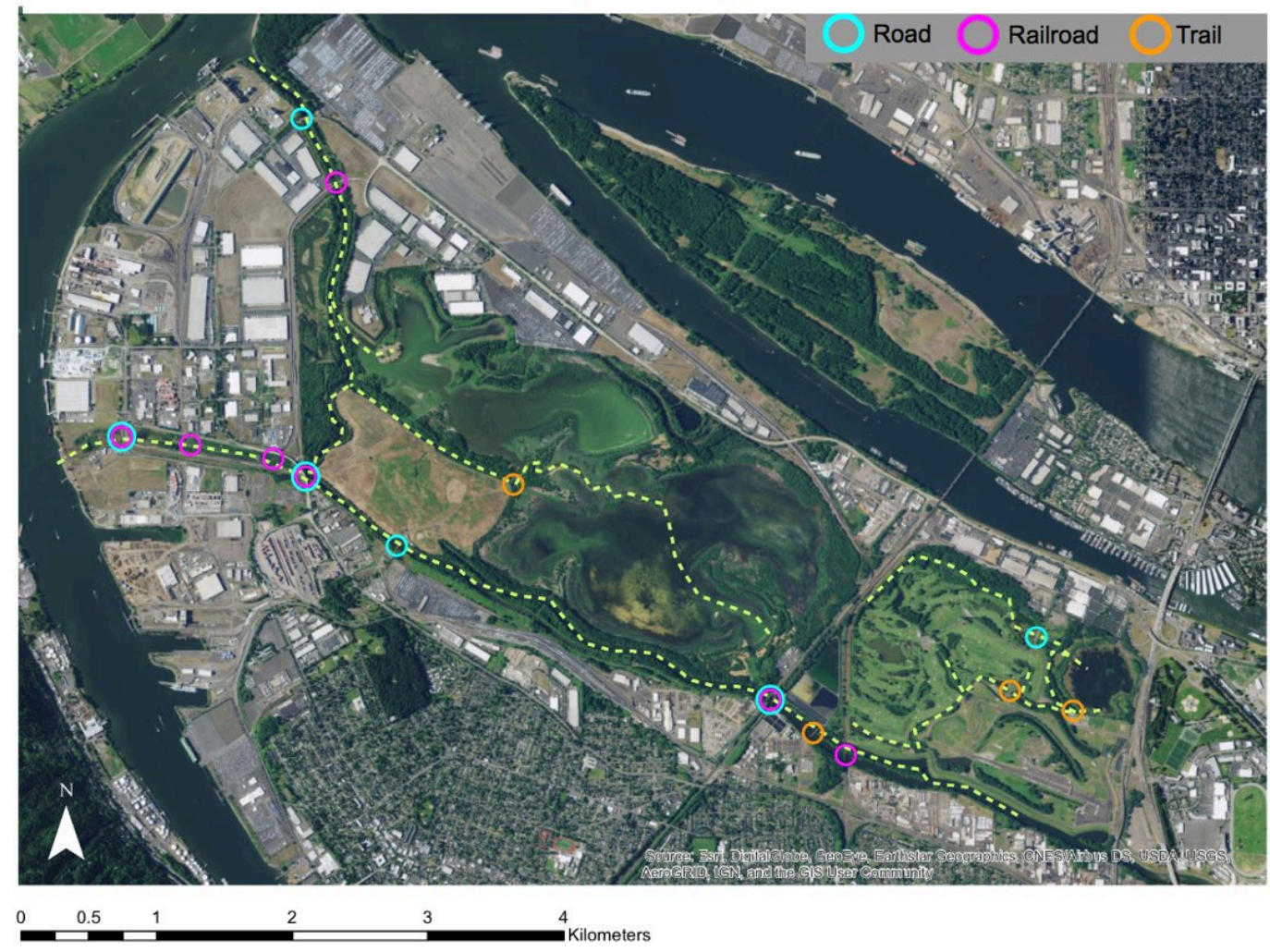

Figure 6: Barriers crossing American Beaver (C. canadensis) manager identified pathways. Circle symbols surround the barrier and pathway cross point, with blue circles representing road barriers, pink representing railroads, and orange representing trails.

A total of 17 barriers were crossed by the corridors drawn by land managers for beaver movement through the study area. The entire drawn path network crossed six roads, seven railroads, and four trails. Similar to western painted turtle, some trails were utility roads with low frequency of use. Ten of the barriers possessed crossing structures or were bridged, allowing movement underneath the infrastructure barrier. 


\section{Red-legged Frog}

Unlike the western painted turtle and the American beaver, the red-legged frog was absent from the majority of the properties. The manager of Smith and Bybee reported historical sightings of the species on the property, and participated in the corridor mapping portion of the interview.

Red-legged frog (Rana aurora aurora) Land Manager Assigned Corridors

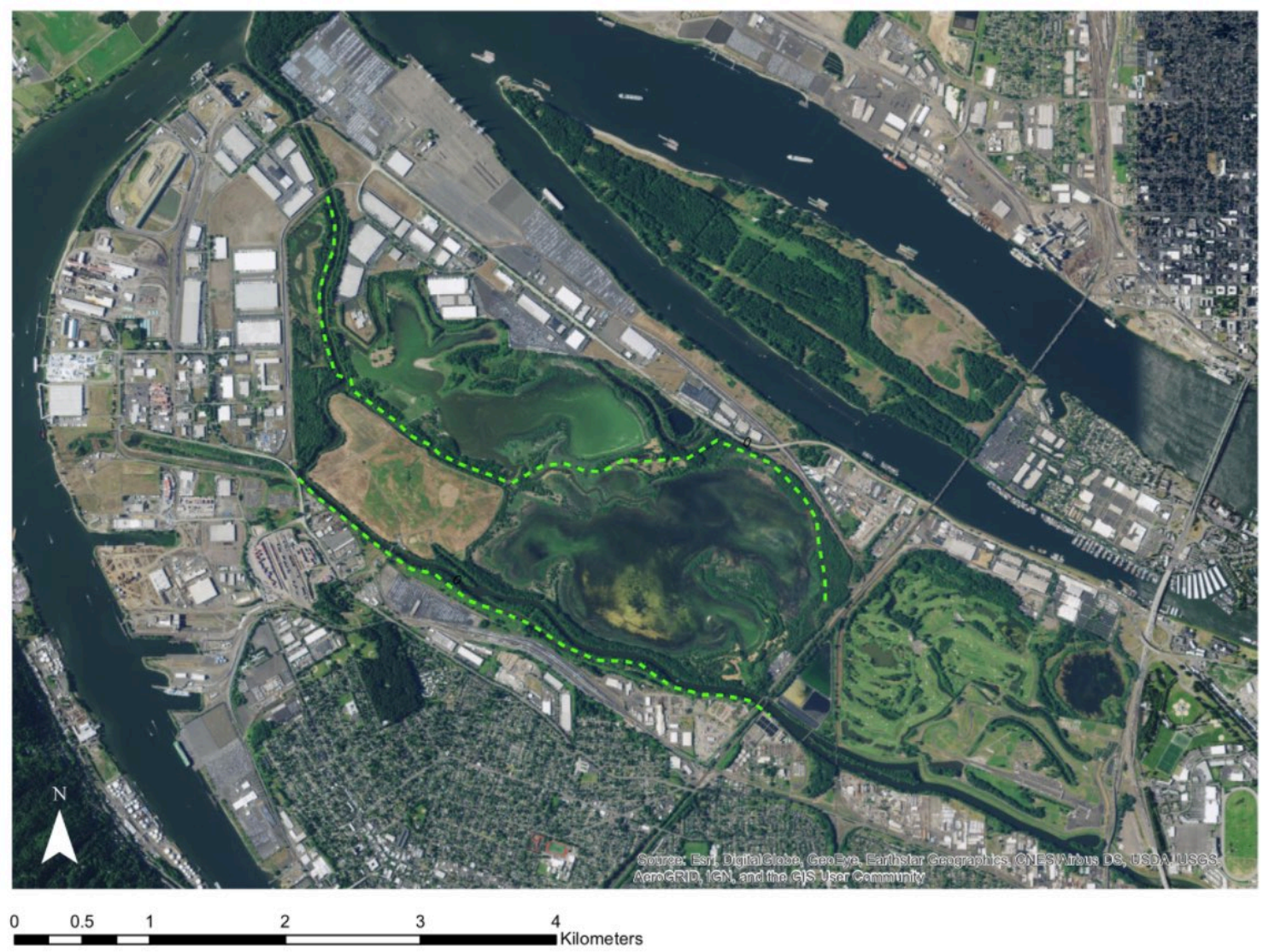

Figure 7: Land manager identified potential corridors for red-legged frog (R. aurora aurora) Pathway disconnect represents that no connections between property pathways were identified 


\section{Corridor Identification}

The red-legged frog paths were only drawn for the Smith and Bybee property and portions of the Columbia Slough south of the wetlands (Figure 7). The pathways drawn avoided open water, and ran along the riparian edge of the Columbia Slough to the south of the study area, and along the riparian portions of the Port of Portland mitigation sites into the upland and forested areas in Smith and Bybee. The pathway then curves along the northeast edge of the Smith and Bybee (still in the upland forest, high canopy cover habitat) and ends in the bulk of the upland forest habitat on the eastern portion of the site.

\section{Barriers to Movement}

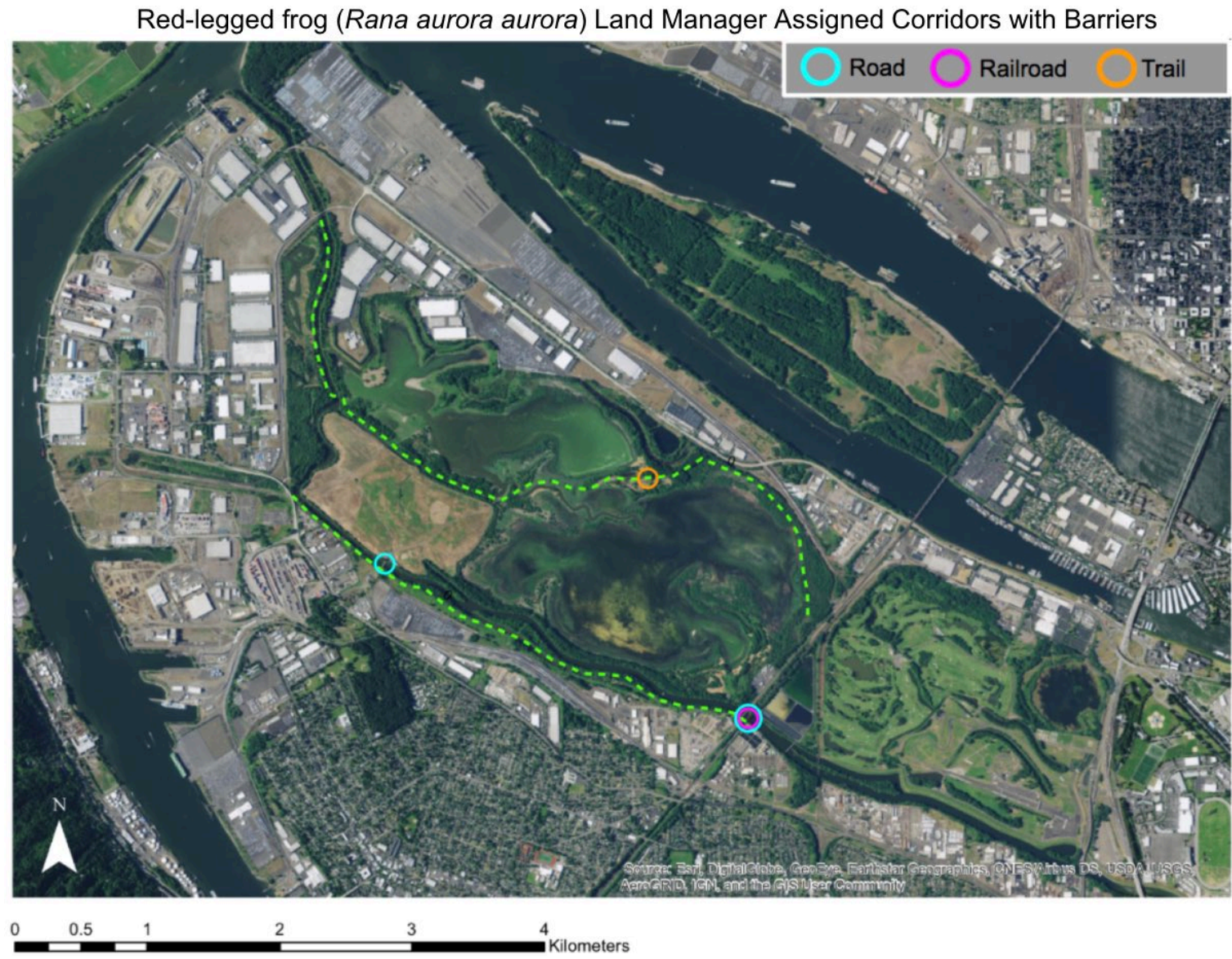

Figure 8: Barriers crossing red-legged frog (R. aurora aurora) manager identified pathways. Circle symbols surround the barrier and pathway cross point, with blue circles representing road barriers, pink representing railroads, and orange representing trails.

Four barriers were crossed in the length of corridor that the single manager drew for the red-legged frog: one railroad, two roads, and one trail network (Figure 8). The frog corridor also 
crossed into the network of trails that are present in the northern portion of smith and Bybee Wetlands, though this may be avoided if the right turns were made while still headed in the same general direction.

\section{Landscape Accuracy}

When asked to draw corridors on their property, managers were aware of the individual habitat needs of the species and drew paths through habitats that were preferential for species movement. In addition, land managers knew the current status of the habitats on the properties they managed, and when compared to in-field surveys were accurate in their classification of habitat types. Land managers were very familiar with the lands that they managed and appeared confident describing habitat types on their properties. Because land managers were not asked to define habitat types and corridors outside their property bounds, we cannot speak to the landscape accuracy of land managers for the entire study area. For their individual properties, however, landscape accuracy was high.

\section{Barrier Accuracy}

Managers were aware of barriers located on their sites. Barriers drawn by land managers matched aerial imagery of the site, and exceeded in detail when compared to aerial imagery. Mangers appeared confident in their knowledge of their properties, including barrier presence. When asked to draw pathways for species movement, managers appeared to make deliberate efforts to avoid barrier crossing by species. The western painted turtle and the American beaver corridor drawn by land managers crossed 17 barriers total in the study area, 10 of which possessed or served as crossing structures (Figure 15,17). Large barriers such as North Portland Road and the Columbia Boulevard Wastewater Treatment Plant Lagoon shows awareness of barrier permeability and the limitations of the species when crossing large complex barrier structures.

\section{Ease of Use}

The entire process from start to finish to schedule, interview, process, digitize and assess results for the collaborative approach took about five months. Scheduling conflicts due to busy employees and the holiday season likely extended the timeline of this method. The GIS portion 
of the project to create figures was minor, and the bulk of the time came from the interview sessions and communication breaks. Few resources are needed for this expert driven approach. Access to a GIS program is suggested, though the work could theoretically be done outside of GIS with more time and effort. Overall, the method process was easy and had potential to be performed in a short period of time for the study area. Future use of the method may see an increase in complexity as longer corridors are assessed and they more land managers from smaller, independent properties. More disconnect between drawn pathways could be seen, especially if property managers are more unsure of their responses due to unfamiliarity with the species needs.

\section{Data Output}

The land manager interview method produced only a small amount of material. Two maps were created in the process: the map of potential wildlife corridors for each species, and the map of barriers that the corridors cross. The maps of potential species corridors are valuable and can be used for management decisions, especially at a small extent. The map of barriers can be used to target barriers for mitigation work. However, besides the number and location of barriers crossed by the land manager paths, there was limited quantitative data produced through the collaborative approach and little to no information on barriers or potential corridor habitat outside the path drawn by the land managers. This method could be modified and improved with the inclusion of some sort of rating system or ranking system for habitat sections similar to the GIS modeling method, and by having the land managers identify all barriers that they are aware of in the entire study area, but the inclusion of these steps could compromise the ease of use of the method. The process could also decrease the level of confidence the land managers have in their responses to the activity, as more questions would be asked that require best judgment from the land managers.

The maps of the corridors through the properties can inform future restoration project locations or monitoring efforts, but one would face difficulty in comparing sections of pathway in terms of habitat quality for movement for a particular species. This poses an issue for management decisions and for corridor improvement actions where the corridor map needs to indicate quality to determine target areas for management. 


\section{GIS Analysis: Circuitscape and Least Cost Path}

The GIS models used the RCS land cover data along with the expert rankings to predict paths of movement in the study area. The method was moderately easy to use, with the ranking responses being the most time-intensive component. The GIS models were quick to use once familiar with the process. The method produced a high volume of data, including ranking responses, Circuitscape and Least Cost Path (LCP) maps for all species. While turtle and beaver showed clear areas of likely movement, the red-legged frog Circuitscape model were less distinct than the other species. All species LCPs crossed barriers at higher numbers than the land manager interviews. A misclassification of habitat was also noticed in the study area, with the RCS land cover data marking undeveloped habitat as developed habitat. The dataset was left in its original form, being the most up to date and detailed regional land cover data available. Due to the misclassification and lack of barrier consideration, the GIS analysis methods showed low landscape and barrier accuracy.

\section{Western Painted Turtle}

\section{Habitat Ranking and Resistance Scoring Results}

After sending out ranking sheets to approximately 35 individuals, including local researchers, work groups, and agencies, a total of six surveys were returned complete. It took approximately four months to receive all of the ranking sheets back after initially distributed. The ranking schemes for the six respondents all varied in scale. The simplest scale ranked from 1 to 3 for habitat resistance, and the most complex scale ranked from 1 to 34 . All western painted turtle ranking responses were converted to a 1 to 34 scale in order to average resistance scores for each habitat type. This conversion resulted in highly variable habitat resistance scores for each habitat (Appendix B).

The lowest resistance score for western painted turtles was for open water habitat, scoring as a 5.4 resistance value. The highest resistance score was that of the tall buildings habitat, with a, average resistance score of 34.0 from all respondents. All other microhabitat types fell between those habitat values, with undeveloped sandbars, low and medium herbaceous vegetation, and medium hardwood trees both in and out of wetlands having the lowest resistance habitats for western painted turtle based on average score. Conifer habitats, clear cuts and partial 
cuts, and developed habitats had higher resistance habitats for western painted turtle based on average score.

The largest range in scores of one habitat type was for the agriculture land-cover, scoring an average of 19.6, and a range of values of 27.2 points. While not as large, pavement, low herbaceous vegetation and hardwood habitat types showed similar large ranges of values. Conversely, all respondents scored tall building habitat as the highest resistance score possible, with a range of zero.

\section{Circuitscape Mapping Results}

All habitat types in the RCS land-cover dataset were reclassified to reflect the associated average resistance score. No habitat type was left out, as not including data in the model reflects a $100 \%$ resistance to movement and would appear as though there is no permeability in the habitat for the species of interest. After entering all required data, a Circuitscape map was created for the western painted turtle of the study area (Figure 9). The map uses the resistance score of each habitat in the study area to determine permeability of each pixel of habitat, then it maps the likeliness for wildlife to move through that pixel in an effort to get to the defined start and end points (source and ground points). The gradation from black to white represents the probability of species movement, with black being little to no probability of movement and white being high probability. The start points and the end points can be seen on the map as bright white marks on the western and eastern edges of the study area. The probability of species use for movement is high around these points as all pathways initiate and start at those locations and movement is directed to and from them. It does not reflect the permeability of the habitat types at those locations.

Habitat permeability can be reflected in the probability of movement for each habitat type and feature. Water, the habitat type with the lowest resistance value of 5.4, shows up the lightest on the map, having the highest likeliness of western painted turtle movement according to the model. The industrial properties surrounding the study area show low probability of turtle movement due to the high habitat resistance scores of the developed habitats (pavement - 27.5, medium buildings - 32.8, tall buildings - 34). 


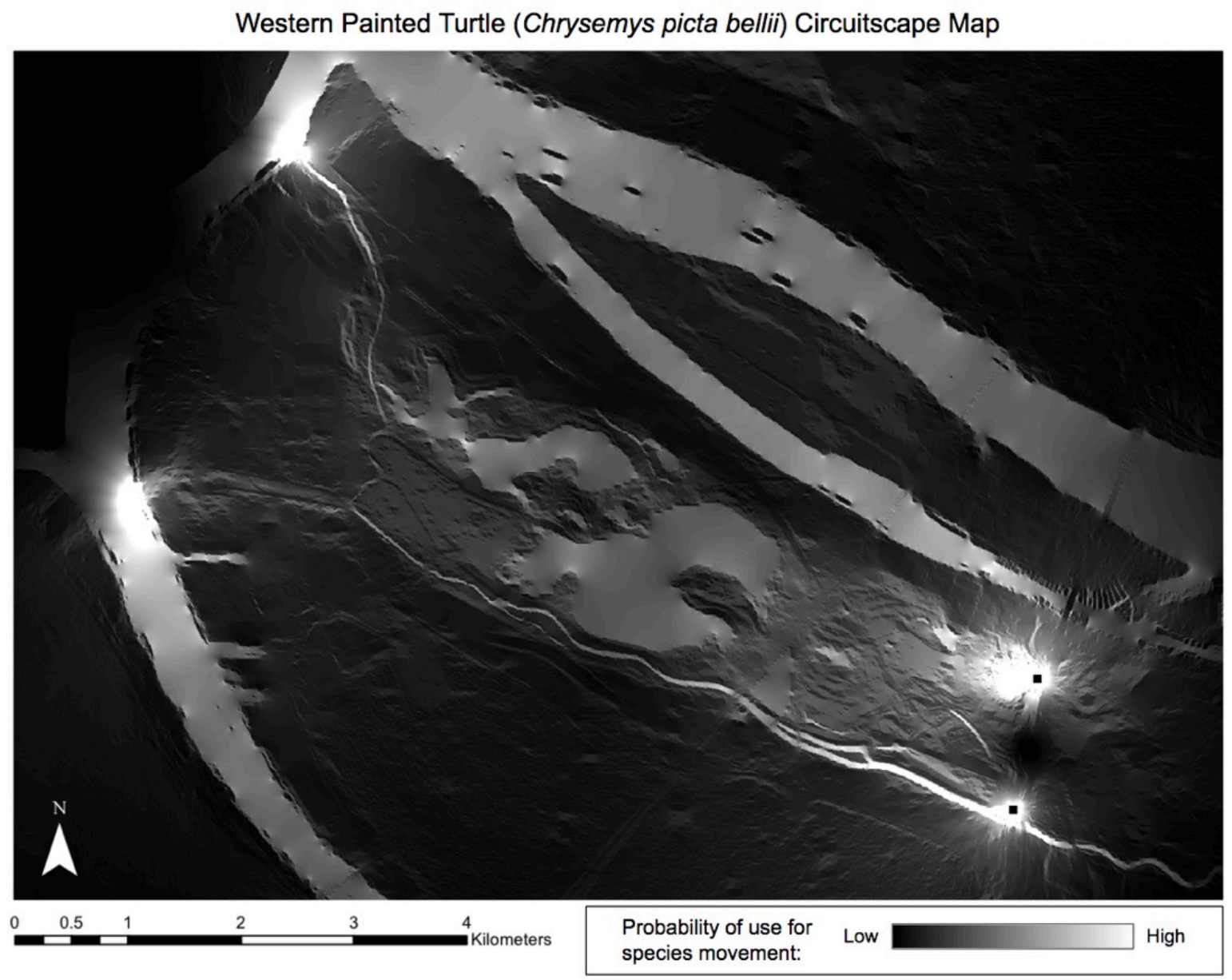

Figure 9: Circuitscape map for western painted turtle (C. picta bellii). Lighter colors represent higher probability of habitat use for species movement. The nodes on the west and east sides of the Circuitscape map show concentrated high permeability of movement due to model forcing movement to and from the nodes. High probability of movement around the nodes does not reflect high habitat permeability.

\section{Least Cost Path Analysis Results}

For the LCP model, each habitat type was ranked based on their resistance score from lowest to highest (Appendix B). This created 27 evenly spaced ranks, with some habitats being evenly ranked if the resistance scores were the same. The habitat ranks were then entered into the LCP tool in ArcMap to create the least cost path for the study area for western painted turtles (Figure 10). The western painted turtle LCP predominantly predicted movement through the low resistance habitats of water and low vegetation. The LCP crossed sites with high human activity (the center of Heron Lakes Golf Course) as well as areas that purposefully exclude wildlife 
movement (Columbia Boulevard Wastewater Treatment Lagoon). The LCP favors short, direct paths, as seen by the path crossing diagonally through Smith and Bybee Wetlands, across Heron Lakes Golf Couse, and over North Portland Road.

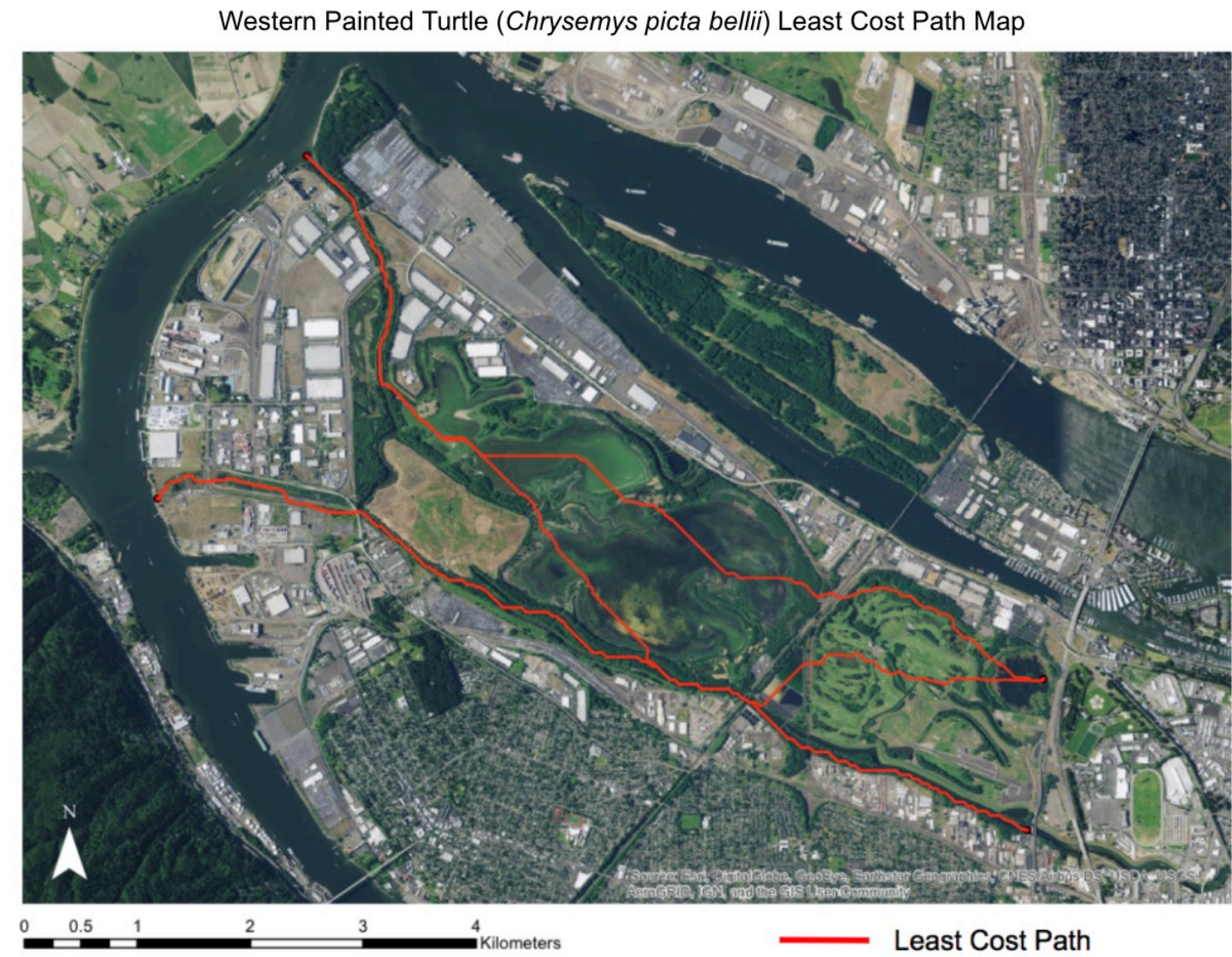

Figure 10: Least Cost Path analysis map for western painted turtle (C. picta bellii) with constraint forcing the path to move through the study area.

The western painted turtle LCP map was overlaid with the generated Circuitscape map, showing a landscape view of the probability of species movement based on habitat resistance along with a path of lowest cost considering distance and resistance rankings (Figure 11). The LCP favors the highest movement probability habitats identified by the Circuitscape model, but also weighs the distance of the path when predicting movement. Overall, both maps show high levels of turtle movement through water, as water habitat possessed the highest permeability ranking and scores for both models. 
Western Painted Turtle (Chrysemys picta bellii) Least Cost Path and Circuitscape Map

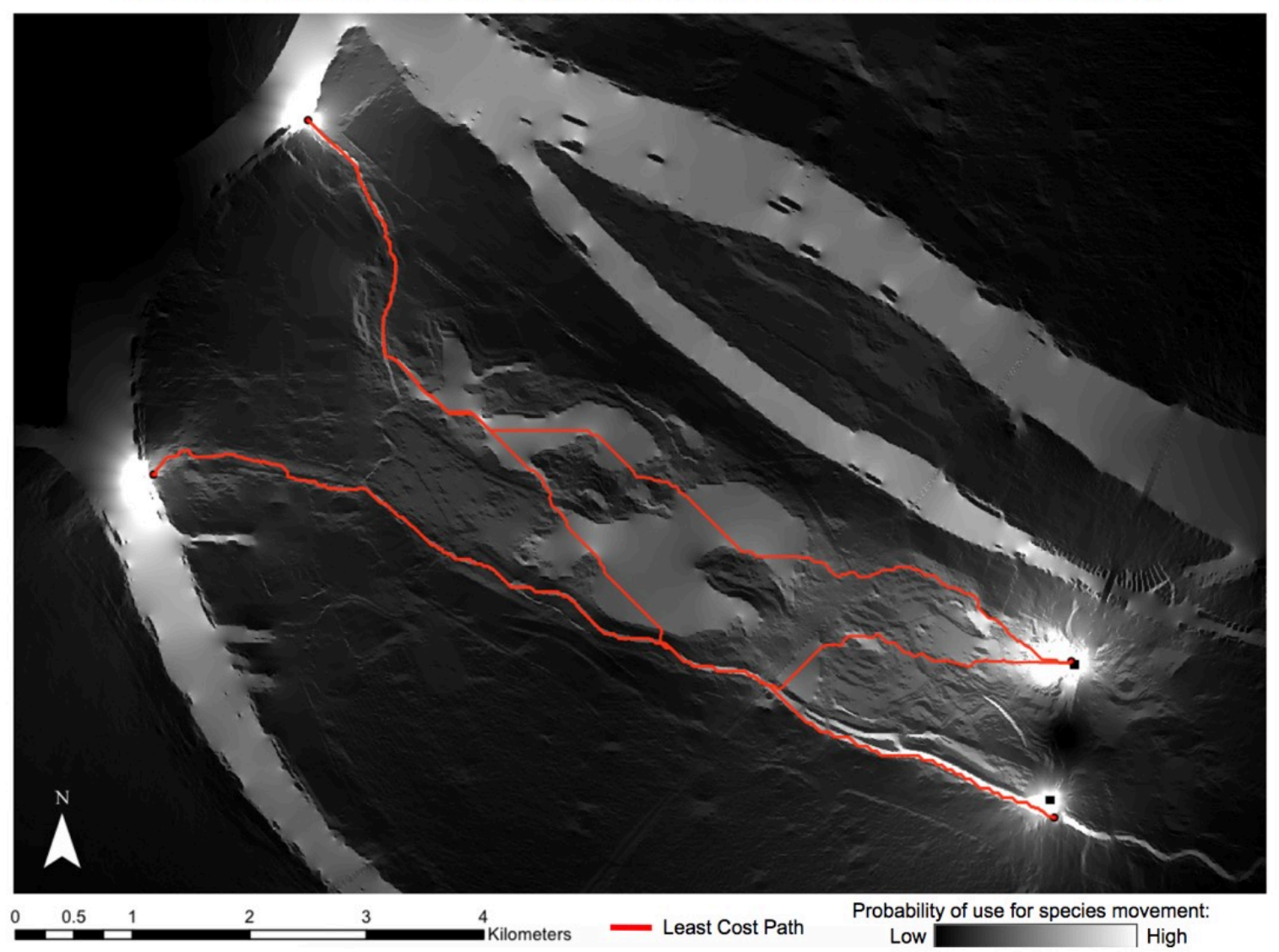

Figure 11: Circuitscape map with Least Cost Path analysis map overlay for western painted turtle (C. picta bellii). Lighter colors on the Circuitscape map represent higher probability of habitat use for species movement. Red lines indicate the least cost paths among the four nodes. The nodes on the west and east sides of the Circuitscape map show concentrated high permeability of movement due to model forcing movement to and from the nodes. High probability of movement around the nodes does not reflect high habitat permeability.

\section{Barriers Crossed by LCP}

The final LCP crossed 20 barriers that were able to be identified through the aerial imagery and GIS railroad and road layers. For this method, aerial imagery and GIS data were used to locate barriers, and as well as identification from the in-field surveys. Barriers were not distinguished by the number of tracks or lanes. Barriers crossed by the LCP include seven roads, nine railroads, and four trails for a total of 20 visible barriers (Figure 12). Of the 20 barriers, 10 of which possessed crossing structures or are bridged, allowing western painted turtle movement underneath the barrier. 


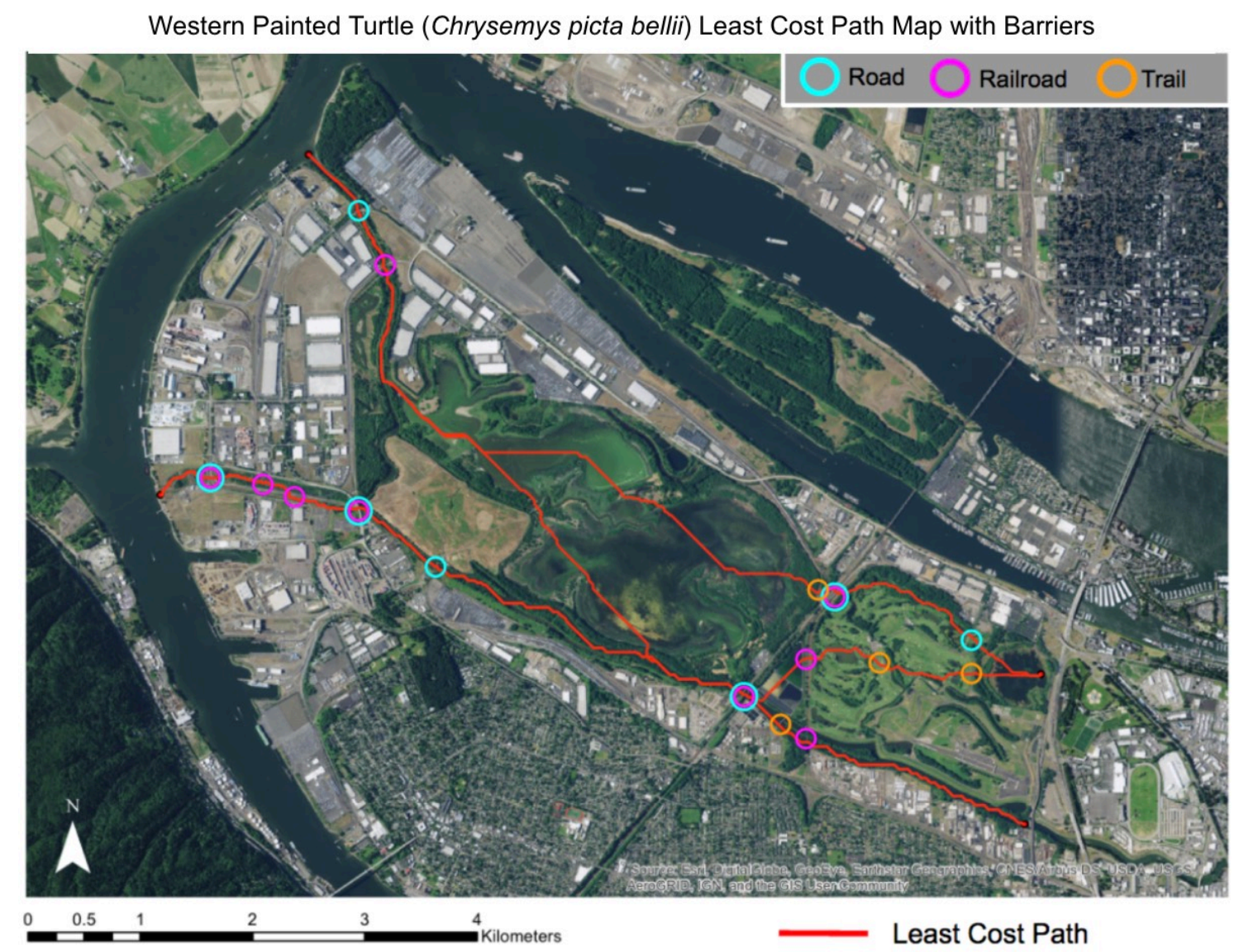

Figure 12: Barriers in study area crossed by western painted turtle (C. picta bellii) Least Cost Path analysis. Circle symbols surround the barrier and pathway cross point, with blue circles representing road barriers, pink representing railroads, and orange representing trails.

\section{American Beaver}

Habitat Ranking and Resistance Scoring Results

There were four respondents for the beaver ranking after distributing ranking sheets both electronically and in person to more than 30 individuals. The rankings for beaver habitat resistances varied by respondent. The smallest ranking ranged 1-4, with four representing the highest resistance score, and the largest ranking scheme spanned 1-10. In a similar process as for the western painted turtle, rankings from all respondents for beaver were reclassified to a 1 to 10 scale, and averaged for each habitat type (Appendix B). Ranges in scores were then viewed as levels of 'agreement' between respondents for the resistance factor for each habitat type.

The habitat type with the lowest resistance score for American beaver was open water habitat at 2.1, followed closely by herbaceous medium habitat (2.6) and undeveloped sandbars in 
wetlands (3.2) (Appendix B). The habitat types with the highest resistance for beaver movement were pavement (8.3) and low and tall buildings (10) (For all habitats rankings - Appendix B).

Some habitats types had large ranges in scores. Medium, tall and very tall conifers in wetland habitats had the largest ranges in scores ( 7 point range) as well as pavement ( 7 points). There was little range for water habitat (1.5 points), herbaceous medium habitat ( 0.5 points) and clear-cuts, which had an average resistance score of 7.1 with a range of 1.5. The medium and tall building habitats had no range in values, with all respondents marking those habitat types as the maximum resistance score possible.

Once the resistance scores were entered into Circuitscape, a map was created of the study area reflecting the likeliness of beaver movement through each habitat type (Figure 13).

\section{Circuitscape Mapping Results}

The Circuitscape map shows a high use of waterways through the study area, especially the eastern portion and the northwest portion of the Columbia Slough, as well as Smith and Bybee Wetlands. There is a decrease in habitat use between the two wetlands in the upland area. The Columbia Boulevard Wastewater Treatment Lagoon is highlighted as a location of high beaver movement, as well as the Columbia and Willamette Rivers. North Portland Road which runs in between Smith and Bybee and Heron Lakes Golf Course shows no difference in movement probability to that of the habitat east and west of the road. This is due to the lack of traffic or barrier data used in the Circuitscape method. 


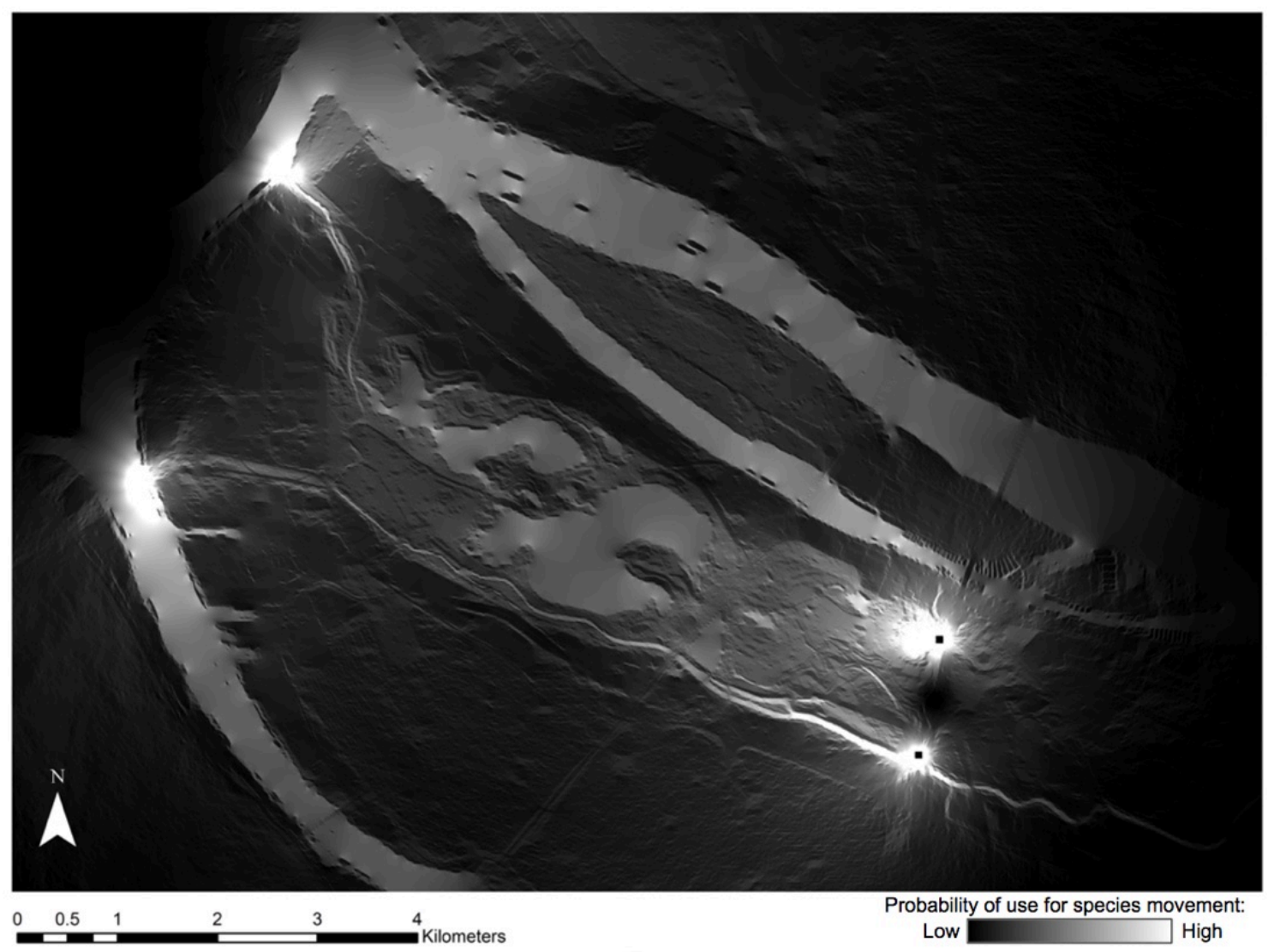

Figure 13: Circuitscape map for American beaver (C. canadensis). Lighter colors represent higher probability of habitat use for species movement. The nodes on the west and east sides of the Circuitscape map show concentrated high permeability of movement due to model forcing movement to and from the nodes. High probability of movement around the nodes does not reflect high habitat permeability.

\section{Least Cost Path Mapping Results}

The produced LCP map for American beaver shows the least costly paths of beaver movement considering distance and habitat resistance (Figure 14). Similar to the other species, the LCP for beaver movement makes some direct paths to minimize distance, such as the linear diagonal movement through Smith and Bybee Wetlands. Beavers are also predicted to cut directly across Heron Lakes Golf Course, taking advantage of small ponds on the go lf course as well as larger ponds on the property. The LCP leads beavers across North Portland Road, as well as through the Columbia Boulevard Wastewater Treatment Plant Lagoon. 


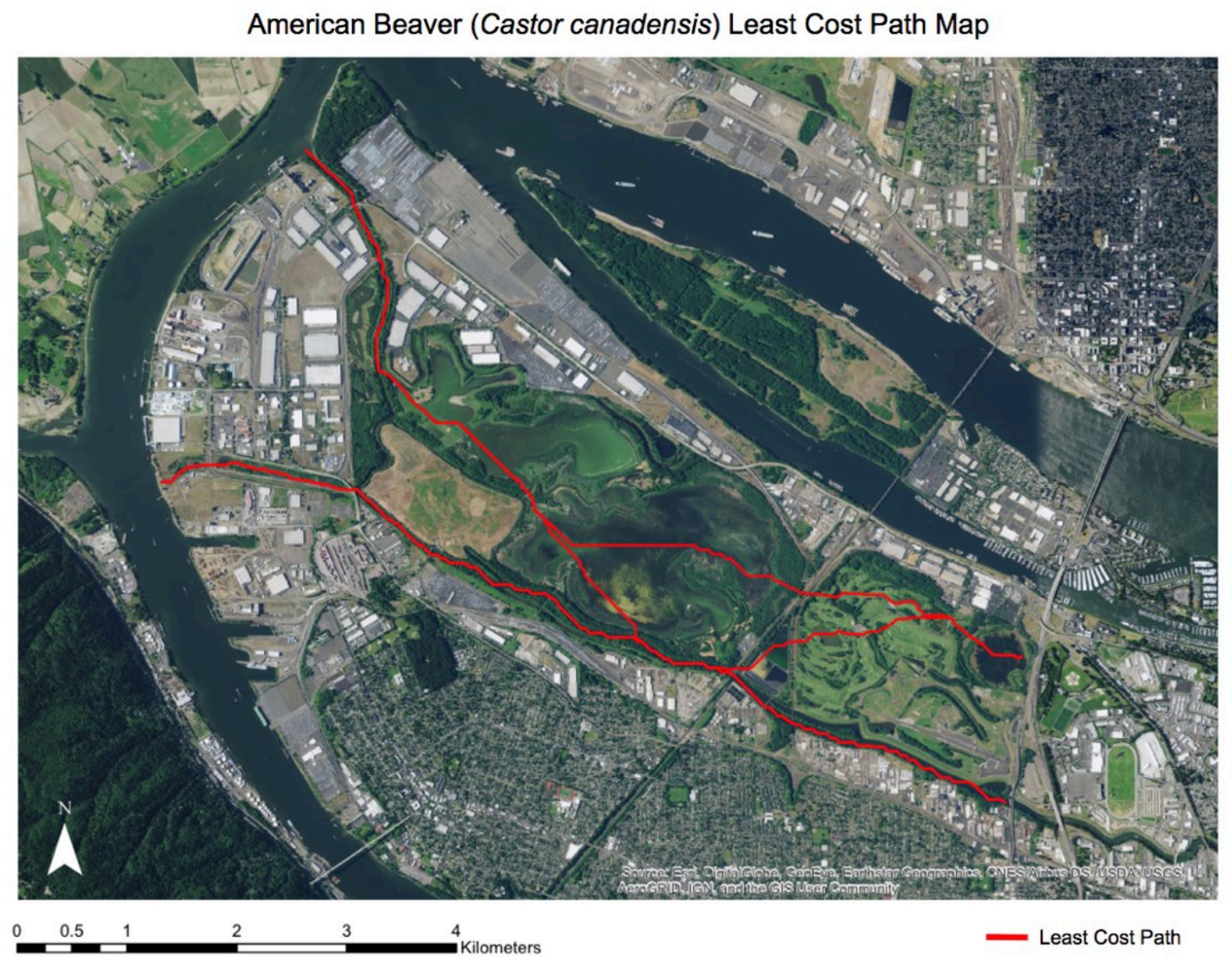

Figure 14: Least Cost Path analysis map for American beaver (C. canadensis) with constraint forcing the path to move through the study area.

The LCP map was then overlaid on top of the Circuitscape map to better visualize the GIS predicted corridor in the scope of the landscape permeability and probable habitat used by beaver for movement (Figure 15). Waterways are highly valued for movement for both Circuitscape and Least Cost Path, and we can see that the LCP method leads beavers through high resistance habitat types in favor of shorter distances traveled in some areas, such as the center of Smith and Bybee Wetlands. Developed land-cover from barriers such as roads do not appear on the map, and the LCP does not seem to deviate with the narrow strips of pavement on the landscape. 


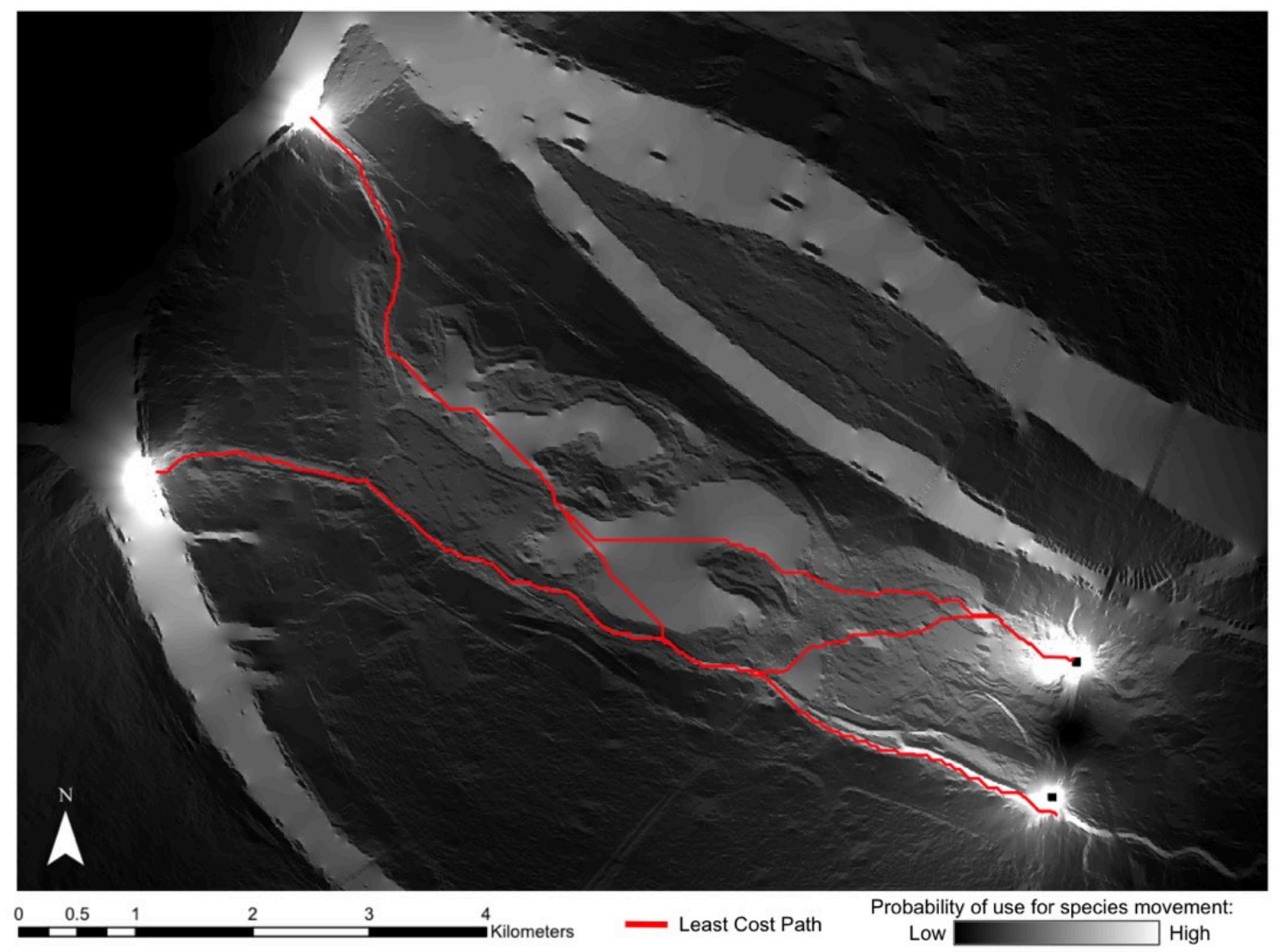

Figure 15: Circuitscape map with Least Cost Path analysis map overlay for American beaver (C. canadensis). Lighter colors on the Circuitscape map represent higher probability of habitat use for species movement. The nodes on the west and east sides of the Circuitscape map show concentrated high permeability of movement due to model forcing movement to and from the nodes. High probability of movement around the nodes does not reflect high habitat permeability.

\section{Barriers Crossed by $L C P$}

In total, 19 barriers were crossed by the beaver Least Cost Path model: nine roads, eight railroads and two trails (Figure 16). In addition, the LCP led the beavers through the Columbia Boulevard Wastewater Treatment Plant Lagoon in order to access the Columbia Slough from Heron Lakes Golf Course. Nine of the 19 barriers were either bridged, or had crossing structures aiding wildlife movement under the barrier. Some of the barriers crossed by the beaver LCP include North Portland Road with multiple lanes of railroad tracks and vehicular traffic, as well as trails and road systems in the center of Heron Lakes Golf Course. 
American Beaver (Castor canadensis) Least Cost Path Map - Barrier Map

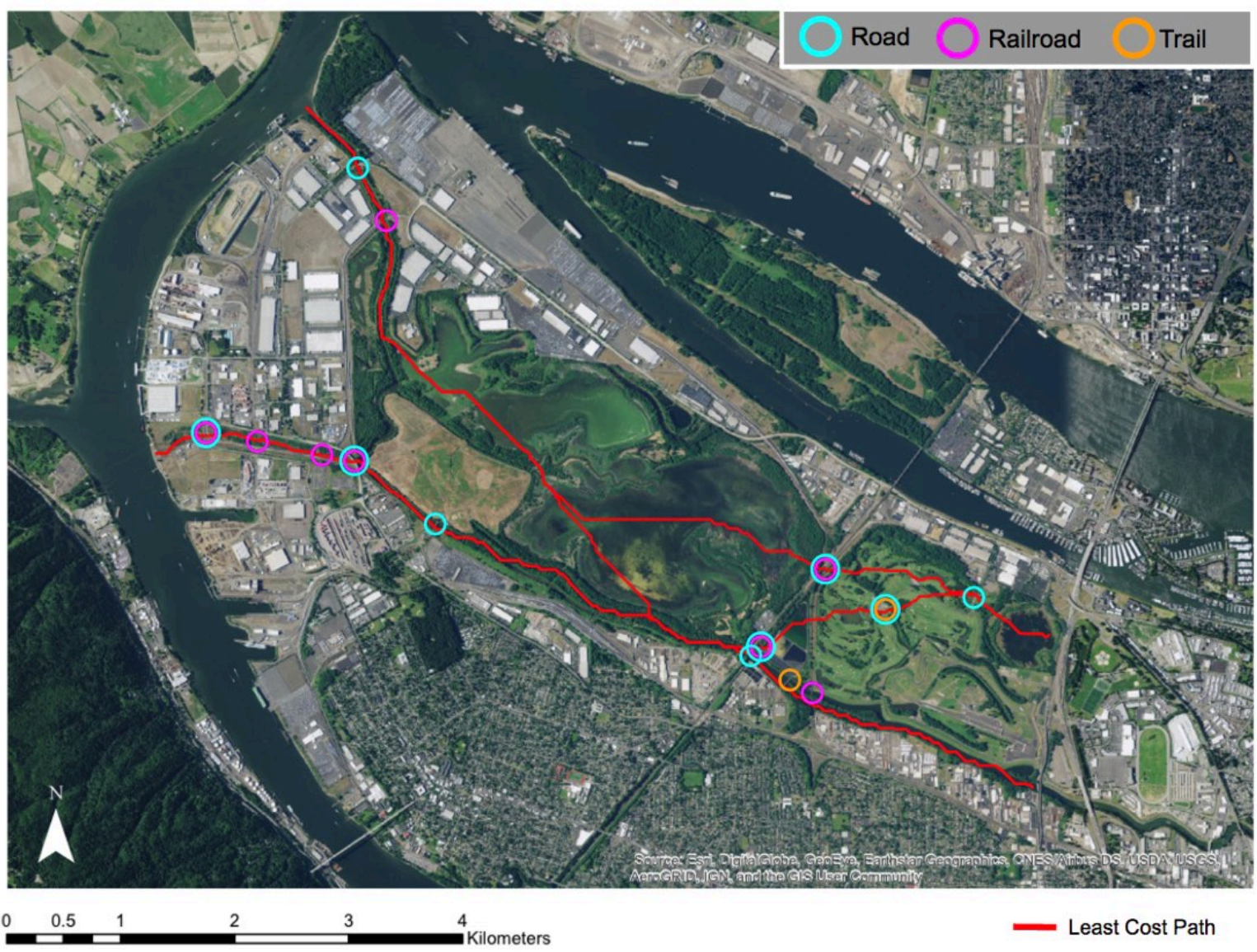

Figure 16: Barriers in study area crossed by American beaver (C. canadensis) Least Cost Path analysis. Circle symbols surround the barrier and pathway cross point, with blue circles representing road barriers, pink representing railroads, and orange representing trails.

\section{Red-legged Frog}

Habitat Ranking and Resistance Scoring Results

A total of five ranking sheets were returned from respondents for red-legged frog habitat resistance ranking. The smallest ranking range of resistance scores for all habitat types was from $1-4$, with four representing the highest resistance rank score, and all rankings were converted to the widest ranking scale of 1-15.

Final scores ranged from the lowest resistance at 4.05 for medium herbaceous wetland to the highest resistance at 13.2 points for tall buildings. All developed habitat types scored as the most resistant for red-legged frog movement, while medium height hardwoods and conifers scored as some of the best habitat for movement. Wetland habitat types generally scored as less resistant to movement than their non-wetland counterparts. All habitat types showed a wide 
variance in scores, likely due to conversion of ranking scales. Developed habitats had the smallest range in scoring,

\section{Circuitscape Mapping Results}

The Circuitscape map for the red-legged frog shows the riparian edges of Smith and Bybee, Heron Lakes Golf Course and the edges of the Columbia Slough as having higher likeliness for frog movement than the open water, developed, and even low herbaceous habitats (Figure 17). The water sources stand out as darker values, and the developed areas surrounding the study area reflect the lowest likeliness for red-legged frog movement. The low herbaceous area of St. John's Prairie also shows low movement probability, as does the very center of Smith and Bybee Wetlands between Smith and Bybee Lakes. Port of Portland's West Wye, Bonneville Pond and T5 Powerline sites show very high likeliness of frog movement as the frogs approach the Willamette River.

The Circuitscape map reflects high probability of red-legged frog movements around the northern edge of Heron Lakes Golf Course, then lessens over North Portland Road between Heron Lakes and Smith and Bybee Wetlands. The probability of habitat use increases for frog movement at the upland forest on the northwest edge of the wetland. The map shows high probability habitat use for movement in the riparian and upland forest portions of Smith and Bybee Wetlands for red-legged frog. 


\section{Red-legged frog (Rana aurora aurora) Circuitscape Map}
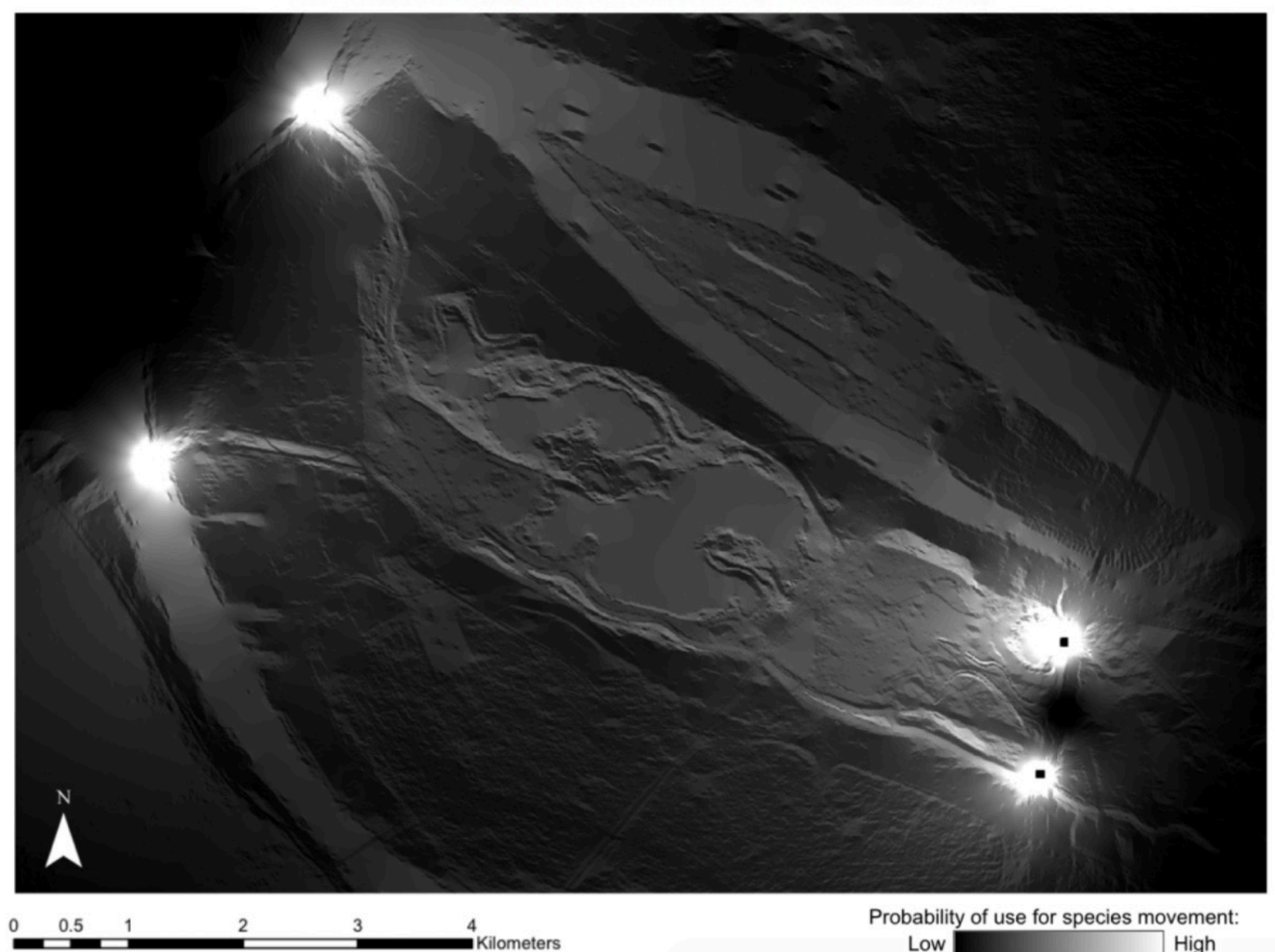

Probability of use for species movement: Low High

Figure 17: Circuitscape map for red-legged frog (R. aurora aurora). Lighter colors represent higher probability of habitat use for species movement. The nodes on the west and east sides of the Circuitscape map show concentrated high permeability of movement due to model forcing movement to and from the nodes. High probability of movement around the nodes does not reflect high habitat permeability.

\section{Least Cost Path Mapping Results}

Habitat resistance scores were ranked to enter into the LCP tool in ArcMap. The LCP ranking resulted in a range from 1 (low) to 21 (high) resistance values. A LCP map was created with four movement pathways connecting the four start and end points, resulting in four westeast or east-west directional paths (Figure 18). The LCP for red-legged frog utilizes the low rankings of hardwoods and conifers and sends the frogs in a path along the vegetated riparian edges of the Columbia Slough, and along the forested perimeter of Smith and Bybee. Similar to the other species, the red-legged frog LCP predicts frog movement straight across North Portland Boulevard to access Heron Lakes Golf Course, as well as movement through the wastewater 
treatment lagoon. The red-legged frog LCP crosses the Columbia Slough multiple times to access patches of riparian wooded habitat on both banks. The LCP appears to avoid open water for frog movement unless cutting across the water habitat is the more direct, shorter path, as seen in Smith and Bybee Wetlands with the LCP taking the frogs across the lake to access the northern edge of the property.

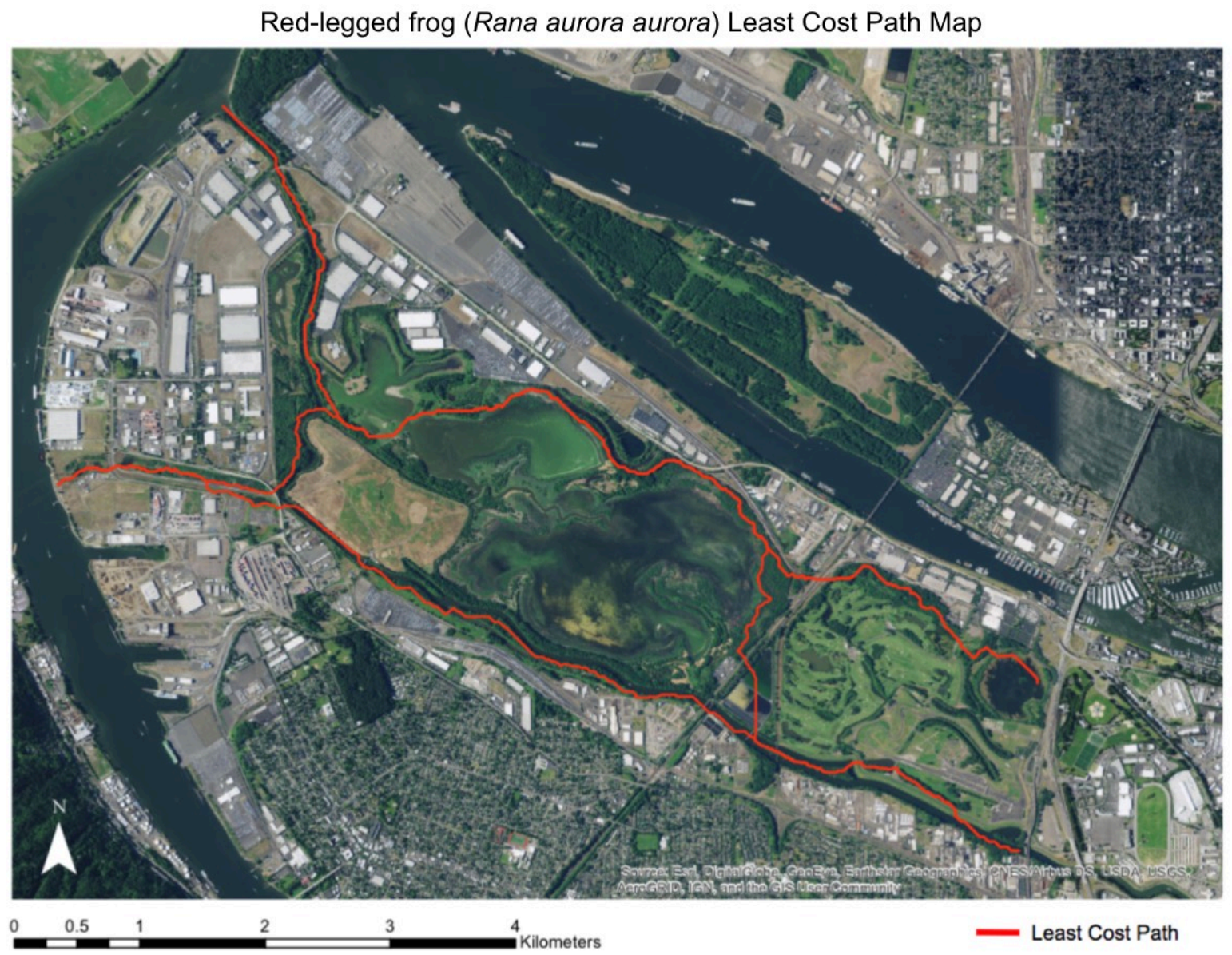

Figure 18: Least Cost Path analysis map for red-legged frog (R. aurora aurora) movement through the most permeable habitats based on expert opinion ranking.

The LCP map was overlaid on top of the Circuitscape map to compare landscape permeability and probability of wildlife movement with the predicted corridor by LCP analysis (Figure 19). The LCP was useful for red-legged frog movement path identification, as the map for the Circuitscape showed fewer defined areas of high movement probability and low probability in the study area. 


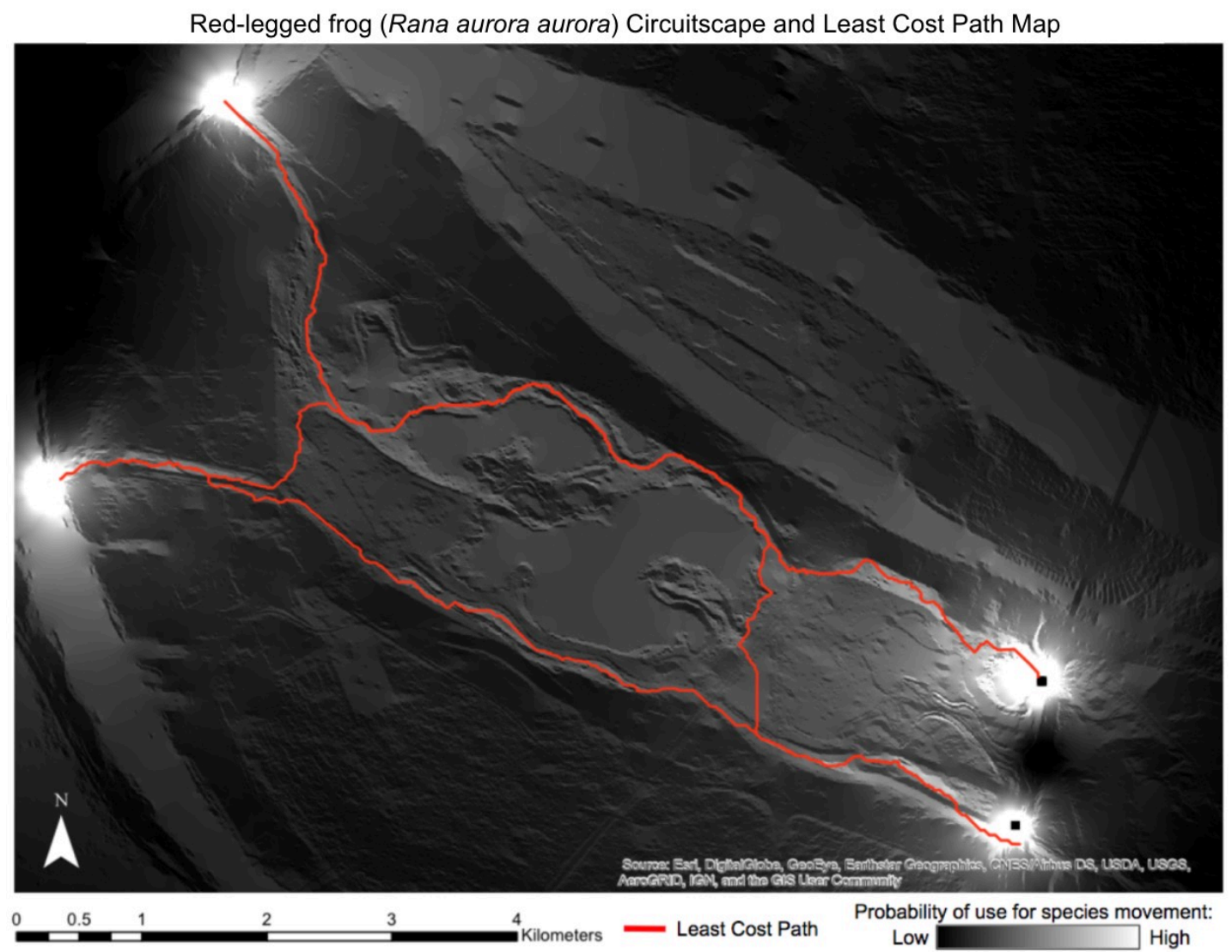

Figure 19: Circuitscape map with Least Cost Path analysis map overlay red-legged frog $(R$. aurora aurora). Lighter colors on the Circuitscape map represent higher probability of habitat use for species movement.

\section{Barriers Crossed by LCP}

There were a total of 26 barriers identified that were crossed by the Least Cost Path model (Figure 20). Of the 26 barriers, ten were roads, five were trails or trail networks, and eleven were railroad lines. There were 12 barriers that were bridged or possessed crossing structures. Some barriers were counted multiple times, as they had multiple crossing points by the LCP, including the bridged road overpass near the Bonneville Pond site and the railroad network near the West Wye Site. The LCP also takes the red-legged frogs through the Columbia Boulevard Wastewater Treatment Plant Lagoon, which is surrounded by fencing, though possibly permeable to red-legged frog movement. 


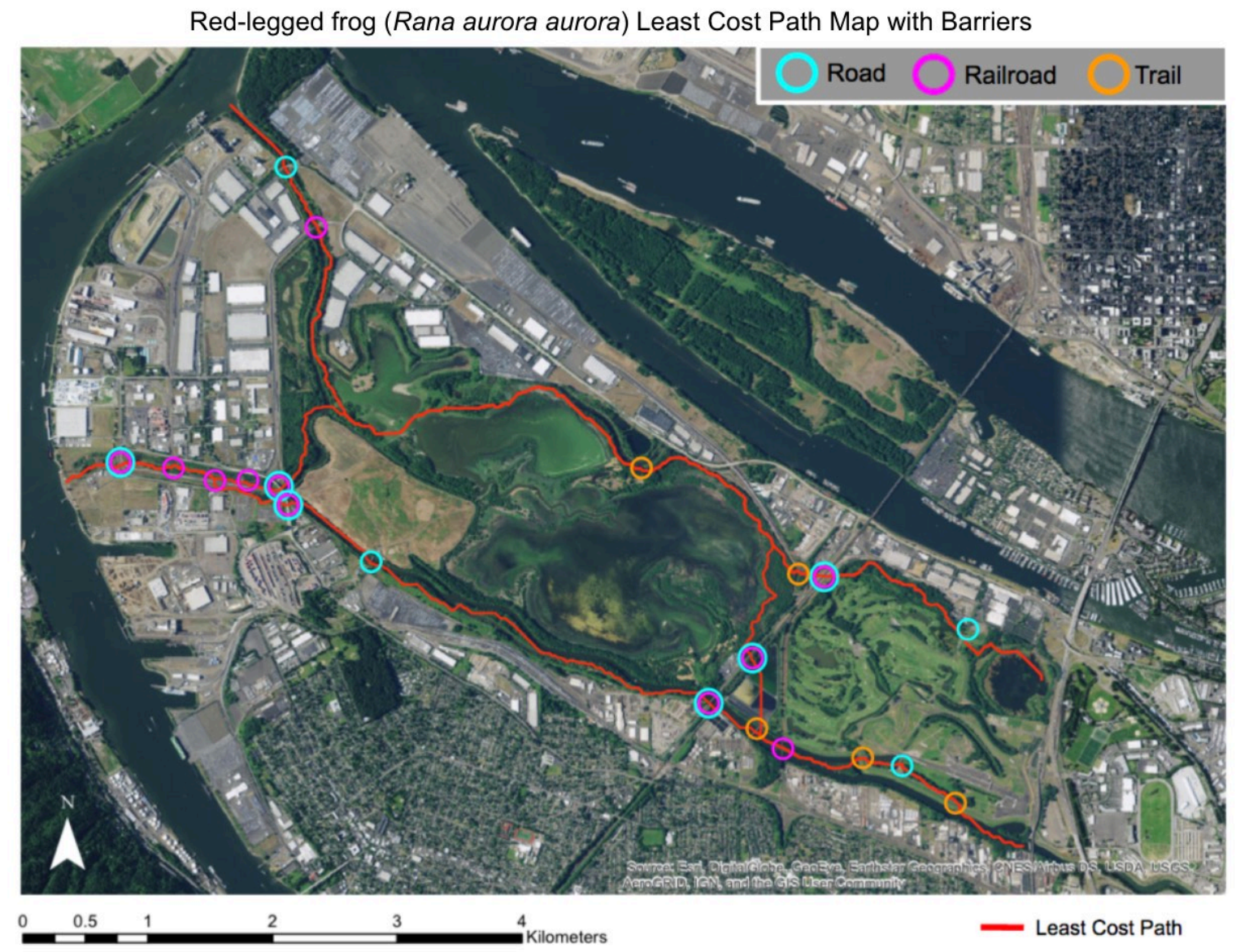

Figure 20: Barriers in study area crossed by red-legged frog (R. aurora aurora) Least Cost Path analysis. Circle symbols surround the barrier and pathway cross point, with blue circles representing road barriers, pink representing railroads, and orange representing trails.

\section{Misclassification of Habitat Types}

When comparing the results for all species models, a large misclassification of landscape habitat data was apparent in the Regional Conservation Strategy land cover data set. Some locations that do not contain developed habitat were reflecting high percentages of developed habitat types, predominantly pavement (Figure 21). This could not be corrected without extensive work to reclassify the raster data, so the Circuitscape and LCP models were left as-is without modification. This misclassification is likely to have altered the results of the Circuitscape and Least Cost Path models for all species, as developed habitat is ranked as having the highest resistance of all habitat types for all species (Appendix B). The area with the most apparent need for reclassification is the center of Smith and Bybee where Smith Lake and Bybee Lake are separated by an increase in elevation. 
The misclassification of habitat is likely due to the similarity in coloration between the low water and bare ground habitats to the gray pavement of developed habitat. As classifications were made through hand combination of modeling and hand digitizing from color and color infrared aerial photography, there is room for both computer error and human error (Regional Conservation Strategy 2012). The Regional Conservation Strategy Biodiversity Guide acknowledged the issue of misclassification of sand and cobble as pavement, and in response buffered major rivers by 50 feet and reclassified the habitat contained in the buffer from developed to sand and cobble. However, it is apparent from the landscape classification of the study area that there is bare ground, sand, cobble or water being misclassified as development.

It is unlikely that an independent researcher or land manager performing GIS analysis of corridors would have the time or expertise to reclassify the dataset, and instead would use the dataset in it's original form. Therefore, the dataset was used as-is for the method without reclassification. The Regional Conservation Strategy and Institute for Natural Resources land cover dataset is highly detailed with small $5 \times 5$ meter pixel classification in order to visualize the fine scale landscape pattern in the region, and the best available data for public use. However, misclassifications still occurred in some habitats, and while it may be hidden in large scale views of the Portland Metro region, small scale analysis and modeling could be greatly affected by the misclassification of habitat types.

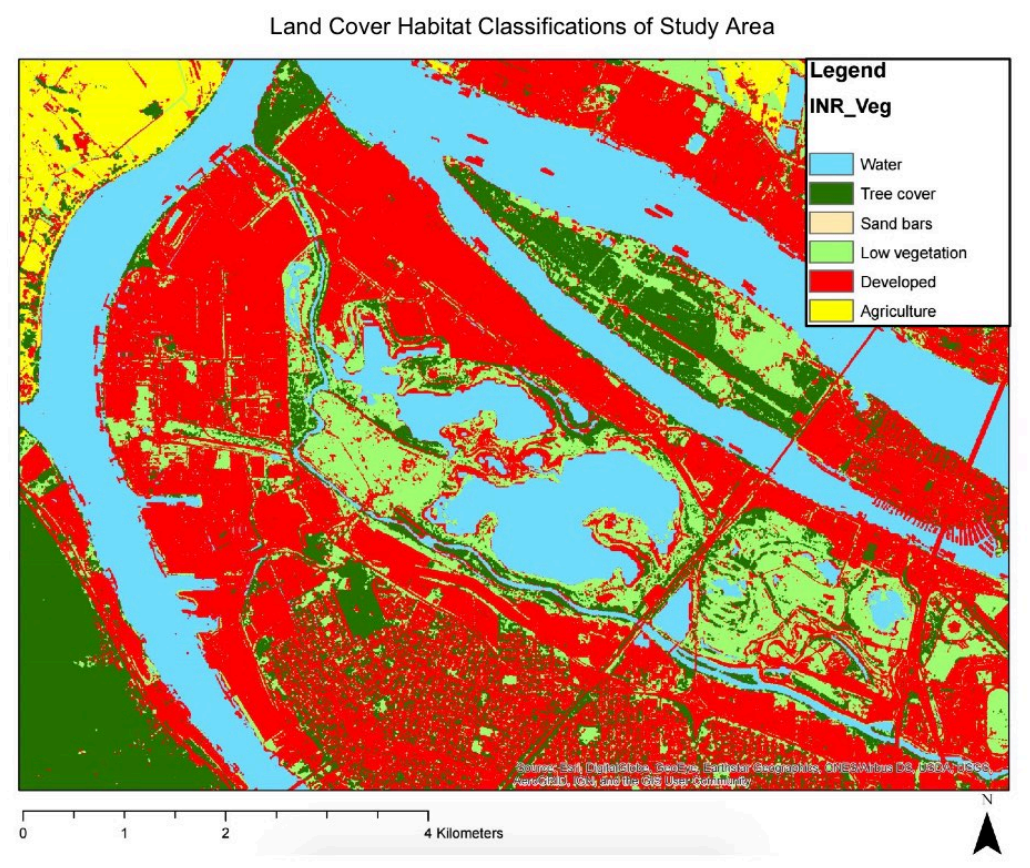

Figure 21: Regional

Conservation Strategy (RCS) and Institute of Natural Resources (INR) land cover GIS data. Data is in the most general classification scheme (Tier 0) to group the developed habitat types. Misclassification of habitat as developed habitat can be seen throughout the map, most notably in the Smith and Bybee and St. John's prairie areas. 


\section{Landscape Accuracy}

The GIS models are highly dependent on the data used to classify habitats for species movement. By using the RCS land cover dataset without alteration, misclassified pavement habitat was included in the models and the dataset was used in the models as-is. It is unlikely that an independent researcher or land manager performing GIS analysis of corridors would have the time or expertise to reclassify the dataset, and instead would use the dataset in it's original form. This dataset does have high detail habitat mapping for the region, and in proportion to the entire region that the data set is available, the amount of misclassified habitat is small. However, due to the small extent of the study area evaluated, the misclassification of habitat may have played a large role and skewed final habitat permeability results and LCP models.

In addition to the misclassification of habitat, habitat elements such as water velocity, sun exposure, and human activity were not included in the GIS data. Another level of classification would need to be performed to include physical elements such as water velocity, but ever changing and non-physical elements such as human activity cannot be easily translated to GIS data. These additional components of a habitat contribute significantly to the overall corridor quality, as high human presence can impact wildlife behavior and habitat (Metro 2010), and water velocity and sun exposure which may affect species that prefer still water or are at risk of desiccation, such as the western painted turtle and red-legged frog (ODFW 2015; Nussbaum et al. 1983; Biosystems Analysis 1989). Because of the wide amount of information not included in the GIS model, the overall landscape accuracy was low when compared to other methods.

\section{Barrier Accuracy}

The Circuitscape model could not see barriers beyond the habitat they were classified as. Roads and parking lots appear as narrow strips of pavement, while railroads were often viewed as pavement or bare ground. While these habitats were ranked as less permeable than the other habitat types, they exclude barrier details such as traffic, human activity, vertical structures and other attributes which significantly decrease the permeability of the area. In addition, barriers such as fencing are not captured in the land cover data at all and is nearly invisible on aerial imagery. Without a dataset containing the fencing of an area, it is nearly impossible to include all fencing in the study area into the GIS models. This compounds in difficulty as the method is used on multiple smaller properties where boundary fencing and smaller barriers are more 
frequently used on the landscape. Where a dataset exists of barrier presence such as road and railroad layers for GIS, the barriers can be classified as another habitat type. This has its own issues as each barrier has unique levels of permeability and crossing structures would alter the score for the barriers.

Barriers that were crossed by the Least Cost Path analysis were identified and counted using aerial imagery. Barriers crossed by the LCP ranged from 19 to 26 individual barriers depending on the species, ranging in structure and size. The LCP model likely could not identify between barriers and pavement through the land cover dataset, therefore, cost of moving through low permeability barriers was not factored into the total cost of the pathway. If the cost were to be factored in, the LCP may have taken the species in a different direction.

Overall, the GIS process used for this project had low barrier accuracy. This could be improved upon with more inclusion of data to increase the number of classifications of habitats for Circuitscape, or through marking barriers as costlier for the LCP analyses, but one would need to identify all barrier types and locations in the study area in order to more accurately reflect barrier presence in each method.

\section{Ease of Use}

The most significant amount of time required for the Circuitscape and Least Cost Path models was for collecting the ranking responses from the species experts. This stage in the method took longer than intended to ensure the largest possible number of responses were collected. Once this portion of the method was complete, and technical user-based issues with the models were solved, both Circuitscape and Least Cost Path tools were quick to process the data. Since the method required no trips into the field or scheduling of interviews, the process could be done at a self-guided pace. The method also required few resources besides the GIS data layers required to classify the habitat and the ranking responses to order the habitat preferences. While the GIS layers are simple to obtain with public data caches, the ranking responses were not easy to produce, and were an essential component of the modeling process. This component decreased the ease of use of the method, as it relies heavily on specific data that are not commonly published or available. If the species of interest is rare and with few species experts to provide rankings, the ease of use of the model decreases significantly as the results are based off of one or two individuals' opinions on the habitat preference of a species. 


\section{Data Output}

Once complete, the GIS modeling method using both Circuitscape and Least Cost Path provides both species ranking lists of preferable habitat for movement, landscape prediction maps of species movement, distinct paths of likely movement, and identification of potential barriers crossing those paths. The ranking lists of habitat preferences can be used on their own for future restoration and management products, though the managers should keep in mind that species preference for habitats may change in the urban context. The ability of the method to create a landscape view of habitat including the properties surrounding the study area is valuable when deciding where restoration activities should take place, or where land acquisition for conservation should occur. In total, the GIS models produced a ranking of habitat preferences for each species of interest, as well as a landscape view map of movement probabilities and a single corridor of highest use probability. Quality of any corridor of interest in the study area can be inferred based on the habitat permeability assigned by the ranking exercise, as well as the probability of movement shown by overlaying a corridor on the Circuitscape map. 


\section{In-field Survey: Habitat Connectivity Toolkit}

The Habitat Connectivity Toolkit survey of the study area was completed between September and December of 2016, totaling 12 weeks of surveying. The method showed a low ease of use compared to other methods, due to the time and resources needed to go collect data in the field. Habitat quality scores for the north and south connectivity zones were calculated using habitat features that were identified on site and through GIS analysis, leading to high landscape accuracy overall. Barrier accuracy was also high for the method, as barriers that were identified by GIS analysis or identified in the field were scored, and permeability percentages for barriers were calculated. The final scores for habitat quality and permeability show a pattern of high quality habitat through the highly conserved natural areas on the interior of the connectivity zones, and a general decrease in habitat quality for species movement of all species on the ends of the corridors. Barriers increase in number on the tails of the north and south connectivity zones, as the corridors reach into more developed areas where undeveloped habitat patch size is limited. Barrier permeability scores greatly depended on the presence or absence of a crossing structure, as long as the crossing structure was of appropriate size and composition to allow for species passage. The method showed high data output, as detailed information about zone habitat composition and barrier structures were created, allowing for future site specific management decisions.

\section{Habitat Zones}

Two connectivity paths were assigned in the study area for the Habitat Connectivity Toolkit (HCT) analysis. Paths were determined though best judgment based on wetland species utilization of aerial imagery-identified habitat, as well as an initial Circuitscape model for the painted turtle. A north corridor was created following a path that moved through the northern parts of the properties. The corridor was curved downwards into the center of Smith and Bybee in order to avoid the greatest amount of known barriers, predominantly the trail system in the northern portion of the property. In addition, because the species of interest were wetland species, the assigned north corridor followed the greatest amount of wetland habitat for that area. The southern corridor moved along the Columbia Slough, through the Port of Portland properties 
to the Willamette River. Corridor ends were chosen to align with the start and end points of the land manager interview assessment and the GIS assessment.

Once corridors were assigned, they were split into the habitat zones (Figure 22). In total, 37 habitat zones were created. The north corridor had 17 habitat zones for assessment, and the south corridor had 20 zones for assessment. Zones were surveyed and scored for each species of interest.

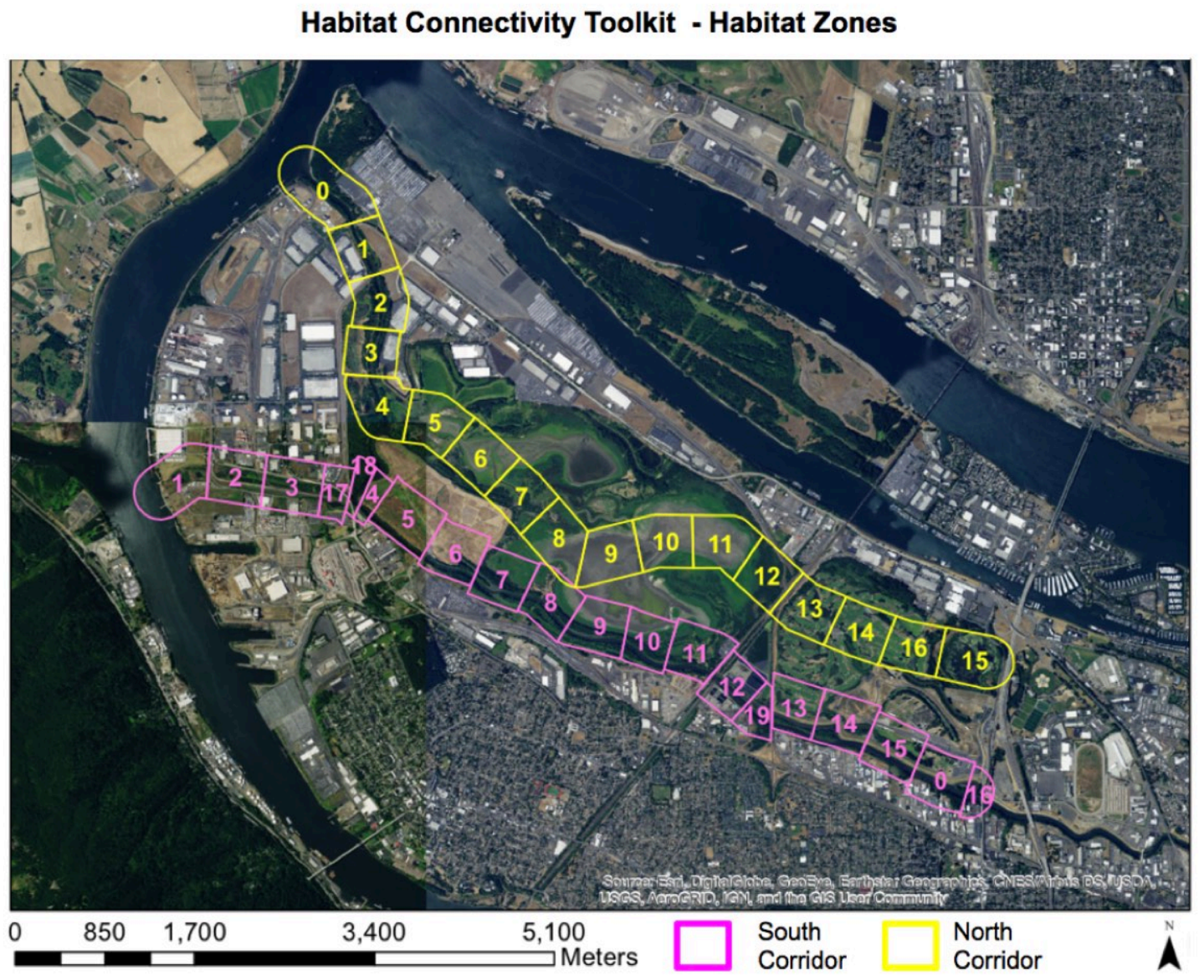

Figure 22: HCT habitat zone composition of the assigned north and south corridors in study area. All zones are $500 \mathrm{~m}$ wide, and vary in length with zones being divided by barriers, but not exceeding $600 \mathrm{~m}$. Pink outlines represent the south corridor zones, and yellow outlines represent the north corridor zones. Zone numbers are not sequential, as zones were further divided later as more barriers were identified in the field.

\section{Barriers Identified}

Through both GIS pre-assessment of the study area as well in-field surveying, 37 potential infrastructure barriers to species movement were identified and given unique barrier 
IDs. All of the barriers were crossing the north and south corridors and were assessed using toolkit protocol (Appendix C). Of the 37 barriers, 14 roads were identified, as well as 11 railroads, 4 trails, 6 fences, one trail/fence combination and one pipeline (table 3 ). Barrier information such as bridging, crossing structures, and additional features that may affect wildlife movement was noted for species scoring.

Table 3: Types and counts of barriers crossing the north and south corridors for Habitat Connectivity Toolkit analysis, as well as a list of unique barrier identifiers.

\begin{tabular}{|l|c|l|l|}
\hline Barrier Type & $\begin{array}{c}\text { Total \# } \\
\text { of Type }\end{array}$ & Barrier IDs \\
\hline Road & 14 & B5, B6, B8, B10, B11, B17, B19, B20, B23, B27, B28, B32, B35, B37 \\
\hline Railroad & 11 & B2, B3, B14, B15, B16, B18, B22, B24, B25, B31, B36 \\
\hline Trail & 4 & B7, B30, B33, B34 \\
\hline Fence & 6 & B1, B9, B12, B13, B21, B29 \\
\hline Trail/Fence & 1 & B4 \\
\hline Pipeline & 1 & B26 \\
\hline
\end{tabular}

Total Number of Barriers Assessed: 37

Roads

Fourteen roads were identified as barriers to movement in either the north or south corridor (Figure 23). Of those roads, four were bridged across waterways or dry terrain, two possessed culvert structures larger than two feet in diameter, one possessed a culvert structure equal or less than two feet in diameter, and seven had no crossing structure or means of passage besides crossing the road itself (Table 4). These roads varied in number of lanes, median structure, shoulder structure, and traffic speeds and frequency.

Table 4: Road barriers identified through with crossing structure details and associated barrier ID numbers

\begin{tabular}{|c|c|c|l|}
\hline Barrier Type & $\begin{array}{c}\text { Crossing Structure } \\
\text { Type }\end{array}$ & Count & \multicolumn{1}{|c|}{ Barrier IDs } \\
\hline Road & None & 7 & B06, B20, B23, B27, B28, B35, B37 \\
\hline & Bridge & 4 & B05, B17, B19, B32 \\
\hline & Culvert $(>2 \mathrm{ft})$ & 2 & B10, B11 \\
\hline & Culvert $(<=2 \mathrm{ft})$ & 1 & B08 \\
\hline & Total number of roads: & $\mathbf{1 4}$ & \\
\hline
\end{tabular}




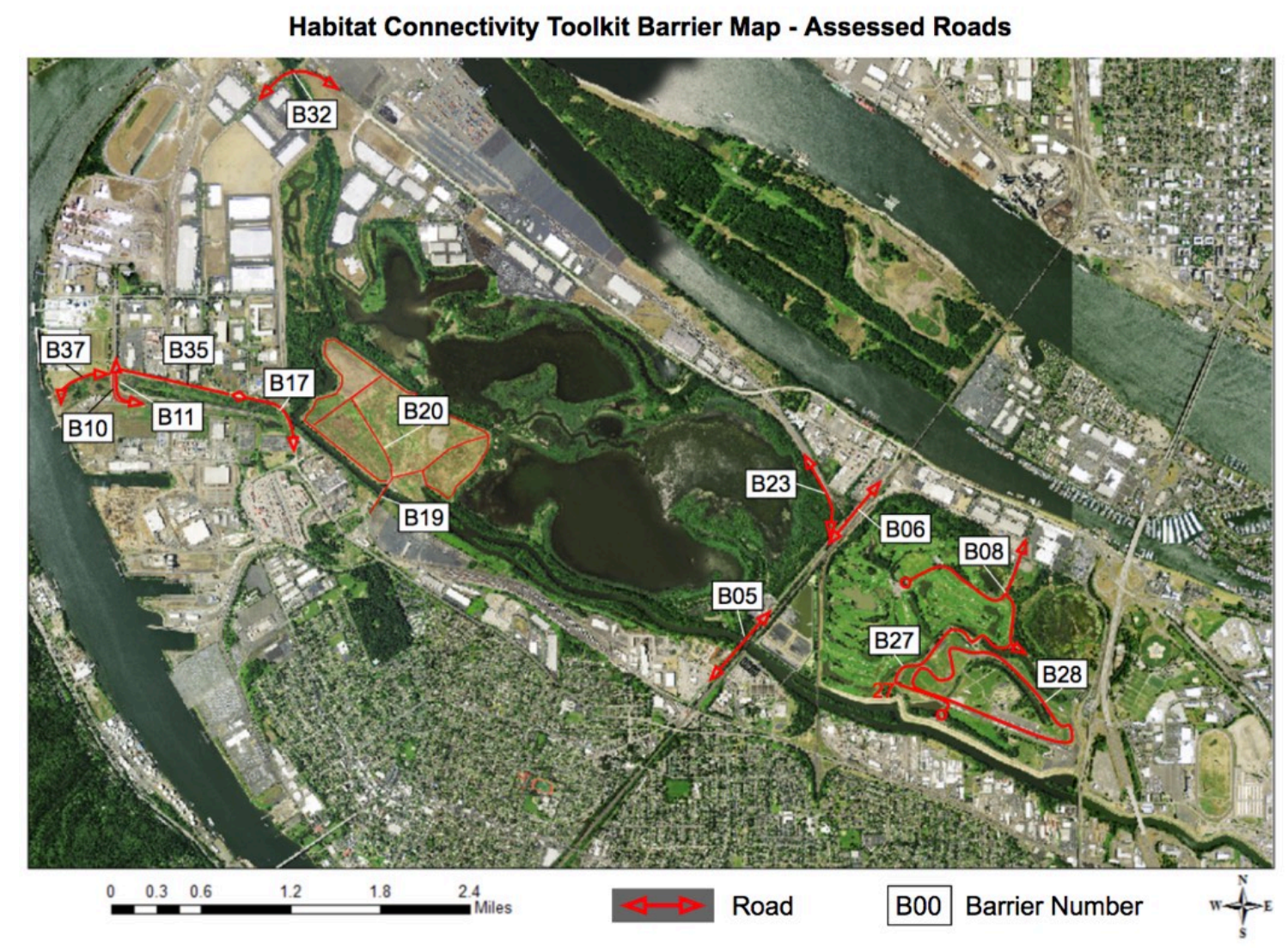

Figure 23: Road barriers present in study area with unique barrier IDs. Only shown are the roads intersecting the north and south corridors for the HCT analysis.

\section{Railroads}

Eleven railroads were identified as barriers to movement for the north and south corridors (Figure 24). Railroads consisted of single or multiple tracks, and varied in shoulder substrate and associated barriers but all consisted of the same typical rail line construction. One rail yard was included in the assessment (Barrier ID:B22) as the location of the rail yard blocks clear access to the Columbia River from Smith and Bybee Wetlands. Of the railroads assessed, five possessed no crossing structure or bridging allowing wildlife movement. Four railroads were bridged across waterways and terrestrial landscape, and two railroads possessed crossing structures allowing wildlife movement (Table 5). 
Table 5: Railroad barriers identified in survey with crossing structure details and associated barrier ID numbers

\begin{tabular}{|c|c|c|l|}
\hline Barrier Type & $\begin{array}{c}\text { Crossing Structure } \\
\text { Type }\end{array}$ & Count & \multicolumn{1}{|c|}{ Barrier IDs } \\
\hline Railroad & None & 5 & B15, B16, B22, B25, B36 \\
\hline & Bridge & 4 & B02, B03, B24, B31 \\
\hline & Culvert $(>2 \mathrm{ft})$ & 2 & B14, B18 \\
\hline & Culvert $(<=2 \mathrm{ft})$ & 0 & N/A \\
\hline & Total number of Railroads & $\mathbf{1 1}$ & \\
\hline
\end{tabular}

Habitat Connectivity Toolkit Barrier Map - Assessed Railroads

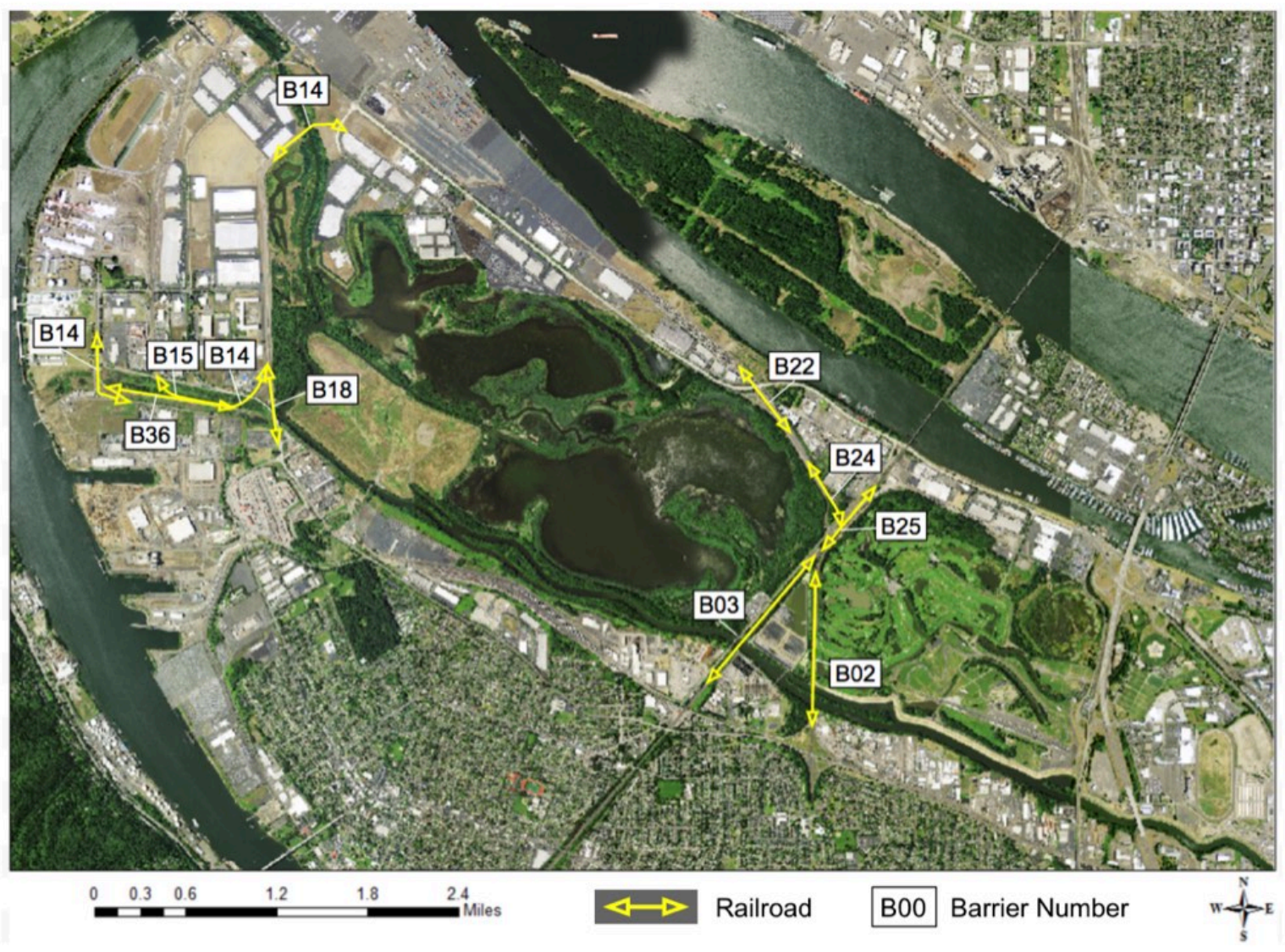

Figure 24: Railroad barriers present in study area with unique barrier IDs. Only shown are the railroads intersecting the north and south corridors for the HCT analysis as well as one rail yard blocking passage from Smith and Bybee Wetlands to the Columbia River (B22). 


\section{Trails and Fences}

There were five trails and trail networks that crossed the north and south corridors

(Figure 25). Of those five, three were single path trails with no crossing structures and one was a trail network of motorized golf course trails in Heron Lakes Golf Course (Barrier ID: B07). This trail network crossed the north corridor approximately five times. There was also one bridged trail over the Columbia Slough (Table 6). Also crossing the study area was six fence structures (Figure 25). Of the fence structures, three possessed no crossing structures, two possessed wildlife crossing structures of greater than two feet diameter, and the final fence, which surrounds Vanport Wetlands, had a single culvert of less than two feet diameter running underneath the structure (Table 7). This fence was assessed as being complete around the wetlands; however, a large portion of the fence on the western side of the property has fallen down and has not been repaired.

Table 6: Trail barriers identified in survey with crossing structure details and associated barrier ID numbers

\begin{tabular}{|c|c|c|l|}
\hline Barrier Type & $\begin{array}{c}\text { Crossing Structure } \\
\text { Type }\end{array}$ & Count & Barrier IDs \\
\hline Trail & None & 4 & B04, B07, B33, B34 \\
\hline & Bridge & 1 & B30 \\
\hline & Culvert $(>2 \mathrm{ft})$ & 0 & N/A \\
\hline & Culvert $(<=2 \mathrm{ft})$ & 0 & N/A \\
\hline & Total number of Trails: & $\mathbf{5}$ & \\
\hline
\end{tabular}

Table 7: Fence barriers with crossing structure details and associated barrier ID numbers

\begin{tabular}{|c|c|c|l|}
\hline Barrier Type & $\begin{array}{c}\text { Crossing Structure } \\
\text { Type }\end{array}$ & Count & \multicolumn{1}{|c|}{ Barrier IDs } \\
\hline Fence & None & 3 & B01, B09, B29 \\
\hline & Bridge & 0 & N/A \\
\hline & Culvert $(>2 \mathrm{ft})$ & 2 & B12, B13 \\
\hline & Culvert $(<=2 \mathrm{ft})$ & 1 & B21 \\
\hline & Total number of fences: & $\mathbf{6}$ & \\
\hline
\end{tabular}




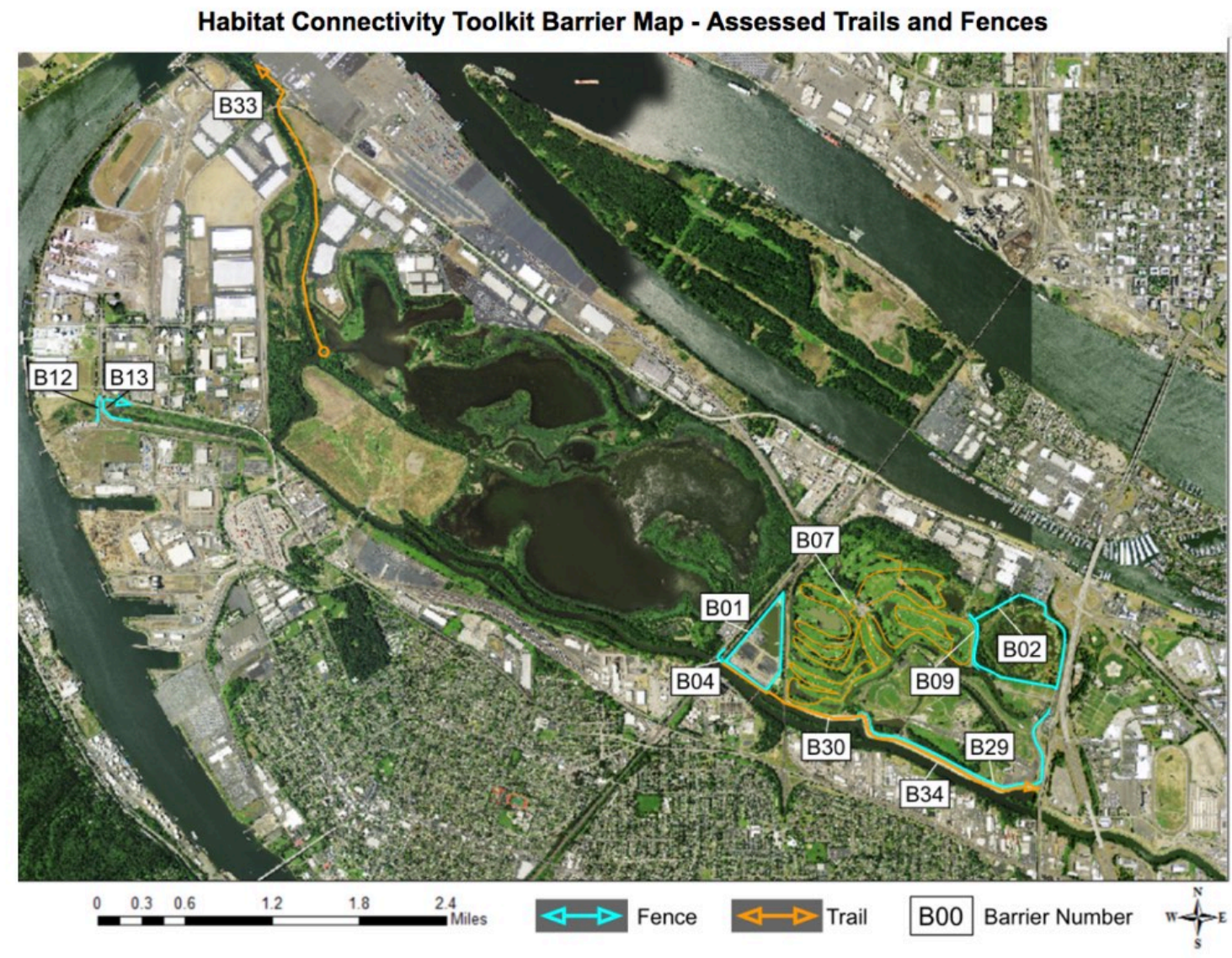

Figure 25: Fence and Trail barriers present in study area with unique barrier IDs. Only shown are the fences and trails intersecting the north and south corridors for the HCT analysis.

\section{Western Painted Turtle}

\section{Habitat Quality Scores}

Habitat zones in the north and south corridors were scored for western painted turtle and habitat quality percentages were calculated (Table 8). These percentages reflect the percent quality of habitat structure for species movement, not residence. Percent quality values for the north corridor ranged from a low of $62 \%$ to a high of $87 \%$ for western painted turtle movement (Figure 26). Percent quality values for the south corridor ranged from a low of $54 \%$ to a high of $92 \%$ for habitat quality. The higher scored centers of both the north and south corridor showed high proportions of open water, logs and woody debris in streams, mix of canopy and exposed habitat and little human activity, as seen by the scoring of Port of Portland's Vanport Wetlands at $85 \%$. The tails of both corridors captured higher development, human activity, and lower 
proportions of open water and wetland habitats, which decreased the overall scores of those zones. As the toolkit is still in the process of being developed, no baseline for percent thresholds of habitat quality exists for rural or urban areas.

Table 8: HCT percent habitat quality scores for western painted turtle in all north and south corridor habitat zones. Percent quality calculated by scoring habitat features based on species preference, then dividing the score by the maximum possible.

\begin{tabular}{|c|c|c|c|c|c|c|c|}
\hline \multicolumn{8}{|c|}{$\begin{array}{l}\text { Western Painted Turtle Percent Habitat Quality for } \\
\text { North and South HCT Corridors }\end{array}$} \\
\hline \multicolumn{4}{|c|}{ North Corridor } & \multicolumn{4}{|c|}{ South Corridor } \\
\hline Zone & $\begin{array}{c}\% \\
\text { Quality }\end{array}$ & Zone & $\begin{array}{c}\% \\
\text { Quality }\end{array}$ & Zone & $\begin{array}{c}\% \\
\text { Quality }\end{array}$ & Zone & $\begin{array}{c}\% \\
\text { Quality }\end{array}$ \\
\hline No & $62 \%$ & N10 & $78 \%$ & S0 & $57 \%$ & S10 & $83 \%$ \\
\hline N1 & $57 \%$ & N11 & $87 \%$ & S1 & $65 \%$ & S11 & $73 \%$ \\
\hline N2 & $65 \%$ & N12 & $63 \%$ & S2 & $54 \%$ & S12 & $62 \%$ \\
\hline N3 & $58 \%$ & N13 & $62 \%$ & S3 & $62 \%$ & S13 & $75 \%$ \\
\hline N4 & $72 \%$ & N14 & $58 \%$ & S4 & $65 \%$ & S14 & $56 \%$ \\
\hline N5 & $80 \%$ & N15 & $85 \%$ & S5 & $63 \%$ & S15 & $60 \%$ \\
\hline N6 & $83 \%$ & N16 & $65 \%$ & S6 & $67 \%$ & S16 & $57 \%$ \\
\hline N7 & $72 \%$ & & & S7 & $92 \%$ & S17 & $63 \%$ \\
\hline N8 & $80 \%$ & & & S8 & $87 \%$ & S18 & $68 \%$ \\
\hline N9 & $78 \%$ & & & S9 & $81 \%$ & S19 & $65 \%$ \\
\hline
\end{tabular}

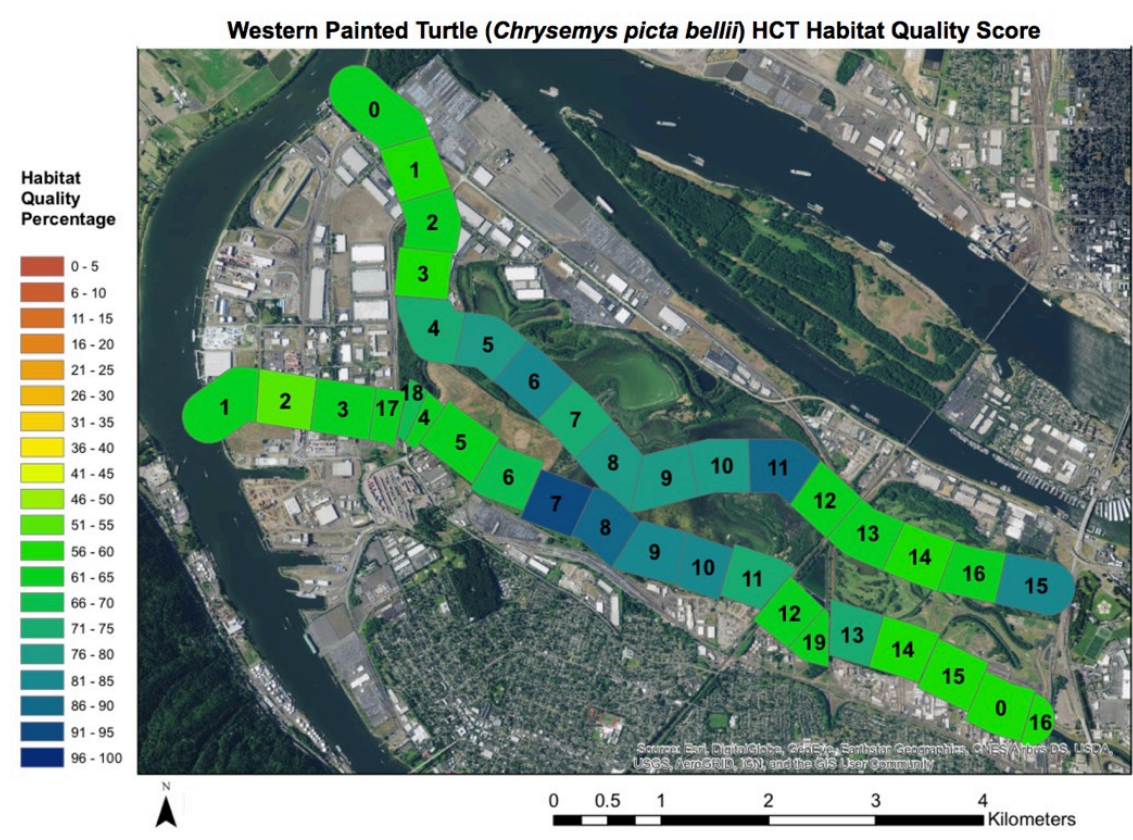

Figure 26: Habitat zones for the north and south corridor and coded with HCT percent habitat quality scores for western painted turtle (Chrysemys picta bellii) movement. Zones are not sequential as new zones were created with later barrier identification and zone division. Percent quality calculated by scoring habitat features based on species preference, then dividing the score by the maximum possible. 


\section{Barrier Permeability Scores}

Barrier scores for western painted turtle ranged from a low score of $27 \%$ permeability for a tall chain link fence to a high score of $87 \%$ for a low-use dirt utility road. Barrier scores were calculated for any infrastructure or built feature that decreases wildlife movement into or out of the defined habitat zones. All barriers that crossed zones are mapped and scaled for percent permeability on top of the western painted turtle scored habitat zones for the north and south corridors (Figure 27).

Western Painted Turtle (Chrysemys picta bellii) Barrier Permeability Scoring (HCT)

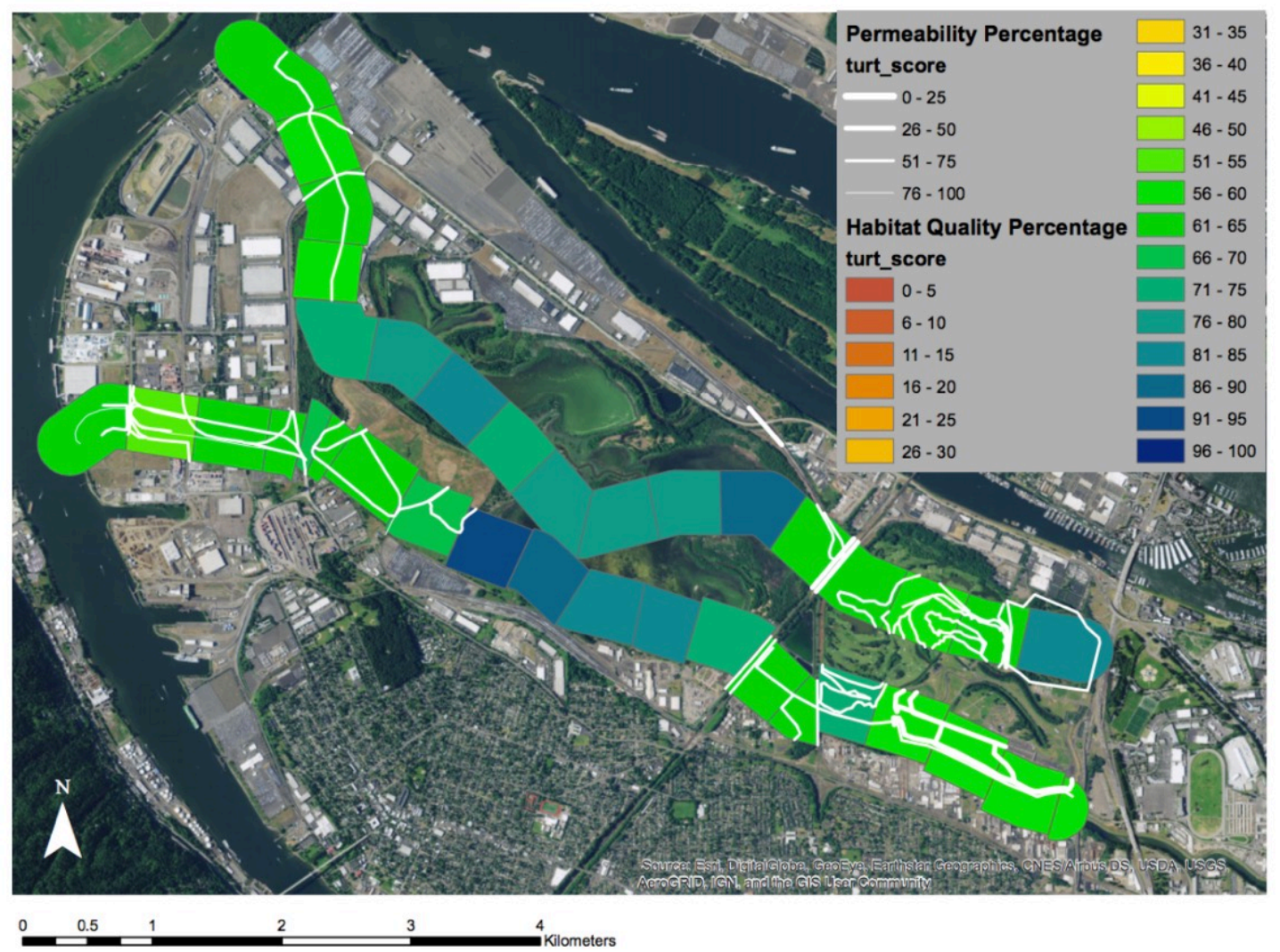

Figure 27: Barrier permeability percentages for western painted turtle (Chrysemys picta bellii) overlaid with the habitat quality percentages for each zone in the north and south corridor. Only barriers that blocked or excluded habitat in the zones are displayed. Thickness of barrier lines represents permeability of the barrier, with thicker lines being less permeable.

$\underline{\text { Roads }}$

Road permeability scores varied for western painted turtle depending on the presence or absence of a crossing structure or bridge (Table 9). The highest score was given to the road with a culvert less than two feet in diameter. The road is often closed to traffic and used more 
commonly as a bike path and walking trail, and the culvert allows aquatic and terrestrial passage. This culvert has seasonal aquatic passage, however, which currently is not accounted for in the scoring process. The general lack of motorized traffic gave it an initial high base permeability score that improved slightly with crossing structure addition (See crossing structure results section). The individual road with the lowest permeability was the Portland International Raceway racetrack (B28), which scored a 29\% permeability due to the high speed traffic, lighting, and high human presence.

Road presence was concentrated around the borders of the properties (Figure 27). The road with the most complex composition (consisting of multiple lanes of traffic, highly developed shoulders and adjacent rail lines) was North Portland Road (B6) between Heron Lakes Golf Course and Smith and Bybee Wetlands. Roads that served more as walking trails or utility roads (B8, B37) had higher permeability (Table 9).

Table 9: Road barrier permeability scores for western painted turtles, organized by crossing structure type.

\begin{tabular}{|c|c|c|c|}
\hline \multicolumn{4}{|c|}{ Permeability Scores for Western Painted Turtle Road Barriers } \\
\hline Barrier ID & Barrier Type & Crossing Structure Type & Permeability Score \\
\hline B8 & Road & $<=2 \mathrm{ft}$ Culvert & $74 \%$ \\
\hline \multicolumn{3}{|c|}{ Average Road with $<=2$ ft Culvert Score $(n=1)$} & $74 \%$ \\
\hline $\mathrm{B} 10$ & Road & $>2 \mathrm{ft}$ Culvert & $66 \%$ \\
\hline B11 & Road & $>2 \mathrm{ft}$ Culvert & $58 \%$ \\
\hline \multicolumn{3}{|c|}{ Average Road with $>2 \mathrm{ft}$ Culvert Score $(n=2)$} & $62 \%$ \\
\hline B5 & Road & Bridge & $72 \%$ \\
\hline B17 & Road & Bridge & $65 \%$ \\
\hline B19 & Road & Bridge & $77 \%$ \\
\hline B32 & Road & Bridge & $70 \%$ \\
\hline \multicolumn{3}{|c|}{ Average Bridged Road Score $(n=4)$} & $71 \%$ \\
\hline B6 & Road & None & $48 \%$ \\
\hline $\mathrm{B} 20$ & Road & None & $67 \%$ \\
\hline $\mathrm{B} 23$ & Road & None & $57 \%$ \\
\hline $\mathrm{B} 27$ & Road & None & $43 \%$ \\
\hline $\mathrm{B} 28$ & Road & None & $29 \%$ \\
\hline B35 & Road & None & $65 \%$ \\
\hline \multirow[t]{2}{*}{ B37 } & Road & None & $79 \%$ \\
\hline & & Average Road Score $(n=7)$ & $55 \%$ \\
\hline
\end{tabular}




\section{$\underline{\text { Railroads }}$}

Permeability scores of individual railroads for western painted turtles ranged from $33 \%$ to $75 \%$, with the lowest individual score being a multitrack rail line (B25) adjacent to Heron Lakes Golf Course (Table 10). The highest individually scored railroads for western painted turtle permeability were the railroad overpass over North Portland Road (B24) and the rail line under Lombard Avenue, which has a three-foot diameter culvert running underneath into the Columbia Slough (B18). The average permeability scores of railroads with crossing structures or bridges were higher than that of non-bridged railroads with no crossing structures.

Railroads with culverts were only found in the Port of Portland T5 Powerline, West Wye and Bonneville Pond property area. While one of the culverts is an intentional wildlife crossing location, the other culvert appears to be a storm water culvert that can be used by terrestrial or aquatic wildlife to move through the railroad barrier (B18), depending on the current water level. Rail lines were most numerous around the Port of Portland mitigation sites as well as around Heron Lakes Golf Course (Figure 27).

Table 10: Railroad barrier permeability scores for western painted turtles, organized by crossing structure type.

\begin{tabular}{|c|c|c|c|}
\hline \multicolumn{4}{|c|}{ Permeability Scores for Western Painted Turtle Railroad Barriers } \\
\hline Barrier ID & Barrier Type & Crossing Structure Type & Permeability Score \\
\hline B14 & Railroad & $>2 \mathrm{ft}$ Culvert & $69 \%$ \\
\hline B18 & Railroad & $>2 \mathrm{ft}$ Culvert & $75 \%$ \\
\hline \multicolumn{3}{|c|}{ Average Railroad with $>\mathbf{2 f t}$ Culvert Score (n=2) } & $\mathbf{7 2 \%}$ \\
\hline B2 & Railroad & Bridge & $74 \%$ \\
\hline B3 & Railroad & Bridge & $72 \%$ \\
\hline B24 & Railroad & Bridge & $75 \%$ \\
\hline B31 & Railroad & Bridge & $70 \%$ \\
\hline & Average Bridged Railroad Score (n=4) & $\mathbf{7 3 \%}$ \\
\hline B15 & Railroad & None & $62 \%$ \\
\hline B16 & Railroad & None & $62 \%$ \\
\hline B22 & Railroad & None & $43 \%$ \\
\hline B25 & Railroad & None & $33 \%$ \\
\hline B36 & Railroad & None & $62 \%$ \\
\hline & Average Un-Modified Railroad Score (n=5) & $\mathbf{5 2 \%}$ \\
\hline
\end{tabular}

$\underline{\text { Trails and Fences }}$

Permeability scores for western painted turtle movement across trail barriers ranged from $63 \%$ to $75 \%$, with the bridged trail across the Columbia Slough having the highest average 
permeability score, and un-modified trails having the lowest (Table 11). Future toolkit modifications will consider the scoring of trails to increase the permeability in relation to roads, which scored similarly but are theoretically much less permeable.

The fence barrier type has the lowest average permeability scores out of all barrier types for turtles, even with the addition of crossing structures. Actual fence permeability for turtles is influenced by features such as material type, height, and gaps/holes between the fence and ground. The toolkit accounted for height and material type, but gaps and holes were not considered in the scoring unless the material or fence type captured it. Overall, tall fences ( $>7 \mathrm{ft}$ ) with no holes that turtles would have to 'topple' over scored the lowest permeability. Some fences were scored as more impermeable than they likely are, such as the fence surrounding Vanport Wetlands (B2) that has small holes that could allow movement, though turtles would need to locate the holes. According to land managers, the Vanport Fence is also currently down on the western edge of the property. Due to safety concerns, that could not be verified in field, so the fence was scored as continuous.

Table 11: Fence and trail barrier permeability scores for western painted turtles, organized by crossing structure type.

\begin{tabular}{|c|c|c|c|}
\hline \multicolumn{4}{|c|}{$\begin{array}{l}\text { Permeability Scores for Western Painted Turtle } \\
\text { Trail and Fence Barriers }\end{array}$} \\
\hline Barrier ID & $\begin{array}{c}\text { Barrier } \\
\text { Type }\end{array}$ & $\begin{array}{l}\text { Crossing } \\
\text { Structure Type }\end{array}$ & $\begin{array}{l}\text { Permeability } \\
\text { Score }\end{array}$ \\
\hline $\mathrm{B} 21$ & Fence & $<=2 \mathrm{ft}$ Culvert & $55 \%$ \\
\hline \multicolumn{3}{|c|}{ Average Fence with $<=2 \mathrm{ft}$ Culvert Score $(n=1)$} & $55 \%$ \\
\hline B12 & Fence & $>2 \mathrm{ft}$ Culvert & $56 \%$ \\
\hline B13 & Fence & $>2 \mathrm{ft}$ Culvert & $56 \%$ \\
\hline \multicolumn{3}{|c|}{ Average Fence with $>2 \mathrm{ft}$ Culvert Score $(n=2)$} & $56 \%$ \\
\hline B1 & Fence & None & $27 \%$ \\
\hline B9 & Fence & None & $33 \%$ \\
\hline B29 & Fence & None & $33 \%$ \\
\hline \multicolumn{3}{|c|}{ Average Un-modified Fence Score $(n=3)$} & $31 \%$ \\
\hline B4 & Trail/Fence & None & $63 \%$ \\
\hline \multicolumn{3}{|c|}{ Average Trail/Fence Composition Score $(n=1)$} & $63 \%$ \\
\hline \multirow[t]{2}{*}{ B30 } & Trail & Bridge & $75 \%$ \\
\hline & \multicolumn{2}{|c|}{ Trail $\quad$ Bridge } & $75 \%$ \\
\hline B7 & Trail & None & $61 \%$ \\
\hline B33 & Trail & None & $67 \%$ \\
\hline B34 & Trail & None & $67 \%$ \\
\hline \multicolumn{3}{|c|}{ Average Un-Modified Trail Score $(n=3)$} & $65 \%$ \\
\hline
\end{tabular}




\section{American Beaver}

\section{Habitat Scores}

Habitat quality scores of the north and south corridors were high for beaver movement, with an average corridor habitat quality score of $76 \%$ for each zone (Table 12). The highest habitat quality percentage for beaver movement in the north corridor was $92 \%$ for zone N5, and the south corridor's highest percentage was $98 \%$ for zone S10, all of which are in Smith and Bybee Wetlands with high open water cover and wetland habitat. Zone S10 with the highest scoring also contained a fish and riparian restoration site in the Columbia Slough. Lowest scores belonged to zones N13 at 57\% and zone S2 at 53\% habitat quality on the ends of the corridors, where percent cover of development is higher and there is greater human activity (Figure 28). A decrease in habitat quality scoring is seen over the managed turf and developed habitat areas, such as Portland International Raceway and the Rivergate Industrial area to the northwest of the study area.

Table 12: HCT percent habitat quality scores for American Beaver

(Castor canadensis) in the north and south corridor habitat zones

\begin{tabular}{|c|c|c|c|c|c|c|c|}
\hline \multicolumn{8}{|c|}{$\begin{array}{l}\text { American Beaver Percent Habitat Quality } \\
\text { for North and South HCT Corridors }\end{array}$} \\
\hline \multicolumn{4}{|c|}{ North Corridor } & \multicolumn{4}{|c|}{ South Corridor } \\
\hline Zone & $\begin{array}{c}\% \\
\text { Quality }\end{array}$ & Zone & $\begin{array}{c}\% \\
\text { Quality }\end{array}$ & Zone & $\begin{array}{c}\% \\
\text { Quality }\end{array}$ & Zone & $\%$ Quality \\
\hline No & $63 \%$ & N10 & $78 \%$ & S0 & $63 \%$ & S10 & $98 \%$ \\
\hline N1 & $55 \%$ & N11 & $90 \%$ & S1 & $80 \%$ & S11 & $87 \%$ \\
\hline $\mathbf{N 2}$ & $72 \%$ & N12 & $75 \%$ & $\mathbf{S 2}$ & $53 \%$ & S12 & $63 \%$ \\
\hline N3 & $73 \%$ & N13 & $57 \%$ & S3 & $68 \%$ & S13 & $70 \%$ \\
\hline N4 & $88 \%$ & N14 & $62 \%$ & S4 & $82 \%$ & S14 & $60 \%$ \\
\hline N5 & $92 \%$ & N15 & $83 \%$ & S5 & $78 \%$ & S15 & $72 \%$ \\
\hline N6 & $90 \%$ & N16 & $62 \%$ & S6 & $73 \%$ & S16 & $57 \%$ \\
\hline N7 & $87 \%$ & & & S7 & $97 \%$ & S17 & $73 \%$ \\
\hline N8 & $82 \%$ & & & S8 & $95 \%$ & S18 & $82 \%$ \\
\hline N9 & $78 \%$ & & & S9 & $95 \%$ & S19 & $73 \%$ \\
\hline
\end{tabular}




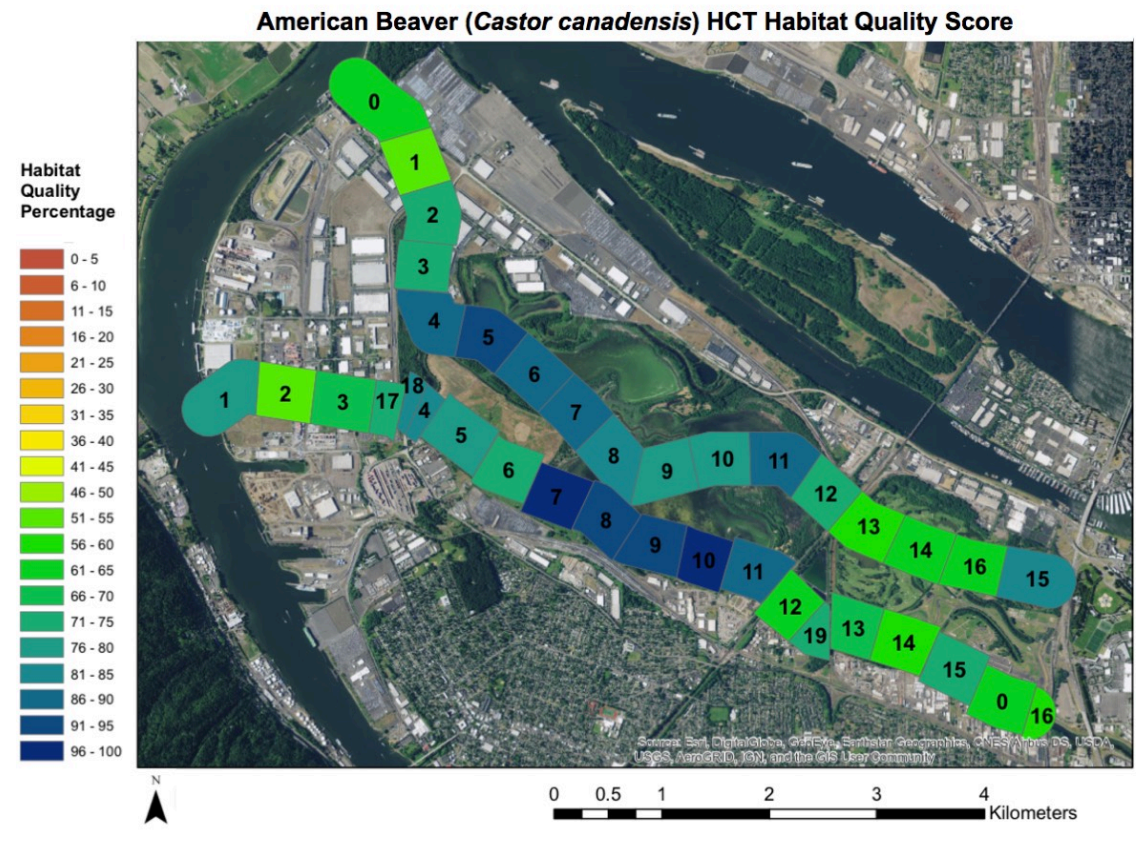

Figure 28: Habitat zones for the north and south corridor and their scored HCT percent habitat quality for American beaver (Castor canadensis) movement. Zones are not sequential as new zones were created with later barrier identification and zone division. Percent quality calculated by scoring habitat features based on species preference, then dividing the score by the maximum possible.

\section{Barrier Scores}

Barriers scores ranged from $89 \%$ for a dirt utility road (B37) to fences with $0 \%$ permeability (B09, B21, B29). Crossing structures improved barrier scores if the crossing structure was larger than $2 \mathrm{ft}$ in diameter. There were numerous barriers on the eastern and western ends of the corridors, and the center stretch of corridors in Smith and Bybee Wetlands had little to no barriers present, except for high permeability roads located in St. John's Prairie. Barriers with high scores were more prevalent on the eastern ends of both the north and south corridors (Figure 29). 
American Beaver (Castor canadensis) Barrier Permeability Scoring (HCT)

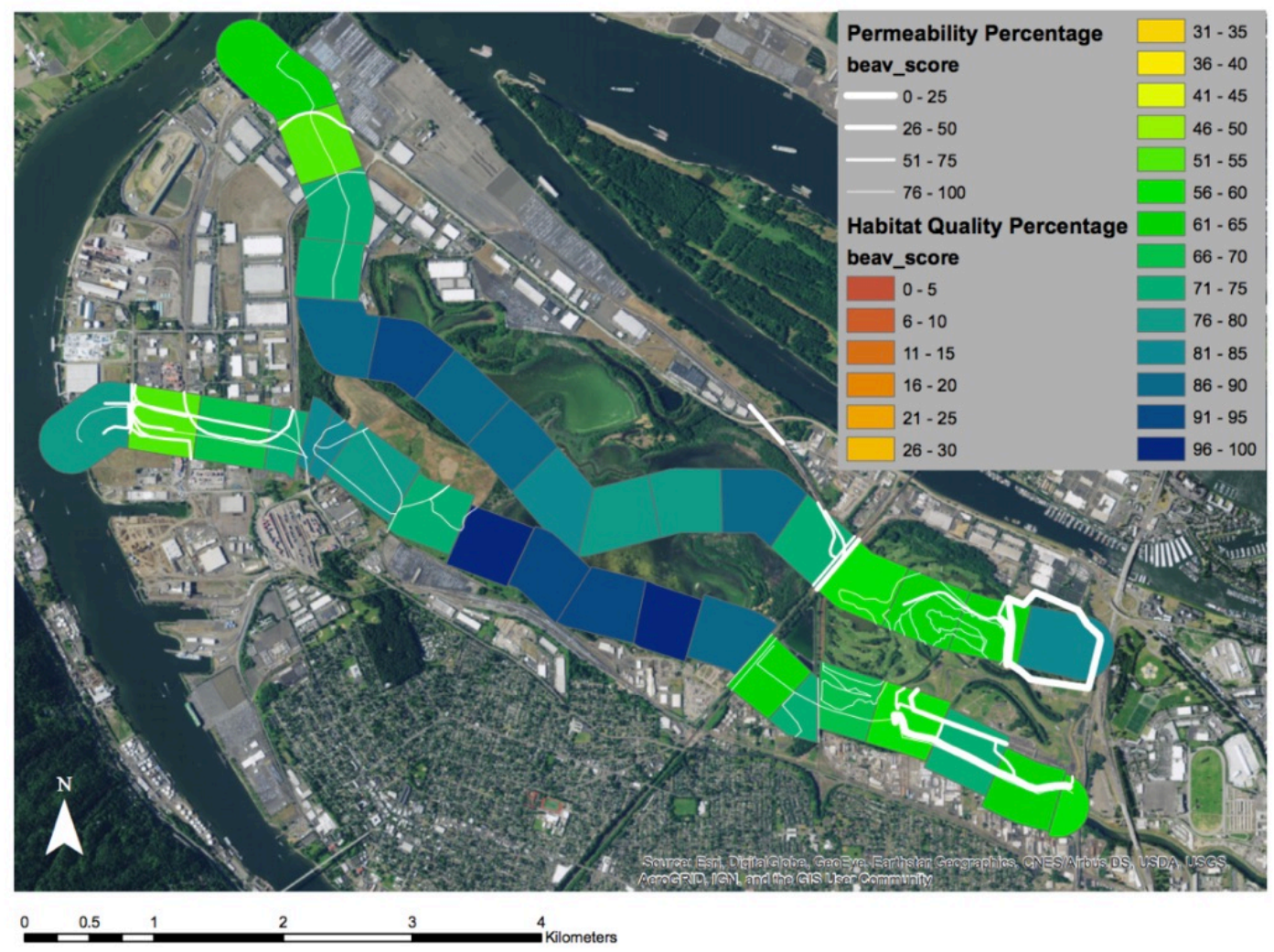

Figure 29: Barrier permeability percentages (white lines) for American beaver (Castor canadensis) overlaid with the habitat quality percentages (colored bars) for each zone in the north and south corridor. Only barriers that blocked or excluded habitat in the zones are displayed. The thickness of barrier lines represents permeability of the barrier, with thicker lines being less permeable.

\section{$\underline{\text { Roads }}$}

Road permeability percentages for beaver ranged from $30 \%$ to $89 \%$ depending on road features, traffic, surroundings and modifications including crossing structures (Table 13). The lowest scored road was the racetrack at Portland International Raceway (B28 with a score of $30 \%$ permeability. Elements such as traffic speed, lighting, human use and lack of crossing structure eliminated points in the scoring process, decreasing the permeability score. The highest permeability score for roads was with Barrier B37 on the western side of the T5 Powerline site adjacent to the Willamette River. This road was a dirt utility road with no additional structures, qualities which lose fewer points for beavers, thus increasing the permeability score. 
Table 13 Road barrier permeability scores for American beavers, sorted by crossing structure type.

\begin{tabular}{|c|c|c|c|}
\hline \multicolumn{4}{|c|}{$\begin{array}{c}\text { Permeability Scores for American Beaver } \\
\text { Road Barriers }\end{array}$} \\
\hline Barrier ID & $\begin{array}{l}\text { Barrier } \\
\text { Type }\end{array}$ & $\begin{array}{l}\text { Crossing } \\
\text { Structure }\end{array}$ & $\begin{array}{l}\text { \% Permeability } \\
\text { Score }\end{array}$ \\
\hline B8 & Road & $<=2 \mathrm{ft}$ Culvert & $74 \%$ \\
\hline \multicolumn{3}{|c|}{$\begin{array}{r}\text { Average Road with }<=2 \mathrm{ft} \text { Culvert Score } \\
(\mathrm{n}=1)\end{array}$} & $74 \%$ \\
\hline $\mathrm{B} 10$ & Road & $>2 \mathrm{ft} \mathrm{Culvert}$ & $75 \%$ \\
\hline B11 & Road & $>2 \mathrm{ft}$ Culvert & $70 \%$ \\
\hline \multicolumn{3}{|c|}{$\begin{array}{r}\text { Average Road with }>2 \mathrm{ft} \text { Culvert Score } \\
(\mathrm{n}=2)\end{array}$} & $72 \%$ \\
\hline B5 & Road & Bridge & $78 \%$ \\
\hline B17 & Road & Bridge & $76 \%$ \\
\hline B19 & Road & Bridge & $82 \%$ \\
\hline B32 & Road & Bridge & $74 \%$ \\
\hline \multicolumn{3}{|c|}{ Average Bridged Road Score $(n=4)$} & $77 \%$ \\
\hline B6 & Road & None & $63 \%$ \\
\hline $\mathrm{B} 20$ & Road & None & $85 \%$ \\
\hline B23 & Road & None & $67 \%$ \\
\hline $\mathrm{B} 27$ & Road & None & $59 \%$ \\
\hline B28 & Road & None & $30 \%$ \\
\hline B35 & Road & None & $73 \%$ \\
\hline B37 & Road & None & $89 \%$ \\
\hline \multicolumn{3}{|c|}{ Average Unmodified Road Score $(n=7)$} & $67 \%$ \\
\hline
\end{tabular}

\section{$\underline{\text { Railroads }}$}

Beaver permeability scores for individual railroads ranged from $43 \%$ to $82 \%$ (Table 14 ). The railroad with the lowest score was the multi track rail yard (B22) situated between Smith and Bybee Wetlands and the Columbia River. The rail yard possessed multiple tracks, with high frequency of use and human activity and no crossing structure. The railroads tied for the highest permeability at $82 \%$ were two rail line bridges that cross the Columbia Slough, south of the Columbia Boulevard Wastewater Treatment Lagoon. Both railroads were single rail line aquatic and terrestrial bridges, with no human activity in the crossing structures and no pet access. Bridging improved railroad permeability scores overall for beaver, as long as they crossed over a body of water. 
Table 14: Railroad barrier permeability scores for American beavers, sorted by crossing structure type,

\begin{tabular}{|cccc|}
\hline \multicolumn{4}{|c|}{$\begin{array}{c}\text { Permeability Scores for American Beaver } \\
\text { Railroad Barriers }\end{array}$} \\
Barrier ID & $\begin{array}{c}\text { Barrier } \\
\text { Type }\end{array}$ & $\begin{array}{c}\text { Crossing Structure } \\
\text { Permeability } \\
\text { Score }\end{array}$ \\
\hline B14 & Railroad & $>2 \mathrm{ft}$ Culvert & $71 \%$ \\
B18 & Railroad & $>2 \mathrm{ft}$ Culvert & $76 \%$ \\
Average Railroad with $>\mathbf{2 f t}$ Culvert Score & $\mathbf{7 4 \%}$ \\
(n=2) & & $82 \%$ \\
B2 & Railroad & Bridge & $82 \%$ \\
B3 & Railroad & Bridge & $75 \%$ \\
B24 & Railroad & Bridge & $80 \%$ \\
B31 & Railroad & Bridge & $\mathbf{8 0 \%}$ \\
Average Bridged Railroad Score (n=4) & $67 \%$ \\
B15 & Railroad & None & $67 \%$ \\
B16 & Railroad & None & $48 \%$ \\
B22 & Railroad & None & $43 \%$ \\
B25 & Railroad & None & $62 \%$ \\
B36 & Railroad & None & $\mathbf{5 7 \%}$ \\
\hline Average Unmodified Railroad Score (n=5)
\end{tabular}

\section{$\underline{\text { Fences and Trails }}$}

Individual trail permeability scores for beaver movement ranged from $78 \%$ to $83 \%$, with the lowest score being two trails without bridging or crossing structures, and the highest score being the trail network in Heron Lakes Golf Course, also without crossing structures or bridging (Table 15). Only one trail identified had some sort of crossing structure. The average unmodified trails score and the bridged trail score only differed by $1 \%$. However, the only bridged trail identified (B30) originally had a permeability score of $61 \%$ not counting the crossing structure additional points. Without the additional points gained back by the bridge crossing structure, B30 trail was already $19 \%$ lower in score than the average unmodified trail.

The Trail/Fence combination was scored as $63 \%$ permeable, with the associated fence causing loss of scoring points, decreasing the permeability of the barrier. Fences had the lowest permeability percentages of all barrier types, as beavers have difficulty climbing fences. Holes or gaps in the fences were not included in the scoring process, but modifications are being made to the method to include these features in the future. 
Table 15: Trail and Fence barrier permeability scores for American beavers, sorted by crossing structure type

\begin{tabular}{|c|c|c|c|}
\hline \multicolumn{4}{|c|}{$\begin{array}{c}\text { Permeability Scores for American Beaver } \\
\text { Trail and Fence Barriers }\end{array}$} \\
\hline Barrier ID & $\begin{array}{l}\text { Barrier } \\
\text { Type }\end{array}$ & $\begin{array}{l}\text { Crossing } \\
\text { Structure }\end{array}$ & $\begin{array}{l}\text { Permeability } \\
\text { Score }\end{array}$ \\
\hline \multirow[t]{2}{*}{ B30 } & Trail & Bridge & $79 \%$ \\
\hline & \multicolumn{2}{|c|}{ Average Bridged Trail Score } & $79 \%$ \\
\hline B7 & Trail & None & $83 \%$ \\
\hline B33 & Trail & None & $78 \%$ \\
\hline \multirow[t]{2}{*}{ B34 } & Trail & None & $78 \%$ \\
\hline & \multicolumn{2}{|c|}{ Average Unmodified Trail Score } & $80 \%$ \\
\hline \multirow[t]{2}{*}{ B4 } & Trail/Fence & None & $63 \%$ \\
\hline & Unmodified & Trail/Fence Score & $63 \%$ \\
\hline $\mathrm{B} 21$ & Fence & $<=2 \mathrm{ft}$ Culvert & $0 \%$ \\
\hline \multicolumn{3}{|c|}{ Average Fence with $<=2 \mathrm{ft}$ Culvert Score } & $\mathbf{0 \%}$ \\
\hline B12 & Fence & $>2 \mathrm{ft}$ Culvert & $66 \%$ \\
\hline B13 & Fence & $>2 \mathrm{ft}$ Culvert & $66 \%$ \\
\hline \multicolumn{3}{|c|}{ Average Fence with $>$ 2ft Culvert Score } & $66 \%$ \\
\hline B1 & Fence & None & $33 \%$ \\
\hline B9 & Fence & None & $0 \%$ \\
\hline B29 & Fence & None & $0 \%$ \\
\hline \multicolumn{3}{|c|}{ Average Unmodified Fence Score } & $11 \%$ \\
\hline
\end{tabular}

\section{Red-legged Frog}

\section{Habitat Scores}

The north and south corridors scored an average of $63 \%$ habitat quality for movement for red -legged frogs using the Habitat Connectivity Toolkit (Table 16). The red-legged frog had the lowest average habitat quality percent score for both corridors out of all species assessed. The north and south corridor's highest scored zones contain high canopy cover, wetland habitat and little development or human activity (Figure 30).

The north and south corridor had the same average habitat quality percent for red-legged frog movement, but the south corridor showed a few discrete areas of higher and lower quality and had more variance in scoring compared to the north corridor, which had moderately low quality. The lowest scored zones for both corridors (N1, S2) contained a continuous narrow corridor surrounded by highly developed habitat which lowered the overall score. 
Table 16: Percent quality habitat for red-legged frog movement for the north and south corridors using the Habitat Connectivity Toolkit.

\begin{tabular}{|c|c|c|c|c|c|c|c|}
\hline \multicolumn{8}{|c|}{$\begin{array}{l}\text { Red-legged frog Percent Habitat Quality } \\
\text { for North and South Corridors }\end{array}$} \\
\hline \multicolumn{4}{|c|}{ North Corridor } & \multicolumn{4}{|c|}{ South Corridor } \\
\hline Zone & $\%$ Quality & Zone & $\%$ Quality & Zone & $\%$ Quality & Zone & $\%$ Quality \\
\hline N0 & $56 \%$ & N10 & $65 \%$ & S0 & $54 \%$ & $\mathrm{~S} 10$ & $79 \%$ \\
\hline N1 & $51 \%$ & N11 & $71 \%$ & S1 & $63 \%$ & $\mathrm{~S} 11$ & $73 \%$ \\
\hline $\mathrm{N} 2$ & $57 \%$ & $\mathrm{~N} 12$ & $62 \%$ & S2 & $49 \%$ & $\mathrm{~S} 12$ & $54 \%$ \\
\hline N3 & $60 \%$ & N13 & $54 \%$ & S3 & $60 \%$ & $\mathrm{~S} 13$ & $57 \%$ \\
\hline N4 & $71 \%$ & N14 & $54 \%$ & S4 & $62 \%$ & $\mathrm{~S} 14$ & $56 \%$ \\
\hline N5 & $70 \%$ & N15 & $73 \%$ & S5 & $59 \%$ & $\mathrm{~S} 15$ & $59 \%$ \\
\hline N6 & $70 \%$ & N16 & $62 \%$ & S6 & $62 \%$ & $\mathrm{~S} 16$ & $52 \%$ \\
\hline N7 & $71 \%$ & & & S7 & $81 \%$ & S17 & $57 \%$ \\
\hline N8 & $65 \%$ & & & S8 & $81 \%$ & $\mathrm{~S} 18$ & $65 \%$ \\
\hline N9 & $63 \%$ & & & S9 & $78 \%$ & S19 & $62 \%$ \\
\hline \multicolumn{4}{|c|}{$\begin{array}{l}\text { North Corridor Habitat \% Quality: } \\
63 \%\end{array}$} & \multicolumn{4}{|c|}{$\begin{array}{l}\text { South Corridor Habitat \% Quality: } \\
63 \%\end{array}$} \\
\hline
\end{tabular}

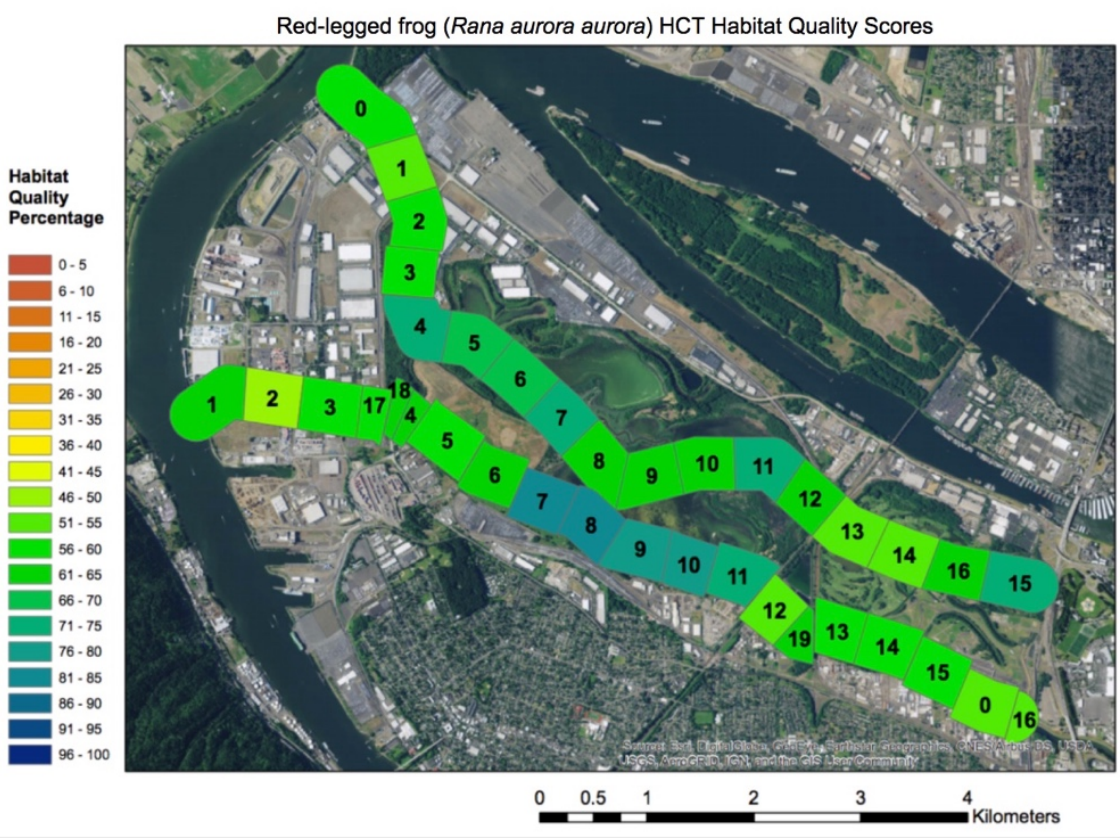

Figure 30: Habitat zone percent habitat quality scores for red-legged frog movement in the North corridor (top line of zones) and South corridor (bottom line of zones). Zones are not sequential as new zones were created with later barrier identification and zone division. Percent quality calculated by scoring habitat features based on species preference, then dividing the score by the maximum possible. 


\section{Barrier Scores}

We found 37 barriers in the red-legged frog corridors, which were mostly concentrated in the five segments on either end of each corridor (Figure 31). Barriers differed in permeability depending on crossing structure presence, with individual barrier features such as traffic, barrier size and length, and barrier material decreased the barrier scores.

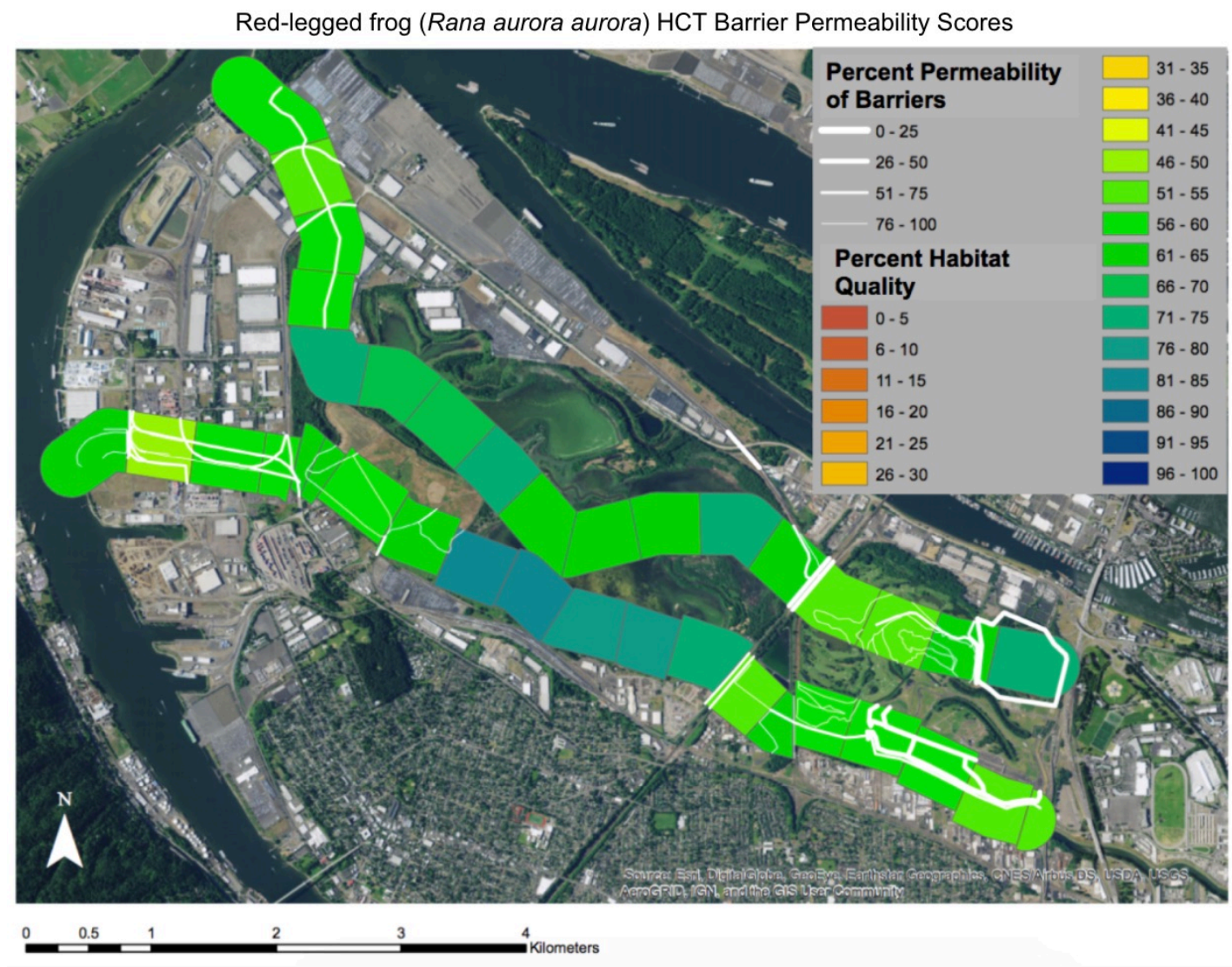

Figure 31: Barrier permeability percentages for red-legged frog (Rana aurora aurora) overlaid with the habitat quality percentages for each zone in the north and south corridor. Only barriers that blocked or excluded habitat in the zones are displayed. Thickness of barrier lines represent permeability of the barrier, with thicker lines being less permeable.

$\underline{\text { Roads }}$

Road permeability for red-legged frog movement ranged from a low of $38 \%$ to a high of $79 \%$ permeability (Table 17). North Portland road scored the lowest permeability percentage at $38 \%$ due to a high number of lanes of traffic, active road use, high human presence and lacking a crossing structure for possible additional points. The highest scoring roads for red-legged frog were both dirt utility roads with little traffic and human presence, possessing vegetated road 
shoulders and no associated structures such as fences or walls. Roads improved with crossing structure addition or bridging.

Table 17: Road barrier permeability scores for red-legged frogs, sorted by crossing structure type

\begin{tabular}{|c|c|c|c|}
\hline \multicolumn{4}{|c|}{$\begin{array}{c}\text { Permeability Scores for Red-legged frog } \\
\text { Road Barriers }\end{array}$} \\
\hline Type & $\begin{array}{l}\text { Barrier } \\
\text { Type }\end{array}$ & $\begin{array}{l}\text { Crossing } \\
\text { Structure Type }\end{array}$ & RLF \\
\hline $\mathrm{B} 8$ & Road & $<=2 \mathrm{ft}$ Culvert & $72 \%$ \\
\hline \multicolumn{3}{|c|}{ Average Road with $<=2 \mathrm{ft}$ Culvert Score } & $72 \%$ \\
\hline $\mathrm{B} 10$ & Road & $>2 \mathrm{ft}$ Culvert & $74 \%$ \\
\hline B11 & Road & $>2 \mathrm{ft}$ Culvert & $66 \%$ \\
\hline \multicolumn{3}{|c|}{ Average Road with $>2$ ft Culvert } & $66 \%$ \\
\hline B5 & Road & Bridge & $69 \%$ \\
\hline B17 & Road & Bridge & $70 \%$ \\
\hline B19 & Road & Bridge & $74 \%$ \\
\hline B32 & Road & Bridge & $66 \%$ \\
\hline \multicolumn{3}{|c|}{ Average Bridged Road } & $70 \%$ \\
\hline B6 & Road & None & $38 \%$ \\
\hline $\mathrm{B} 20$ & Road & None & $79 \%$ \\
\hline $\mathrm{B} 23$ & Road & None & $54 \%$ \\
\hline B27 & Road & None & $50 \%$ \\
\hline B28 & Road & None & $33 \%$ \\
\hline B35 & Road & None & $70 \%$ \\
\hline B37 & Road & None & $79 \%$ \\
\hline \multicolumn{3}{|c|}{ Average Unmodified Road } & $58 \%$ \\
\hline
\end{tabular}

$\underline{\text { Railroads }}$

Railroads scored between $38 \%$ and $76 \%$ permeability for red-legged frog in the north and south corridors (Table 18). The lowest scored individual railroads were a multi-line track adjacent to Portland Boulevard between Heron Lakes Golf Course as well as a rail yard between Smith and Bybee and the Columbia Slough. Both barriers possessed more than three frequently used tracks and wide gravel shoulders. They were also adjacent to locations of high human activity. The highest scored railroad was a railroad bridged over the Columbia Slough with a large vegetated terrestrial crossing adjacent to the waterway. 
Table 18: Railroad barrier permeability scores for red-legged frogs,

sorted by crossing structure type

Permeability Scores for Red-legged frog

Railroad Barriers

\begin{tabular}{|c|c|c|c|}
\hline Barrier ID & $\begin{array}{c}\text { Barrier } \\
\text { Type }\end{array}$ & $\begin{array}{c}\text { Crossing } \\
\text { Structure Type }\end{array}$ & RLF \\
\hline B14 & Railroad & $>2 \mathrm{ft}$ Culvert & $72 \%$ \\
\hline B18 & Railroad & $>2 \mathrm{ft}$ Culvert & $75 \%$ \\
\hline \multicolumn{3}{|c|}{ Average Railroad with $>2 \mathrm{ft}$ culvert } & $73 \%$ \\
\hline B2 & Railroad & Bridge & $76 \%$ \\
\hline B3 & Railroad & Bridge & $74 \%$ \\
\hline B24 & Railroad & Bridge & $77 \%$ \\
\hline B31 & Railroad & Bridge & $74 \%$ \\
\hline \multicolumn{3}{|c|}{ Average Bridged Railroad } & $75 \%$ \\
\hline B15 & Railroad & None & $67 \%$ \\
\hline B16 & Railroad & None & $67 \%$ \\
\hline B22 & Railroad & None & $38 \%$ \\
\hline $\mathrm{B} 25$ & Railroad & None & $38 \%$ \\
\hline B36 & Railroad & None & $63 \%$ \\
\hline \multicolumn{3}{|c|}{ Average Unmodified Railroad } & $54 \%$ \\
\hline
\end{tabular}

\section{$\underline{\text { Trails and Fences }}$}

The range of trail scores for red-legged frog permeability was between $63 \%$ for a trailfence combination and $78 \%$ for a bridged trail over the Columbia Slough (Table 19). All of the trails scored with relatively high levels of permeability, both with and without crossing structures. The average unmodified trail scored at $74 \%$ and was the lowest scored trail type, yet was only $4 \%$ less permeable than the highest scored trail type, the bridged trail, with $78 \%$ permeability.

Fence barrier permeability's ranged widely from 33\% to $79 \%$ (Table 19). The fencing scored with the least permeability was chain-link fence around Vanport Wetlands and along the south edge of the Portland International Raceway. The most permeable fencing scored was on Time Oil Road between Port of Portland's T5 Powerline Site and West Wye Sites, due to the presence of a large crossing structure and fence construction with fewer features that are scored as impactful to red-legged frog movement. B21 (fence around Vanport Wetland) possessed a culvert less than two feet in diameter, though the crossing structure added few points back due to possessing undesirable features to red-legged frogs, such as exclusively aquatic passage. Fencing 
with crossing structures more than two feet in diameter scored the highest, with 79\% permeability.

Similar to western painted turtle, the fence scoring for red-legged frog does not consider gaps underneath fencing small holes in fences. This absence may be decreasing the permeability scores for some barriers that are actually more permeable to movement than currently predicted.

Table 19: Trail and fence barrier permeability scores for red-legged frogs, sorted by crossing structure type

Permeability Scores for Red-legged frog Trail and Fence Barriers

\begin{tabular}{|c|c|c|c|}
\hline $\begin{array}{l}\text { Barrier } \\
\text { ID }\end{array}$ & Barrier Type & $\begin{array}{c}\text { Crossing } \\
\text { Structure Type }\end{array}$ & RLF \\
\hline B30 & Trail & Bridge & $78 \%$ \\
\hline \multicolumn{3}{|c|}{ Average Bridged Trail $(n=1)$} & $78 \%$ \\
\hline B7 & Trail & None & $76 \%$ \\
\hline B33 & Trail & None & $72 \%$ \\
\hline B34 & Trail & None & $72 \%$ \\
\hline \multicolumn{3}{|c|}{ Average Unmodified Trail $(n=3)$} & $74 \%$ \\
\hline B4 & Trail/Fence & None & $63 \%$ \\
\hline \multicolumn{3}{|c|}{ Average Trail/Fence Combination $(n=1)$} & $63 \%$ \\
\hline B21 & Fence & $<=2 \mathrm{ft}$ Culvert & $38 \%$ \\
\hline \multicolumn{3}{|c|}{ Average Fence with $<=2 \mathrm{ft}$ Culvert $(n=1)$} & $38 \%$ \\
\hline B12 & Fence & $>2 \mathrm{ft}$ Culvert & $79 \%$ \\
\hline B13 & Fence & $>2 \mathrm{ft}$ Culvert & $79 \%$ \\
\hline \multicolumn{3}{|c|}{ Average Fence with $>2 \mathrm{ft}$ Culvert $(n=2)$} & $79 \%$ \\
\hline B1 & Fence & None & $44 \%$ \\
\hline B9 & Fence & None & $33 \%$ \\
\hline B29 & Fence & None & $33 \%$ \\
\hline \multicolumn{3}{|c|}{ Average Unmodified Fence $(n=3)$} & $37 \%$ \\
\hline
\end{tabular}

\section{Crossing Structure Improvements}

Crossing structures, both culverts and bridging of barriers, improved the permeability scores of barriers for most of the species (Table 20). No clear patterns emerged from this Toolkit-based assessment about the importance of some types of crossing structures or the importance of crossing structures for some types of barriers, other than two expected findings. First, obviously, crossing structures that are too small for the species of interest do not improve connectivity for that or larger species. Second, bridges in general -but not always-- improve 
connectivity slightly more than do culverts that are large enough for the species of interest to pass through (Table 20). We expected this based on other studies such as the survey of wildlife use through Boeckman Road's multiple types of crossing structures (Bliss-Ketchum and de Rivera 2010).

Table 20: Improvements in barrier permeability score with crossing structure addition for western painted turtle, beaver, and red-legged frog. Percent values in table represent the increase in permeability score for each barrier after crossing structures were included in the total score.

Average increase in barrier permeability due to crossing structures

\begin{tabular}{|c|c|c|c|c|c|}
\hline \multirow{2}{*}{$\begin{array}{c}\text { Crossing } \\
\text { Structure Type }\end{array}$} & \multirow{2}{*}{$\begin{array}{l}\text { Barrier } \\
\text { Type }\end{array}$} & \multirow{2}{*}{$\mathrm{N}$} & \multicolumn{3}{|c|}{ Improved Permeability Score } \\
\hline & & & $\begin{array}{c}\text { Western Painted } \\
\text { Turtle }\end{array}$ & Beaver & Red-legged frog \\
\hline$<=2 \mathrm{ft}$ Culvert & Road & 1 & $16 \%$ & $0 \%$ & $10 \%$ \\
\hline$<=2 \mathrm{ft}$ Culvert & Fence & 1 & $28 \%$ & $0 \%$ & $21 \%$ \\
\hline$>2 \mathrm{ft}$ Culvert & Road & 2 & $26 \%$ & $13 \%$ & $18 \%$ \\
\hline$>2 \mathrm{ft}$ Culvert & Railroad & 2 & $20 \%$ & $14 \%$ & $15 \%$ \\
\hline$>2 \mathrm{ft}$ Culvert & Fence & 2 & $31 \%$ & $16 \%$ & $13 \%$ \\
\hline Bridge & Road & 4 & $22 \%$ & $17 \%$ & $20 \%$ \\
\hline Bridge & Railroad & 4 & $20 \%$ & $14 \%$ & $17 \%$ \\
\hline Bridge & Trail & 1 & $22 \%$ & $18 \%$ & $16 \%$ \\
\hline
\end{tabular}

\section{Landscape Accuracy}

Pre-assessment GIS analysis for the Habitat Connectivity Toolkit contained the same land cover dataset used for the GIS analysis method. The same misclassification of habitat occurred in the HCT as the GIS method. The toolkit accounts for inaccurate GIS data through a validation process of pre-assessment GIS information in the field, as seen by the fields requesting verification of information on the field sheets (Appendix C). When assessing the habitat zones, the GIS proportion of developed habitat was edited to reflect the true composition of habitat in the field. In addition, the HCT process records even more habitat structure and composition details than what is available through GIS analysis, including basking structure presence, sun exposure, rocky slopes, and invasive and native species presence. The Habitat Connectivity Toolkit showed high landscape accuracy due to a thorough GIS verification process 
as well as recording extensive habitat details that can be used to predict species movement and habitat quality.

\section{Barrier Accuracy}

Pre-assessment GIS analysis of barriers was limited in this project to aerial identification, though the toolkit has additional information requested. Even though some pre-assessment elements were not included, there was still a detailed in-field analysis of each identified barrier and thorough recording process of structure details. Barriers were also identified when out in the field walking the habitat zones. This additional step ensured that all barriers possibly crossing the assigned corridor were accounted for and scored for permeability.

There were still some flaws in species-specific barrier accuracy with the Habitat Connectivity Toolkit. Chain link fencing had a low permeability score for red-legged frog, yet it is possible that they may be able to move through the fence links if the space allows. The fencing section for the red-legged frog was the only area in the barrier assessment where improvements should be made to either require more barrier information in field to determine passability or adjust scoring of the field sheets to reflect higher permeability.

The multi-step identification process paired with the detailed scoring of barrier qualities leads to a high barrier accuracy for the Habitat Connectivity Toolkit. Small species-specific problems can and should be addressed as the toolkit's first version is finished, and as needed in future versions of the method.

\section{Ease of Use}

The Habitat Connectivity Toolkit (HCT) was the most time and resource intensive method performed, but it also yielded the most results out of all assessment methods. The HCT was comprised of three sections: pre-assessment GIS analysis, in-field surveying, and scoring of habitat zones and barriers. The pre-assessment GIS analysis component was performed quickly once we had access to the required data. Resources required for this section included GIS software and access to the GIS data called for on the survey sheets (Appendix C). The in-field surveying was the most time and resource intensive component of the HCT, as on site visits are required for both habitat zone and barrier assessment. Surveying of each zone took approximately one hour with site evaluation, and barrier surveys take 30 minutes to 1 hour per 
barrier, depending on size and accessibility. Depending on the proximity of the barriers and the location of the corridor, each field day consisted of 4-5 zones or barriers, with increasing number of zones and barriers surveyed as we became more confident in the process and the habitat and barrier evaluation was expedited. Once the surveying was complete, the scoring process could start, which was just basic calculations of habitat quality and permeability percentages based on the scores from the field sheets.

\section{Data Output}

The HCT once complete produced corridors with quantifiable levels of habitat quality and permeability. Each zone and barrier has unique scores based on the features that they possessed, and the survey information can be saved for future assessments or comparisons once restoration actions have been performed on the sites. The maps can also be used to inform managers of target locations for restoration, either by selecting zones with low habitat quality scores, barriers with low permeability scores, or by finding high quality habitat that is separated by a barrier of moderate to low permeability. The multi-functional use of the toolkit products justifies the increased time and resources required of the process. 


\section{Discussion}

All methods produced results that would be of value when assessing corridors in a study area. Ease of use, data output, landscape accuracy and barrier accuracy were all taken into consideration when assessing the collaborative approach, GIS modeling, and in-field survey methods. The resulting products of each method differed in quantity and depth of information, suggesting that researchers should choose a method that would best answer the question at hand. Land manager interviews provided a quick and easy overview of potential corridors in the study area based on manager expert opinion on species needs. However, the structure of the interview process did not allow for much data collection and in-depth analysis of corridor quality and permeability, limiting the volume of data created by the land manager interview method. The GIS modeling methods using Circuitscape and Least Cost Path created clear maps of landscape permeability and potential corridor locations based on quality of habitat for species movement.

The modeling was a quick process once expert responses on habitat rankings were collected, and it produced a multiple maps and species-specific habitat preference data. However, the inaccuracies in habitat classification and the methods inability to capture the presence or permeability of barriers limited the use of the method for assessing connectivity in urban areas with complex habitat and barrier composition, and created need for extensive vetting of data inputs and outputs. Finally, the in-field survey method using the Habitat Connectivity Toolkit produced an in-depth map of two corridors in the study area with quantitative comparisons on habitat quality and permeability of barriers. The method required a larger amount of time and resources to complete than the other methods. However, the Habitat Connectivity Toolkit produced the most amount of data for corridor assessment purposes and likely had the highest accuracy for the assessed area.

\section{Collaborative Approach: Land Manager Interviews}

The land manager interview process resulted in a map of potential corridors for western painted turtle and American beaver through the study area, and short corridors for red-legged frog through the center of the study area. In addition, through interview questions and aerial imagery, potential barriers crossing the pathways of the species could be identified. This map of corridors and barriers can be used in future monitoring surveys as well as restoration work. 
While limited quantitative data came out of the process, the method was easy to perform and showed high levels of landscape and barrier accuracy.

\section{Species-Specific Corridor Results}

The land manager interview method identified potential corridors for western painted turtle, American beaver and partial corridors for red-legged frog. Corridors were identified based on the pathways drawn by the land mangers in the interview process, and the number of identified barriers crossed served as a rough view of corridor permeability for species-specific movement.

For all species, land managers made conscious efforts to draw paths that were avoiding impermeable barriers and prioritized high quality habitat for the species. The species needs identified by the land managers match the literature showing turtle preference for exposed ponds, slow moving bodies of water and emergent wetland habitat (ODFW 2015). Open water, stream bodies and high canopy cover was prioritized by land managers for beaver movement, also matching existing knowledge on beaver habitat (Naiman et al. 1988). Similarly, red-legged frog habitat needs were accurately matched to literature showing preference for upland forest and moist, wetland adjacent habitats that were not open water (Leonard et al. 1993; Corkran and Thoms 1996; IUCN 2017).

There was a disconnect between the land manager drawn pathway around Heron Lakes Golf Course and Vanport Wetlands and the rest of the properties for both western painted turtle and beaver. This may be due to the recognition by the land managers of the impermeability of the North Portland Road barrier separating the properties from Smith and Bybee that possessed no crossing structure. Managers had no hesitations about drawing pathways through bridged barriers or barriers with established crossing structures for all species, showing awareness of barrier permeability depending on crossing structure presence and type.

\section{Disadvantages of the Land Manager Interview Method}

The collaborative approach method of land manager interviews also possessed a few disadvantages. Some land managers were uncomfortable documenting their opinions on pathways through the properties, and had to be reassured that the process was based off of best judgment, and accuracy if corridor placement could not be tested without extensive tracking 
studies of the species. The land managers were hesitant about drawing definite paths through the property, since there would be high variability in specific species paths even though the larger movement pattern may be all in the same direction.

The land manager interview process also requires participation from all of the study area land managers in order to have the highest confidence in answers and the inclusion of all properties. As seen by the red-legged frog results, if only a portion of the land managers participate the final product cannot speak to the entirety of the corridor and land managers would need to feel comfortable drawing corridors through properties adjacent to their own. All of the land managers participating in this project were primarily natural resource managers who work closely with one another for project planning, making them very aware of the status of properties adjacent to their own. If this process were to be repeated in a more privatized location where there was less collaboration and property managers focused exclusively on their own land, absences in participation would result in clear gaps in the final corridor maps for the species.

Finally, the largest disadvantage when using the collaborative approach method is the small amount of data that is produced in the process. While the method may be perfect for broader questions and initial investigative work on corridor potential in the area, the method would be improved through the addition of quantitative assessment of corridors and barriers instead of just identification of their location.

\section{Improvements for Future Use}

The lack of data produced through this method could be significantly increased through a redesign of the interview process. Properties could be divided into grid-like patterns, and managers could be asked to grade each grid cell for permeability for movement and habitat quality. In addition, barriers could be graded for permeability for each species. A standardized ranking scale or gradient for habitat quality would need to be created, and all land managers would need to be aware of species needs and habitat requirements. These requirements may limit the ability of land managers lacking in habitat or species experience to participate in this process, unless they had a strong natural resource background or supplemental information on species needs, thought they may still have valuable anecdotal observations. The addition of a ranking component may have the effect of lowering participation rates by land managers, as they may perceive the activity requiring more time, effort, and experience with the species. However, such 
an approach may be especially beneficial if there are many options for management across an area.

Land managers could also be asked to draw corridors through the entire study area in order to create one composite map of possible corridors. This would also increase the resulting information on land manager awareness of permeability and connectivity in the study area, and it would help supplement information on properties where the managers are less confident in their answers.

\section{GIS Modeling: Circuitscape and Least Cost Path}

The GIS models were beneficial in creating a landscape map of connectivity as well as a defined path for species movement. The process of having species experts rank habitat types for species preference for movement in itself provided a valuable dataset for future connectivity and corridor assessment work. The maps created by the models face some challenges, including lack of barrier inclusion and misclassification of habitat. Overall, the GIS analysis method using Circuitscape and Least Cost Path analysis had high data output and while the modeling itself was easy to use and time effective, the ranking process needed for the model was time intensive and had low ease of use. Finally, the landscape and barrier accuracy were relatively low, as barrier permeability was based off of land cover classification and habitats were occasionally coded incorrectly in the dataset. Both of these elements can be improved with updated GIS data, however, this will result in an even more intensive ranking process, as all types of barriers (including structural features and crossing structure presence) would need to be classified and ranked independently along with the habitat types.

\section{Species-Specific Corridor Results}

From the Circuitscape and LCP maps, western painted turtles and American beavers showed clear preference for movement through open water habitat, and the overall study area possessed habitats that turtles and beaver were likely to pass through. Experts ranked open water as the most preferential habitat type for western painted turtle, followed by low vegetation and sandbars in wetlands, all of which are potential turtle habitat (ODFW 2015). The expert rankings for beaver habitat shows low ranking habitats matching literature defining good beaver habitat as 
open water riparian areas with wooded tree species and herbaceous vegetation (Naiman et al. 1988). Open water was all classified as the same resistance value for all species, and the final Circuitscape map shows a high level of permeability and turtle movement probability through the large water bodies of Smith and Bybee and the Columbia Slough. The Circuitscape map did not categorize water bodies by distances from land or depth. The inclusion of this information into the dataset would possibly alter the results for all species, including the western painted turtle with a preference for shallow water bodies (Gervais et al 2009).

Red-legged frog, the only species not established in the study area, showed less ability to move through the study area in the GIS analysis due to a smaller proportion of preferred habitat for red-legged frog movement. Moist environments with canopy cover near bodies of water are documented to be the best habitat for red-legged frog movement (Leonard et al. 1993; Corkran and Thoms 1996; IUCN 2017) and the results from the rankings appear to confirm that the experts are in agreement with the research. The habitat matrix of the study area may not be of appropriate composition to encourage red-legged frog dispersal. Using the GIS models, we can see that the northern edges of the properties have the highest likeliness to support red-legged frog movement, and possibly residence. Unfortunately, the area of best habitat for red-legged frog is also crossed by an intense barrier, which is not seen by the GIS models and not factored into the LCP created for red-legged frog movement. In addition, the industrial properties surrounding the study area show high resistance to red-legged frog movement. Overall, the study area may be more preferential for species willing to move through lowland wetland and aquatic corridors, rather than species that prefer upland habitat for dispersal such as the red-legged frog.

The Circuitscape model and LCP also highlighted properties as high movement probabilities that are inaccessible to the species. The Columbia Boulevard Wastewater Treatment Lagoon shows as high likeliness of turtle use for movement on the Circuitscape map (Figure 20). High exclusion fencing and concrete around the open water pools of the lagoon would prevent any turtles from entering the property. This inaccuracy is tied to the land cover data used for the model. Changes can be made to the land cover data to exclude properties such as the Lagoon by blocking off areas as "no data" or 100\% impermeability, however, there must be existing knowledge of such properties before hand, which is not always the case when assessing connectivity. The LCP for all species also predicts movement through the Lagoon, as well as other barriers such as North Portland Road and the trail and road network in the Heron Lakes 
Golf Course. The lack of specific barrier data with high resistance values leads the LCP to cross the less permeable land-cover types of the barriers in favor of a short, direct path.

\section{Disadvantages of the GIS Analysis Method}

The Circuitscape and Least Cost Path model produced maps of the study area that allowed visualization of wildlife movement through the properties. In addition, it provided a clear path based on objective data on habitat permeability and minimizing distance traveled. However, there are some challenges to using this method including reliance on expert opinion, high initial data access, and verification of landscape and barrier accuracy.

The ranking activity for western painted turtle, beaver, and red-legged frog proved to be more difficult to complete than expected. Collecting enough ranking results from experts, combined with the expert's hesitancy to distinguish habitat preferences for species based on personal opinion made for a low response rate when collecting ranking sheets and a ranking dataset with high variability. In order to have more confidence in the ranking results, more experts need to be involved in the ranking activity, which could be a whole project in itself. Additionally, in order to improve accuracy of the data entered into the model, more classifications of habitat types and features need to be made to distinguish the high quality habitat and poor quality habitat for movement. This means more data layers need to be used in the model, which in turn increases the amount of habitat types to be ranked, potentially furthering expert disinclination to participate in the ranking process.

Another problem with using GIS modeling exclusively in a small-scale study area is that the results from both the Circuitscape and Least Cost Path model need to be checked for accuracy in both the landscape and habitat classification and the barrier presence. Because barrier features can 'hide' on the landscape, persons performing the GIS analysis method need to be diligent about checking the paths for barrier crossings and presence either through aerial imagery or in-field verification. Additionally, researchers need to be confident in their land cover data as even small proportions of misclassified habitat on a regional scale can translate to large areas of misclassified habitat and incorrect habitat quality assessment on a smaller corridor scale. 


\section{Improvements for Future Use}

The GIS layers used for the Circuitscape and Least Cost Path model could be improved with a thorough verification process of habitat classifications. Both models could be modified to include buffers around barriers to reflect new barrier-adjacent habitat classifications, such as in Larkin et al.'s 2004 LCP study where roads were buffered by 60 meters to increase the resistance in the LCP model. Though as Rothley (2005) points out, this buffering could cause a masking of even more impermeable features underneath the buffer, and it requires justification for buffer width and impact (Adriaensen et al. 2003; Rothley 2005). Rothley does offer a method to 'patch' the LCP model where it jumps over impermeable barriers in order to prioritize distance; however, she points out that it could result in a similar masking of other more impermeable features on the landscape.

Another improvement that can be made in the Circuitscape and Least Cost path processes is a better standardized ranking format. When ranking habitats, experts were allowed to choose the scale that they felt comfortable with, creating high variability in answers as well as skewed data once the ranks were standardized to the same range of rankings. This could be mitigated through the requirement to use one ranking scheme, such as a 1-10 scale for habitat types. Or, instead of a ranking process, experts could be asked to assign a permeability value to each habitat type, though issues of range may still come into play if experts are uncomfortable in making clear definitions between habitat scores due to lack of literature on the subject. The inclusion of more habitat types and features such as barriers and water velocity in open water would improve the landscape and barrier accuracy for the GIS models but would also significantly increase the difficulty of the ranking process.

\section{In-field Survey: Habitat Connectivity Toolkit}

The Habitat Connectivity Toolkit provided a large volume of data for analysis, resulting in defined segmented corridors with habitat quality values for each segment for each species. In addition, each barrier encountered in the corridor was scored for permeability. This breakdown of corridor quality and functionality can then be used to assess species specific movement abilities through the corridor, and specific locations and barriers needing restoration to improve the permeability of the corridor. 


\section{Species-Specific Corridor Results}

The scores for both habitat quality and permeability of barriers is uniquely tailored for each species included in the Habitat Connectivity Toolkit. As such, corridor scores can vary greatly depending on species habitat needs and life strategies. For the two corridors assessed using the HCT in this project, corridor quality was higher for the aquatic western painted turtle and American beaver than red-legged frog, due to the high percentage of wetland and open water habitat. The corridors showed decreased habitat scores on the ends of the corridors, likely due to the increased industrialization and development captured in the assessment as the corridor is forced between industrial properties. The center zones of Smith and Bybee show higher percent quality scores for the western painted turtle and beaver in comparison to the corridor ends, as the zones contain higher wetland and water percent cover and less habitat. Overall, red-legged frog did not display as high corridor habitat quality scores as the other species, as they are documented to prefer upland forest habitats adjacent to wetlands and water bodies (Leonard et al. 1993; Corkran and Thoms 1996; IUCN 2017), which is limited in the study area.

It is important to note that the HCT habitat quality scores are not intended to be a measure of habitat quality for population residence, and instead is a measure of habitat composition that is suitable for species movement. The focus on scoring habitat best for movement, not residence, is an important factor when interpreting the results of the toolkit. The difference between scoring for residence habitat and movement habitat can be seen in Port of Portland's T5 Powerline site, which scored a habitat quality percentage of $65 \%$ due to lack of continuous water source and low wetland percent cover, but historically and presently contains an active western painted turtle population (Port of Portland 2015).

All species assessed were impacted by barriers in the study area. As barrier presence was heavier around the edges of the corridors, they appear to 'stack up', meaning their adjacent presence compounds the permeability scores and makes them appear more prohibitive for turtle movement. With over 35 barriers identified through the toolkit, fencing had the lowest permeability scores for all species, though modification to scoring of fencing may be needed to improve permeability estimates for smaller species. Crossing structure inclusion or bridging improved the permeability of barriers for all species, pointing to the need for barrier modification to improve connectivity in the area and increase access to zones with high habitat quality scores. 


\section{Disadvantages of the HCT Method}

The main disadvantages of using the Habitat Connectivity Toolkit is that the method requires an initial identified corridor to assess, existing score sheets for the species of interest, and the time and effort to perform the in-field surveys.

The HCT does not identify corridors on the landscape for the researcher. Instead, it requires a corridor of interest to be defined, either through GIS analysis such as Circuitscape, or through expert opinion on management goals for connectivity in the area. The toolkit was created for urban use, where corridors are often small, non-linear paths through a complex urban matrix. For this project, the study area was instead a connection of large greenspaces, making corridor identification difficult to identify out of the entire landscape. It proved to be difficult to select a potential corridor for movement of species with different habitat preferences and requirements. Land managers who are interested in performing this method may have an easier time, as their property would either be an end point of the corridor, or a stepping stone along the corridor pass, and so a corridor may be easier to define due to the focus on a single property.

Development of score sheets for a species outside of the list of HCT species also proved to be difficult. Western painted turtles are not a species that the HCT provides scoring and permeability sheets for, therefore, to use the toolkit scoring sheets had to be created. These were created for this project with the aid of a local turtle researcher in order to test the HCT method and study the products created, but if the method were to be performed with the goal of western painted turtle restoration in mind, more vetting of the score sheet would be necessary. This means a panel of experts should assess the sheets for accuracy, and debate the scoring as there is limited research on some elements of the species scoring sheets. This vetting process is currently being performed by the toolkit developers for the final version of the Habitat Connectivity Toolkit.

Finally, the surveying method, while producing a high volume of results, took significantly more effort than the other methods. While the products justified the resources and time expended in the process, it would be a serious project to undertake for a land manager. As the HCT gets further developed and the process is expedited, the ease of use will increase and more land managers may be willing to try to use the Toolkit to assess the connectivity around their properties. 


\section{Improvements for Future Use}

The Habitat Connectivity Toolkit is still currently in development. Small problems that occurred in the field such as clarification needed on the scoring sheets, or need for expansion on barrier types were recorded and brought to the Toolkit developers for assessment and modification. Improvements that were recommended included developing a larger railroad barrier scoring section, requiring more detailed information for aquatic habitats on scoring sheets (including aquatic vegetation and water movement), as well as tailoring the permeability scoring process to increase the contribution crossing structures make to the overall barrier permeability score. Other than these small issues, there was little room for improvement of the method process for better results. A potential expansion of the toolkit could be to widen the connectivity zone of assessment to reflect more of a grid structure. This would aid in situations where determining a single 500-meter-wide path of movement is difficult due to the availability of habitat, such as in Smith and Bybee wetlands.

\section{Comparison of Assessment Methods}

All methods provided a unique view of the study area and the corridors it may possess. The accuracy of each method in predicting wildlife movement and habitat use can only be tested through the tagging and tracking of wildlife. Therefore, we cannot speak to which corridor assessment method is the most correct or true, instead, we can only compare the products of each method and the relative accuracy of the data put in to each model. Each method was assessed for ease of use, data output, landscape accuracy and barrier accuracy (Table 21). Ease of use was judged based on the time, resources and overall effort required to complete the method. Data output was compared based on the amount of quantitative data created or data that can be used for a specific process such as restoration site location or mitigation. Landscape accuracy was assessing both the input and the output of a method to aerial imagery and existing site knowledge to see how much habitat information is correct and described by the method. Finally, barrier accuracy was compared to determine how well each method identifies and considers barriers in the corridors. 


\section{Landscape Accuracy Comparison}

The Habitat Connectivity Toolkit had the highest landscape accuracy out of all methods. The in-field survey portion combined with the GIS pre-assessment provided large quantities of detailed information on habitat type quantity and quality, including fine detailed habitat information including abiotic and biotic habitat features that are not distinguishable through exclusive GIS assessment. In addition, all information gathered through GIS was compared to infield results to determine accuracy and allow for modification of the data. Similarly, GIS information was used to help in-field decision making on percent cover of habitat type in each habitat zone.

The method with the next highest landscape accuracy was the Land Manager Interview method. Land managers knew their properties well, and were making species corridor decisions based on species habitat preference and existing habitat on the property. When comparing the land manager corridors to species habitat requirements, land managers accounted for species needs as best as they could and directed movement though the most preferable habitat, taking into account habitat details such as water velocity and human presence.

The GIS Analysis method had the lowest landscape accuracy, purely because of the misclassification of habitat in the land cover data source. The regional dataset used for land cover data was some of the most detailed data available for public use, and is overall highly accurate in classification. However, since the scale of the project is so small when it comes to study area size, any misclassification can have significant impact, as seen by the possible deviation of LCP for western painted turtle and beaver moving through the center of Smith and Bybee. GIS analysis also cannot currently account for more variable habitat features such as human activity, invasive species presence or habitat structures such as downed logs. With improvements to existing landscape datasets, GIS Analysis landscape accuracy can be comparable to the Land Manager Interview method, and even surpass the collaborative approach depending on how much and how fine of data is available for analysis. 


\section{Barrier Accuracy Comparison}

Similar to the landscape accuracy comparison, the Habitat Connectivity Toolkit showed higher barrier accuracy than the other methods due to the in-field surveying of each barrier. The ability to go to the site and record information on crossing structure presence, barrier features, and human activity allowed for more accurate scoring of the barriers for comparison between and within each barrier type. This allowed for accurate barrier information that could be used for management and project planning to improve permeability of a corridor through barrier restoration. The corridors chosen for assessment by the habitat connectivity toolkit were identified based on aerial imagery of the study area. This allowed us to initially avoid as many barriers as possible when choosing a potential corridor. The HCT method identified 37 barriers crossing through the 500-meter-wide corridor, and each barrier was assessed for structure features and permeability score.

The Land Manager Interview and GIS Analysis methods are similar in that a single linear path is created rather than the wide buffered corridor in the HCT method. Instead of recording as many barriers as possible in the corridor, the goals of the Least Cost Path GIS Analysis method and the land manager drawn path in the Land Manager Interviews methods are the same: create a path that traverses the study area crossing the least amount of barriers. The Land Manager Interview method path crossed 17 barriers, of which 10 had crossing structures. The LCP path for all species averaged 21.7 barriers crossed (range from 19-26), with an average of 10 possessing crossing structures. The land manager pathway crossed fewer barriers, and a larger percentage of those barriers contained crossing structures or were bridged, therefore the Land Manager Interview process has higher barrier accuracy. The Circuitscape method could not contribute to the identification of barriers as none were recognized in the landscape data beyond being developed habitat.

\section{Ease of Use Comparison}

The land manager interview method was the easiest method to perform, as the largest time commitment was scheduling with busy professionals. Few resources were required besides GIS software, which all methods needed. Following the land manager interviews, the GIS analysis method using Circuitscape and Least Cost Path had the next highest ease of use. Besides GIS and ranking data, no other resources were required. The time commitment for processing the 
data was small, as models could all be run in the same day once the appropriate data was collected. However, the collection of the ranking data was a long process, requiring the reaching out to many individuals to ask for participation. The ranking process of the GIS analysis greatly lowered the ease of use for the entire method, though the resulting ranking data are very useful for future assessments and projects. Finally, the Habitat Connectivity Toolkit had the lowest ease of use, simply because it took the most amount of time and resources to complete. The process of pre-assessment and collection of data was simple and easy, but the method requires commitment to on site surveying and property access rights and permits, which increases in difficulty the longer the corridor extends.

\section{Data Output Comparison}

In reverse order of the ease of use category, the Habitat Connectivity Toolkit provided the largest volume of data as well as the highest quality of data out of all methods tested. Detailed field sheets for each habitat zone on the corridor was collected and scored, as well as sheets for every barrier and crossing structure. Pre-assessment GIS information provided information on habitat containment that was validated in field to ensure accuracy. Final scores of the corridor habitat zones and permeability scores of the barriers allows for comparison of corridor segments and barriers for future management decisions and restoration locations. A significant amount of data came out of the toolkit for the three species of interest, but the field sheets can also be scored in the future for any species included in the Habitat Connectivity Toolkit species suite.

Following the HCT, the GIS analysis methods had the next highest amount of data coming out of the method. The ranking of habitat types for movement for all of the species assessed is not available in literature and is a valuable start to predicting corridor habitat permeability for a species anywhere a corridor is located. While the ranking method needs to be improved to standardize the process and limit variability, the information gathered through this method can still be used for initial predictions of wildlife use of habitats. In addition, the Circuitscape and Least Cost Path methods provide some visual representation of both connectivity in the study area as well as potential corridors through the properties. This is valuable for areas where corridors cannot easily be predicted, or the length of the corridor is so extensive that an in-field survey method would be unfeasible. 
Finally, the Land Manager Interview method produced the least amount of data out of all of the methods. The collaborative approach method can be improved to include more interview questions and scoring exercises to better create quantitative data for predicting wildlife movement and habitat permeability. As the method was designed for this project, there were few products created through the process, and little could be said about the permeability of the habitat and barriers.

Table 21: Final comparison of method attributes including ease of use (time, resources, effort), Data Output (quality and quantity of data), Landscape Accuracy and Barrier Accuracy.

\begin{tabular}{|cccc|}
\hline \multicolumn{3}{|c}{ Final Comparison of Method Attributes } \\
Land \\
& $\begin{array}{c}\text { Manager } \\
\text { Interview }\end{array}$ & $\begin{array}{c}\text { GIS } \\
\text { Analysis }\end{array}$ & $\begin{array}{c}\text { Habitat } \\
\text { Connectivity } \\
\text { Toolkit }\end{array}$ \\
Ease of Use & High & Medium & Low \\
Data Output & Low & High & High \\
Landscape Accuracy & High & Low & High \\
Barrier Accuracy & High & Low & High \\
\hline
\end{tabular}

\section{Study Area Management Recommendations}

There are a few management actions that can remediate influences of barriers and poor quality habitat on corridor permeability in the study area. One restoration activity to improve corridor use by riparian species and increase zone scores from the toolkit would be to replace the grass on the northern bank of the Columbia Slough just south of Heron Lakes Golf Course and Portland International Raceway with native flowering shrubs and riparian hardwood trees. A sandbar or exposed patches should remain to allow south facing sun exposure for western painted turtle nesting, and the increased canopy cover and moist understory would benefit other wetland species. By replacing the manicured grass with native vegetation on the banks, the corridor would also have greater structural vegetative buffer between the waterway and the human presence in the adjacent trail and golf course. Another restoration activity to improve habitat composition for species movement would be the suppression and removal of invasive species, including the invasive Himalayan blackberry located at the edges of many properties in the study area. All agencies should look to identify small, unincorporated sites between properties to improve habitat structure for wetland species movement and increase corridor 
widths, including the banks of the Columbia Slough and adjacent unused industrial properties which regress into fields.

Actions should be taken by all agencies to improve wildlife movement across barriers, either through the inclusion of crossing structures or by lessening the impact of infrastructure through modifications to structure and use. Railroads lines should be filled with cement or gravel at key locations to allow wildlife to cross the tracks more efficiently. Sites where this is needed are the railroads crossing and surrounding the West Wye and Bonneville Pond properties in between the Willamette River and the Columbia Slough. This stretch of corridor possesses multiple ponds and ephemeral wetland sites, and western painted turtles have been recorded moving through this section of the corridor (Hays 1999). Filling of portions of the railroad would allow for turtles to move quickly across the railroad barrier and not become stuck in between the tracks.

The largest barrier requiring work to improve wildlife movement is North Portland Road, located between Heron Lakes Golf Course and Smith and Bybee Wetlands. This road and railroad barrier is low in permeability for all species, and appears to divide the northern stretch of greenspaces in the study area. Actions such as lowering speed limits, filling railroad lines in a few locations, and improving shoulder vegetation composition with native shrub and tree species would improve the permeability for some species. Larger and more effective steps would be to construct an undercrossing to allow species to avoid crossing over the barrier and risking consequences such as vehicular collision and desiccation. This would be a large endeavor, but would greatly improve the permeability of the barrier for wildlife movement, and would be a great step in addressing the disconnect in species movement pathways identified by the land managers.

Similar crossing structures should be built where roads and railroads divide wildlife habitat. Existing storm water infrastructure can be modified to allow for wildlife use as a crossing structure. One such storm water culvert exits Port of Portland's Vanport Wetlands into an adjacent waterway, and currently has limited capability for wildlife use. The culvert passes beneath a chain-link fence and a private road adjacent to the site, but is rusted out at the exit point and is suspended by over three feet in the dry seasons as water levels drop. By widening the culvert and adding a ramp-like system, the culvert could allow western painted turtle and beaver movement into Vanport Wetland. 
Actions to improve barrier and habitat permeability have already taken place in the area. Port of Portland installed an undercrossing structure which passes underneath two of the recorded roads, two of the fences, and a rail line. Port of Portland also actively manages the T5 Powerline and West Wye sites for invasive species removal and wetland conservation (Port of Portland 2015). Similarly, Smith and Bybee has an active management plan that includes painted turtle conservation and habitat work (Metro 2012), as does City of Portland on Heron Lakes Golf Course through their Audubon Society certification (Audubon International 2017).

In addition, collaboration between managing agencies and local businesses should occur to initiate and cooperate on restoration and mitigation. Transportation agencies such as Oregon Department of Transportation (ODOT) and Portland Department of Transportation (PDOT), as well as railroad networks including BNSF and Union Railways should be involved in improving the permeability of roads and railroads in the urban area. Multnomah County Drainage District would be a valuable collaborator in assessing and improving existing storm water infrastructure for potential wildlife crossing structures. Adjacent private companies should also be encouraged to participate in discussions on improving urban habitats for movement, and facilitating wildlife movement through or around their properties. Finally, local neighborhood, watershed councils and other conservation-oriented organizations should bolster community support for restoration work to improve habitat connectivity in the St. Johns and Rivergate areas.

\section{Recommendations for Manager Use}

Land managers willing to perform these assessments could greatly contribute to the current data on regional urban connectivity zones. It is the goal of this project to provide introductory information on a variety of current corridor assessment methods, including their products, successes, and their challenges. This will allow land managers to pick the method which best suits their resources and research question, be it the suitability of habitat on their property for wildlife movement or the permeability of barriers located on their site.

It is recommended that managers combine methods to fully explore the location and quality of corridors in the area to the best of their ability and resource availability. An initial GIS analysis using Circuitscape and Least Cost path can be performed with basic habitat rankings based off of available literature of species habitat preferences, or, the land manager interview method can be implemented through a quick survey of surrounding property managers to define 
a potential corridor or wildlife path in the area. These pieces of information can then be used to inform the location of the connectivity zones for assessment through the Habitat Connectivity Toolkit.

The Habitat Connectivity Toolkit had the highest ranked attributes out of all of the methods, so it is suggested that land managers use the Toolkit as their primary method where resources are available. Eventually, a database can be created with publicly available habitat zone, habitat quality, and barrier information for regional connectivity comparison and wildlife corridor identification. Property managers can contribute information gathered through any of these methods to the database, and corridors around the city can be mapped and evaluated for their contribution to the overall urban connectivity.

Land managers should be critical of any data that they use to perform these methods, and make every attempt to verify the accuracy of the data through on-site visits or comparison to other data sets. The information gathered through any of these methods should also be viewed as introductory research, as the only way to determine true corridor or connectivity pathway locations is through the tracking of wildlife using GPS, radio telemetry, or other means. However, this introductory information could be used as a first step in management decisions including identifying locations for crossing structures or habitat restoration. The Habitat Connectivity Toolkit best aides in the identification of these potential restoration locations, though all methods could benefit management decisions.

\section{Final Comments}

Habitat connectivity is essential in promoting biodiversity and healthy wildlife populations, and is impacted by urbanization through the isolation and limitation of habitat patches, which limits the ability of wildlife to move safely across the landscape (Metro 2010). Corridors and zones of connectivity such as greenspaces and natural areas provide pathways of movement through complex urban environments, increasing the connectivity of the landscape (Lidicker and Koening 1996; Rudd et al 2002; Gibbons 2003). These zones and corridors can range in habitat quality and permeability, affecting the functionality of the corridor in facilitating wildlife movement. In efforts to improve connectivity in an urban landscape, assessments of corridor and connectivity zone functionality need to be performed to determine the current status

of habitat quality, barrier presence, and potential use by species. The status of these elements 
can be identified through land manager interviews, GIS modeling, the Habitat Connectivity Toolkit, or any combination of methods. Where habitat quality, barrier presence, or any landscape feature is impacting the functionality of a connectivity zone, restorative or management actions should be taken to improve the area for urban connectivity. With a larger collaborative effort, paths of connectivity across the Portland Metro region can be improved upon and strengthened for use by local species, re-connecting wildlife with urban habitats. 


\section{Referenced Literature}

Adriaensen, F., J. P. Chardon, G. DeBlust, E. Swinnen, S. Villalba, H. Gulinck, and E. Matthysen. 2003. The application of 'least-cost' modelling as a functional landscape model. Landscape and Urban Planning. 64:233-247.

Alvey, A.A., 2006. Promoting and preserving biodiversity in the urban forest. Urban Forestry \& Urban Greening, 5(4), pp.195-201.

Andrews, K.M., Gibbons, J.W., Jochimsen, D.M. and Mitchell, J., 2008. Ecological effects of roads on amphibians and reptiles: a literature review. Herpetological Conservation, 3 , pp.121-143.

Ashor, J.L., McCool, S.F. and Stokes, G.L., 1986. Improving wilderness planning efforts: Application of the transactive planning approach. USDA Forest Service general technical report INT-Intermountain Research Station (USA).

Baldwin, E.A., Marchand, M.N. and Litvaitis, J.A., 2004. Terrestrial habitat use by nesting painted turtles in landscapes with different levels of fragmentation. Northeastern Naturalist, 11(1), pp.41-48.

Beier, P., Majka, D., Jenness, J. 2009. Conceptual steps for designing wildlife corridors. Northern Arizona University, Flagstaff, AZ, Environmental Research, Development and Education for the New Economy. Ref Type: Report pp.1-89.

Bennett, G. and Mulongoy, K.J., 2006. Review of experience with ecological networks, corridors and buffer zones. In Secretariat of the Convention on Biological Diversity, Montreal, Technical Series (Vol. 23, p. 100).

Berry, J. (1996). Beyond mapping: Concepts, Algorithms, and Issues in GIS. Fort Collins, CO: John Wiley Publishers.

Biosystems Analysis, Inc. 1989. Endangered Species Alert Program Manual: Species Accounts and Procedures. Southern California Edison Environmental Affairs Division.

Bliss-Ketchum, L., Lafrenz,M., de Rivera, C. and L. Hennings. 2016. Metro Regional Habitat Connectivity Project: Phase 2 Report.

Bolger, D.T., Scott, T.A. and Rotenberry, J.T., 2001. Use of corridor-like landscape structures by bird and small mammal species. Biological Conservation, 102(2), pp.213-224.

Bowne, D.R. and White, H.R., 2004. Searching strategy of the painted turtle Chrysemys picta across spatial scales. Animal Behaviour, 68(6), pp.1401-1409.

Burgman, M. A., and D. B. Lindenmayer. 1998. Conservation biology for the Australian environment. Surrey Beatty and Sons, Chipping Norton, New South Wales, Australia .

Buttrick, S., K. Popper, M. Schindel, B. H. McRae, B. Unnasch, A. Jones, and J. Platt. 2015. Conserving Nature's Stage: Identifying Resilient Terrestrial Landscapes in the Pacific Northwest. The Nature Conservancy, Portland, Oregon.

Cadenasso M.L., Pickett S.T.A. 2008. Urban principles for ecological landscape design and management: Scientific fundamentals. Cities and the Environment [online] 1(4).

Carr, A.F. 1952. "Genus Chrysemys: The Painted Turtles". Handbook of Turtles: The Turtles of the United States, Canada, and Baja California.Handbooks of American Natural History. Binghamton, New York: Comstock Publishing Associates a Division of Cornell University Press. pp. 213-234.

Carroll, C. 2013. Connectivity Analysis Toolkit Manual, version 1.3. Klamath Center for Conservation Research, Orleans, CA. 
City of Portland. (2017). About the Watershed: Columbia Slough Watershed. [online] Available at: https://www.portlandoregon.gov/bes/article/147238\#about [Accessed 13 Jul. 2017].

City of Portland. 2010. Terrestrial Ecology Enhancement Strategy Guidance: Living with American Beaver. Bureau of Environmental Services, City of Portland.

Clarke, G.P., White, P.C.L. and S. Harris. 1998. Effects of roads on badger Meles meles populations in south-west England. Biological Conservation 86 pp.117-124.

Clevenger, A.P., Chrusz, C.Z. \& Gunson, K. 2001. Drainage culverts as habitat linkages and factors affecting passage by mammals. Journal of Applied Ecology, 38, pp.1340-1349.

Clevenger, A.P. \& Waltho, N. (2000) Dry drainage culvert use and design considerations for small and medium-sized mammal movement across a major transportation corridor. Proceedings of the Third International Conference on Wildlife Ecology and Transportation (eds G. L.Evinuk, P.Garrett \& D.Ziegler), pp. 263-278. Florida Department of Transportation, Tallahassee, FL

Clevenger, A.P.; \& Waltho, N. 2003. Long-term, year-round monitoring of wildlife crossing structures and the importance of temporal and spatial variability in performance studies. Road Ecology Center. UC Davis: Road Ecology Center.

Clevenger, A.P. and Waltho, N., 2005. Performance indices to identify attributes of highway crossing structures facilitating movement of large mammals. Biological conservation, 121(3), pp.453-464.

Conservationgateway.org. (2017). The Freshwater Connectivity Toolkit: Road Stream Crossing Field Assessment Tools. [online] Available at: https://www.conservationgateway.org/ConservationPractices/Freshwater/HabitatProtectio nandRestoration/Pages/road-stream-assessment-tools.aspx [Accessed 13 Jul. 2017]

Corkran, C.C. and C.R. Thoms. 1996. Amphibians of Oregon, Washington, and British Columbia. Lone Pine Publishing, Vancouver.

Cushman, S.A., 2006. Effects of habitat loss and fragmentation on amphibians: a review and prospectus. Biological conservation, 128(2), pp.231-240.

Dearborn, DC, Kark, S. 2009. Motivations for Conserving Urban Biodiversity. Conservation Biology, Vol. 24, No. 2: 432-440

Delgado, J.D., Arroyo, N.L., Arévalo, J.R. and Fernández-Palacios, J.M., 2007. Edge effects of roads on temperature, light, canopy cover, and canopy height in laurel and pine forests (Tenerife, Canary Islands). Landscape and Urban planning, 81(4), pp.328-340.

Bliss-Ketchum, LL., and C.E. de Rivera. 2010. "The Effectiveness of Vertebrate Passage and Prevention Structures: a Study of Boeckman Road in Wilsonville.” OTREC RR-07-01

Ernst, Carl H., Barbour, R.W. and J.E. Lovich. 1994. Dutro, N.P., eds. Turtles of the United States and Canada. Washington and London: Smithsonian Institution Press. pp. 276-296.

Fahrig, L., Rytwinski, T. 2009. Effects of roads on animal abundance: An empirical review and synthesis. Ecology and Society [online] 14 (21).

Forman, R.T., 2003. Road ecology: science and solutions. Island Press.

Forman, R.T. and Alexander, L.E., 1998. Roads and their major ecological effects. Annual review of ecology and systematics, 29(1), pp.207-231.

Funk, W.C., Greene, A.E., Corn, P.S. and Allendorf, F.W., 2005. High dispersal in a frog species suggests that it is vulnerable to habitat fragmentation. Biology Letters, 1(1), pp.13-16.

Gallant, D., Bérubé, C.H., Tremblay, E. and Vasseur, L., 2004. An extensive study of the foraging ecology of beavers (Castor canadensis) in relation to habitat quality. Canadian Journal of Zoology, 82(6), pp.922-933. 
Gaston, K.J., Davies, T.W., Bennie, J. and Hopkins, J., 2012. Reducing the ecological consequences of night- time light pollution: options and developments. Journal of Applied Ecology, 49(6), pp.1256-1266.

Gervais, J., Rosenburg, D., Barnes, S., Puchy, C., and E. Stewart. 2009. Conservation Assessment For The Western Painted Turtle In Oregon. Version 1.

Gibbons, J.W. , 2003. Terrestrial habitat: a vital component for herpetofauna of isolated wetlands. Wetlands, 23(3), pp.630-635.

Gibbs, J.P., 1998. Amphibian movements in response to forest edges, roads, and streambeds in southern New England. The Journal of Wildlife Management, pp.584-589.

Gibbs, J.P. and Shriver, W.G., 2002. Estimating the effects of road mortality on turtle populations. Conservation Biology, 16(6), pp.1647-1652.

Gibson, R.J., Haedrich, R.L. and Wernerheim, C.M., 2005. Loss of fish habitat as a consequence of inappropriately constructed stream crossings. Fisheries, 30(1), pp.10-17.

Gomez, D.M. and R.G. Anthony. 1996. Amphibian and reptile abundance in riparian and upslope areas of five forest types in western Oregon. Northwest Science 70(2):109-119.

Gontier, M., 2007. Scale issues in the assessment of ecological impacts using a GIS-based habitat model - A case study for the Stockholm region. Environmental Impact Assessment Review, 27(5), pp.440-459.

Gribb, W.J. and Harlow, H., 2013. Central Place Foraging Characteristics of Beavers (Castor Canadensis) and Habitat Modeling in Grand Teton National Park. University of Wyoming National Park Service Research Center Annual Report, 36(1), pp.18-27.

Haddad, N.M., Bowne, D.R., Cunningham, A., Danielson, B.J., Levey, D.J., Sargent, S. and Spira, T., 2003. Corridor use by diverse taxa. Ecology, 84(3), pp.609-615.

Hedrick, P. W. 2001. Conservation genetics: where are we now? Trends in Ecology \& Evolution16:629-636.

Hibbard, E.A., 1958. Movements of beaver transplanted in North Dakota. The Journal of Wildlife Management, 22(2), pp.209-211.

Hilty, J.A. and Merenlender, A.M., 2004. Use of riparian corridors and vineyards by mammalian predators in northern California. Conservation Biology, 18(1), pp.126-135.

Hilty, J.A., Lidicker Jr, W.Z. and Merenlender, A., 2012. Corridor ecology: the science and practice of linking landscapes for biodiversity conservation. Island Press.

House, W.J., Nall, I.M. and Thomas, R.B., 2010. Interpond movements of western painted turtles (Chrysemys picta) in east-central Kansas. The Southwestern Naturalist, 55(3), pp.403410.

IUCN SSC Amphibian Specialist Group. 2015. Rana aurora aurora. The IUCN Red List of Threatened Species 2015: e.T58553A78906924

Jackson, S.D., 2000. Overview of transportation impacts on wildlife movement and populations. Wildlife and highways: seeking solutions to an ecological and socioeconomic dilemma. The Wildlife Society, pp.7-20.

Lafrenz,M., Bliss-Ketchum, L., de Rivera, C. and L. Hennings. 2017. Metro Regional Habitat Connectivity Project: Phase 4 Report.

Larkin, J. L., D. S. Maehr, T. S. Hoctor, M. A. Orlando, and K. Whitney. 2004. Landscape linkages and conservation planning for the black bear in west-central Florida. Animal Conservation. 7:23-34.

Leonard, W.P., H.A. Brown, L.L.C. Jones, K.R. McAllister, and R.M. Storm. 1993. Amphibians of Washington and Oregon. Seattle Audubon Society, Seattle, WA. 
Laurance, S.G. and Laurance, W.F., 1999. Tropical wildlife corridors: use of linear rainforest remnants by arboreal mammals. Biological Conservation, 91(2), pp.231-239.

Libby, W.L., 1957. Observations on beaver movements in Alaska. Journal of Mammalogy, 38(2), pp.269-269.

Leege, T.A., 1968. Natural movements of beavers in southeastern Idaho. The Journal of Wildlife Management, pp.973-976.

Lidicker Jr, W.Z. and Koenig, W.D., 1996. Responses of terrestrial vertebrates to habitat edges and corridors. Metapopulations and wildlife conservation, pp.85-109.

Lindenmayer, D.B., Cunningham, R.B., Donnelly, C.F., Triggs, B.E. and Belvedere, M., 1994. Factors influencing the occurrence of mammals in retained linear strips (wildlife corridors) and contiguous stands of montane ash forest in the Central Highlands of Victoria, southeastern Australia. Forest Ecology and Management, 67(1-3), pp.113-133.

Mann, C.C. and M.L. Plummer,. 1995. Are wildlife corridors the right path?. Science, 270(5241), pp.1428-1431.

Martinig, A., \& Bélanger-Smith, K. 2016. Factors influencing the discovery and use of wildlife passages for small fauna. Journal of Applied Ecology 53(3) pp. 825-836.

McDowell, D. M., and R. J. Naiman. 1986. Structure and function of a benthic inverte- brate stream community as influenced by beaver (Castor canadensis). Oecologia 68: pp. 481489.

McRae, B.H. and Shah, V.B., 2009. Circuitscape user's guide. The University of California, Santa Barbara.

McRae, B.H., K. Popper, A. Jones, M. Schindel, S. Buttrick, K. Hall, R.S. Unnasch, and J. Platt. 2016. Conserving Nature's Stage: Mapping Omnidirectional Connectivity for Resilient Terrestrial Landscapes in the Pacific Northwest. The Nature Conservancy, Portland Oregon. 47 pp.

Metro. 2012. Smith and Bybee Natural Resource Area Comprehensive Management Plan. Metro. Portland, OR.

Metro. 2012. Smith and Bybee Natural Resource Area Comprehensive Management Plan: Appendix. Metro. Portland, OR.

Metro. 2016. Parks and Nature Plan; Winter 2016. Metro. Portland, OR.

Metro. (2017). What is Metro?. [online] Available at: http://www.oregonmetro.gov/regionalleadership/what-metro [Accessed 13 Jul. 2017].

Metro (2017). St. John's Landfill. [online] Available at: http://www.oregonmetro.gov/st-johnslandfill

Millennium Ecosystem Assessment. 2005. Millennium Ecosystem Assessment Ecosystems and Human Well-Being: Synthesis. Island Press, Washington, D.C.

Nussbaum, R.A., E.D. Brodie Jr., and R.M. Storm. 1983. Amphibians and Reptiles of the Pacific Northwest. University of Idaho Press, Moscow.

Nwrc.usgs.gov. (2017). USGS National Wetlands Research Center: Habitat Suitability Index Models Introduction. [online] Available at: https://www.nwrc.usgs.gov/wdb/pub/hsi/hsiintro.htm [Accessed 13 Jul. 2017].

Olsson, M. P. O., and P. Widen. 2008. Effects of highway fencing and wildlife crossing on moose Alces alces movements and space use in southwestern Sweden. Wildlife Biology 14:111-117. 
Phillipsen, I.C. and Lytle, D.A., 2013. Aquatic insects in a sea of desert: population genetic structure is shaped by limited dispersal in a naturally fragmented landscape. Ecography, 36(6), pp.731-743.

Orchard, S.A. 1984. Amphibians and reptiles of B.C.: an ecological review. Research Branch, Ministry of Forests. WHR-15. Victoria, B.C.

Oregon Department of Fisheries and Wildlife (ODFW). 2012. Guidelines for Relocation of Beaver in Oregon Oregon Department of Fish and Wildlife. Salem, OR.

ODFW. 2015. Guidance for Conserving Oregon's Native Turtles including Best Management Practices. Oregon Dept. of Fish and Wildlife. 99 pp.

The Oregonian (2014). From frog massacre to frog rescue: Oregonians rush to help when migration meets traffic. [online] Available at: http://www.oregonlive.com/environment/index.ssf/2014/03/from_frog_massacre_to_frog res.html [Accessed 13 Jul. 2017].

Pickett S.T.A., Cadenasso M.L., Grove J.M., Groffmman P.M., Band L.W., Boone C.G., Burch W.R., Jr., Grimmond C.S.B., Hom J., Jenkins J.C., Law N.L., Nilon C., Pouyat R.V., Szlavecz K., Warren P.S., Wilson M.A. 2008. Beyond urban legends: An emerging framework of urban ecology, as illustrated by the Baltimore Ecosystem Study. BioScience 58, pp.139- 150.

Pocock, Z. \& Lawrence, R.E. (2005) How far into a forest does the effect of a road extend? Defining road edge effect in eucalypt forests of south-eastern Australia. Proceedings of the 2005 International Conference on Ecology and Transportation(eds C.L. Irwin, P. Garrett \& K.P. McDermott), pp. 397-405. Center for Transportation and Environment, North Carolina State University, Raleigh, North Carolina, USA.

Port of Portland. (2013). Mitigation management program: Operational environmental, natural resources, site status report for 2012. Port of Portland. Portland, OR.

Port of Portland. (2015). Mitigation management program: Operational environmental, natural resources, site status report for 2013-2014. Port of Portland. Portland, OR.

Port of Portland (2004). Vanport Wetlands Comprehensive Management Plan. Port of Portland. Portland, OR.

Raffel, T.R., Smith, N., Cortright, C. and Gatz, A.J., 2009. Central place foraging by beavers (Castor canadensis) in a complex lake habitat. The American Midland Naturalist, 162(1), pp.62-73.

Rao, K., and C. Geisler. 1990. The social consequences of protected areas development for resident people. Society and Natural Resources 3(1):19-32.

Rittenhouse, T.A., Harper, E.B., Rehard, L.R. and Semlitsch, R.D., 2008. The role of microhabitats in the desiccation and survival of anurans in recently harvested oakhickory forest. Copeia, 2008(4), pp.807-814.

Rothermel, B.B. and Semlitsch, R.D., 2002. An experimental investigation of landscape resistance of forest versus old- field habitats to emigrating juvenile amphibians. Conservation biology, 16(5), pp.1324-1332.

Rothley, K. 2005. Finding and Filling the "Cracks" in Resistance Surfaces for Least-cost Modeling. Ecology and Society 10(1): pp 4.

Selin, S. and Chevez, D., 1995. Developing a collaborative model for environmental planning and management. Environmental management, 19(2), pp.189-195.

Shah, V.B. and McRae, B.H., 2008, August. Circuitscape: a tool for landscape ecology. In Proceedings of the 7th Python in Science Conference(Vol. 7, pp. 62-66). 
Shepard, D.B., Kuhns, A.R., Dreslik, M.J. and Phillips, C.A., 2008. Roads as barriers to animal movement in fragmented landscapes. Animal Conservation, 11(4), pp.288-296.

Soule, M.E. and Gilpin, M.E., 1991. The theory of wildlife corridor capability. Nature conservation, 2, pp.3-8.

Spencer, W. D., P. Beier, K. Penrod, M. Parisi, A. Pettler, K. Winters, J. Strittholt, C. Paulman, and H. Rustigian-Romsos. 2010. California Essential Habitat Connectivity Project: a strategy for conserving a connected California. Report. California Department of Transportation and California Department of Fish \& Game, Sacramento, California.

Sun, L., Müller-Schwarze, D. and Schulte, B.A., 2000. Dispersal pattern and effective population size of the beaver. Canadian Journal of Zoology, 78(3), pp.393-398.

Taylor, Philip D., Lenore Fahrig, Kringen Henein, and Gray Merriam. 1993. Connectivity Is a Vital Element of Landscape Structure. Oikos 68(3) pp. 571-73.

Theobald, D.M., Miller, J.R. and Hobbs, N.T., 1997. Estimating the cumulative effects of development on wildlife habitat. Landscape and urban planning, 39(1), pp.25-36.

Toepfer, C.S., Fisher, W.L. and Haubelt, J.A., 1999. Swimming performance of the threatened leopard darter in relation to road culverts. Transactions of the American Fisheries Society, 128(1), pp.155-161.

U.S.Department of Agriculture (USDA).2005. How to keep beavers from plugging culverts. Technology and Development Program: United States Department of Fishers and Wildlife and United States Forestry Services. Missoula, MT.

U.S. Forest Service. 1980. Habitat Evaluation Procedures (HEP) ESM 102. Division of Ecological Services, US Fish and Wildlife, Department of the Interior. Washington, D.C.

U. S. Fish and Wildlife Service. 2016. National Wetlands Inventory website. U.S. Department of the Interior, Fish and Wildlife Service, Washington, D.C. http://www.fws.gov/wetlands/

Verts, B.J. and L.N. Carraway. 1998. Land Mammals of Oregon. Family Castoridae. University of California Press; 1st Edition. Los Angeles, CA. pp. 256-252.

Welch, N., 2015. Designing a Regional Network of Fuel Breaks to Protect Greater Sage-Grouse Habitat: An Experimental Approach using Circuitscape. Oral presentation at the 2015 Restoring the West Conference. Logan, Utah.

Woltz, H.W., Gibbs, J.P. and Ducey, P.K., 2008. Road crossing structures for amphibians and reptiles: informing design through behavioral analysis. Biological Conservation, 141(11), pp.2745-2750.

$\mathrm{Wu}$, J., 2004. Effects of changing scale on landscape pattern analysis: scaling relations. Landscape ecology, 19(2), pp.125-138.

Yale Conrey, R.C. and Mills, L.S., 2001. Do highways fragment small mammal populations?. Road Ecology Center.

Zeigler, S.L., Neel, M.C., Oliveira, L., Raboy, B.E. and Fagan, W.F., 2011. Conspecific and heterospecific attraction in assessments of functional connectivity. Biodiversity and conservation, 20(12), pp.2779-2796. 


\section{Referenced GIS Data and Tools}

Maps throughout this document were created using ArcGIS $®$ software by Esri. ArcGIS $®$ and $\operatorname{ArcMap}^{\mathrm{TM}}$ are the intellectual property of Esri and are used herein under license. Copyright (C) Esri. All rights reserved. For more information about Esri ${ }^{\circledR}$ software, please visit www.esri.com

McRae, B., V. Shah, and T. Mohapatra. 2014. CircuitScape [computer software]. http://www.circuitscape.org (last accessed 06 July 2017)

Metro Data Resource Center. Transit: Railroads. Updated Jan. 2016. Portland, OR: Metro, 1995. Metro Data Resource Center. Transit: Arterials. Updated Apr. 2017. Portland, OR: Metro, 1998.

Metro Data Resource Center. Transit: Trails. Updated Apr. 2017. Portland, OR: Metro, 2010.

U. S. Fish and Wildlife Service. 2016. National Wetlands Inventory website. U.S. Department of the Interior, Fish and Wildlife Service, Washington, D.C. http://www.fws.gov/wetlands/ 


\title{
Urban Connections: A comparison of connectivity assessment methods
}

\section{Appendices}

\author{
Natalie M Rogers \\ A report submitted in fulfillment \\ of the degree requirements for: \\ Professional Science Masters \\ in the department of \\ Environmental Science and Management
}

Thesis Committee:

Joseph Maser

Catherine de Rivera

Martin Lafrenz

Carrie Butler

\section{Portland State University \\ August 14 ${ }^{\text {th }}, 2017$}




\section{Appendix A: Land Manager Interview Associated Materials............ 3}

Appendix B: GIS Analysis Associated Materials.................................... 4

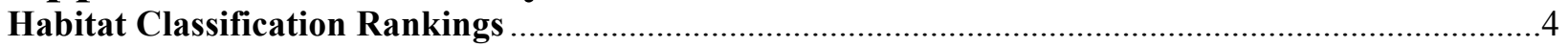

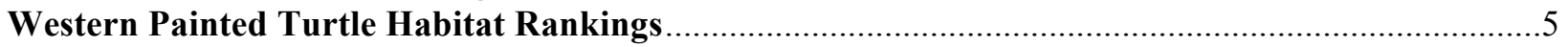

American Beaver Habitat Rankings .............................................................................................6

Red-legged frog Habitat Rankings …………………………………………………………....

Appendix C: Habitat Connectivity Toolkit Associated Materials..... 8

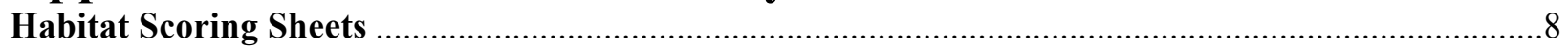

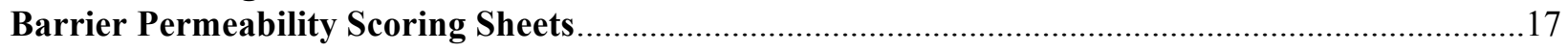

Appendix D: Site Maps......................................................................... 26 


\section{Appendix A: Land Manager Interview Associated Materials}

Land Manager Interview Questions - Urban Corridor Assessment Methods Comparison

Date:

Property:

Manager Name:

1. Do you have the following species on your property (yes/no): western painted turtles, red legged frog, deer, beaver, coyote. If yes, how frequently do you have a sighting or report of presence?

2. On the provided map, mark potential barriers and list the species that they may affect in terms of movement.

3. On the provided map, draw the corridors (or the most frequently used paths) across the property for the species identified as present on your site

4. Are there any areas on your property that are inaccessible to wildlife? If yes, mark on the map.

5. Are there any areas on your property with high human activity? If yes, mark on the map.

Materials Needed: Pen, printed out map of property, IRB consent form

Above: Interview questions asked at each land manager interview session. Institutional Research Board (IRB) consent form signed at each interview. 


\section{Appendix B: GIS Analysis Associated Materials}

\section{Habitat Classification Rankings}

Table of microhabitat classifications defined by the Regional Conservation Strategy land cover map data (Regional Conservation Strategy 2011). The land cover classifications were identified by using a compilation of Land Cover 2 classes. Some classes were combined in an effort to simplify the dataset.

\begin{tabular}{|c|c|}
\hline Microhabitat Classification & Dataset Provided Description \\
\hline \multicolumn{2}{|l|}{ Open water } \\
\hline \multicolumn{2}{|l|}{ Undeveloped areas; sandbars } \\
\hline $\begin{array}{l}\text { Undeveloped areas; sandbars, } \\
\text { Wetland }\end{array}$ & Sandbars + Wetland Delineation \\
\hline Paved, small buildings & Sandbars + Wetland Delineation \\
\hline \multicolumn{2}{|l|}{ Buildings, medium } \\
\hline \multicolumn{2}{|l|}{ Buildings, tall } \\
\hline Herbaceous, low & Herbaceous I - Low sparse veg $(0-2 f t$. $)$ \\
\hline Herbaceous, low, Wetland & Herbaceous I - Low sparse veg $(0-2 f t)+$. Wetland Delineation \\
\hline Herbaceous, medium & Herbaceous I - Low sparse veg $(0-2 f t)$. \\
\hline Herbaceous, medium, Wetland & Herbaceous I - Low sparse veg $(0-2 f t)+$. Wetland Delineation \\
\hline Herbaceous, high & Herbaceous II - Low vegetation (2 - 7 ft.) \\
\hline Herbaceous, high, Wetland & $\begin{array}{l}\text { Herbaceous II - Low vegetation }(2-7 f t .)+\text { Wetland } \\
\text { Delineation }\end{array}$ \\
\hline Conifers, small & Large shrub/small trees (7 - $30 \mathrm{ft}$.) \\
\hline Conifers, small, Wetland & Large shrub/small trees $(7-30 \mathrm{ft})+$. Wetland Delineation \\
\hline Conifers, medium & Conifers (30-120 ft.) \\
\hline Conifers, medium, Wetland & Conifers (30-120 ft.) + Wetland Delineation \\
\hline Conifers, medium - tall & Conifers $(30-120 \mathrm{ft})$. \\
\hline Conifers, medium - tall, Wetland & Conifers (30-120 ft.) + Wetland Delineation \\
\hline Conifers, tall & Conifers (over $120 \mathrm{ft}$.) \\
\hline Conifers, tall, Wetland & Conifers (over $120 \mathrm{ft}$.) + Wetland Delineation \\
\hline Conifers, very tall & Conifers (over $120 \mathrm{ft}$.) \\
\hline Conifers, very tall, Wetland & Conifers (over $120 \mathrm{ft}$. ) + Wetland Delineation \\
\hline Hardwood, small & Large shrub/small trees (7 - $30 \mathrm{ft}$.) \\
\hline Hardwood, small, Wetland & Large shrub/small trees $(7-30 \mathrm{ft})+$. Wetland Delineation \\
\hline Hardwood, medium & Broadleaf (over $30 \mathrm{ft}$.) \\
\hline Hardwood, medium, Wetland & Broadleaf (over $30 \mathrm{ft}$.) + Wetland Delineation \\
\hline Hardwood, medium-tall & Broadleaf (over $30 \mathrm{ft}$.) \\
\hline Hardwood, medium-tall, Wetland & Broadleaf (over $30 \mathrm{ft}$.) + Wetland Delineation \\
\hline Hardwood, tall & Broadleaf (over $30 \mathrm{ft}$.) \\
\hline Hardwood, tall, Wetland & Broadleaf (over $30 \mathrm{ft}$.) + Wetland Delineation \\
\hline \multicolumn{2}{|l|}{ Mixed forest } \\
\hline Mixed forest, Wetland & Mixed Forest + Wetland Delineation \\
\hline Clear cuts, 2006-2008 & Clear cut years 2006-2010 \\
\hline Partial cuts, 2006-2008 & Partially cut years $2006-2010$ \\
\hline Agriculture & \\
\hline
\end{tabular}




\section{Western Painted Turtle Rankings}

Below: Cumulative scores for western painted turtle expert opinion ranking exercise, including minimum score and maximum score ranked after adjustment of scale. Least Cost Path rank in order from most preferential (1.0) to least preferential (27.0) for species movement based on the adjacent ranking scores.

\begin{tabular}{|c|c|c|c|c|c|}
\hline \multicolumn{6}{|c|}{ Western Painted Turtle (Chrysemys picta bellii) Resistance Scores } \\
\hline \multirow[b]{2}{*}{ Habitat Type } & \multicolumn{4}{|c|}{ Resistance Scores } & \multirow[b]{2}{*}{$\begin{array}{l}\text { LCP } \\
\text { Rank }\end{array}$} \\
\hline & Min & Max & Range & $\begin{array}{l}\text { Average } \\
\text { Score }\end{array}$ & \\
\hline Water & 1.0 & 11.3 & 10.3 & 5.2 & 1.0 \\
\hline Herbaceous, low, Wetland & 2.0 & 22.7 & 20.7 & 9.6 & 2.0 \\
\hline Undeveloped areas; sandbars, Wetlands & 3.0 & 22.7 & 19.7 & 10.6 & 3.0 \\
\hline Undeveloped areas; sandbars & 4.0 & 22.7 & 18.7 & 11.4 & 4.0 \\
\hline Herbaceous, low & 6.8 & 22.7 & 15.9 & 11.8 & 4.0 \\
\hline Herbaceous, medium, Wetland & 5.0 & 22.7 & 17.7 & 12.7 & 6.0 \\
\hline Herbaceous, medium, & 8.5 & 22.7 & 14.2 & 12.9 & 7.0 \\
\hline Herbaceous, high, Wetland & 5.0 & 22.7 & 17.7 & 15.0 & 8.0 \\
\hline Hardwood, medium, Wetland & 5.0 & 25.5 & 20.5 & 17.1 & 9.0 \\
\hline Hardwood, medium-tall, Wetland & 5.0 & 25.5 & 20.5 & 17.1 & 9.0 \\
\hline Hardwood, tall, Wetland & 5.0 & 25.5 & 20.5 & 17.1 & 9.0 \\
\hline Hardwood, small, Wetland & 5.0 & 25.5 & 20.5 & 17.7 & 10.0 \\
\hline Herbaceous, high & 13.6 & 22.7 & 9.1 & 18.0 & 11.0 \\
\hline Conifers, tall, Wetland & 10.2 & 25.5 & 15.3 & 18.9 & 12.0 \\
\hline Conifers, very tall, Wetland & 10.2 & 25.5 & 15.3 & 18.9 & 12.0 \\
\hline Mixed forest, Wetland & 11.0 & 25.5 & 14.5 & 19.2 & 13.0 \\
\hline Hardwood, medium & 11.0 & 25.5 & 14.5 & 19.3 & 14.0 \\
\hline Hardwood, medium-tall & 11.0 & 25.5 & 14.5 & 19.3 & 14.0 \\
\hline Hardwood, tall & 11.0 & 25.5 & 14.5 & 19.3 & 14.0 \\
\hline Conifers, small, Wetland & 13.6 & 25.5 & 11.9 & 19.4 & 15.0 \\
\hline Conifers, medium, Wetland & 10.2 & 25.5 & 15.3 & 19.4 & 15.0 \\
\hline Conifers, medium - tall, Wetland & 10.2 & 25.5 & 15.3 & 19.4 & 15.0 \\
\hline Agriculture & 6.8 & 34.0 & 27.2 & 19.6 & 16.0 \\
\hline Hardwood, small & 11.0 & 25.5 & 14.5 & 19.9 & 17.0 \\
\hline Mixed forest & 11.0 & 25.5 & 14.5 & 20.4 & 18.0 \\
\hline Conifers, small & 17.0 & 26.0 & 9.0 & 21.8 & 19.0 \\
\hline Conifers, medium & 13.6 & 27.0 & 13.4 & 22.0 & 20.0 \\
\hline Conifers, tall & 13.6 & 31.0 & 17.4 & 22.1 & 21.0 \\
\hline Conifers, very tall & 13.6 & 32.0 & 18.4 & 22.2 & 22.0 \\
\hline Partial cuts & 17.0 & 29.0 & 12.0 & 22.2 & 22.0 \\
\hline Conifers, medium - tall & 13.6 & 30.0 & 16.4 & 22.5 & 23.0 \\
\hline Clear cuts & 15.1 & 34.0 & 18.9 & 22.9 & 24.0 \\
\hline Paved, small buildings & 10.2 & 34.0 & 23.8 & 27.5 & 25.0 \\
\hline Buildings, medium & 30.2 & 34.0 & 3.8 & 32.8 & 26.0 \\
\hline Buildings, tall & 34.0 & 34.0 & 0.0 & 34.0 & 27.0 \\
\hline
\end{tabular}




\section{American Beaver Rankings}

Below: Cumulative scores for American beaver expert opinion exercise, including minimum score and maximum score ranked after adjustment of scale. Least Cost Path rank in order from most preferential (1.0) to least preferential (26.0) for species movement based on the adjacent ranking scores.

\section{American Beaver (Castor canadensis) Resistance Scores}

\begin{tabular}{|c|c|c|c|c|c|}
\hline \multirow[b]{2}{*}{ Habitat Type } & \multicolumn{4}{|c|}{ Resistance Scores } & \multirow[b]{2}{*}{$\begin{array}{l}\text { LCP } \\
\text { Rank }\end{array}$} \\
\hline & Min & Max & Range & $\begin{array}{l}\text { Average } \\
\text { Score }\end{array}$ & \\
\hline Water & 1 & 2.5 & 1.5 & 2.1 & 1 \\
\hline Herbaceous, medium, & 2.5 & 3 & 0.5 & 2.6 & 2 \\
\hline Undeveloped areas; sandbars, Wetlands & 2 & 5 & 3 & 3.2 & 3 \\
\hline Herbaceous, medium, Wetland & 2.5 & 5 & 2.5 & 3.3 & 4 \\
\hline Hardwood, medium, Wetland & 2.5 & 5 & 2.5 & 3.5 & 5 \\
\hline Undeveloped areas; sandbars & 2 & 7.5 & 5.5 & 3.6 & 6 \\
\hline Herbaceous, low, Wetland & 2 & 5 & 3 & 3.6 & 6 \\
\hline Hardwood, small, Wetland & 2.5 & 5 & 2.5 & 3.8 & 7 \\
\hline Herbaceous, high, Wetland & 2.5 & 5 & 2.5 & 4.1 & 8 \\
\hline Herbaceous, low & 2 & 7.5 & 5.5 & 4.3 & 9 \\
\hline Hardwood, medium & 2.5 & 5 & 2.5 & 4.4 & 10 \\
\hline Herbaceous, high & 2.5 & 7.5 & 5 & 4.8 & 11 \\
\hline Hardwood, tall, Wetland & 2.5 & 7.5 & 5 & 4.8 & 11 \\
\hline Hardwood, medium-tall & 2.5 & 7.5 & 5 & 5.0 & 12 \\
\hline Mixed forest, Wetland & 2.5 & 7.5 & 5 & 5.0 & 12 \\
\hline Hardwood, small & 2.5 & 7.5 & 5 & 5.3 & 13 \\
\hline Conifers, small, Wetland & 4 & 7.5 & 3.5 & 5.4 & 14 \\
\hline Hardwood, medium-tall, Wetland & 2.5 & 7.5 & 5 & 5.4 & 14 \\
\hline Hardwood, tall & 2.5 & 7.5 & 5 & 5.6 & 15 \\
\hline Conifers, medium, Wetland & 3 & 7.5 & 4.5 & 5.8 & 16 \\
\hline Agriculture & 2 & 7.5 & 5.5 & 6.1 & 17 \\
\hline Conifers, small & 5 & 7.5 & 2.5 & 6.3 & 18 \\
\hline Mixed forest & 5 & 7.5 & 2.5 & 6.5 & 19 \\
\hline Conifers, medium & 4 & 7.5 & 3.5 & 6.6 & 20 \\
\hline Partial cuts & 5 & 7.5 & 2.5 & 6.9 & 21 \\
\hline Conifers, medium - tall, Wetland & 3 & 10 & 7 & 7.0 & 22 \\
\hline Conifers, tall, Wetland & 3 & 10 & 7 & 7.0 & 22 \\
\hline Conifers, very tall, Wetland & 3 & 10 & 7 & 7.0 & 22 \\
\hline Clear cuts & 6 & 7.5 & 1.5 & 7.1 & 23 \\
\hline Conifers, medium - tall & 4 & 10 & 6 & 7.3 & 24 \\
\hline Conifers, tall & 4 & 10 & 6 & 7.3 & 24 \\
\hline Conifers, very tall & 4 & 10 & 6 & 7.3 & 24 \\
\hline Paved, small buildings & 3 & 10 & 7 & 8.3 & 25 \\
\hline Buildings, medium & 10 & 10 & 0 & 10.0 & 26 \\
\hline Buildings, tall & 10 & 10 & 0 & 10.0 & 26 \\
\hline
\end{tabular}




\section{Red-legged frog Rankings}

Below: Cumulative scores for red-legged frog expert opinion exercise, including minimum score and maximum score ranked after adjustment of scale. Least Cost Path rank in order from most preferential (1.0) to least preferential (16.0) for species movement based on the adjacent ranking scores.

\begin{tabular}{|c|c|c|c|c|c|}
\hline \multicolumn{6}{|c|}{ Red-legged frog (Rana aurora) Resistance Scores } \\
\hline \multirow[b]{2}{*}{ Habitat Type } & \multicolumn{4}{|c|}{ Resistance Scores } & \multirow[b]{2}{*}{$\begin{array}{l}\text { LCP } \\
\text { Rank }\end{array}$} \\
\hline & Min & Max & Range & $\begin{array}{l}\text { Average } \\
\text { Score }\end{array}$ & \\
\hline Herbaceous, medium, Wetland & 1.0 & 6.0 & 5.0 & 4.05 & 1.0 \\
\hline Conifers, medium, Wetland & 1.5 & 7.5 & 6.0 & 4.13 & 2.0 \\
\hline Conifers, medium - tall, Wetland & 1.5 & 7.5 & 6.0 & 4.13 & 2.0 \\
\hline Hardwood, medium, Wetland & 1.5 & 7.5 & 6.0 & 4.13 & 2.0 \\
\hline Hardwood, medium-tall, Wetland & 1.5 & 7.5 & 6.0 & 4.13 & 2.0 \\
\hline Conifers, tall, Wetland & 1.7 & 7.5 & 5.8 & 4.43 & 3.0 \\
\hline Conifers, very tall, Wetland & 1.7 & 7.5 & 5.8 & 4.43 & 3.0 \\
\hline Hardwood, tall, Wetland & 1.7 & 7.5 & 5.8 & 4.43 & 3.0 \\
\hline Herbaceous, low, Wetland & 3.0 & 6.0 & 3.0 & 4.45 & 4.0 \\
\hline Mixed forest, Wetland & 1.7 & 7.5 & 5.8 & 4.73 & 5.0 \\
\hline Undeveloped areas; sandbars, Wetlands & 3.0 & 7.5 & 4.5 & 5.30 & 6.0 \\
\hline Conifers, small, Wetland & 4.0 & 7.5 & 3.5 & 5.40 & 7.0 \\
\hline Hardwood, small, Wetland & 4.0 & 7.5 & 3.5 & 5.40 & 7.0 \\
\hline Herbaceous, high, Wetland & 1.5 & 15.0 & 13.5 & 5.45 & 8.0 \\
\hline Water & 3.0 & 11.0 & 8.0 & 6.42 & 9.0 \\
\hline Conifers, medium & 3.3 & 9.0 & 5.7 & 6.67 & 10.0 \\
\hline Conifers, medium - tall & 3.3 & 9.0 & 5.7 & 6.67 & 10.0 \\
\hline Conifers, tall & 3.3 & 9.0 & 5.7 & 6.97 & 10.0 \\
\hline Conifers, very tall & 3.3 & 9.0 & 5.7 & 6.97 & 10.0 \\
\hline Hardwood, medium & 3.3 & 9.0 & 5.7 & 6.97 & 10.0 \\
\hline Hardwood, medium-tall & 3.3 & 9.0 & 5.7 & 6.97 & 10.0 \\
\hline Hardwood, tall & 3.3 & 9.0 & 5.7 & 6.97 & 10.0 \\
\hline Mixed forest & 3.3 & 9.0 & 5.7 & 6.97 & 10.0 \\
\hline Herbaceous, medium, & 3.8 & 9.0 & 5.3 & 7.08 & 11.0 \\
\hline Herbaceous, low & 3.8 & 10.5 & 6.8 & 7.58 & 12.0 \\
\hline Conifers, small & 6.7 & 9.0 & 2.3 & 7.83 & 13.0 \\
\hline Hardwood, small & 6.0 & 10.5 & 4.5 & 7.93 & 14.0 \\
\hline Herbaceous, high & 3.8 & 15.0 & 11.3 & 7.98 & 14.0 \\
\hline Partial cuts & 6.0 & 12.0 & 6.0 & 8.57 & 15.0 \\
\hline Undeveloped areas; sandbars & 3.0 & 12.0 & 9.0 & 8.98 & 16.0 \\
\hline Clear cuts & 6.0 & 13.5 & 7.5 & 10.15 & 17.0 \\
\hline Agriculture, digitized & 6.0 & 13.0 & 7.0 & 10.18 & 18.0 \\
\hline Paved, small buildings & 6.0 & 15.0 & 9.0 & 12.67 & 19.0 \\
\hline Buildings, medium & 6.0 & 15.0 & 9.0 & 13.00 & 20.0 \\
\hline Buildings, tall & 6.0 & 15.0 & 9.0 & 13.20 & 21.0 \\
\hline
\end{tabular}




\section{Appendix C: Habitat Connectivity Toolkit Associated Materials}

Habitat Scoring and Permeability scoring sheets for western painted turtle (Chysemys picta bellii), American beaver (Castor canadensis) and red-legged frog (Rana aurora)

\begin{tabular}{|c|c|c|c|}
\hline \multicolumn{4}{|c|}{ Habitat Scoring Rubric for the American Beaver **DRAFT VERSION** } \\
\hline & Characteristic & $\begin{array}{l}\text { Field data category options (to be verified [GIS data] } \\
\text { and measured [field data] by technicians on site) }\end{array}$ & Scoring Values \\
\hline \multirow{6}{*}{$\begin{array}{l}\text { Connectivity } \\
\text { patch and } \\
\text { matrix } \\
\text { characteristics }\end{array}$} & Land Ownership/Zoning & (marked on accompanying aerial photo) & $\begin{array}{l}\text { Not scored for present } \\
\text { connectivity value but important } \\
\text { to prioritizing and for assessing } \\
\text { future condition }\end{array}$ \\
\hline & Dominant matrix type (GIS) & $\begin{array}{l}\text { Agriculture } \% \\
\text { Developed } \%\end{array}$ & $\begin{array}{l}\text { Agriculture: } 2 \\
\text { Developed: } 1\end{array}$ \\
\hline & $\begin{array}{l}\text { Dominant matrix type } \\
\text { (FIELD) }\end{array}$ & $\begin{array}{l}\text { Agriculture type } \\
\text { (low crop, orchard, corn etc.) } \\
\text { Developed type } \\
\text { (residential, commercial, industrial) }\end{array}$ & $\mathrm{N} / \mathrm{S}$ \\
\hline & $\begin{array}{l}\text { Minimum width of non- } \\
\text { developed connectivity zone }\end{array}$ & Meters & $\begin{array}{l}0 \mathrm{~m}: 0 \\
1-15 \mathrm{~m}: 1 \\
15-50 \mathrm{~m}: 2 \\
>50 \mathrm{~m}: 3\end{array}$ \\
\hline & $\begin{array}{l}\text { \% Hardscaping (roads, parking } \\
\text { lots etc. does not include structures) }\end{array}$ & $\begin{array}{l}\text { Hardscaping (impervious, not including structures) } \\
\%\end{array}$ & $\begin{array}{l}>50 \% \text { hardscaping: } 0 \\
25-49 \% \text { hardscaping: } 1 \\
\text { 10-20\% hardscaping: } 2 \\
<10 \% \text { hardscaping: } 3\end{array}$ \\
\hline & $\%$ Structures & $\begin{array}{c}\text { Structures } \\
\%\end{array}$ & $\begin{array}{l}>50 \% \text { hardscaping: } 0 \\
25-49 \% \text { structures: } 1 \\
10-20 \% \text { structures: } 2 \\
<10 \% \text { structures: } 3\end{array}$ \\
\hline \multirow[t]{5}{*}{ Water source } & $\begin{array}{l}\text { Water source within } \\
\text { connectivity zone }\end{array}$ & $\begin{array}{l}\text { Yes / No } \\
\text { Type: stream pond }\end{array}$ & $\begin{array}{l}\text { Yes }=3 \\
\text { No }=0 \\
\text { Any type }\end{array}$ \\
\hline & $\begin{array}{r}\text { (Habitat type and type of } \\
\text { connectivity) }\end{array}$ & $\begin{array}{ll}\text { Open water } & \% \\
/ & \text { Contiguous }\end{array}$ & $\begin{array}{l}0 \%: 0 \\
1-10 \%: 1 \\
10-49 \%: 2 \\
>50 \%: 3 \\
\text { Fragmented: } 1 \\
\text { Contiguous: } 3\end{array}$ \\
\hline & $\begin{array}{r}\text { Distance of corridor } \\
\text { edge from water }\end{array}$ & $\begin{array}{l}\text { If answer to water source is no then report distance to } \\
\text { water here: } \quad \text { Meters }\end{array}$ & $\begin{array}{l}\text { If }>300 \mathrm{~m}: 0 \\
150-299 \mathrm{~m}: 1 \\
50-149 \mathrm{m:}: 2 \\
\text { If }<50 \mathrm{~m}: 3\end{array}$ \\
\hline & Seasonality & Ephemeral Intermittent $\quad$ Perennial & $\begin{array}{l}\text { Ephemeral: } 1 \\
\text { Intermittent: } 2 \\
\text { Perennial: } 3\end{array}$ \\
\hline & Channel stability (streams) & Incised $\quad$ Straight $\quad$ Meandering & $\mathrm{N} / \mathrm{S}$ \\
\hline \multirow[t]{7}{*}{ Vegetation } & $\begin{array}{r}\text { (Habitat type and type of } \\
\text { connectivity) }\end{array}$ & $\begin{array}{l}\text { Wetland }{ }_{\text {Fragmented }} \% \\
\text { / Contiguous }\end{array}$ & $\begin{array}{l}0 \%: 0 \\
\text { 1-4\%: } 1 \\
5-20 \%: 2 \\
>20 \%: 3 \\
\text { Fragmented:1 } \\
\text { Contiguous: } 3\end{array}$ \\
\hline & $\begin{array}{r}\text { (Habitat type and type of } \\
\text { connectivity) }\end{array}$ & $\begin{array}{l}\text { Conifer Forest } \\
\text { Fragmented } /\end{array}$ & $\mathrm{N} / \mathrm{S}$ \\
\hline & $\begin{array}{r}\text { (Habitat type and type of } \\
\text { connectivity) }\end{array}$ & $\begin{array}{l}\text { Deciduous Forest } \% \\
\text { Fragmented / Contiguous }\end{array}$ & $\mathrm{N} / \mathrm{S}$ \\
\hline & $\begin{array}{r}\text { (Habitat type and type of } \\
\text { connectivity) }\end{array}$ & $\begin{array}{l}\text { Oak Woodland } \\
\text { Fragmented / Contiguous }\end{array}$ & $\mathrm{N} / \mathrm{S}$ \\
\hline & Maximum canopy gap (trees) & Meters & $\mathrm{N} / \mathrm{S}$ \\
\hline & $\begin{array}{l}\text { Riparian area/Woody species } \\
\text { along stream (if present) }\end{array}$ & $\begin{array}{r}\text { Yes } / \text { No } \\
\% \text { cover } \\
\end{array}$ & $\begin{array}{l}0-4 \% \text { riparian: } 0 \\
5-24 \% \text { riparian: } 1 \\
25-49 \% \text { riparian: } 2 \\
>50 \% \text { riparian: } 3 \\
\end{array}$ \\
\hline & $\begin{array}{l}\text { Of the trees present, estimate } \\
\text { the proportion of specific tree }\end{array}$ & $\begin{array}{c}\text { Douglas fir } \\
\%\end{array}$ & $\begin{array}{l}\text { Deciduous species: } \\
\text { If }>10 \%\end{array}$ \\
\hline
\end{tabular}




\begin{tabular}{|c|c|c|c|c|c|}
\hline & $\begin{array}{l}\text { species and estimated tree age } \\
\text { composing the canopy }\end{array}$ & 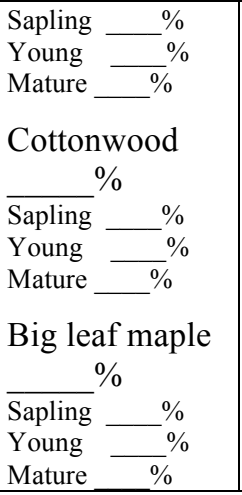 & 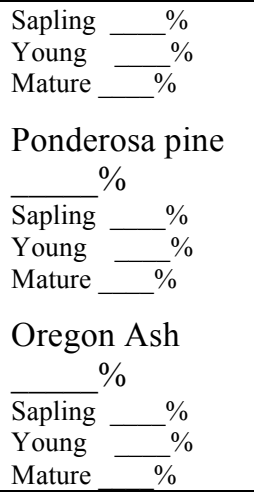 & 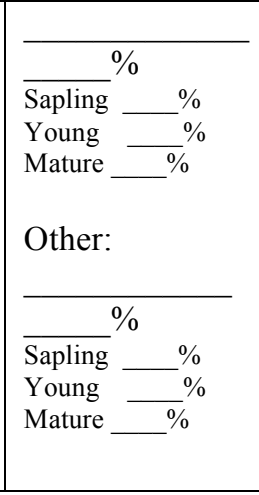 & $\begin{array}{l}\text { Sapling \& young: } 3 \\
\text { Mature: } 2 \\
\text { (Aspen, alder, birch, cottonwood) }\end{array}$ \\
\hline & $\begin{array}{l}\text { Overall structural diversity of } \\
\text { vegetation }\end{array}$ & $\begin{array}{l}\text { No vegetation } \\
\text { Few or one layer } \\
\text { Two layers prese } \\
\text { Most canopy lay } \\
\text { Well defined mu }\end{array}$ & $\begin{array}{l}\text { nt } \\
\text { ers present } \\
\text { Iti-storied canopy }\end{array}$ & & $\mathrm{N} / \mathrm{S}$ \\
\hline & $\begin{array}{r}\text { (Habitat type and type of } \\
\text { connectivity) }\end{array}$ & $\begin{array}{l}\text { Shrubs } \angle \% \\
\text { Fragmented / }\end{array}$ & Contiguous & & $\mathrm{N} / \mathrm{S}$ \\
\hline & $\begin{array}{l}\text { Native shrub layer percent } \\
\text { cover (includes willow) }\end{array}$ & $\begin{array}{l}\text { \% cover estimate } \\
0-5 \% \quad 5-25 \% \\
\text { Species: } \\
\text { Willow } \\
\text { Dogwood } \\
\text { Oregon Grape }\end{array}$ & $\begin{array}{l}\text { of native shrubs } \\
25-50 \% \\
\text { Vine Maple } \\
\text { Indian Plumb } \\
\text { Douglas Spirea }\end{array}$ & $\begin{array}{l}\text { D\% } 75-100 \% \\
\text { Native rose } \\
\text { Pacific ninebark } \\
\text { Mock Orange }\end{array}$ & $\begin{array}{l}0-5 \%: 1 \\
5-25 \%: 2 \\
25-50 \%: 3 \\
50-75 \%: 2 \\
>75 \%: 1 \\
\text { Willow }=3\end{array}$ \\
\hline & $\begin{array}{l}\text { Presence and abundance of } \\
\text { native nectaring (flowering) } \\
\text { shrub species }\end{array}$ & $\begin{array}{l}\text { \% cover nectarin } \\
0-5 \% \quad 5-25 \% \\
\text { Species: } \\
\text { Salmon berry } \\
\text { Snowberry } \\
\text { Oregon Grape }\end{array}$ & $\begin{array}{l}\text { g shrub species } \\
25-50 \% \\
\text { Native rose } \\
\text { Pacific ninebark } \\
\text { Douglas Spirea }\end{array}$ & $\begin{array}{l}\text { Mock Orange } \\
\text { Dogwood } \\
\text { Thimbleberry }\end{array}$ & $\mathrm{N} / \mathrm{S}$ \\
\hline & Percent non-native vegetation & $\begin{array}{l}\% \text { cover non-nat } \\
0-5 \% \quad 5-25 \% \\
\text { Species: } \\
\text { Blackberry, Reec }\end{array}$ & $\begin{array}{l}\text { ve vegetation } \\
25-50 \% \\
\text { Canary Grass, Hc }\end{array}$ & $\begin{array}{l}5 \%-100 \% \\
11 \mathrm{y}, \text { English Ivy }\end{array}$ & $\begin{array}{l}>25 \%: 1 \\
5-25 \%: 2 \\
0-5 \%: 3\end{array}$ \\
\hline & $\begin{array}{r}\text { (Habitat type and type of } \\
\text { connectivity) }\end{array}$ & $\begin{array}{l}\text { Grassland } \% \\
\text { Fragmented / }\end{array}$ & Contiguous & & $\mathrm{N} / \mathrm{S}$ \\
\hline & $\begin{array}{l}\text { Top 1-2 dominant herbaceous } \\
\text { species }\end{array}$ & $\begin{array}{l}\text { Species: } \\
\text { If unable to see o } \\
\text { Terrestrial: Unde } \\
\text { Combination (pa } \\
\text { Aquatic: Emerge }\end{array}$ & $\begin{array}{l}\text { r ID positively des } \\
\text { rstory (shaded), } \\
\text { rt sun) } \\
\text { nt, submerged }\end{array}$ & $\begin{array}{l}\text { cribe the setting: } \\
\text { en (full sun), }\end{array}$ & $\mathrm{N} / \mathrm{S}$ \\
\hline & $\begin{array}{r}\text { Maximum ground cover gap } \\
\text { (no veg) }\end{array}$ & $\begin{array}{c}\text { Meters } \\
\text { Gap of type: Ope }\end{array}$ & n water Develop & ed Bare ground & $\begin{array}{l}\text { Open water }=3 \\
\text { Bare ground }=2 \\
>15 \mathrm{~m}=1 \\
5-15 \mathrm{~m}=2 \\
<5 \mathrm{~m}=3 \\
\text { Developed }=1 \\
>5 \mathrm{~m}=0 \\
2-5 \mathrm{~m}=1 \\
<2 \mathrm{~m}=3\end{array}$ \\
\hline $\begin{array}{l}\text { Other } \\
\text { structural } \\
\text { components }\end{array}$ & Downed wood & $\begin{array}{l}\text { Logs } \\
\text { High density } \\
\text { Medium density } \\
\text { Low density } \\
\text { None }\end{array}$ & $\begin{array}{l}\text { Branches } \\
\text { High density } \\
\text { Medium } \\
\text { density } \\
\text { Low density } \\
\text { None }\end{array}$ & $\begin{array}{l}\text { Rootwad/Stumps } \\
\text { High density } \\
\text { Medium density } \\
\text { Low density } \\
\text { None }\end{array}$ & $\mathrm{N} / \mathrm{S}$ \\
\hline
\end{tabular}




\begin{tabular}{|c|c|c|c|}
\hline & Snags & $\begin{array}{l}\text { Yes / No } \\
\text { Ifyes describe (abundance, height and dbh species } \\
\text { and grade of decay where possible) }\end{array}$ & $\mathrm{N} / \mathrm{S}$ \\
\hline & $\begin{array}{l}\text { Talus slopes/rock piles } \\
\text { (reptiles) }\end{array}$ & $\begin{array}{l}\text { Yes / No / Not visible } \\
\text { If yes, in flooded area? Yes/No } \\
\text { If yes, receiving sun/percent cover above? }\end{array}$ & $\mathrm{N} / \mathrm{S}$ \\
\hline & Duff layer/Thatch & $\begin{array}{l}\text { None } \\
<10 \mathrm{~cm} \text { partially decomposed } \\
>10 \mathrm{~cm} \text { partially decomposed }\end{array}$ & $\mathrm{N} / \mathrm{S}$ \\
\hline $\begin{array}{l}\text { Wildlife } \\
\text { observations }\end{array}$ & $\begin{array}{l}\text { Wildlife sign and observations } \\
\text { in the field } \\
\text { (tracks, droppings burrows, etc.) }\end{array}$ & List species \& associated sign: & $\begin{array}{l}\text { If Beaver: } 3 \text { (nutria: } 2 \text { ) } \\
\text { Any } 1 \\
\text { None } 0\end{array}$ \\
\hline \multirow[t]{3}{*}{$\begin{array}{l}\text { Human } \\
\text { disturbance }\end{array}$} & $\begin{array}{l}\text { Use by pets or domestic } \\
\text { animals }\end{array}$ & $\begin{array}{l}\text { Describe and rate intensity: } \\
\text { No evidence, Some evidence, } \\
\text { Regular use apparent } \\
\text { Describe: }\end{array}$ & $\begin{array}{l}\text { Regular: } 0 \\
\text { Some: } 1 \\
\text { None: } 3\end{array}$ \\
\hline & $\begin{array}{l}\text { Trails/other evidence of } \\
\text { regular human } \\
\text { presence/activity }\end{array}$ & $\begin{array}{l}\text { Describe and rate intensity of trail use: } \\
\text { No evidence, Some evidence, } \\
\text { Regular use apparent } \\
\text { Describe: }\end{array}$ & $\begin{array}{l}\text { Regular: } 0 \\
\text { Some: } 2 \\
\text { None: } 3\end{array}$ \\
\hline & $\begin{array}{l}\text { Specific activities that may } \\
\text { influence wildlife movements } \\
\text { (attraction to refuse, avoidance of } \\
\text { industrial activities and noise) }\end{array}$ & $\begin{array}{l}\text { Describe and rate intensity of human activity: } \\
\text { Zero Low Medium High } \\
\text { Describe: }\end{array}$ & $\begin{array}{l}\text { High: } 0 \\
\text { Med: } 1 \\
\text { Low: } 2 \\
\text { Zero: } 3\end{array}$ \\
\hline
\end{tabular}




\begin{tabular}{|c|c|c|c|}
\hline \multicolumn{4}{|c|}{ Habitat Scoring Rubric for the Red Legged Frog **DRAFT VERSION** } \\
\hline & Characteristic & $\begin{array}{l}\text { Field data category options (to be verified [GIS data] } \\
\text { and measured [field data] by technicians on site) }\end{array}$ & Scoring Values \\
\hline \multirow[t]{6}{*}{$\begin{array}{l}\text { Connectivity } \\
\text { patch and } \\
\text { matrix } \\
\text { characteristics }\end{array}$} & Land Ownership/Zoning & (marked on accompanying aerial photo) & $\begin{array}{l}\text { Not scored for present } \\
\text { connectivity value but } \\
\text { important to prioritizing and } \\
\text { for assessing future condition }\end{array}$ \\
\hline & Dominant matrix type (GIS) & $\begin{array}{l}\text { Agriculture } \% \\
\text { Developed \% }\end{array}$ & $\begin{array}{l}\mathrm{Ag}=2 \\
\mathrm{Dev}=1\end{array}$ \\
\hline & $\begin{array}{l}\text { Dominate matrix type } \\
\text { (FIELD) }\end{array}$ & $\begin{array}{l}\text { Agriculture type } \\
\text { (low crop, orchard, corn etc.) } \\
\text { Developed type } \\
\text { (residential, commercial, industrial) }\end{array}$ & $\begin{array}{l}\text { Ag type: } \\
\text { Orchard - } 2 \\
\text { Other - } 1 \\
\text { Dev type: } \\
\text { Residential - } 1 \\
\text { Commercial - } 0 \\
\text { Industrial - } 0\end{array}$ \\
\hline & $\begin{array}{l}\text { Minimum width of non- } \\
\text { developed connectivity zone }\end{array}$ & Meters & $\begin{array}{l}<15 \mathrm{~m}: 1 \\
15-50 \mathrm{~m}: 2 \\
>50 \mathrm{~m}: 3\end{array}$ \\
\hline & $\begin{array}{l}\text { \% Hardscaping (roads, parking } \\
\text { lots etc. does not include structures) }\end{array}$ & $\begin{array}{l}\text { Hardscaping (impervious, not including structures) } \\
\quad \%\end{array}$ & $\begin{array}{l}>50 \%: 0 \\
25-50 \%: 1 \\
10-25 \%: 2 \\
<10 \%: 3\end{array}$ \\
\hline & $\%$ Structures & $\begin{array}{c}\text { Structures } \\
\%\end{array}$ & $\begin{array}{l}>50 \%: 0 \\
25-50 \%: 1 \\
10-20 \%: 2 \\
<10 \%: 3\end{array}$ \\
\hline \multirow[t]{5}{*}{ Water source } & $\begin{array}{l}\text { Water source within } \\
\text { connectivity zone }\end{array}$ & $\begin{array}{l}\text { Yes / No } \\
\text { Type: stream pond }\end{array}$ & $\begin{array}{l}\text { Yes: } 3 \\
\text { No: } 1\end{array}$ \\
\hline & $\begin{array}{r}\text { (Habitat type and type of } \\
\text { connectivity) }\end{array}$ & Fragmented $/ \stackrel{\%}{\text { Contiguous }}$ & $\begin{array}{l}0-10 \%: 1 \\
10-50 \%: 3 \\
50-75 \%: 2 \\
>75 \% 1\end{array}$ \\
\hline & $\begin{array}{r}\text { Distance of corridor } \\
\text { edge from water }\end{array}$ & $\begin{array}{l}\text { If answer to water source is no then report distance to } \\
\text { water here: } \quad \text { Meters }\end{array}$ & $\begin{array}{l}\text { If }>300 \mathrm{m:}: 1 \\
50-299 \mathrm{m:} 2 \\
\text { If }<50 \mathrm{m:}: 3\end{array}$ \\
\hline & Seasonality & Ephemeral Intermittent Perennial & $\begin{array}{l}\text { Perennial: } 1 \\
\text { Intermittent: } 2 \\
\text { Ephemeral: } 3\end{array}$ \\
\hline & Channel stability (streams) & Incised $\quad$ Straight $\quad$ Meandering & $\mathrm{n} / \mathrm{s}$ \\
\hline \multirow[t]{6}{*}{ Vegetation } & $\begin{array}{r}\text { (Habitat type and type of } \\
\text { connectivity) }\end{array}$ & $\begin{array}{lc}\text { Conifer Forest } & \% \\
\text { Fragmented } & / \\
\text { Contiguous }\end{array}$ & $\begin{array}{l}0-10 \%: 0 \\
10-50 \%: 1 \\
50-75 \%: 2 \\
75-90 \% 3 \\
>90 \%: 2\end{array}$ \\
\hline & $\begin{array}{r}\text { (Habitat type and type of } \\
\text { connectivity) }\end{array}$ & $\begin{array}{l}\text { Deciduous Forest } \% \% \\
\text { Fragmented / Contiguous }\end{array}$ & $\begin{array}{l}0-10 \%: 0 \\
10-50 \%: 1 \\
50-75 \%: 2 \\
75-90 \% 3 \\
>90 \%: 2 \\
\end{array}$ \\
\hline & $\begin{array}{r}\text { (Habitat type and type of } \\
\text { connectivity) }\end{array}$ & $\begin{array}{l}\text { Oak Woodland } \% \\
\text { Fragmented } / \text { Contiguous }\end{array}$ & $\begin{array}{l}0-10 \%: 0 \\
10-50 \%: 1 \\
50-75 \%: 2 \\
75-90 \% 3 \\
>90 \%: 2 \\
\end{array}$ \\
\hline & Maximum canopy gap (trees) & Meters & $\mathrm{n} / \mathrm{s}$ \\
\hline & $\begin{array}{l}\text { Riparian area/Woody species } \\
\text { along stream (if present) }\end{array}$ & $\begin{aligned} \text { Yes } / \text { No } \\
\\
\quad \% \text { cover }\end{aligned}$ & $\begin{array}{l}\text { None: } 0 \\
1-10 \% \text { riparian: } 1 \\
11-40 \% \text { riparian: } 2 \\
>40 \% \text { riparian: } 3 \\
\end{array}$ \\
\hline & $\begin{array}{l}\text { Of the trees present, estimate } \\
\text { the proportion of specific tree }\end{array}$ & $\begin{array}{c}\text { Douglas fir } \\
\%\end{array}$ & $\mathrm{n} / \mathrm{s}$ \\
\hline
\end{tabular}




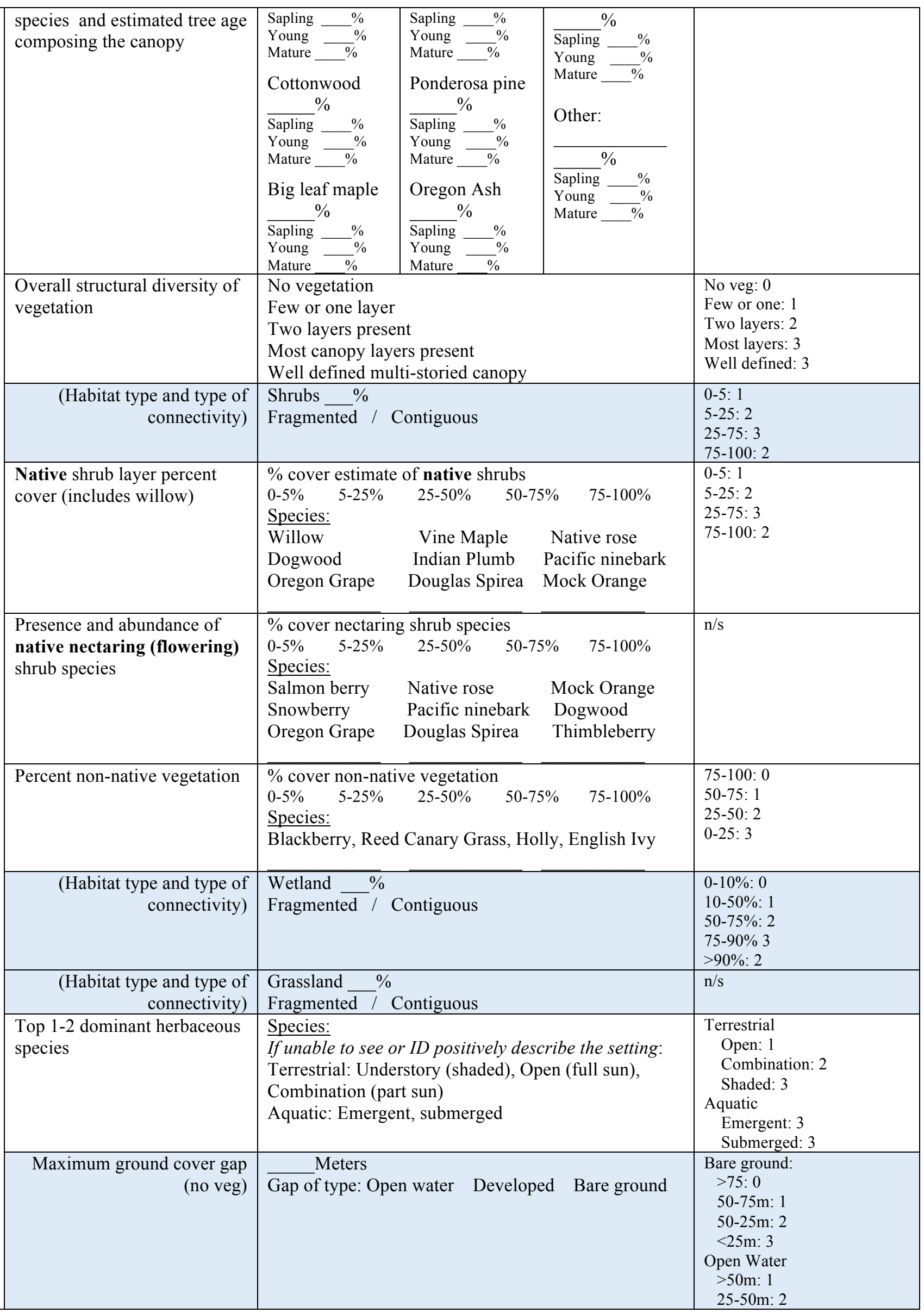




\begin{tabular}{|c|c|c|c|c|c|}
\hline & & & & & $\begin{array}{l}<25 \mathrm{~m}: 3 \\
\text { Developed: } \\
>35 \mathrm{~m}: 0 \\
35-15 \mathrm{~m}: 1 \\
14-5 \mathrm{~m}: 2 \\
<5 \mathrm{~m}: 3\end{array}$ \\
\hline \multirow[t]{4}{*}{$\begin{array}{l}\text { Other } \\
\text { structural } \\
\text { components }\end{array}$} & Downed wood & $\begin{array}{l}\text { Logs } \\
\text { High density } \\
\text { Medium density } \\
\text { Low density } \\
\text { None }\end{array}$ & $\begin{array}{l}\text { Branches } \\
\text { High density } \\
\text { Medium } \\
\text { density } \\
\text { Low density } \\
\text { None }\end{array}$ & $\begin{array}{l}\text { Rootwad/Stumps } \\
\text { High density } \\
\text { Medium density } \\
\text { Low density } \\
\text { None }\end{array}$ & $\mathrm{n} / \mathrm{s}$ \\
\hline & Snags & \multicolumn{3}{|c|}{$\begin{array}{l}\text { Yes / No } \\
\text { If yes describe (abundance, height and dbh species } \\
\text { and grade of decay where possible) }\end{array}$} & $\mathrm{n} / \mathrm{s}$ \\
\hline & $\begin{array}{l}\text { Talus slopes/rock piles } \\
\text { (reptiles) }\end{array}$ & \multicolumn{3}{|c|}{$\begin{array}{l}\text { Yes / No / Not visible } \\
\text { If yes, in flooded area? Yes/No } \\
\text { If yes, receiving sun/percent cover above? }\end{array}$} & $\mathrm{n} / \mathrm{s}$ \\
\hline & Duff layer/Thatch & \multicolumn{3}{|c|}{$\begin{array}{l}\text { None } \\
<10 \mathrm{~cm} \text { partially decomposed } \\
>10 \mathrm{~cm} \text { partially decomposed }\end{array}$} & $\begin{array}{l}\text { None: } 0 \\
<10 \mathrm{~cm}: 1 \\
>10 \mathrm{~cm}: 3\end{array}$ \\
\hline $\begin{array}{l}\text { Wildlife } \\
\text { observations }\end{array}$ & $\begin{array}{l}\text { Wildlife sign and observations } \\
\text { in the field } \\
\text { (tracks, droppings burrows, etc.) }\end{array}$ & \multicolumn{3}{|c|}{ List species \& associated sign: } & $\begin{array}{l}\text { If Red Legged Frog: } 3 \\
\text { Any } 1 \\
\text { None } 0\end{array}$ \\
\hline \multirow[t]{3}{*}{$\begin{array}{l}\text { Human } \\
\text { disturbance }\end{array}$} & $\begin{array}{l}\text { Use by pets or domestic } \\
\text { animals }\end{array}$ & \multicolumn{3}{|c|}{$\begin{array}{l}\text { Describe and rate intensity: } \\
\text { No evidence, Some evidence, } \\
\text { Regular use apparent } \\
\text { Describe: }\end{array}$} & $\begin{array}{l}\text { Heavy: } 0 \\
\text { Regular: } 1 \\
\text { Some: } 2 \\
\text { None: } 3\end{array}$ \\
\hline & $\begin{array}{l}\text { Trails/other evidence of } \\
\text { regular human } \\
\text { presence/activity }\end{array}$ & \multicolumn{3}{|c|}{$\begin{array}{l}\text { Describe and rate intensity of trail use: } \\
\text { No evidence, Some evidence, } \\
\text { Regular use apparent } \\
\text { Describe: }\end{array}$} & $\begin{array}{l}\text { Heavy: } 1 \\
\text { Regular: } 2 \\
\text { Some: } 3 \\
\text { None: } 3\end{array}$ \\
\hline & $\begin{array}{l}\text { Specific activities that may } \\
\text { influence wildlife movements } \\
\text { (attraction to refuse, avoidance of } \\
\text { industrial activities) }\end{array}$ & \multicolumn{3}{|c|}{$\begin{array}{l}\text { Describe and rate intensity of human activity: } \\
\text { Zero Low Medium High } \\
\text { Describe: }\end{array}$} & $\begin{array}{l}\text { High: } 0 \\
\text { Med: } 1 \\
\text { Low: } 2 \\
\text { Zero: } 3\end{array}$ \\
\hline
\end{tabular}




\section{Scoring Rubric for the Western Painted Turtle $\quad * *$ DRAFT VERSION $* * *$}

After the GIS and field assessment has been completed for a given corridor, these data can be post processed to determine the connectivity value for a given (or multiple) surrogate species. Corridor scoring data will be entered into a database, then queried for surrogate species specific conditions. Each field data category is assigned a value (range 1-3, with 1 suggesting an animal might pass but the zone does not offer favorable conditions for passage; 3 indicates positive conditions for connectivity) depending on the movement and habitat needs of the given surrogate species. If all field data category options are of equal importance the scoring values do not differ (for example the Characteristic of "Connectivity Type"). When a selected scoring value is zero (see "Freeways" in Road Type) it is indicative of a field condition that poses a complete or near complete barrier to the movement ability of that species. Any zero values selected in field assessments are considered individually post scoring to determine if management techniques or mitigation can correct the barrier effect. Other categories such as the presence of high value and endangered plants are not species or habitat specific but increase the value of a given corridor. Shaded cells indicate data provided by GIS analysis.

\begin{tabular}{|c|c|c|c|}
\hline & Characteristic & $\begin{array}{l}\text { Field data category options (to be verified [GIS } \\
\text { data] and measured [field data] by technicians on } \\
\text { site) }\end{array}$ & $\begin{array}{l}\text { Turtle Database Scoring } \\
\text { Values } \\
\text { (to be queried from } \\
\text { database of previously } \\
\text { assessed corridors) } \\
\end{array}$ \\
\hline \multirow[t]{9}{*}{$\begin{array}{l}\text { Connectivity } \\
\text { patch and } \\
\text { matrix } \\
\text { characteristics }\end{array}$} & Surrounding Land Ownership & (marked on accompanying aerial photo) & $\begin{array}{l}\text { Not scored for present } \\
\text { connectivity value but } \\
\text { important to prioritizing } \\
\text { and for assessing future } \\
\text { condition }\end{array}$ \\
\hline & $\begin{array}{l}\text { Habitat type and type of } \\
\text { connectivity } \\
\text { (view on map): for each habitat } \\
\text { classification indicate \% of that type in area } \\
\text { surveyed and the type of connection of that } \\
\text { habitat. For potential connection and each } \\
\text { habitat type, circle one of Stepping stones } \\
\text { (more matrix habitat than habitat }\end{array}$ & $\begin{array}{l}\text { Forested __\% Stepping stones, Corridor } \\
\text { Wetland } \% \text { Stepping stones, Corridor } \\
\text { Oak _ } \% \text { Stepping stones, Corridor } \\
\text { Grassland __ } \% \text { Stepping stones, Corridor } \\
\text { Open water_ \% Stepping stones, Corridor }\end{array}$ & $\begin{array}{l}\text { Use highest score for } \\
\text { Wetland or Open water for } \\
\text { turtle; other two habitats } \\
\text { don't affect score: } \\
\text { Wetland } 0 \% \text { : } 0\end{array}$ \\
\hline & $\begin{array}{l}\text { classification type in } 50 \mathrm{~m} \text { band with highest } \\
\text { amount of that habitat class); Corridor } \\
\text { (continuous, though perhaps narrow, habitat } \\
\text { of that habitat type); }\end{array}$ & Shrubs__ \% Stepping stones, Corridor & $\begin{array}{l}\text { Wetland 5-20\%: } \\
\text { Stepping stone: } 1 \\
\text { Corridor: } 1.5\end{array}$ \\
\hline & & & $\begin{array}{l}\text { Wetland }>\mathbf{2 0} \% \text { : } \\
\text { Stepping stone: } 2.5 \\
\text { Corridor: } 3\end{array}$ \\
\hline & & & $\begin{array}{l}\text { Open water } \mathbf{0 \%}: 0 \\
\text { Open water 1-10\% } \\
\text { Stepping: } 1 \\
\text { Corridor: } 1.5\end{array}$ \\
\hline & & & $\begin{array}{l}\text { Open water }>\mathbf{1 0} \% \\
\text { Stepping stone: } \\
10 \%-49 \% 2 \\
>50 \%=2 \\
\text { Corridor: } 10 \%-49 \% 3 \\
>50 \%=3\end{array}$ \\
\hline & Dominant matrix type & $\begin{array}{l}\text { Forest, Wetland, Oak, Grassland, Agriculture, } \\
\text { Developed, } \\
\text { Other (Low veg, tree cover, water) } \\
\text { Agriculture } \% \\
\text { Developed } \%\end{array}$ & $\begin{array}{l}\text { Wetland: } 3 \\
\text { Forest: } 2.5 \\
\text { Oak: } 2.5 \\
\text { Grassland: } 1.5 \\
\text { Agriculture (terr/aquat): } 1 / 1.5 \\
\text { Developed (Res/industrial): } 0\end{array}$ \\
\hline & Dominate matrix type & $\begin{array}{l}\text { Agriculture: type } \quad \text { (low crop, orchard, } \\
\text { corn, etc) } \\
\begin{array}{l}\text { Developed: type } \\
\text { commercial industrial) }\end{array} \text { (residential, }\end{array}$ & $\begin{array}{l}\text { Residential: } 1 \\
\text { Commercial: } 0 \\
\text { Industrial: } 0\end{array}$ \\
\hline & $\begin{array}{l}\text { Minimum width of non-developed } \\
\text { connectivity zone }\end{array}$ & Meters & $\begin{aligned} \text { 0 m: } 0 \\
\text { 1- } 15 \mathrm{~m}: 1\end{aligned}$ \\
\hline
\end{tabular}




\begin{tabular}{|c|c|c|c|c|}
\hline & & & & $\begin{array}{r}\text { 15-30 } \mathbf{~ m : ~} 2 \\
\text { 30-50 m: } 3 \\
>\mathbf{5 0} \mathbf{~ m}: 3\end{array}$ \\
\hline & $\begin{array}{l}\text { \%hardscaping (roads, parking lots } \\
\text { etc) }\end{array}$ & \multicolumn{2}{|c|}{$\begin{array}{l}\% \text { hardscaping (impervious, not including } \\
\text { structures) }\end{array}$} & $\begin{array}{l}>50 \% \text { hardscaping: } 0 \\
\mathbf{2 5 - 4 9 \%} \text { hardscaping: } 1 \\
\mathbf{1 0 - 2 0 \%} \text { hardscaping: } 2 \\
<\mathbf{1 0} \% \text { hardscaping: } 3\end{array}$ \\
\hline & \%structures & \multicolumn{2}{|l|}{ \%structures } & $\begin{array}{l}>50 \% \text { hardscaping: } 0 \\
\mathbf{2 5 - 4 9 \%} \text { structures: } 1 \\
10-20 \% \text { structures: } 2 \\
<\mathbf{1 0 \%} \text { structures: } 3\end{array}$ \\
\hline \multirow[t]{5}{*}{ Water source } & $\begin{array}{l}\text { Water source within connectivity } \\
\text { zone? Type }\end{array}$ & \multicolumn{2}{|l|}{ Yes/No, Type } & $\begin{array}{l}\text { Not scored for turtle } \\
\text { because this criteria is } \\
\text { already captured above } \\
\text { in the turtle scoring }\end{array}$ \\
\hline & & \multicolumn{2}{|c|}{$\begin{array}{l}\text { if answer to water source is no then: } \\
\text { Report distance to water here ___ meters }\end{array}$} & $\begin{array}{l}\text { If }>250 \mathrm{~m}: 0 \text { 100-250: } 1 \\
\mathbf{5 0}-\mathbf{1 0 0} \mathrm{m:}: 2 \\
\text { If }<50 \mathrm{~m}: 3\end{array}$ \\
\hline & Ponding frequency & \multicolumn{2}{|l|}{$\%$} & $\mathrm{~N} / \mathrm{A}$ \\
\hline & Seasonality & \multicolumn{2}{|l|}{$\begin{array}{l}\text { Ephemeral } \\
\text { Intermittent } \\
\text { Perennial }\end{array}$} & $\begin{array}{l}\text { Ephemeral: } 1 \\
\text { Intermittent: } 2 \\
\text { Perennial: } 3\end{array}$ \\
\hline & Channel stability & \multicolumn{2}{|l|}{$\begin{array}{l}\text { Incised } \\
\text { Straight } \\
\text { Meandering }\end{array}$} & $\begin{array}{l}\text { Not scored for turtle } \\
\text { because this criteria is } \\
\text { already captured above in } \\
\text { the turtle scoring }\end{array}$ \\
\hline \multirow[t]{8}{*}{ Vegetation } & Maximum canopy gap (trees) & Meters & & Not scored for turtle \\
\hline & $\begin{array}{l}\text { Maximum ground cover gap (no } \\
\text { veg) }\end{array}$ & Meters & $\begin{array}{l}\text { Gap of type: } \\
\text { Open water, developed, } \\
\text { bare ground }\end{array}$ & $\begin{array}{l}\text { If dev/bare ground: } \\
0 \mathrm{~m}: 3 \\
0-10 \mathrm{~m}: 2 \\
>10 \mathrm{~m}: 1\end{array}$ \\
\hline & $\begin{array}{l}\text { Riparian area/Woody species along } \\
\text { stream }\end{array}$ & \multicolumn{2}{|l|}{ Yes/No - \% cover } & $\begin{array}{l}0-4 \% \text { riparian: } 1 \\
5-24 \% \text { riparian: } 3 \\
25-49 \% \text { riparian: } 3 \\
>50 \% \text { riparian: } 1\end{array}$ \\
\hline & $\begin{array}{l}\text { Specific tree species and estimated } \\
\text { tree age composing the canopy }\end{array}$ & 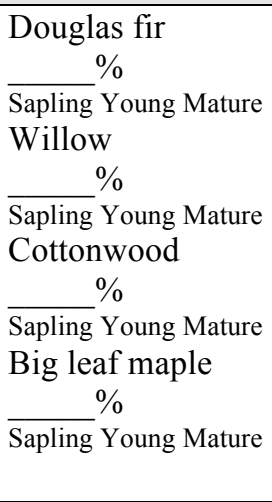 & 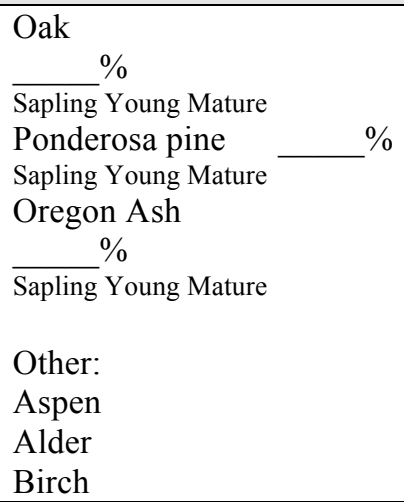 & $\mathbf{n} / \mathbf{s}$ \\
\hline & Canopy percent cover & \multicolumn{2}{|c|}{$\begin{array}{l}\text { \% cover estimate of canopy } \\
0-5 \% 5-25 \% 25-50 \% 50-75 \% 75-100 \%\end{array}$} & $\begin{array}{l}0-5 \%: 3 \\
6-25 \% ; 3 \\
26-50 \%: 2.5 \\
51-75 \%: 2 \\
76-90 \%: 1 \\
90-100 \%:: 0\end{array}$ \\
\hline & Native shrub layer percent cover & \multicolumn{2}{|c|}{$\begin{array}{l}\text { \% cover estimate of native shrubs } \\
0-5 \% 5-25 \% 25-50 \% 50-75 \% 75-100 \%\end{array}$} & $\mathrm{n} / \mathrm{s}$ \\
\hline & $\begin{array}{l}\text { Presence and abundance of native } \\
\text { flowering shrub species }\end{array}$ & \multicolumn{2}{|c|}{$\begin{array}{l}\text { \% cover flowering shrub species } \\
0-5 \% 5-25 \% 25-50 \% 50-75 \% 75-100 \%\end{array}$} & $\mathrm{n} / \mathrm{s}$ \\
\hline & Percent non-native vegetation & \multicolumn{2}{|c|}{$\begin{array}{l}\text { \% cover non-native vegetation } \\
0-5 \% 5-25 \% 25-50 \% 50-75 \% 75-100 \% \\
\text { Species: }\end{array}$} & \\
\hline
\end{tabular}




\begin{tabular}{|c|c|c|c|c|c|}
\hline & $\begin{array}{l}\text { Overall structural diversity of } \\
\text { vegetation }\end{array}$ & \multicolumn{3}{|c|}{$\begin{array}{l}\text { No vegetation } \\
\text { Few or one layer } \\
\text { Most canopy layers present } \\
\text { Well defined multi-storied canopy }\end{array}$} & $\begin{array}{l}\text { No Veg: } 3 \\
1-2 \text { (few):2 } \\
3 \text { (most): } 1 \\
4 \text { (well): } 0.5\end{array}$ \\
\hline & Top 1-2 dominant veg species & \multicolumn{3}{|c|}{$\begin{array}{l}\text { Type } \quad \text { Species } \\
\text { Herbaceous: } \\
\text { Shrub: } \\
\text { Tree: }\end{array}$} & $\mathrm{n} / \mathrm{s}$ \\
\hline \multirow[t]{4}{*}{$\begin{array}{l}\text { Other } \\
\text { structural } \\
\text { components }\end{array}$} & Downed wood & $\begin{array}{l}\frac{\text { Logs }}{\text { High density }} \\
\text { Medium } \\
\text { density } \\
\text { Low density } \\
\text { None }\end{array}$ & $\begin{array}{l}\text { Branches } \\
\text { High density } \\
\text { Medium } \\
\text { density } \\
\text { Low density } \\
\text { None }\end{array}$ & $\begin{array}{l}\text { Rootwads/Stumps } \\
\text { High density } \\
\text { Medium density } \\
\text { Low density } \\
\text { None }\end{array}$ & $\begin{array}{l}\text { Logs: } \\
\text { None: } 0 \text { low: } 1 \mathrm{Med}: 3 \\
\text { High:3 } \\
\text { Branches: } \\
\text { None: } 0 \text { low: } 1 \text { Med:3 } \\
\text { High:3 } \\
\text { Rootwads/Stumps: } \\
\text { None: } 0 \text { low: } 1 \text { Med:2 } \\
\text { High:3 }\end{array}$ \\
\hline & Snags & \multicolumn{3}{|c|}{$\begin{array}{l}\text { Yes/No } \\
\text { If yes describe (abundance, height and dbh, } \\
\text { species, grade of decay where possible) }\end{array}$} & $\mathrm{n} / \mathrm{s}$ \\
\hline & Talus slopes/rock piles (reptiles) & \multicolumn{3}{|c|}{$\begin{array}{l}\text { Yes/No } \\
\text { If yes, in flooded area? Yes/No } \\
\text { If yes, receiving sun/percent cover above? }\end{array}$} & $\begin{array}{l}\text { Talus Slopes } \\
\text { Yes w/ sun:3 } \\
\text { Yes w/o sun: } 1 \\
\text { No: } 1\end{array}$ \\
\hline & Duff layer/Thatch & \multicolumn{3}{|c|}{$\begin{array}{l}\text { None } \\
<10 \mathrm{~cm} \text { partially decomposed } \\
>10 \mathrm{~cm} \text { partially decomposed }\end{array}$} & $\mathrm{n} / \mathrm{s}$ \\
\hline $\begin{array}{l}\text { Wildlife } \\
\text { observations }\end{array}$ & $\begin{array}{l}\text { Wildlifesign and observations in } \\
\text { the field(tracks, droppings etc.) }\end{array}$ & \multicolumn{3}{|c|}{ List species\& associated sign } & $\begin{array}{l}\text { If turtle } 3 \\
\text { Other than pred } 1 \\
\text { None/pred } 0 \\
\text { Pred=coyote, raccoon etc }\end{array}$ \\
\hline \multirow[t]{3}{*}{$\begin{array}{l}\text { Human } \\
\text { disturbance }\end{array}$} & Use by pets/domestic animals & \multicolumn{3}{|c|}{$\begin{array}{l}\text { Describe and rate intensity: } \\
\text { No evidence } \\
\text { Some evidence } \\
\text { Regular use apparent }\end{array}$} & $\begin{array}{l}\text { Regular: } 0 \\
\text { Some: } 0 \\
\text { None: } 3\end{array}$ \\
\hline & $\begin{array}{l}\text { Trails/other evidence of regular } \\
\text { human presence/activity }\end{array}$ & \multicolumn{3}{|c|}{$\begin{array}{l}\text { Describe and rate intensity of trail use: } \\
\text { No evidence, Some evidence } \\
\text { Regular use apparent }\end{array}$} & $\begin{array}{l}\text { Regular: } 1 \\
\text { Some: }{ }^{1}- \\
\text { None: } 3\end{array}$ \\
\hline & $\begin{array}{l}\text { Specific activities that may } \\
\text { influence wildlife movements } \\
\text { (attraction to refuse, avoidance of } \\
\text { industrial activities) }\end{array}$ & \multicolumn{3}{|c|}{$\begin{array}{l}\text { Describe and rate intensity of human activity: } \\
\text { Zero } \\
\text { Low } \\
\text { Medium } \\
\text { High }\end{array}$} & $\begin{array}{l}\text { High: } 1 \\
\text { Med: } 1 \\
\text { Low: } 2 \\
\text { Zero: } 3 \\
* * \text { if intermittent** }\end{array}$ \\
\hline
\end{tabular}




\section{American Beaver Permeability Assessment Species Scoring Form \\ Species Beaver **DRAFT VERSION**}

Site name/intersection/coordinates:

Attached photos:

Pre assessment GIS Information:

\begin{tabular}{|l|r|l|}
\hline Road & (if yes, road type) & Score \\
& Freeway & 0 \\
& Highway & 0 \\
& Arterial & 1 \\
& Residential & 2 \\
& Other: & \\
\hline Estimated Traffic & Low $(<500)$ & 2 \\
Volume (AADT or & Moderate $(500-5,000)$ & 2 \\
ADT)_High $(5,000-10,000)$ & 1 \\
& Very high $(10,000-35,000)$ & 0 \\
Existing culvert & Extreme $(>35,000)$ & 0 \\
\hline (if yes, culvert type) & \\
Box & 2 \\
& Bridged & 3 \\
& Pipe & 2 \\
\hline
\end{tabular}

Feature(s):

Road/Railroad/Trail

Culvert/Bridge

Fence

Road/Railroad/Trail details:

\begin{tabular}{|c|c|c|c|c|c|}
\hline $\begin{array}{r}\text { Type: } \\
\text { None } \\
\text { Highway } \\
\text { Local } \\
\text { County } \\
\text { Gravel } \\
\text { Dirt } \\
\text { Railroad } \\
\text { Trail } \\
\text { Estimated } \\
\text { Traffic } \\
\text { volume } \\
\mathrm{L} \\
\mathrm{M} \\
\mathrm{H}\end{array}$ & $\begin{array}{l}\text { Score } \\
3 \\
0 \\
2 \\
1 \\
3 \\
3 \\
2 \\
3\end{array}$ & $\begin{array}{r}\text { Total \# lanes } \\
\text { or sets of } \\
\text { tracks: } \\
1 \\
2 \\
3 \\
4+ \\
\\
\text { Posted Speed } \\
\text { limit (roads): } \\
0-25 \\
30-45 \\
55+ \\
\\
\text { Estimated } \\
\text { line of sight } \\
\text { distance for }\end{array}$ & $\begin{array}{l}2 \\
1 \\
0 \\
<40 \mathrm{ft} 0 \\
40-120 \mathrm{ft}=1 \\
121-220 \mathrm{ft}= \\
2\end{array}$ & $\begin{array}{l}\text { Roadkill: } \\
\text { Lighting: } \\
\text { Species } \\
\text { lights } \\
\text { ambient } \\
\text { ambient } \\
\text { ambient }\end{array}$ & $\begin{array}{l}\text { Score } \\
(\mathrm{n} / \mathrm{s})\end{array}$ \\
\hline
\end{tabular}




\begin{tabular}{|l|l|l|l|l|l|}
\hline & $\begin{array}{l}\text { drivers/oper } \\
\text { ators }\end{array}$ & $>221 \mathrm{ft}=3$ & & \\
\hline
\end{tabular}

Road/Railroad/Trail details Continued:

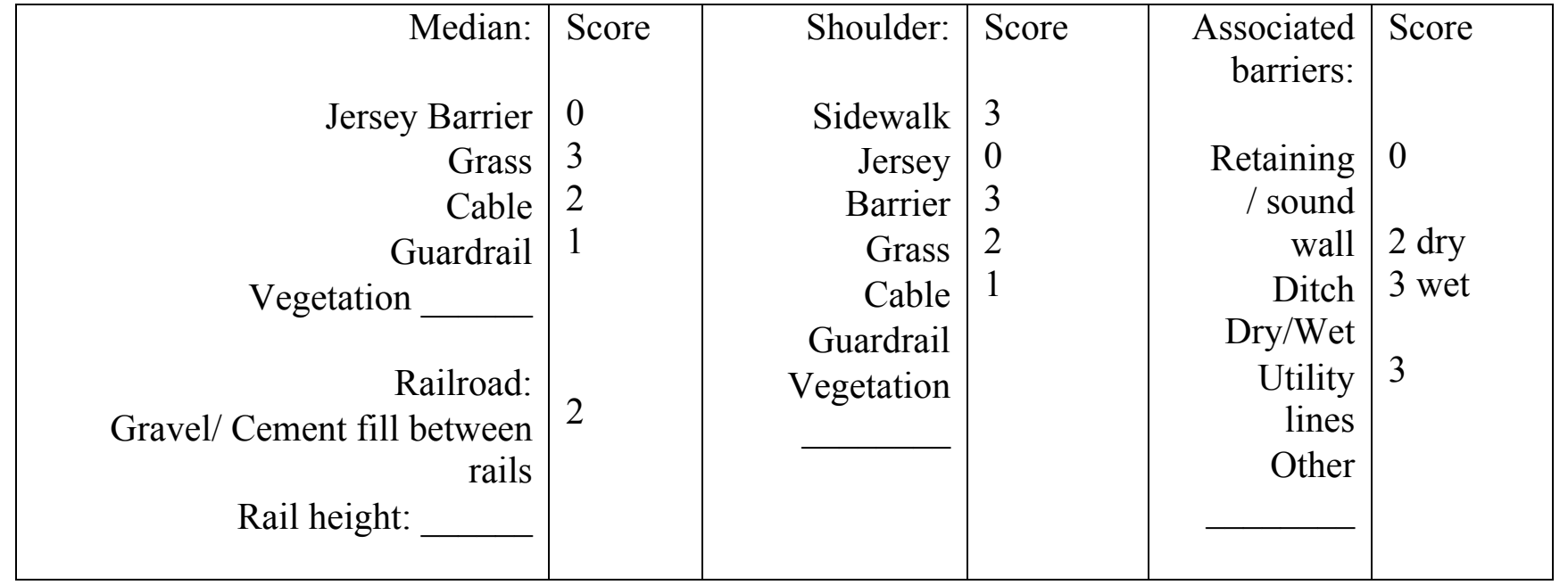

Fence details:

\begin{tabular}{|l|l|l|l|l|l|}
\hline Type: & Score & Body: & Score & Top Wire: & Score \\
None & 3 & Metal & $(\mathrm{n} / \mathrm{s})$ & Metal & $(\mathrm{n} / \mathrm{s})$ \\
Chain link & 0 & Welded wire & & Welded wire & \\
Strand & 2 & Barbed wire & & Barbed wire & \\
Mesh & 0 & Wood & & Razor wire & \\
Strand/mesh & 0 & Plastic & & Wood & \\
Rail & 2 & Mix & & Plastic & \\
Plank & 2 & Other: & & Mix & \\
Other: & & & & Other: & \\
& & & & & \\
\hline
\end{tabular}

Fence details continued:

\begin{tabular}{|l|l|l|l|l|l|}
\hline Purpose: & Score & $\begin{array}{l}\text { How fence } \\
\text { connects to } \\
\text { culvert/bridge: }\end{array}$ & Score & Continuation: & Score \\
Right of Way & & Attached & $\mathrm{n} / \mathrm{s}$ & None & 3 \\
Boundary & & Into & Brambles \\
Property & & Set back & & 0 \\
Boundary & & Parallel to & \\
Human Barrier & & associated & & Road & 1 \\
Livestock & & & Road except & \\
Barrier & & & accesses & 1 \\
Wildlife Barrier & & & Into Fill & 0 \\
Other: & & & Into Wall & \\
& & & Other: & \\
& & & & \\
\hline
\end{tabular}


Culvert details:

\begin{tabular}{|c|c|c|c|c|c|}
\hline Type: & Score & Size: & Score & Substrate: & Score \\
\hline None/not visible & \multirow{10}{*}{$\begin{array}{l}3 \\
(\mathrm{n} / \mathrm{s}) \\
(\mathrm{n} / \mathrm{s}) \\
\text { Single } 2 \\
\text { Double } 3 \\
(\mathrm{n} / \mathrm{s})\end{array}$} & \multirow{3}{*}{$\begin{array}{r}\text { Max } \\
\text { height }\end{array}$} & \multirow{5}{*}{$\begin{array}{l}>5 \mathrm{ft}=3 \\
3 \mathrm{ft} \text { to } 5 \mathrm{ft}=2 \\
2 \mathrm{ft}-3 \mathrm{ft}=1 \\
<2 \mathrm{ft}=0\end{array}$} & \multirow{10}{*}{$\begin{array}{r}\text { Dirt } \\
\text { Cobble } \\
\text { Gravel } \\
\text { Riprap } \\
\text { Gabion } \\
\text { Grate } \\
\text { Concrete } \\
\text { Asphalt } \\
\text { Mixed } \\
\text { Other: }\end{array}$} & \multirow{10}{*}{$\begin{array}{l}3 \\
3 \\
2 \\
1 \\
0 \\
1 \\
2 \\
2 \\
\text { Average of } \\
\text { above scores }\end{array}$} \\
\hline & & & & & \\
\hline Bridge & & & & & \\
\hline Concrete/Metal & & Min & & & \\
\hline other & & height & & & \\
\hline$\overline{\mathrm{Box} / \mathrm{Arch}}$ & & & & & \\
\hline other & & Length & $<75 \mathrm{ft}=3$ & & \\
\hline Single/Double & & (Across & $75 \mathrm{ft}-125 \mathrm{ft}=$ & & \\
\hline other $\quad$ span & & $\mathrm{Rd})$ & $>125 \mathrm{ft}=1$ & & \\
\hline $\begin{array}{r}\text { Open bottom } \\
\mathrm{Y} / \mathrm{N}\end{array}$ & & $\begin{array}{l}\text { Width } \\
\text { (Span) }\end{array}$ & $\begin{array}{l}<5 \mathrm{ft}=0 \\
5-10 \mathrm{ft}=1 \\
11-20 \mathrm{ft}=2 \\
>20 \mathrm{ft}=3\end{array}$ & & \\
\hline
\end{tabular}

Culvert details continued:

\begin{tabular}{|c|c|c|c|c|c|}
\hline $\begin{array}{r}\text { Human use: } \\
\text { None } \\
\text { Light } \\
\text { Moderate } \\
\text { Heavy } \\
\\
\text { Type of human } \\
\text { use: } \\
\text { Pedestrian } \\
\text { Bicycle } \\
\text { Motorized } \\
\text { Livestock } \\
\text { Camps } \\
\text { Other: }\end{array}$ & $\begin{array}{l}\text { Score } \\
3 \\
2 \\
2 \\
1\end{array}$ & $\begin{array}{r}\text { Dry } \\
\text { Wet } \\
\text { Mixed } \\
\text { Aquatic: } \\
\text { Spans full } \\
\text { width of } \\
\text { culvert: Y/N } \\
\text { Water depth } \\
\text { (thalweg): } \\
\text { Water Width: } \\
\text { Flow type: } \\
\text { Perennial } \\
\text { Ephemeral } \\
\text { Standing } \\
\text { Dammed } \\
\text { Other: }\end{array}$ & $\begin{array}{l}\text { Score } \\
2 \\
3 \\
3 \\
Y=3 \\
N=2\end{array}$ & $\begin{array}{r}\text { Currently } \\
\text { passable by } \\
\text { species } \\
\text { group(s): } \\
\text { Aquatic } \\
\text { Terrestrial } \\
\text { Ungulate } \\
\text { Large } \\
\text { mammal } \\
\text { Med mammal } \\
\text { Small } \\
\text { mammal } \\
\text { Amphibian } \\
\text { Reptile } \\
\text { Bird } \\
\text { Passerine } \\
\text { Waterfowl } \\
\text { Other: }\end{array}$ & $\begin{array}{l}3 \\
1 \\
\mathrm{n} / \mathrm{s}\end{array}$ \\
\hline
\end{tabular}

Animal Sign:

\begin{tabular}{|r|r|l|l|l|}
\hline Type & Browse & Score & Species \& Age & Comments: \\
Live & Slide & Slide $=3$ & class & (adult/juv/unkn): \\
Dead & Nest & Browse(chew) $=3$ & \\
Tracks & Other: & Beaver tracks $=3$ \\
Beaver dam $=3$ & & \\
Live Beaver $=3$ & & & \\
\hline
\end{tabular}

Recommendations to improve permeability for wildlife: 


\section{Red-legged Frog Permeability Assessment Species Scoring Form}

\section{Species: Red-legged Frog **DRAFT VERSION**}

Site name/intersection/coordinates:

Attached photos:

Pre assessment GIS Information:

\begin{tabular}{|l|r|l|}
\hline Road & (if yes, road type) & Score \\
& Freeway & 0 \\
Highway & 0 \\
Arterial & 1 \\
& Residential & 2 \\
& Other: $r$ Low $(<500)$ & 2 \\
\hline Estimated Traffic & Moderate $(500-5,000)$ & 1 \\
Volume (AADT or & High $(5,000-10,000)$ & 0 \\
ADT)_ & Very high $(10,000-35,000)$ & 0 \\
& Extreme $(>35,000)$ & 0 \\
\hline Existing culvert & (if yes, culvert type) & \\
& Box & 2 \\
& Bridged & 3 \\
& Pipe & 1 \\
& Other: & \\
\hline
\end{tabular}

Feature(s):

Road/Railroad/Trail

Culvert/Bridge

Fence

Road/Railroad/Trail details:

\begin{tabular}{|c|c|c|c|c|c|}
\hline $\begin{array}{r}\text { Type: } \\
\text { None } \\
\text { Highway } \\
\text { Local } \\
\text { County } \\
\text { Gravel } \\
\text { Dirt } \\
\text { Railroad } \\
\text { Trail } \\
\\
\text { Estimated } \\
\text { Traffic } \\
\text { volume } \\
\mathrm{L} \\
\mathrm{M} \\
\mathrm{H}\end{array}$ & $\begin{array}{l}\text { Score } \\
3 \\
0 \\
1 \\
1 \\
2 \\
2 \\
2 \\
2\end{array}$ & $\begin{array}{r}\text { Total \# lanes or } \\
\text { sets of tracks: } \\
1 \\
2 \\
3 \\
4+ \\
\\
\text { Posted Speed } \\
\text { limit (roads): } \\
0-25 \\
30-45 \\
55+ \\
\\
\text { Estimated line } \\
\text { of sight distance } \\
\text { for } \\
\text { drivers/operator } \\
\mathrm{s} \\
\end{array}$ & $\begin{array}{l}1 \\
0 \\
0 \\
\text { Not scored for } \\
\operatorname{RLF}(\mathrm{n} / \mathrm{s})\end{array}$ & $\begin{array}{l}\text { Roadkill: } \\
\text { Yes/No } \\
\text { Lighting: } \\
\text { Species } \\
\text { ult/? Juv/Ad } \\
\text { lights } \\
\text { ambient } \\
\text { an ambient } \\
\text { al ambient }\end{array}$ & $\begin{array}{l}\text { Score } \\
\text { Yes }=0 \\
\text { RLF }=0 \\
(\mathrm{n} / \mathrm{s}) \\
1 \\
1 \\
2 \\
1\end{array}$ \\
\hline
\end{tabular}


Road/Railroad/Trail details Continued:

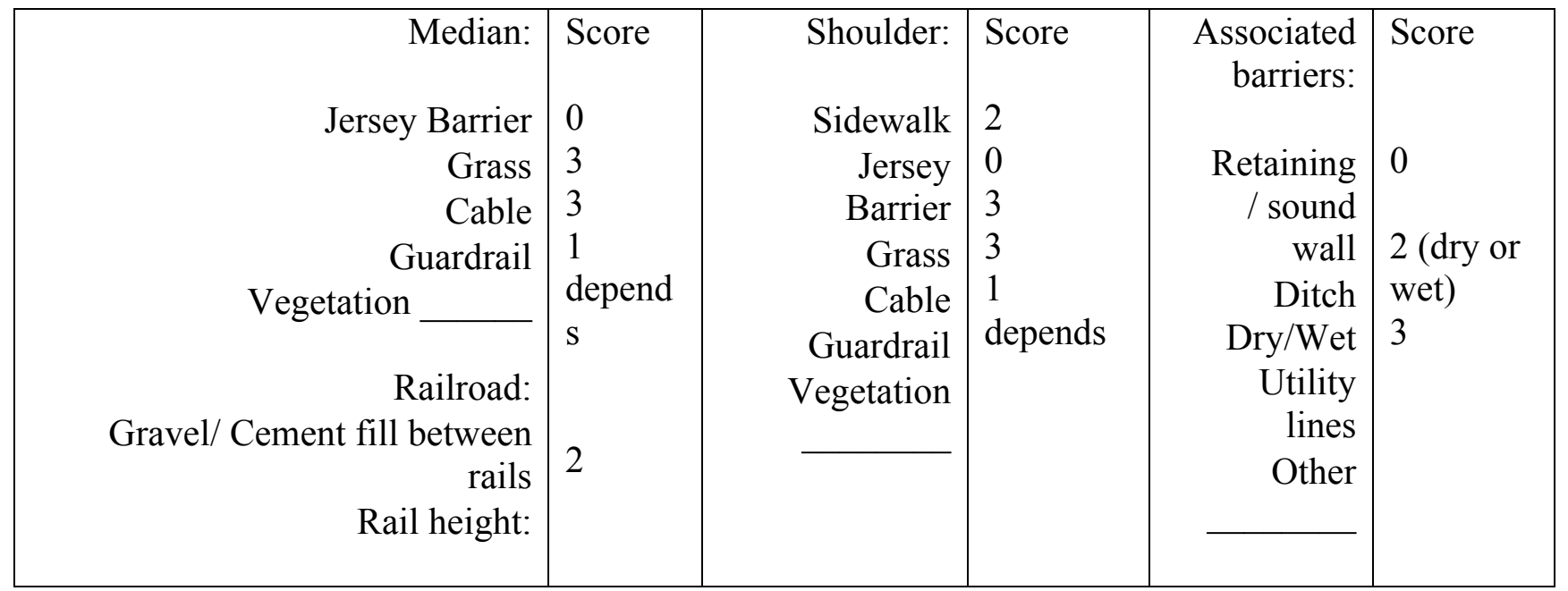

Fence details:

\begin{tabular}{|l|l|l|l|l|l|}
\hline Type: & Score & Body: & Score & Top Wire: & Score \\
None & 3 & Metal & $(\mathrm{n} / \mathrm{s})$ & Metal & $(\mathrm{n} / \mathrm{s})$ \\
Chain link & 1 & Welded wire & & Welded wire & \\
Strand & 3 & Barbed wire & & Barbed wire & \\
Mesh & 1 & Wood & & Razor wire & \\
Strand/mesh & 1 & Plastic & & Wood & \\
Rail & 3 & Mix & & Plastic & \\
Plank & 3 & Other: & & Mix & \\
Other: & & & & Other: & \\
& & & & & \\
\hline
\end{tabular}

Fence details continued:

\begin{tabular}{|l|l|l|l|l|l|}
\hline Purpose: & Score & $\begin{array}{l}\text { How fence } \\
\text { connects to } \\
\text { culvert/bridge: }\end{array}$ & Score & Continuation: & Score \\
Right of Way & $(\mathrm{n} / \mathrm{s})$ & Attached & 0 & None & 3 \\
Boundary & & Into & Brambles & 1 \\
Property & & Not back & 1 & Parallel to & \\
Boundary & & 3 & Road & 1 \\
Human Barrier & & associated & & Road except & \\
Livestock & & & accesses & 0 \\
Barrier & & & Into Fill & 0 \\
Wildlife Barrier & & & & Into Wall & \\
Other: & & & Other: & \\
& & & & \\
\end{tabular}

Culvert details:

\begin{tabular}{|r|l|r|l|r|l|}
\hline Type: & Score & Size: & Score & Substrate: & Score \\
None/not & 0 & & $>5 \mathrm{ft}=3$ & Dirt & 3 \\
visible & 3 & & $3 \mathrm{ft}$ to $5 \mathrm{ft}=2$ & Cobble & 2 \\
\hline
\end{tabular}




\begin{tabular}{|c|c|c|c|c|c|}
\hline $\begin{array}{l}\text { Bridge } \\
\text { Concrete/Metal } \\
\text { other } \\
\text { Box/Arch } \\
\text { other } \\
\text { Single/Double } \\
\text { other } \\
\text { Open bottom } \\
\text { Y/N }\end{array}$ & $\begin{array}{l}(\mathrm{n} / \mathrm{s}) \\
(\mathrm{n} / \mathrm{s}) \\
\text { Single }=2 \\
\text { Double }=3 \\
\text { Yes }=3 \\
\text { No }=1\end{array}$ & $\begin{array}{r}\begin{array}{r}\text { Max } \\
\text { height }\end{array} \\
\begin{array}{l}\text { Min } \\
\text { height }\end{array} \\
\overline{\text { Length }} \\
\text { (Across } \\
\text { Rd) } \\
\text { Width } \\
\text { (Span) }\end{array}$ & $\begin{array}{l}2 \mathrm{ft}-3 \mathrm{ft}=1 \\
<2 \mathrm{ft}=0 \\
<75 \mathrm{ft}=3 \\
75 \mathrm{ft}-125 \mathrm{ft}= \\
2 \\
>125 \mathrm{ft}=1 \\
<5 \mathrm{ft}=0 \\
5-10 \mathrm{ft}=1 \\
11-20 \mathrm{ft}=2 \\
>20 \mathrm{ft}=3\end{array}$ & $\begin{array}{r}\text { Gravel } \\
\text { Riprap } \\
\text { Gabion } \\
\text { Grate } \\
\text { Concrete } \\
\text { Asphalt } \\
\text { Mixed } \\
\text { Other: }\end{array}$ & $\begin{array}{l}2 \\
1 \\
1 \\
0 \\
2 \\
1 \\
\text { Mixed = } \\
\text { average of } \\
\text { scores above? }\end{array}$ \\
\hline
\end{tabular}

Culvert details continued:

\begin{tabular}{|c|c|c|c|c|c|}
\hline $\begin{array}{r}\text { Human use: } \\
\text { None } \\
\text { Light } \\
\text { Moderate } \\
\text { Heavy } \\
\text { Type of human } \\
\text { use: } \\
\text { Pedestrian } \\
\text { Bicycle } \\
\text { Motorized } \\
\text { Livestock } \\
\text { Transient } \\
\text { Camps } \\
\text { Other: } \\
\end{array}$ & $\begin{array}{l}\text { Score } \\
3 \\
2 \\
1 \\
0\end{array}$ & $\begin{array}{r}\text { Terrestrial } \\
\text { Aquatic } \\
\text { Mixed } \\
\\
\text { Aquatic: } \\
\text { Spans full } \\
\text { width of } \\
\text { culvert: Y/N } \\
\text { Water depth } \\
\text { (thalweg): } \\
\text { Water Width: } \\
\text { Flow type: } \\
\text { Perennial } \\
\text { Ephemeral } \\
\text { Standing } \\
\text { Dammed } \\
\text { Other: }\end{array}$ & $\begin{array}{l}\text { Score } \\
3 \\
1 \\
3 \\
1 \\
(\mathrm{n} / \mathrm{s}) \\
(\mathrm{n} / \mathrm{s})\end{array}$ & $\begin{array}{r}\text { Currently } \\
\text { passable by } \\
\text { species } \\
\text { group(s): } \\
\text { Aquatic } \\
\text { Terrestrial } \\
\\
\text { Ungulate } \\
\text { Large } \\
\text { mammal } \\
\text { Med mammal } \\
\text { Small } \\
\text { mammal } \\
\text { Amphibian } \\
\text { Reptile } \\
\text { Bird } \\
\text { Passerine } \\
\text { Waterfowl } \\
\text { Other: }\end{array}$ & $\begin{array}{l}1 \\
3 \\
3 \\
3 \\
1 \\
0 \\
3 \\
1 \\
3\end{array}$ \\
\hline
\end{tabular}

Animal Sign:

\begin{tabular}{|l|l|l|l|}
\hline Type & $\begin{array}{l}\text { Score } \\
\text { Any }=1 \\
\text { RLF }=3\end{array}$ & $\begin{array}{l}\text { Species \& Age class } \\
\text { (adult/juv/unkn): } \\
(\mathrm{n} / \mathrm{s})\end{array}$ & $\begin{array}{l}\text { Comments: } \\
(\mathrm{n} / \mathrm{s})\end{array}$ \\
\hline
\end{tabular}

Recommendations to improve permeability for wildlife:

$(\mathrm{n} / \mathrm{s})$ 


\section{Western Painted Turtle Permeability Assessment Species Scoring Form}

\section{Species: Western Painted Turtle **DRAFT VERSION**}

Site name/intersection/coordinates:

Attached photos:

Pre assessment GIS Information:

\begin{tabular}{|l|r|l|}
\hline Road & (if yes, road type) & Score \\
& Freeway & 0 \\
Highway & 0 \\
& Arterial & 1 \\
& Residential & 2 \\
& Other: & \\
\hline Estimated Traffic & Low $(<500)$ & 1 \\
Volume (AADT or & Moderate $(500-5,000)$ & 1 \\
ADT)_High $(5,000-10,000)$ & 0 \\
& Very high $(10,000-35,000)$ & 0 \\
& Extreme $(>35,000)$ & 0 \\
\hline Existing culvert & (if yes, culvert type) & \\
& Box & 3 \\
& Bridged & 3 \\
& Pipe & 3 \\
& Other: & \\
\hline
\end{tabular}

Feature(s):

Road/Railroad/Trail

Culvert/Bridge

Fence

Road/Railroad/Trail details:

\begin{tabular}{|c|c|c|c|c|c|}
\hline $\begin{array}{r}\text { Type: } \\
\text { None } \\
\text { Highway } \\
\text { Local } \\
\text { County } \\
\text { Gravel } \\
\text { Dirt } \\
\text { Railroad } \\
\text { Trail } \\
\text { Estimated } \\
\text { Traffic } \\
\text { volume } \\
\mathrm{L} \\
\mathrm{M} \\
\mathrm{H}\end{array}$ & $\begin{array}{l}\text { Score } \\
3 \\
0 \\
2 \\
2 \\
3 \\
3 \\
1 \\
3\end{array}$ & $\begin{array}{r}\text { Total \# lanes or } \\
\text { sets of tracks: } \\
\text { Road / RR no } \\
\text { fill/RR fill } \\
1 \\
2 \\
3 \\
4+ \\
\text { Posted Speed } \\
\text { limit (roads): } \\
0-25 \\
30-45 \\
55+ \\
\text { Estimated } \\
\text { line of sight } \\
\text { distance for } \\
\text { drivers/operat } \\
\text { ors }\end{array}$ & $\begin{array}{l}1 \\
1 \\
0 \\
<40 \mathrm{ft} 0 \\
40-120 \mathrm{ft}=1 \\
121-220 \mathrm{ft}=2 \\
>221 \mathrm{ft}=3\end{array}$ & $\begin{array}{l}\text { Roadkill: } \\
\text { Lighting: } \\
\text { ult/? Juv/Ad } \\
\text { Strecties } \\
\text { ambient } \\
\text { an ambient } \\
\text { al ambient }\end{array}$ & $\begin{array}{l}\text { Score } \\
\text { Yes }=0 \\
\text { Beaver }=0 \\
(\mathrm{n} / \mathrm{s})\end{array}$ \\
\hline
\end{tabular}


Road/Railroad/Trail details Continued:

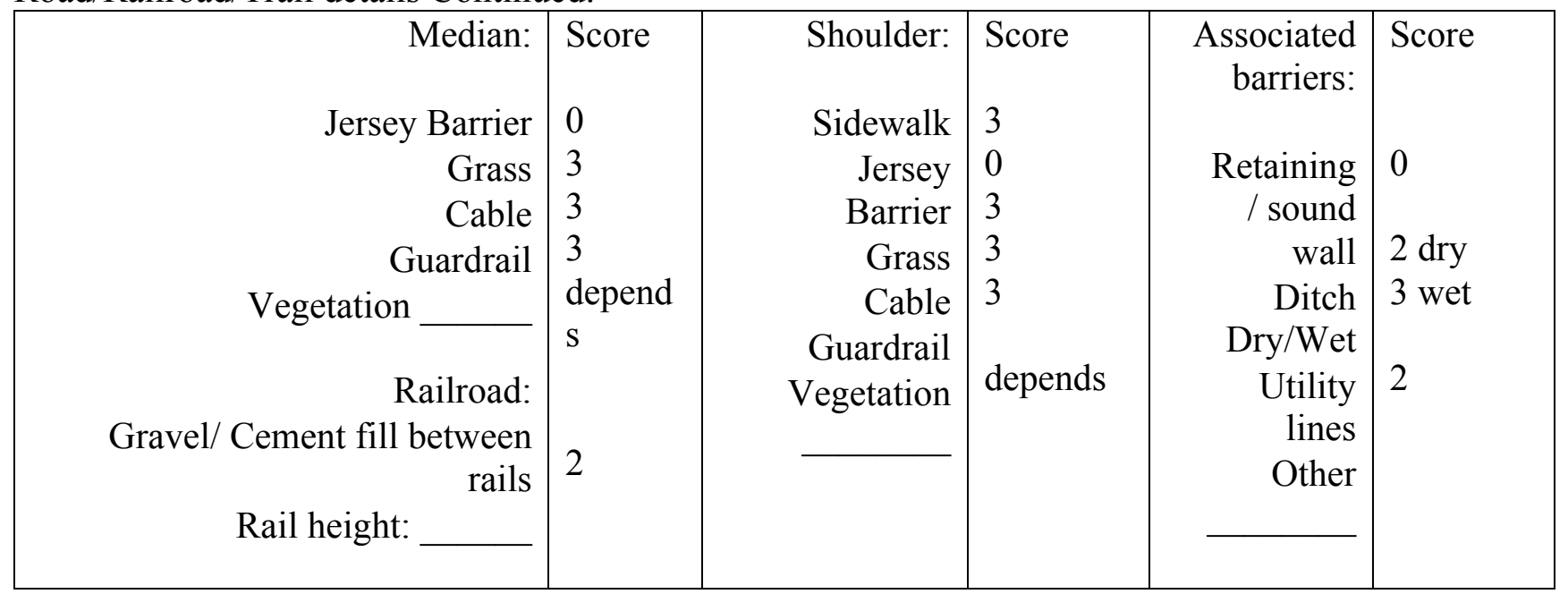

Fence details:

\begin{tabular}{|l|l|l|l|l|l|}
\hline Type: & Score & Body: & Score & Top Wire: & Score \\
None & 3 & Metal & 3 & Metal & 3 \\
Chain link & 1 & Welded wire & 3 & Welded wire & 3 \\
Strand & 3 & Barbed wire & 1 & Barbed wire & 1 \\
Mesh & 2 & Wood & 3 & Razor wire & 1 \\
Strand/mesh & 2 & 0 & Wood & 3 \\
Rail & 3 & Plastic & 2 & Plastic & 0 \\
Plank & 3 & Mix & & Mix & 2 \\
Other: & & Other: & & Other: & \\
& & & & & \\
\hline
\end{tabular}

Fence details continued:

\begin{tabular}{|l|l|l|l|l|l|}
\hline Purpose: & Score & $\begin{array}{l}\text { How fence } \\
\text { connects to } \\
\text { culvert/bridge: }\end{array}$ & Score & Continuation: & Score \\
Right of Way & & Attached & 0 & None & 3 \\
Boundary & & Set back & 1 & Into & Brambles \\
Property & Not & 3 & Parallel to & \\
Boundary & & associated & & Road & 1 \\
Human Barrier & & & Road except & \\
Livestock & & & accesses & 1 \\
Barrier & & & Into Fill & 0 \\
Wildlife Barrier & & & Into Wall & \\
Other: & & & Other: & \\
& & & & \\
\hline
\end{tabular}


Culvert details:

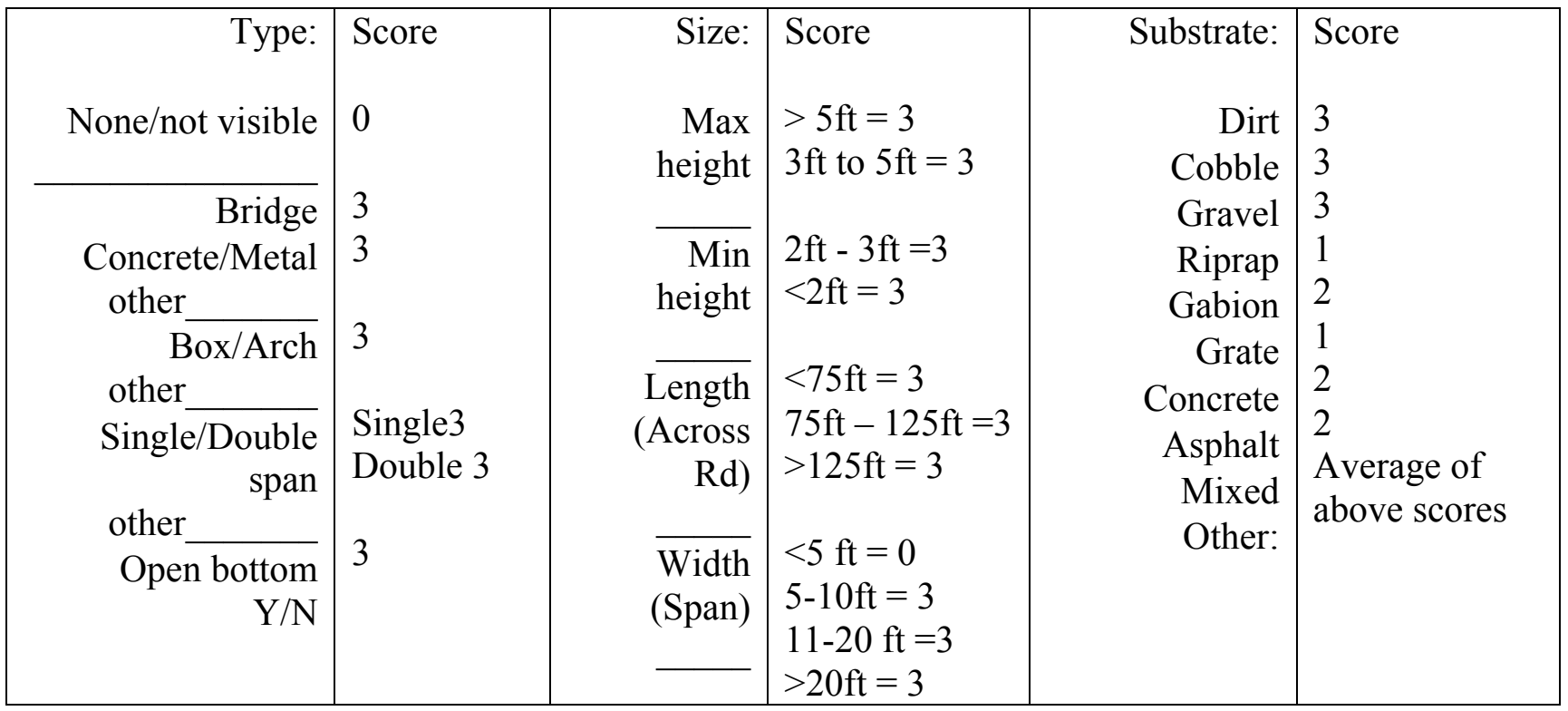

Culvert details continued:

\begin{tabular}{|c|c|c|c|c|c|}
\hline $\begin{array}{r}\text { Human use: } \\
\text { None } \\
\text { Light } \\
\text { Moderate } \\
\text { Heavy } \\
\text { Type of human } \\
\text { use: } \\
\text { Pedestrian } \\
\text { Bicycle } \\
\text { Motorized } \\
\text { Livestock } \\
\text { Camps } \\
\text { Other: }\end{array}$ & $\begin{array}{l}\text { Score } \\
3 \\
2 \\
1 \\
0\end{array}$ & $\begin{array}{r}\text { Terrestrial } \\
\text { Aquatic } \\
\text { Mixed } \\
\text { Aquatic: } \\
\text { Spans full } \\
\text { width of } \\
\text { culvert: Y/N } \\
\text { Water depth } \\
\text { (thalweg): } \\
\text { Water Width: } \\
\text { Flow type: } \\
\text { Perennial } \\
\text { Ephemeral } \\
\text { Standing } \\
\text { Dammed } \\
\text { Other: }\end{array}$ & $\begin{array}{l}\text { Score } \\
3 \\
3 \\
3 \\
\\
Y=3 \\
N=2\end{array}$ & $\begin{array}{r}\text { Currently } \\
\text { passable by } \\
\text { species } \\
\text { group(s): } \\
\text { Aquatic } \\
\text { Terrestrial } \\
\text { Ungulate } \\
\text { Large } \\
\text { mammal } \\
\text { Med mammal } \\
\text { Small } \\
\text { mammal } \\
\text { Amphibian } \\
\text { Reptile } \\
\text { Bird } \\
\text { Passerine } \\
\text { Waterfowl } \\
\text { Other: }\end{array}$ & $\begin{array}{l}\text { Waterfowl=3 } \\
\text { Amphib }=3 \\
\text { Reptile }=3\end{array}$ \\
\hline
\end{tabular}

Animal Sign:

\begin{tabular}{|r|r|l|l|l|}
\hline Type & Browse & Score & Species \& Age & Comments: \\
Live & Slide & Nest $=3$ & class & \\
Dead & Nest & Live $=3$ & (adult/juv/unkn): & \\
Tracks & Other: & Tracks $=3$ & & \\
Scat & & & & \\
\hline
\end{tabular}




\section{Appendix D: Site Maps}

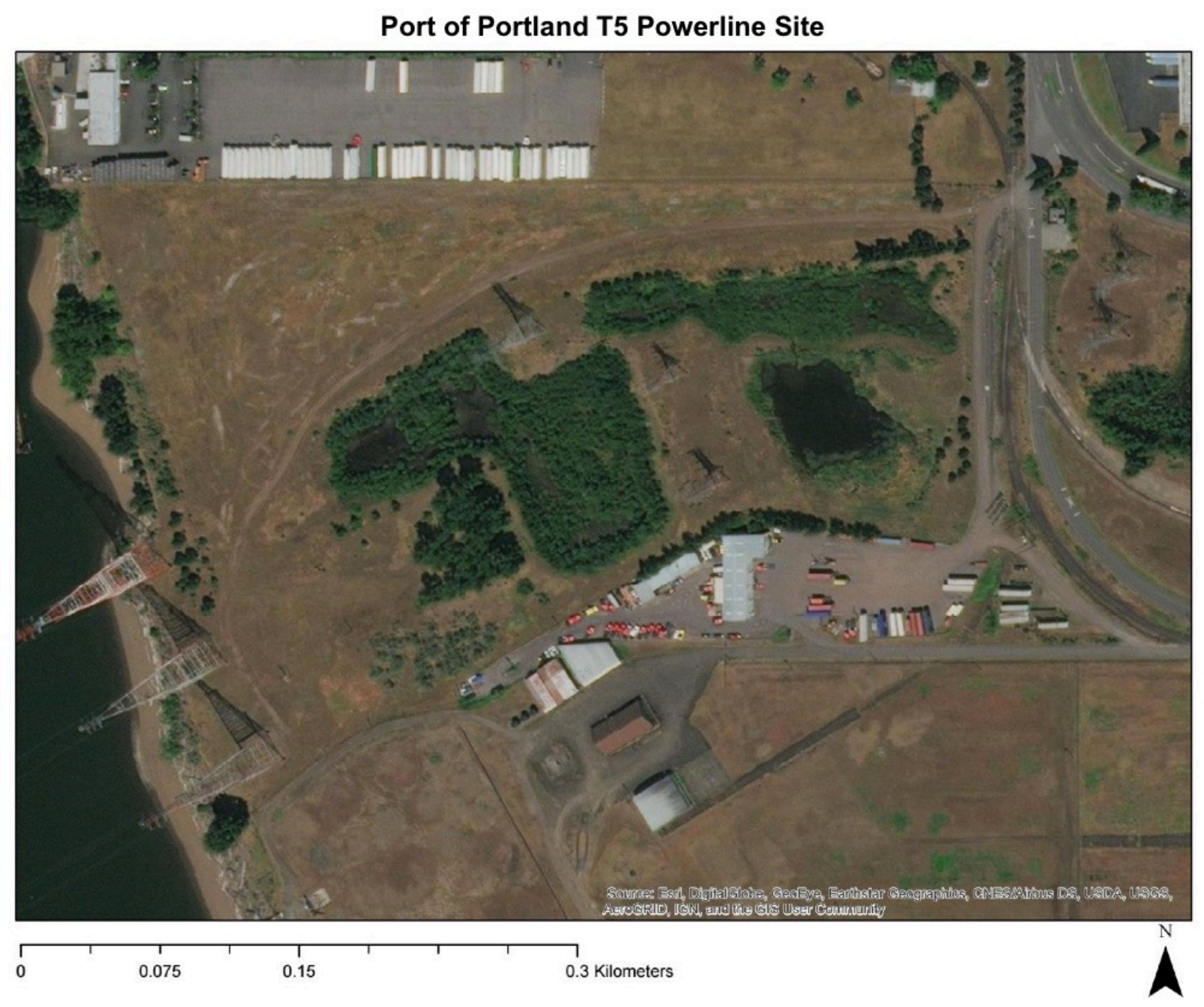

Appendix D Figure 1: Port of Portland T5 Powerline mitigation site in Portland, Oregon. The Willamette River is to the west of the site, and Time Oil Road is to the east. Past Time Oil Road lies the Port of Portland West Wye mitigation site. To the south of the site is a trucking business with parking lot. A crossing structure goes underneath the both roads to the east of the property. 


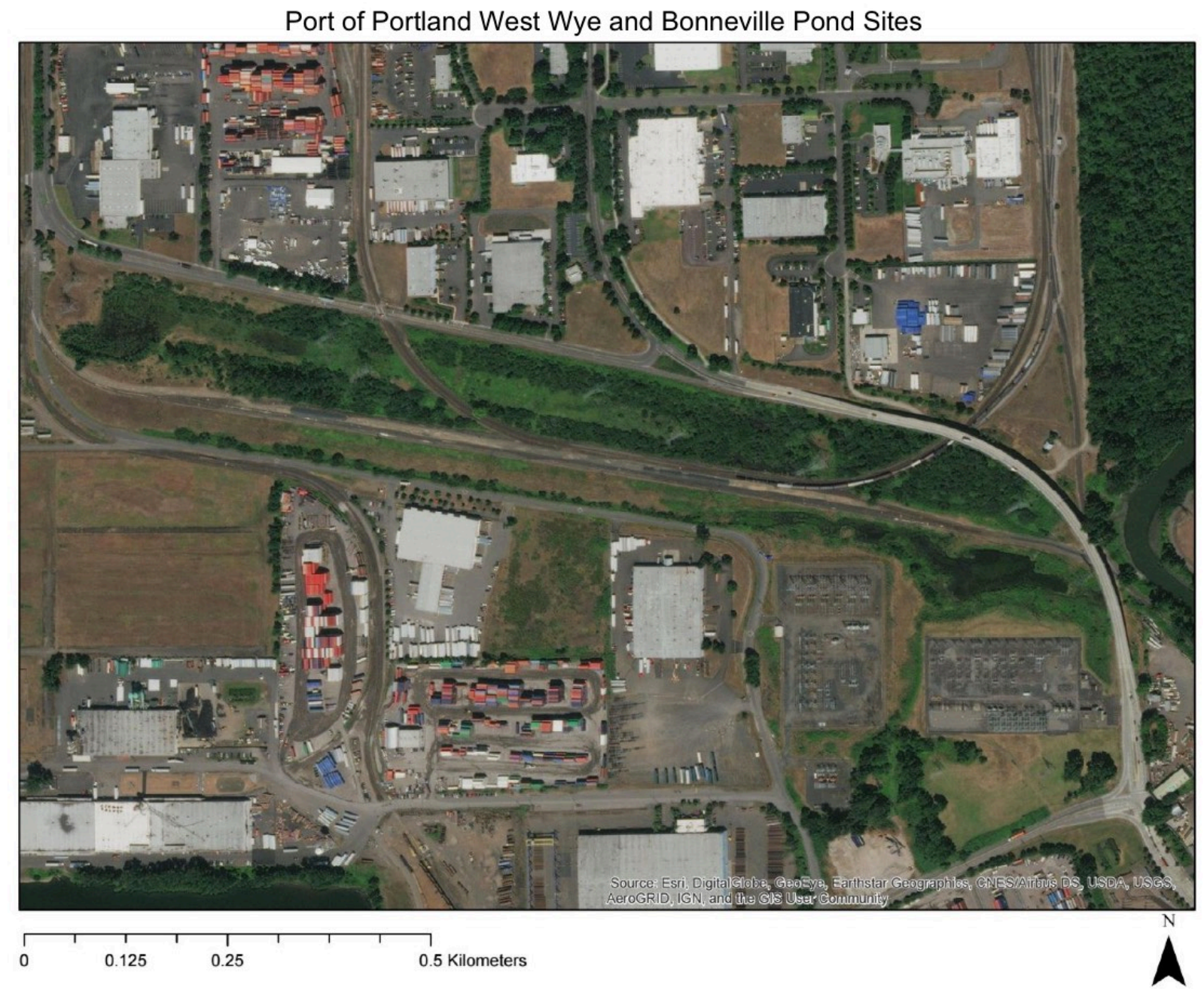

Appendix D Figure 2: Port of Portland owned West Wye and Bonneville Pond Sites in Portland, OR. The T5 Powerline site is past the most western extent of the map, and St. John's Prairie is to the east. West Wye western portion of the greenspace, west of the curved railroad line. Bonneville pond is body of water located on the east most portion of the greenspace. 
Metro St. John's Prairie

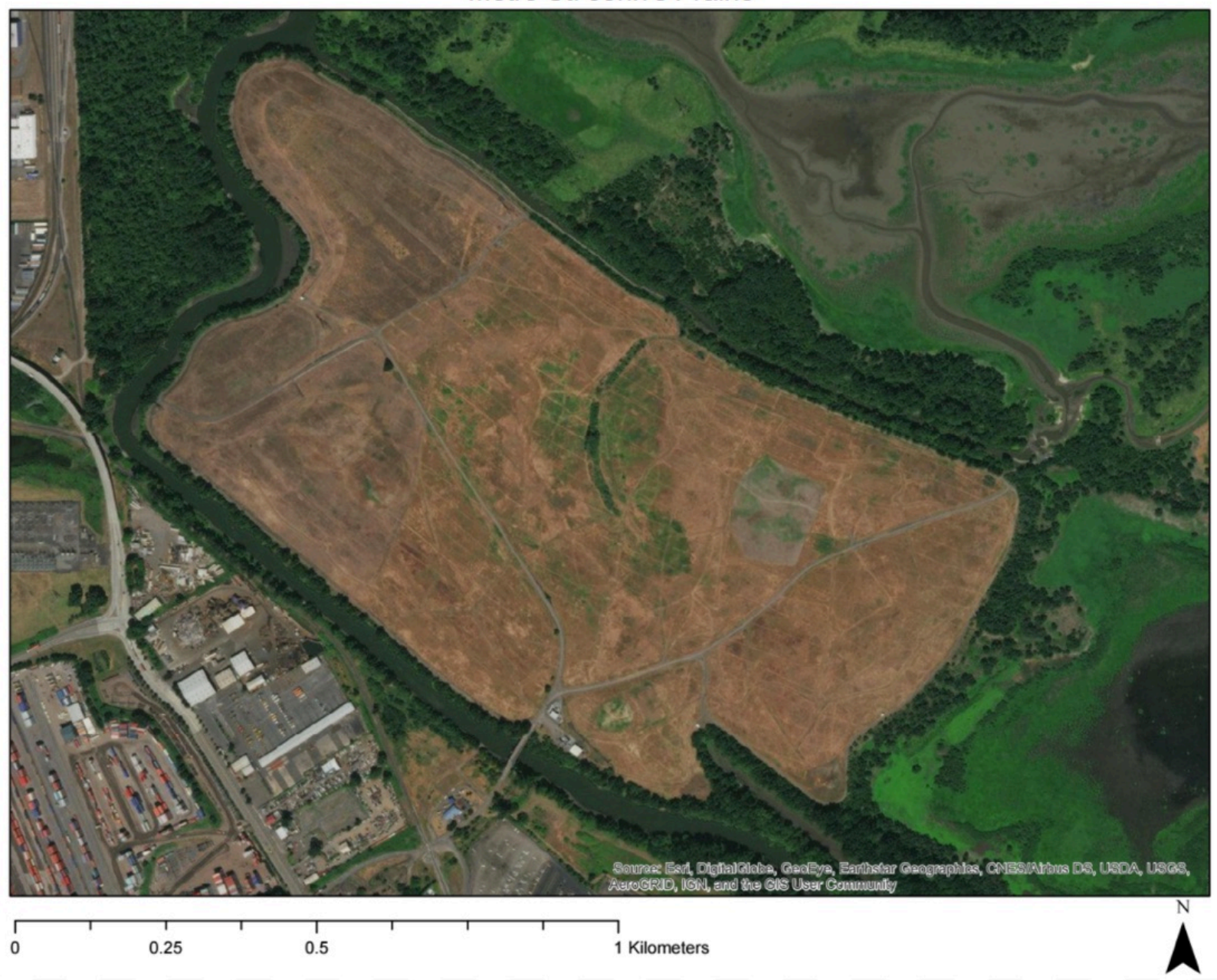

Appendix D Figure 3: Metro managed St. John's Prairie in Portland, Oregon. Smith and Bybee Wetlands surrounds the north and east borders of the property. Port of Portland Ramsey Lakes and Rivergate mitigation sites lie to the north, with the T5 Powerline, West Wye and Bonneville Pond sites to the west. 


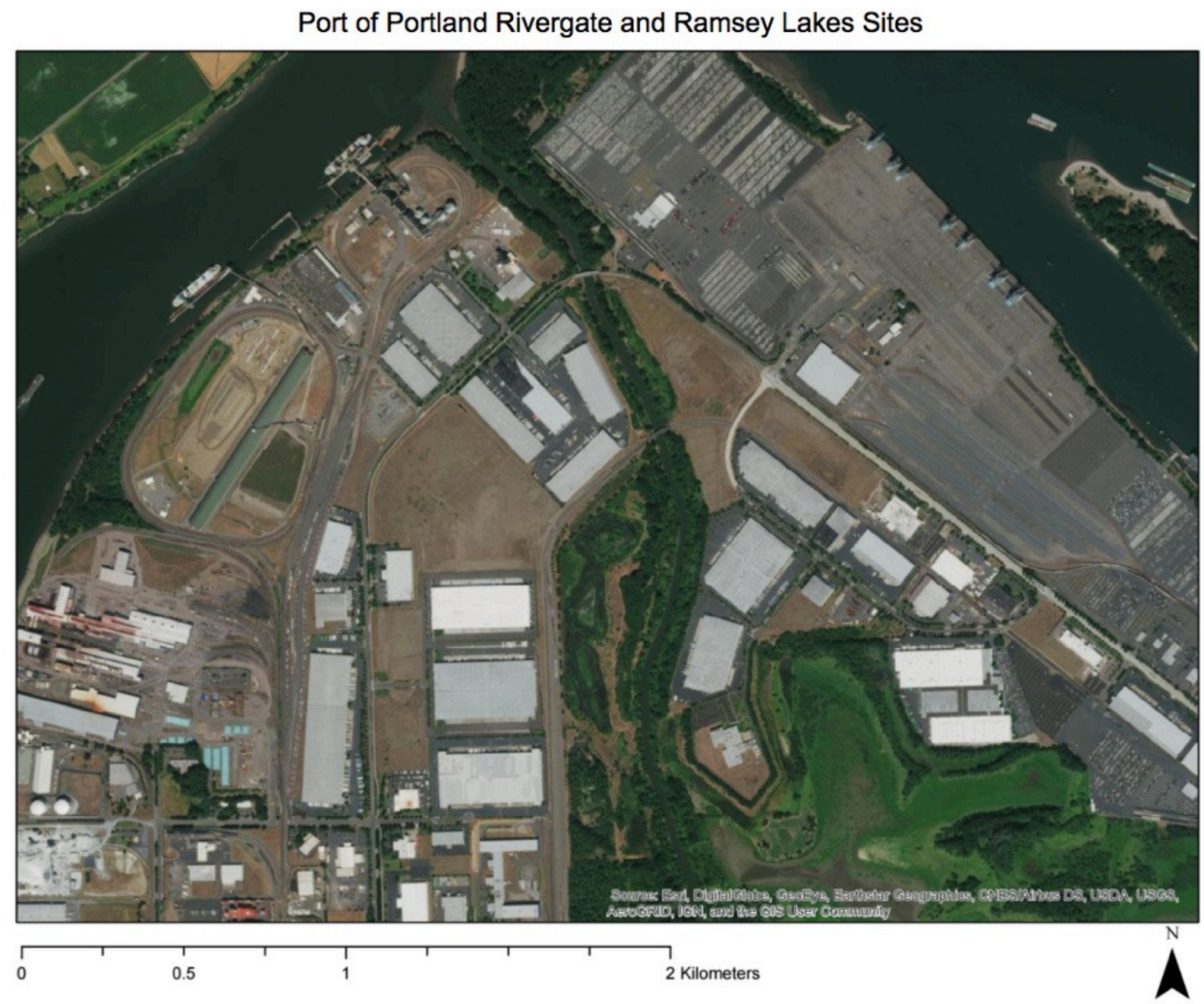

Appendix D Figure 4: Port of Portland's Rivergate Enhancement and Ramsey Lakes Mitigation Sites in Portland, Oregon. The sites border the Columbia Slough travelling in a north-south direction, then widen as they approach Smith and Bybee Wetlands to the south of both mitigation sites. The Columbia River and the Willamette River confluence as well as Kelly Point Park is to the north of the sites. 
Metro Smith and Bybee Wetlands

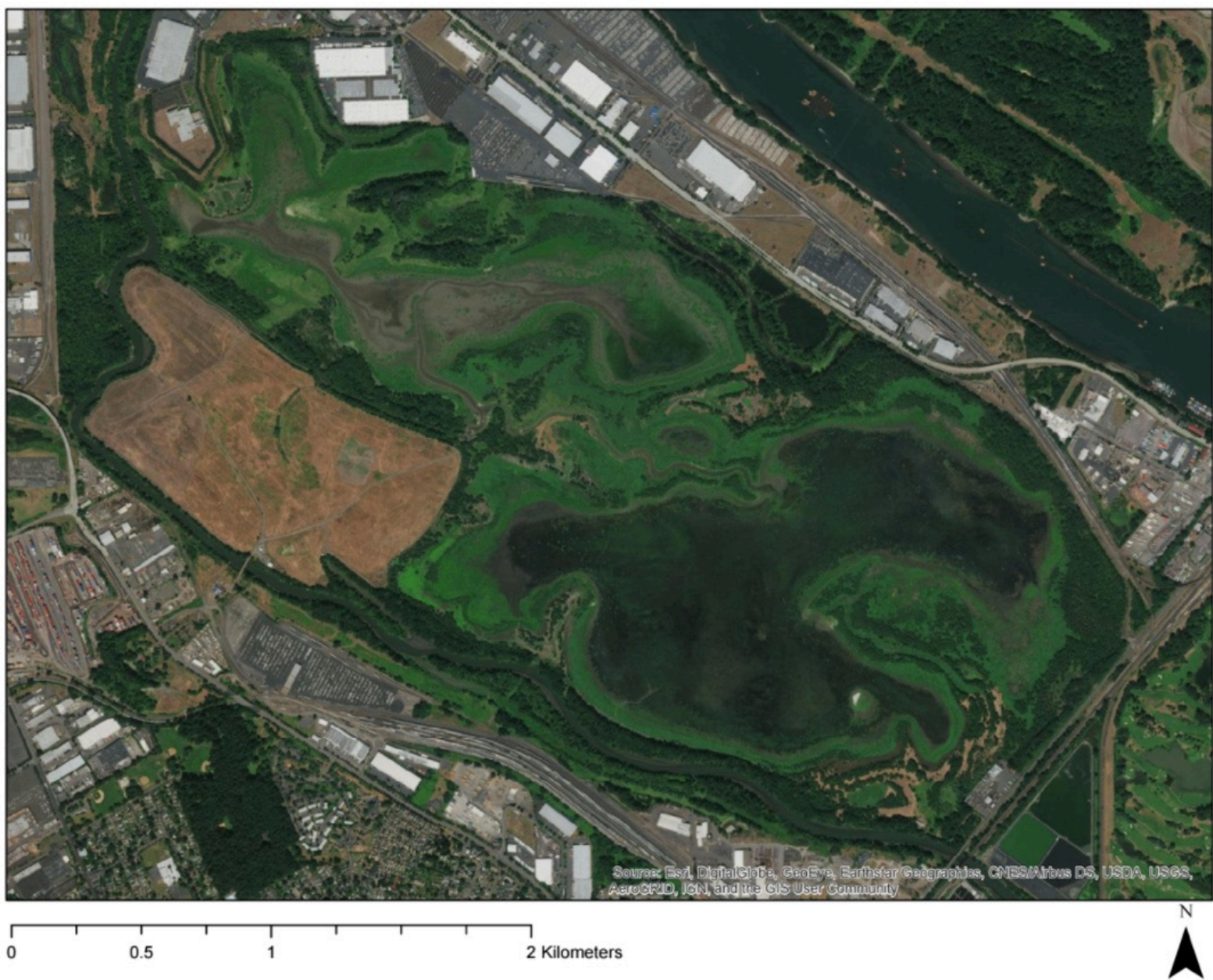

Appendix D Figure 5: Metro managed Smith and Bybee Wetlands in Portland, Oregon. St.

John's Prairie can be seen on the eastern portion of the map, and Heron Lakes Gold Course and the Columbia Boulevard Wastewater Treatment Plant Lagoon to the east of the wetlands. North Portland Road separates Smith and Bybee from the other properties. The Columbia Slough is located to the south of St. John's Prairie and Smith and Bybee Wetlands. 
Columbia Boulevard Wastewater Treatment Plant Lagoon

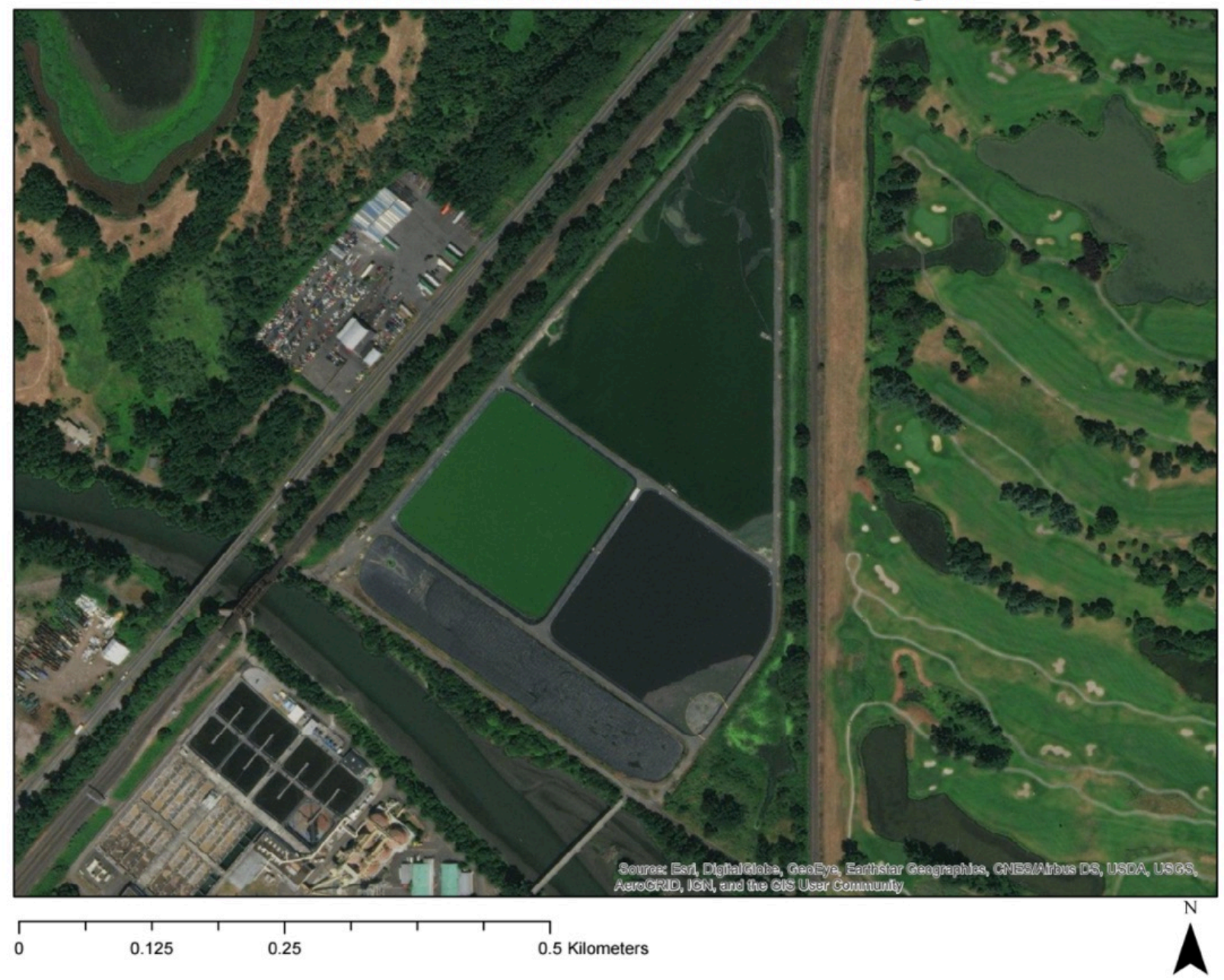

Appendix D Figure 6: The City of Portland owned Columbia Boulevard Wastewater Treatment Plant Lagoon in Portland Oregon. Heron Lakes Golf Course is to the west of the Lagoon, and Smith and Bybee is to the west. The Columbia Slough is to the south of the property. 


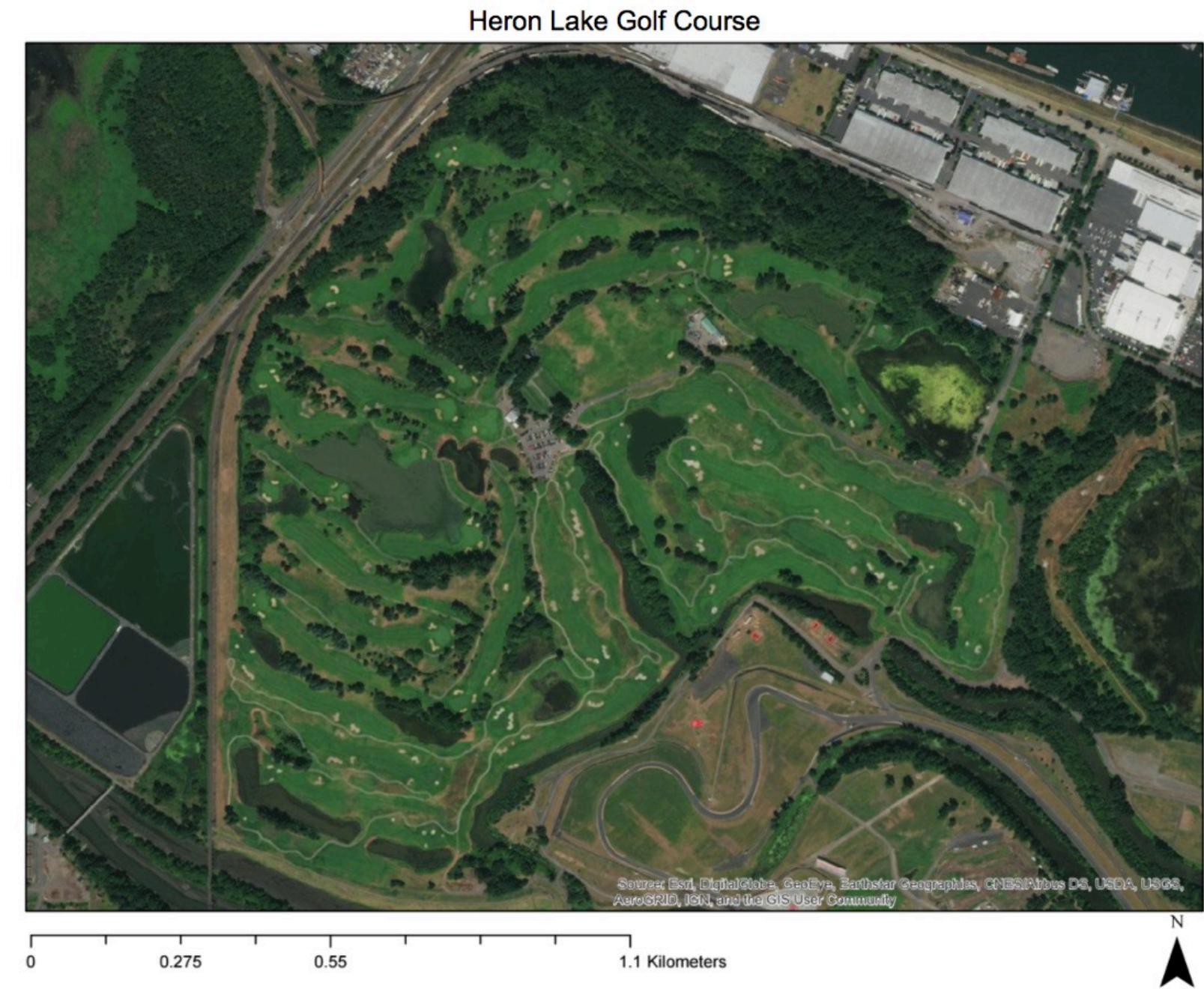

Appendix D Figure 7: Heron Lakes Golf Course managed by the Department of Parks and Recreation in the City of Portland. Vanport Wetlands is to the east, and Smith and Bybee Wetlands is to the west, across North Portland Road. Portland International Raceway is to the southeast of the golf course. 


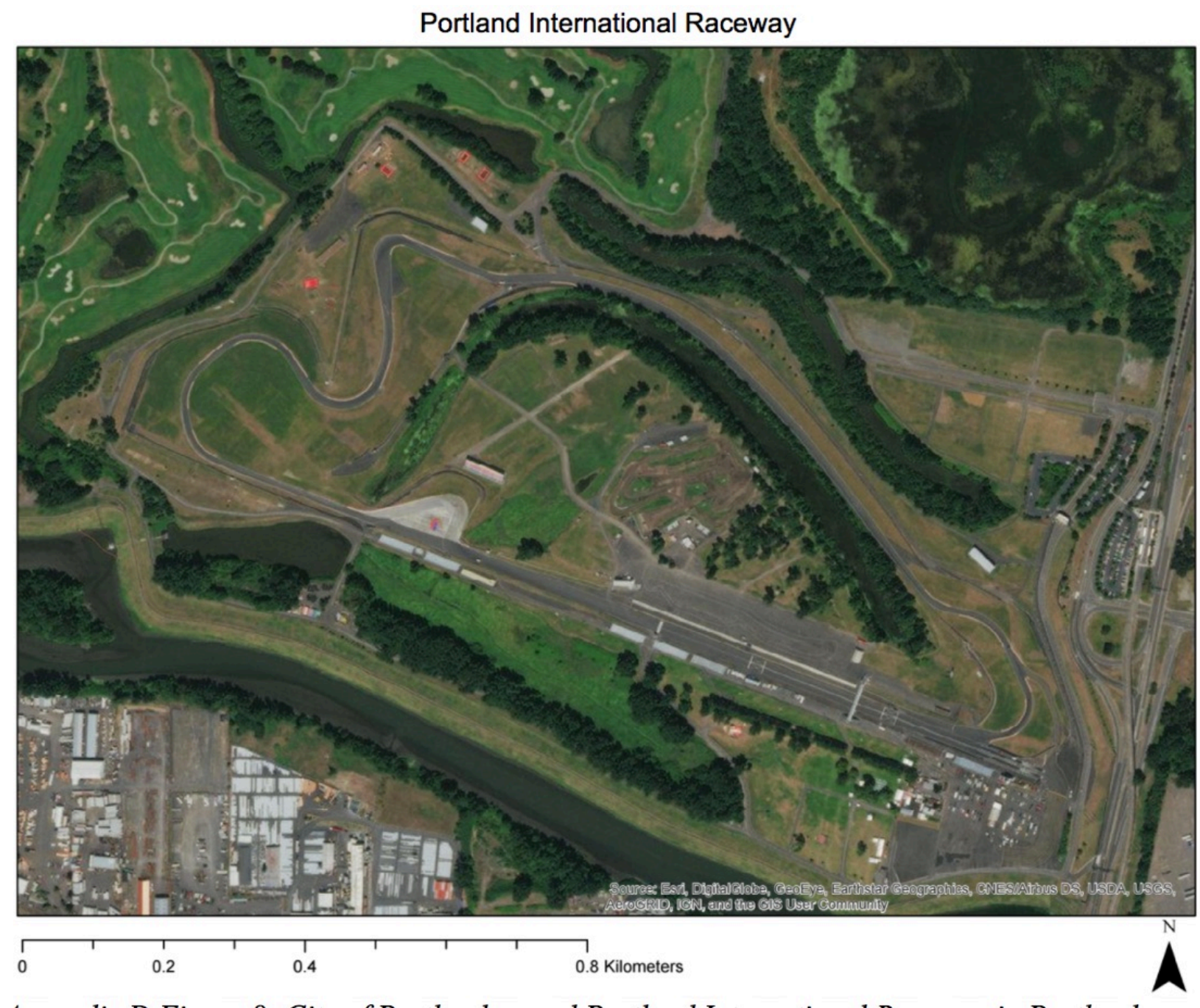

Appendix D Figure 8: Cंity of Portland owned Portland International Raceway in Portland, Oregon. North of the property is Vanport Wetland, and the Columbia Slough is to the south. Interstate 5 is to the east, and Heron Lakes Golf Course surrounds the west and northwest borders of the property. 


\section{Vanport Wetlands}

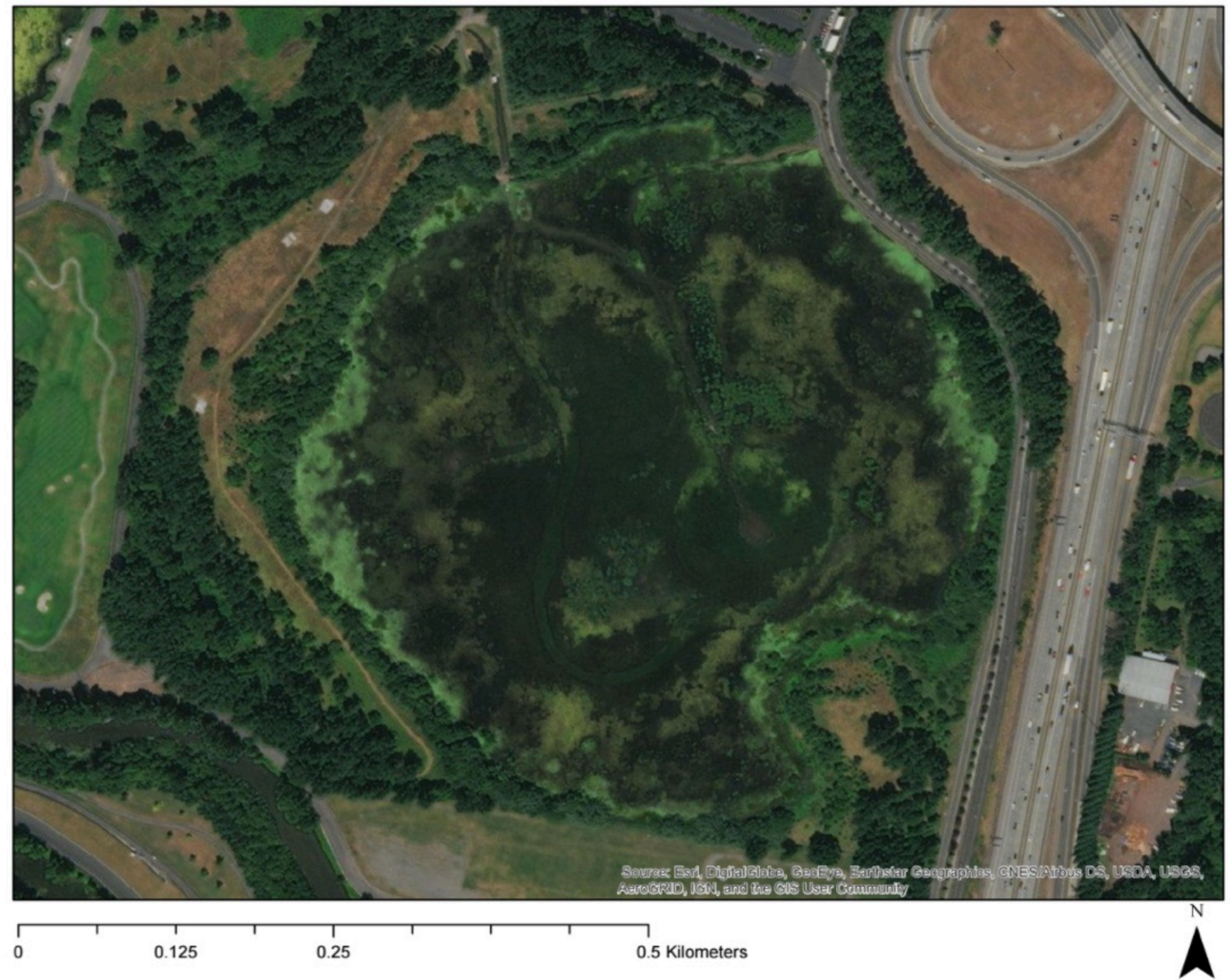

Appendix D Figure 9: Port of Portland owned Vanport Wetlands in Portland, Oregon.

Interstate-5 is to the east of the property, and the Portland International Raceway is to the south, with a dog park in between the properties. Heron Lakes Golf Course is to the west of the wetlands, and the Expo Center is to the North. 
Western Painted Turtle (Chrysemys picta bellii) Least Cost Path Map - Unrestrained Study Area

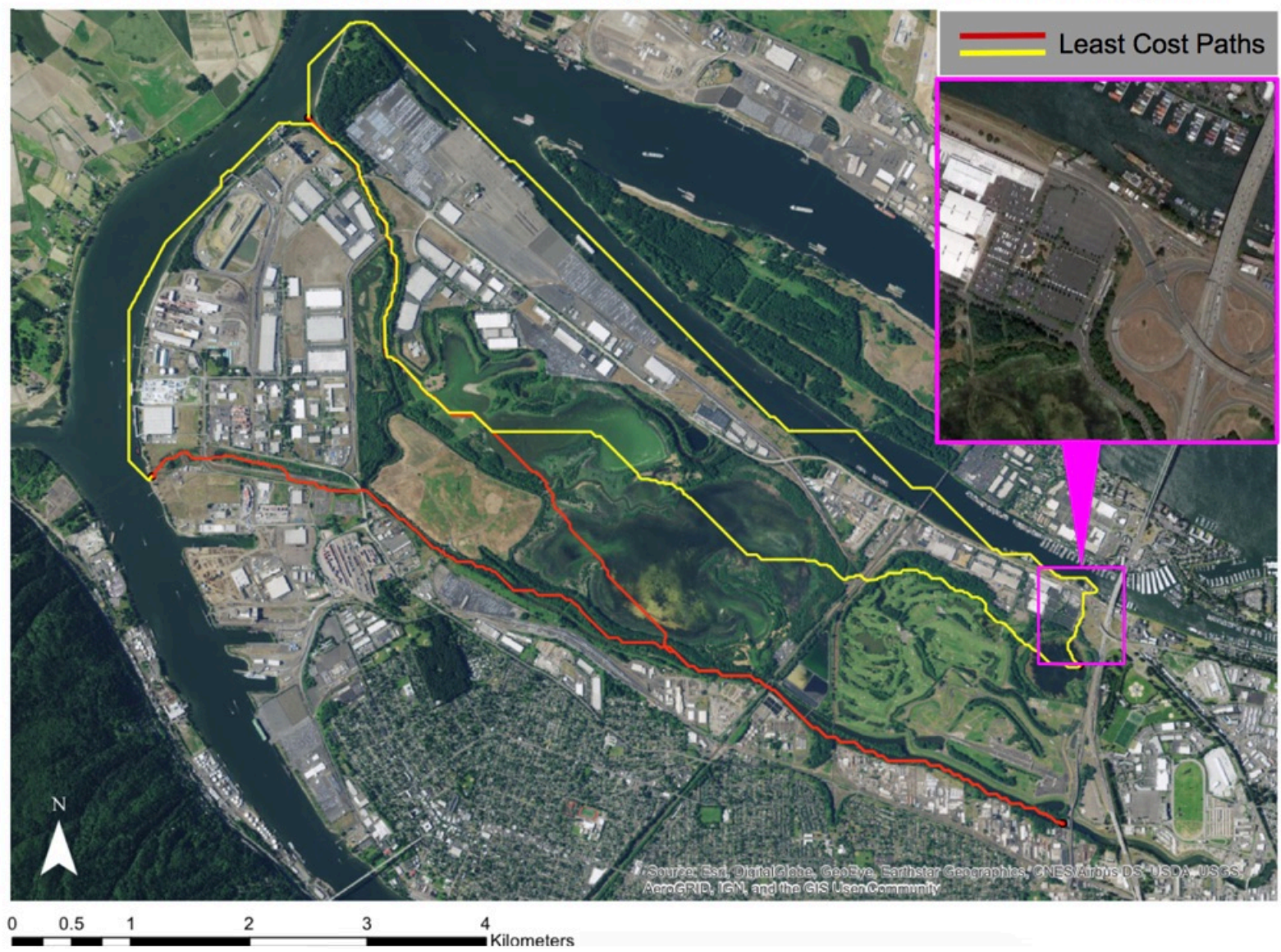

Appendix D Figure 10: Least Cost Path analysis map for western painted turtle (C. picta bellii) without study area constraints. The yellow and red lines represent the least cost paths, with the yellow path leaving the study area showing movement through the Columbia River. The purple box highlights the habitat that the path is predicting turtle movement through, which includes the Expo Center parking lot. 